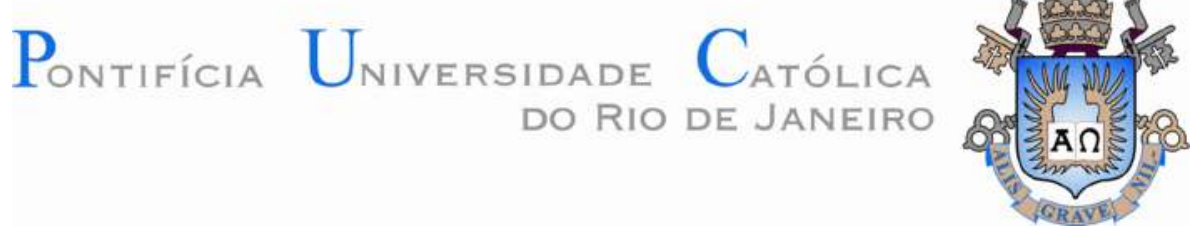

Celso Antero Ivan Salvador Villalobos

\title{
Análise numérica de comportamento sísmico da barragem de rejeitos Otapara, Peru
}

Dissertação de Mestrado

Dissertação apresentada como requisito parcial para obtenção do grau de Mestre em Engenharia Civil pelo programa de PósGraduação em Engenharia Civil do Departamento de Engenharia Civil e Ambiental da PUC-Rio.

Orientador: Prof. Celso Romanel Co-orientador: Dra. Jackeline Castañeda Huertas 


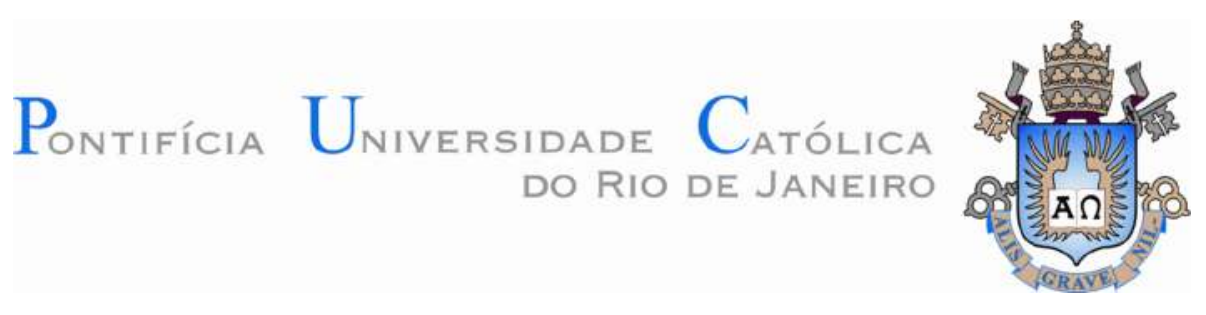

Celso Antero Ivan Salvador Villalobos

\section{Análise numérica de comportamento sísmico da barragem de rejeitos Otapara, Peru}

Dissertação apresentada como requisito parcial para obtenção do grau de Mestre pelo Programa de Pós-Graduação em Engenharia Civil do Departamento de Engenharia Civil e Ambiental do Centro Técnico Científico da PUC-Rio. Aprovada pela Comissão Examinadora abaixo assinada.

Prof. Celso Romanel

Orientador

Departamento de Engenharia Civil e Ambiental - PUC-Rio

Dra. Jackeline Castañeda Huertas

Co-Orientadora

Consultora Independente

Profa. Deane Mesquita Roehl

Departamento de Engenharia Civil e Ambiental - PUC-Rio

Dr. Manuel Gutierrez

EMIN Geoestructuras SAC

Rio de Janeiro, 14 de agosto de 2019 
Todos os direitos reservados. É proibida a reprodução total ou parcial do trabalho sem autorização da universidade, do autor e do orientador.

\section{Celso Antero Ivan Salvador Villalobos}

Graduou-se em Engenharia Civil pela Universidade Nacional de Engenharia - UNI (Lima-Peru) em 2013. Principais áreas de interesse: comportamento sísmico de barragens, geotecnia computacional e experimental.

Ficha Catalográfica

Celso Antero Ivan Salvador Villalobos

Análise numérica de comportamento sísmico da barragem de rejeitos Otapara, Peru / Celso Antero Ivan Salvador Villalobos; orientador: Celso Romanel coorientadora: Jackeline Castañeda Huertas - 2019.

230 f. color. , $30 \mathrm{~cm}$

Dissertação (mestrado) - Pontifícia Universidade Católica do Rio de Janeiro, Departamento de Engenharia Civil e Ambiental, 2020.

Inclui referências bibliografias.

1. Engenharia civil - Teses. 2. Barragem de rejeitos. 3. Terremoto de projeto. 4. Comportamento sísmico. 5. Liquefação. I. Romanel, Celso. II. Huertas, Jackeline Castañeda. III. Pontifícia Universidade Católica do Rio de Janeiro. Departamento de Engenharia Civil e Ambiental. IV. Título. 
A Deus pelo dom da vida. 


\section{Agradecimentos}

A Deus, por ter me abençoado em fazer o mestrado, onde não só aprendi conhecimentos técnicos, mas também tive a oportunidade de fortalecer minha Fé.

Ao professor Celso Romanel, pela orientação e sobretudo a confiança de acreditar em mim em todos esses anos de mestrado.

A Jackeline, pela ajuda constante e suas palavras de apoio, por sua amizade e confiança.

A minha família por ter aguardado por mim com o mesmo amor, em especial a minha mãe Rebeca, meu pai Miguel, irmão Miguel, irmã María, avós Celso e Basi, Antero e Delidia, madrinha Peri, padrinho Joel por todas as palavras de ânimo, suas demonstrações de carinho e por sempre terem acreditado em mim.

A família Fernandes, Sr. Gilder, Sra. Leila e Rebekita, por ter me recebido em sua casa como um filho, e por me ajudar quando eu mais precisava.

Os meus queridos amigos da PUC por serem a familia que Deus deu para me confortar longe de casa. Em especial para Rebekita Fernandes, Lizardo Romero, Jhonatan Garcia, Carlo Aguinda, Kevin Calvay, Paul Pinedo, Andres Castañeda, Judith Ramos, Marcela Strongylis, Jéssica Pereira Nunes, Thamiris Abdala, Erland González, Raul Cordova, Carlos Meza, Anna Caroline, Pamela Oliveira, Pedro Caccavo, Nana Frisoli.

O presente trabalho foi realizado com apoio da Coordenação de Aperfeiçoamento de Pessoal de Nível Superior - Brasil (CAPES) - Código de Financiamento 001. 


\section{Resumo}

Salvador Villalobos Celso Antero Ivan; Romanel, Celso (orientador); Huertas, Jackeline Castañeda (coorientadora) Análise numérica de comportamento sísmico da barragem de rejeitos Otapara, Peru. Rio de Janeiro, 2019. 230 p. Dissertação de Mestrado - Departamento de Engenharia Civil e Ambiental, Pontifícia Universidade Católica do Rio de Janeiro.

O Peru está localizado em uma área de alta atividade sísmica conhecida como cinturão de fogo. Os terremotos registrados com diferentes mecanismos de falha resultam da interação entre as placas tectônicas de Nazca e Sul-americana. É nesta região onde acontecem atividades de mineração no país, juntamente com a construção de grandes estruturas civis, como barragens de rejeitos, projetadas para armazenar grande quantidade de material na menor área possível. Neste trabalho, foi avaliado o comportamento sísmico de uma barragem de rejeitos localizada em Arequipa, Peru, construída com o método a montante. Em evento sísmico ocorrido em 2013, a barragem sofreu trincas no seu corpo, recalques na crista e pequenos vulcões de areia, indicando a redução dos parâmetros de resistência no rejeito devido a possível fenômeno de liquefação. Nesta pesquisa, a estimativa da ameaça sísmica foi feita por métodos probabilísticos, com o terremoto artificial de projeto obtido por método de ajuste espectral. Foram feitas análises pseudo-estáticas de estabilidade dos taludes, bem como estimados deslocamentos permanentes e 0 potencial de liquefação dinâmica por métodos simplificados. A análise global da barragem de rejeitos foi executada pelo método dos elementos finitos, considerando o modelo constituivo UBC3D-PLM para simular o comportamento mecânico dos rejeitos sob carregamento cíclico.

\section{Palavras - chave}

Barragem de rejeitos, sismo de projeto, comportamento sísmico, liquefação dinâmica. 


\section{Abstract}

Salvador Villalobos Celso Antero Ivan; Romanel, Celso (advisor); Hertas, Jackeline Castañeda (co-advisor). Numerical analysis of seismic behavior of the Otapara tailings dam, Peru. Rio de Janeiro, 2019. 230 p. Dissertação de Mestrado - Departamento de Engenharia Civil e Ambiental, Pontifícia Universidade Católica do Rio de Janeiro.

Peru is located in an area of high seismic activity known as the fire belt. Earthquakes recorded with different failure mechanisms result from the interaction between the Nazca and South-American tectonic plates. It is in this region where mining activities take place in the country, along with the construction of large civil structures, such as tailings dams, designed to store large amounts of material in the smallest possible area. In this work, the seismic behavior of a tailings dam located in Arequipa, Peru, built with the upstream method, was evaluated. In a seismic event that occurred in 2013, the dam suffered cracks in its body, settlement in the crest and small sand boils, indicating the reduction of the tailings resistance parameters due to possible dynamic liquefaction. In this research, the seismic hazard assessment was made by probabilistic methods, with the artificial design earthquake obtained by the spectral adjustment method. Pseudo-static analyzes of slope stability were performed, as well as the estimated permanent displacements and the potential of dynamic liquefaction were obtainded by simplified methods. The global seismic analysis of the tailings dam was carried out through the finite element method, considering the UBC3D-PLM constitutive model to simulate the mechanical behavior of tailings under cyclic loading.

\section{Keywords}

Tailings dam, design earthquake, seismic behavior, dynamic liquefaction. 


\section{Sumário}

1 Introdução 25

1.1. Relevância e justificativa da pesquisa 25

1.2. Motivação e objetivos 26

1.3. Estrutura da dissertação 27

1.4. Histórico da linha de pesquisa 27

2 Conceitos de sismologia e ameaça sísmica 31

2.1. Conceitos de sismicidade 31

2.1.1. Placas tectõnicas 31

2.1.1.1. Configuração tectónica do Peru 32

2.1.2. Registros sísmicos 33

2.1.2.1. Correção da linha base 34

2.1.2.2. Porcesso de filtragem $\quad 35$

2.2. Ameaça sísmica $\quad 37$

2.2.1. Ameaça sísmica determinística 37

2.2.2. Ameaça sísmica probabilística 37

2.2.2.1. Catálogo sísmico 38

2.2.2.2. Padronização de magnitude 39

2.2.2.3. Depuração do catálogo sísmico 40

2.2.2.4. Fontes sismogênicas e obtenção de parâmetros 40

2.2.2.5. Relações de atenuação 44

2.2.2.6. Efeito do sítio 45

2.2.2.7. Estimativa probabilística da ameaça sísmica 46

2.2.2.8. Curva de ameaça sísmica 49

2.2.3. Desagregação da ameaça sísmica 52

2.3. Geração de registros sismicos 52

2.3.1. Duração dos Registros Sísmicos 54

2.3.2. Método de Ajuste Espectral 55

2.4. Classificação sismica das barragens 56

2.4.1. Associação canadense de barragens (CDA) 57

2.4.2. Comissão internacional de grandes barragens (ICOLD, 2016) 59 
2.4.2.1. Terminologia 60

2.4.2.2. Parâmetros de entrada sísmica para análise 61

2.4.3. Ministério de energia e minas do Peru (MEM, 1998) 62

2.4.4. Associação brasileira de normas técnicas (ABNT, 2017) 63

3 Avaliação da sísmicidade da barragem de rejeitos Otapara 64

3.1. Localização da área do projeto 64

3.2. Introdução do projeto Otapara 66

3.2.1. Antecedentes do sísmo de $2013 \quad 67$

3.3. Classificação sísmica da barragem 69

3.3.1. Classificação sísmica pela CDA 69

3.3.2. Classificação sísmica pela ICOLD 70

3.4. Ameaça sísmica probabilística do projeto 71

3.4.1. Identificação e caracterização das fontes sismogénicas 72

3.4.1.1. Catálogo sísmico do Peru 72

3.4.1.2. Integridade do catálogo sísmico 73

3.4.1.3. Geometria das fontes sismogênicas 74

3.4.2. Caracterização da sismicidade ou distribuição temporal dos sismos - Análise de recorrência sísmica 76

3.4.3. Determinação do movimento sísmico e analise de incertezas 77

3.4.3.1. Leis de atenuação utilizadas na análise 77

3.4.3.2. Árvore lógica $\quad 80$

3.4.4. Estimação da probabilidade de excedencia do nível de movimento sísmico determinado em um período de tempo 80

3.4.5. Desagregação da ameaça sísmica 83

3.5. Registros sismos empregados na analise 85

3.5.1. Duração dos registros sísmicos 88

3.5.2. Filtragem dos registros sismicos 93

$\begin{array}{ll}\text { 3.5.3. Ajuste espectral } & 97\end{array}$

4 Comportamento dinâmico do solo e fenômeno de liquefação 102

4.1. Caracterização das propriedades dinâmicas 102

4.1.1. Módulo de cisalhamento 102 
4.1.2. Razão de amortecimento 108

4.2. Ensaios para a obtenção das propriedades dinâmicas 110

4.2.1. Ensaio geofísicos 111

4.2.2. Ensaio de laboratório 112

4.3. Modelos constitutivos 114

4.3.1. Modelo elástico 114

4.3.2. Modelo HSM - Hardening Soil Model 117

4.3.3. Modelo hardening soil small 120

4.3.4. Modelo UBC3D-PLM (Petalas e Galavi, 2013) 124

4.3.5. Correlações de SPT com parâmetros UBCSAND 129

4.4. Fenómeno de Liquefação 131

4.4.1. Suscetibilidade à liquefação 131

4.4.2. Parâmetro de estado 132

4.4.3. Avaliação do potencial de liquefação 133

4.4.3.1. Métodos de campo 133

4.4.3.2. Métodos de laboratório 137

4.4.4. Resistência cisalhante não drenada residual 138

4.4.4.1. Idriss \& Boulanger (2007) 138

5 Avaliação da liquefação dos rejeitos da barragem Otapara 141

5.1. Caracterização geotécnica dos materiais 142

5.1.1. Investigação geotécnica 142

5.1.2. Ensaios do laboratório 148

5.2. Suscetibilidade à liquefação 153

5.3. Avaliação do potencial de liquefação 154

5.3.1. Amplificação sísmica 155

5.3.2. Metodo Boulanger e Idriss 2014

5.3.3. Metodo Youd et al 2001

5.3.4. Metodo Castro 2014

6 Aspectos da Modelagem do comportamento sísmico 165

6.1. Análise numérica 165

6.1.1. Amortecimento 166 
6.1.1.1. Amortecimento de Rayleigh 166

6.1.1.2. Amortecimento histerético 168

6.1.2. Integração no tempo 168

6.1.3. Passo de tempo crítico 169

6.1.4. Discretização da malha para a transmissão da onda 170

6.1.5. Considerações de contorno 171

6.1.5.1. Contornos de campo livre 171

6.1.5.2. Considerações sobre a base do modelo 172

6.2. Metodo de equilíbrio limite 173

6.2.1. Análise pseudo-estática 174

6.3. Deformações permanentes por métodos simplificados 174

$\begin{array}{ll}\text { 6.3.1. Metodo de Swaisgood (2013) } & 176\end{array}$

7 Análise da resposta dinâmica da barragem de rejeitos Otapara 177

7.1. Considerações da modelagem 178

$\begin{array}{ll}7.1 .1 . \text { Unidades geotécnicas } & 178\end{array}$

7.1.1.1. Depósito coluvial (Unidad Geotécnica I) 178

7.1.1.2. Depósito aluvial (Unidad Geotécnica II) 178

7.1.1.3. Depósitos antrópicos (Unidad Geotécnica III) 179

7.1.1.4. Basamento rocoso (Unidad Geotécnica IV) 179

7.1.2. Seção de análise 180

7.1.3. Propriedades dos materiais 181

7.1.4. Tamanho máximo de zona da discretização 183

7.2. Análise estático 185

7.2.1. Poropressão na condição de fluxo permanente 186

7.2.2. Distribuição de tensão efetivas 186

$\begin{array}{ll}\text { 7.2.3. Tensões de cisalhamento } & 187\end{array}$

$\begin{array}{ll}\text { 7.2.4. Fator de segurança estático } & 187\end{array}$

$\begin{array}{ll}\text { 7.2.5. Análise estático } & 188\end{array}$

7.2.6. Análise pós-sismo 189

7.3. Análise dinâmico 192

7.3.1. Simulação elástica não amortecida 192

$\begin{array}{ll}\text { 7.3.2. Deslocamento permanentes } & 193\end{array}$ 
7.3.3. Relação de poropressão

7.3.4. Registros sísmicos e espectros de resposta

7.3.5. Deslocamentos pós sismo

209

7.3.6. Deslocamentos verticais Swaisgood (2013)

8 Conclusões e sugestões

214

8.1. Conclusões

214

8.2. Sugestões

216

Referências bibliográficas

218 


\section{Lista de Figuras}

Figura 2.1- Distribuição de sismos e placas tectônicas (apud López, 2015). 31

Figura 2.2- Localização do epicentro e do hipocentro (apud López, 2015). 32

Figura 2.3- Processo de subducção da placa de Nazca sob a placa sulamericana (Kuroiwa, 2002). 32

Figura 2.4- Configuração geométrica da placa nazca (Gamarra, 2009). $\quad 33$

Figura 2.5- Saturação de um registro sísmico (sismograma) devido à proximidade de um grande evento (apud López, 2015). 33

Figura 2.6- Ajuste de Linha base. (Carreño et al.,1999). 34

Figura 2.7- Efeitos de ruídos de alta (esquerda) e de baixa (direita) frequências (Hudson, 1979).

Figura 2.8- (a) Sinal sísmico naão corrigido, com ruído e (b) Sinal sísmico após filtragem (Jiménez, 2007). 36

Figura 2.9- Geometria de fontes sismogênicas: (a) pontual; (b) linear; (c) tridimensional. Fontes: Kramer, 1996; Monroy e Bolaños, 2004.

Figura 2.10- Representação do lei de Gutenberg-Richter com processo de Poisson duplamente truncado.

Figura 2.11- Ajuste pelo método da máxima verossimilhança (esquerda) e pelo método dos mínimos quadrados (direita) (Monroy e Bolaños, 2004). 43

Figura 2.12- Comparação de diferentes relações de atenuação com registros sísmicos da Espanha (Mezcua et al, 2008).

Figura 2.13-Curva de probabilidade de excedência utilizando duas relações de atenuação diferentes.

Figura 2.14- Obtenção do espectro de resposta uniformemente provável a partir das curvas de probabilidades de excedência (Meneses, 2009).

Figura 2.15 - Trifunac and Brady (1975) Duration of Strong Shaking (SD595) for Lake Hughes Acceleration Time History of 1994 Northrige Earthquake. 55

Figura 2.16- Espectros obtidos por meio do método de ajuste espectral 56

Figura 3.1 (a) Localização da barragem no Peru; (a) Localização no estado de Arequipa; (c) situação local. $\quad 65$

Figura 3.2- Seção transversal crítica da barragem Otapara. 66

$\begin{array}{ll}\text { Figura 3.3- Localização e dados do sismo (CISMID). } & 67\end{array}$ 
Figura 3.4- Consequências do sismo na barragem.

Figura 3.5- Fluxograma da classificação do risco na obtenção do período de retorno do simos de desenho.

Figura 3.6- Fluxograma da a ameaça sísmica probabilística.

Figura 3.7- Eventos Sismicos Magnitude Momento (Mw) 1555-2016. (Roncal, 2017).

Figura 3.8- Análise de Completitude do Catálogo (Roncal, 2017). 74

Figura 3.9- Fontes sismogênicas (a) subducção de interface (b) subducção intraplaca e (c) superfícial ou da crosta Continental (Roncal, 2017). $\quad 75$

Figura 3.10- Árvore Lógica usada na barragem de rejeitos Otapara. $\quad 80$

Figura 3.11- Curva de ameaça sísmica para solo tipo B com 5\% de amortecimento crítico.

82

Figura 3.12- Espectro do projeto para 1000 anos de período de recorrência. 83

Figura 3.13 - Desagregação da ameaça sísmica para PGA considerando $\operatorname{Tr}=1000$ anos, probabilidade de excedência de $5 \%$ em 50 anos de exposição.

Figura 3.14-Fluxograma para cpmstrução do sismo de projeto.

Figura 3.15- Registro sísmico de Atico, na direção EW.

Figura 3.16- Registro sísmico de Lima, na direção EW.

Figura 3.17- Registro sísmico de Maule, na direção EW.

Figura 3.18- Critério de Trifunac e Brady para o sismo de Atico EW (2001). 89

Figura 3.19- Duração do registro sísmico com base na conservação da energia Atico EW (2001).

Figura 3.20- Critério de Trifunac e Brady para o sismo de Lima EW (1974). 90

Figura 3.21- Duração do registro sísmico com base na conservaçãoda energia Lima EW (2001).

Figura 3.22- Critério de Trifunac e Brady para o sismo de Maule EW (2010). 92 Figura 3.23- Duração do registro sísmico com base na conservaçãoda energia Maule EW (2010).

Figura 3.24- Registro de (a) aceleração (b) velocidade (c) deslocamento do sismo de Atico (2001) prévio ao ajuste espectral.

Figura 3.25- Registro de (a) aceleração (b) velocidade (c) deslocamento do sismo de Lima (1974) prévio ao ajuste espectral. 
Figura 3.26- Registro de (a) aceleração (b) velocidade (c) deslocamento do sismo de Maule (2010) prévio ao ajuste espectral. 96

Figura 3.27- Espectros de resposta originais dos registros sísmicos considerados. 97

Figura 3.28- Processo de ajuste espectral dos registros sísmicos. $\quad 98$

Figura 3.29- Registro de (a) aceleração (b) velocidade (c) deslocamento do sismo de Atico (2001) após o ajuste espectral. $\quad 99$

Figura 3.30- Registro de (a) aceleração (b) velocidade (c) deslocamento do sismo de Lima (1974) após o ajuste espectral. 100

Figura 3.31- Registro de (a) aceleração (b) velocidade (c) deslocamento do sismo de Maule (2010) após o ajuste espectral. 101

Figura 4.1- (a) Módulo de cisalhamento secante, Gsec, (b) módulo de cisalhamento tangente, Gtan. (Kramer, 1996). 103

Figura 4.2 - Curvas de redução de módulos para solos granulares finos de diferentes plasticidades (After Vucetic \& Dobry, 1991). 106

Figura 4.3- Comparação das curvas de redução do módulo de corte para areia pouco graduada (SP) e cascalho bem graduada (GW) (Menq, 2003). 107

Figura 4.4- Efeito na curva de redução do módulo de cisalhamento pelo aumento da profundidade no solo 1-PCA (Roblee e Chiou, 2004). 107

Figura 4.5- Efeito na curva de redução do módulo de cisalhamento pelo do tipo de solo para profundidade superficial (Roblee e Chiou, 2004). 108

Figura 4.6- Variação da razão de amortecimento de solos granulares finos com a amplitude de deformação cisalhante cíclica e o índice de plasticidade (After Vucetic \& Dobry, 1991).

109

Figura 4.7- Comparação das curvas de amortecimento para areia pouco graduada (SP) e cascalho bem graduada (GW) (Menq, 2003). 109

Figura 4.8- Efeito na curva de amortecimento da profundidade no solo 1-PCA. (Roblee e Chiou, 2004).

Figura 4.9- Relação tensão-deformação hiperbólica para testes triaxiais adensados drenados.

Figura 4.10- Determinação do valor de $E_{o e d}{ }^{\text {ref }}$ em testes oedométricos. $\quad 119$

Figura 4.11- Comportamento de rigidez-deformação. 121

Figura 4.12- Comportamento histerético. 123 
Figura 4.13- Projeção da superfície de escoamento no plano do desvio. Depois $\begin{array}{lr}\text { de Tsegaye (2010) (Petalas e Galavi, 2013). } & 125\end{array}$

Figura 4.14- Regra de endurecimento da UBCSAND original de Beaty e Byrne (1998) (Petalas e Galavi, 2013).

Figura 4.15- Definição do parâmetro de estado $\psi$ (adaptado Kramer, 1996).133

Figura 4.16- Exemplos de curvas de inicio de liquefação baseadas em SPT, inclui os resultados de Youd et al. (2001). (Idriss e Boulanger, 2014). 136

Figura 4.17-. Relação de resistência ao cisalhamento residual normalizada de areia liquefeita versus contagem de sopro corrigida SPT de areia limpa equivalente para $\sigma^{\prime}{ }_{\mathrm{vc}}<400 \mathrm{kPa}$, usando as histórias de casos publicadas por Seed (1987), Seed e Harder (1990) e Olson e Stark (2002). 140

Figura 5.1- Fluxograma da avaliação do potencial de liquefação. 141

Figura 5.2 - Localização dos ensaios SPT e outras sondagens realizadas no projeto.

Figura 5.3- Influência na resistência cíclica dos rejeitos (a) Fino $M L Y_{d}=1.56$ $\mathrm{gr} / \mathrm{cm}^{3}$, (b) Grosso SM DR=40.0\% e (c) Grosso SM DR=60.0\% (Soto 2002).

Figura 5.4- Curva de degradação do modulo de Young e amortecimento para os rejeitos grossos. (Soto 2002).

Figura 5.5- Velocidade de ondas cisalhantes na sondagem (a) SPT-1 e (b) SPT2.

Figura 5.6- Discretização em camadas na sondagem (a) SPT-1 e (b) SPT-2.

Figura 5.7- Curva (a) redução de módulo cisalhante e (b) variação da razão de amortecimento na sondagem SPT-1.

Figura 5.8- Curva (a) redução de módulo cisalhante e (b) variação da razão de amortecimento na sondagem SPT-2.

Figura 5.9- Aceleração a diferente elevação na sondagem (a) SPT-1 e (b) SPT2.

Figura 5.10- Variação do fator de segurança contra liquefação considerando os três sismos de projeto: a) furo SPT-1; b) furo SPT-2 (Boulanger e Idriss, 2014). 
Figura 5.11- Variação do fator de segurança contra liquefação considerando os três sismos de projeto: a) furo SPT-1; b) furo SPT-2 (Youd et al., 2001).162

Figura 5.12- Deformação cisalhante máxima na sondagem (a) SPT-1 e (b) SPT2.

Figura 5.13- Deformação que ativa a liquefação na sondagem (a) SPT-1 e (b) SPT-2. 163

Figura 6.1- Variação da razão de amortecimento crítico normalizado em relação à frequência angular (adaptado Contreras, 2014). 167

Figura 6.2- Condições de contorno de campo livre (Perez, 2013). 172

Figura 6.3- Seção na análise do deslocamento vertical permanente pelo método de Swaisgood (2013). 176

Figura 7.1- Fluxograma da modelagem numérica. 177

Figura 7.2- Corte transversal da barragem de rejeitos de Otapara. $\quad 180$

Figura 7.3- Espectros de potência das velociades e frequências de corte dos sismos artificiais (a) Atico 2001, (b) Lima 1974 e (c) Maule 2010. 184

Figura 7.4- Poropressões ativas no corpo da barragem antes do terremoto. 186 Figura 7.5- Distribuição das tensões efetivas verticais (a) e horizontais (b) na condição estática. 186

Figura 7.6- Tensões de cisalhamento no plano horizontal $\left(\tau_{x y}\right)$ em condição estática.

187

Figura 7.7- Superfície de ruptura da barragem em condição estática. $\quad 187$

Figura 7.8- Campo de deslocamento da barragem em condição estática. 188

Figura 7.9- Análise estática de estabilidade (a) global a jusante, (b) local a jusante e (c) local a montante. 189

Figura 7.10- Análise pós sismo de estabilidade (a) global a jusante (b) local a jusante e (c) local a montante. 191

Figura 7.11- Pontos de controle para deslocamentos e poropressões. 193

Figura 7.12- História de deslocamentos (a) horizontais (b) verticais provocados nos pontos P1 e P2 durante o sismo artificial Atico 2001.

Figura 7.13- História de deslocamentos (a) horizontais (b) verticais provocados nos pontos P1 e P2 durante o sismo artificial Lima 1974.

Figura 7.14- História de deslocamentos (a) horizontais (b) verticais provocados nos pontos P1 e P2 durante o sismo artificial Maule 2010. 
Figura 7.15-. Campos de deslocamento (a) Totais, (b) horizontais e (c) verticais provocados pelo sismo artificial Atico 2001.

Figura 7.16- Campos de deslocamento (a) Totais, (b) horizontais e (c) verticais provocados pelo sismo artificial Lima 1974.

Figura 7.17- Campos de deslocamento (a) Totais, (b) horizontais e (c) verticais provocados pelo sismo artificial Maule 2010.

199

Figura 7.18-. História do parâmetro de poropressão (ru) em alguns pontos de controle durante os sismos artificiais (a) Atico 2001, (b) Lima 1974 e (c) Maule 2010.

201

Figura 7.19-. Distribuição final do parâmetro de pressão de poros (ru) para os sismos artificiais (a) Atico 2001, (b) Lima 1974 e (c) Maule 2010.

Figura 7.20- Pontos de controle das poropressões nas zonas que não liquefaçem.

202

Figura 7.21 - História do parâmetro de poropressão (ru) nos pontos que não liquefaçem durante os sismos artificiais (a) Atico 2001, (b) Lima 1974 e (c) Maule 2010.

Figura 7.22- Resposta em termos de aceleração dos pontos P1 e P2 durante os sismos artificiais (a) Atico 2001, (b) Lima 1974 e (c) Maule 2010.

Figura 7.23-. Acelerações espectrais nos pontos P1 e P2 para os sismos artificiais (a) Atico 2001, (b) Lima 1974 e (c) Maule 2010.

Figura 7.24- Acelerações espectrais em alguns pontos das camadas de rejeitos para os sismos artificiais (a) Atico 2001, (b) Lima 1974 e (c) Maule 2010.

208

Figura 7.25- História de deslocamentos verticais provocados no (a) ponto P1 e (b) ponto P3 durante e pós do sismo artificial Atico 2001.209

Figura 7.26- História de deslocamentos verticais provocados no (a) ponto P1 e (b) ponto P3 durante e pós do sismo artificial Lima 1974.

Figura 7.27- História de deslocamentos verticais provocados no (a) ponto P1 e (b) ponto P3 durante e pós do sismo artificial Maule 2010.

Figura 7.28- Comparação entre a modelagem numérica e a situação após 5 dias ocorrido o sismo em 2013. 


\section{Lista de Tabelas}

Tabela 2.1 - - Classificação de solos em função da velocidade de propagação da onda cisalhante (Vs) - IBC (2012), ASCE 7-10.

Tabela 2.2 - Classificação das barragens por níveis de perdas (adaptado CDA, 2013).

Tabela 2.3 - Níveis Recomendados para o Terremoto de Desenho (adaptado CDA, 2013).

Tabela 2.4- Níveis de terremoto e inundação recomendada (adaptado CDA, 2013).

Tabela 2.5- Quantificação do Fator de Risco (adaptado ICOLD, 2016). 60

Tabela 2.6- Classificação de Risco (adaptado ICOLD, 2016).

60

Tabela 3.1: Localização das estações e os valores máximos de acelerações. 68

Tabela 3.2- Níveis de terremoto (adaptado CDA, 2013). 70

Tabela 3.3- Estimativa do fator de risco da barragem de rejeitos. $\quad 70$

Tabela 3.4- Classificação de Risco (adaptado ICOLD, 2016). 70

Tabela 3.5- Integridade do catálogo sísmico (Roncal, 2017). 76

Tabela 3.6- Parâmetros sismológicos das fontes sismogênicas (Roncal, 2017).

Tabela 3.7- Valores de aceleração máxima do solo (PGA) para solo tipo B. 82 Tabela 3.8-Desagregação de Ameaça Sísmica PGA para Rocha, $T r=1000$ anos, $\mathrm{PE}=5 \%$ em 50 anos. $\quad 84$

Tabela 3.9- Registros sísmicos considerados no ajuste espectral. $\quad 86$

Tabela 3.10- Direções e acelerações máximas dos registros. 86

Tabela 3.11- Tentativas de duração do registro sísmico conservando sua energia, sismo de Atico EW. 89

Tabela 3.12- Tentativas de duração do registro sísmico conservando sua energia, sismo de Lima EW. 91

Tabela 3.13- Tentativas de duração do registro sísmico conservando sua energia, sismo de Maule EW. 92

Tabela 4.1 - Exponente da razão de pre-adensamento, k. (adaptado Hardin \& Drnevich (1972)). 103

Tabela 4.2 - Estimação de K2,max. (adaptado Seed \& Idriss (1970)). 104

Tabela 4.3 - Valores de $\mathrm{Gmax}_{\operatorname{ma}} / \mathrm{Su}^{\mathrm{a}}$ (Kramer, 1996). 105 
Tabela 4.4 - Relações empíricas de correlação entre Gmax e parâmetros de ensaios in situ (adaptado a partir de Kramer, 1996). 105

Tabela 4.5- Parâmetros Hardening soil. 120

Tabela 4.6- Parâmetros adicionais HS small. 124

Tabela 4.7- Parâmetros UBC3D-PLM. 129

Tabela 4.8- Comparação das vantagens e desvantagens de vários testes de campo para avaliação da resistência à liquefação (Hurtado, 2009). 134

Tabela 5.1- Relação entre NSPT com compacidade e consistência (ABNT - NBR 6484). 143

Tabela 5.2- Resumo dos Ensaios SPT 1 y CP - Antes do Sismo. 145

Tabela 5.3- Resumo dos Ensaios SPT 2 y CP - Antes do Sismo. 146

Tabela 5.4- Resumo dos Ensalos SPT 3 - Após do Sismo. 147

Tabela 5.5- Resumo dos Ensaios SPT 4 - Após do Sismo. 147

Tabela 5.6- Resumo de ensaios de Clasificação de solos. 148

Tabela 5.7- Resumo do Ensaio de Corte Direto. 149

Tabela 5.8- Resumo de ensaios de clasificação de solos do rejeito. 149

Tabela 5.9- Resumo de densidade promedio de rejeito. 149

Tabela 5.10- Resumo de ensaios de gravedade específica. 150

Tabela 5.11- Resumo do Ensaios de Compressão Simples. 150

Tabela 5.12- Resumo de ensaios de propriedades fisicas em rocha. 151

Tabela 5.13-. Resumo dos testes de liquefação (adaptado Soto, 2002). 151

Tabela 6.1- Resumo dos métodos de deslocamento permanente (Murphy, 2010)

Tabela 7.1- Avaliação do maciço rochoso 180

Tabela 7.2- Propriedades elasticos dos materiais. 181

Tabela 7.3- Propriedades dos materias usadas na análise estática. 182

Tabela 7.4- Parãmetros utilizados na análise dinámica dos materiais não liquefiáveis. 182

Tabela 7.5- Parâmetros do modelo UBC3D-PLM empregados na análise dinámica dos materiais liquefiáveis.

Tabela 7.6- Determinação do tamanho máximo da discretização dos elementos. 
Tabela 7.8 - Parâmetros de resistência residual para rejeitos.

Tabela 7.9- Fator de segurança para diferentes superfícies de ruptura e condições.

Tabela 7.10- Frequências natural de vibração obtidas nos diferentes materiais.

Tabela 7.11- Deslocamentos permanentes máximos induzidos pelos sismos. 197

Tabela 7.12- Cálculo de deslocamentos verticais - Swaisgood (2013). 212 


\section{Lista de Símbolos}

A - constante de amortecimento proporcional à massa

$a(t) \quad-\quad$ acelerograma sem corrigir

Alaço - área do laço de histerese

B - constante de amortecimento proporcional à rigidez

B - inclinação da curva da lei de recorrência

[C] - matriz de amortecimento viscoso

c - coesão

$\mathrm{Ci}_{1} \alpha_{i}$ - coeficientes das relações de atenuação

di - espessura da camada i

De - matriz de rigidez elástica

e - índice de vazios

$\delta \quad$ - multiplicador plástico

$\varepsilon^{e} \quad$ - deformação elástica

$\varepsilon^{p} \quad$ - deformação plástica

$f_{c} \quad$ - frequência de corte

$f_{i} \quad$ - funções de escoamento

$f_{M}(m)$ - função de densidade de probabilidade da grandeza do sismo

$f_{R}(r)$ - função de densidade de probabilidade da localização do sismo

$\phi \quad$ - ângulo de atrito interno do solo

g - aceleração da gravidade

$g_{i} \quad$ - funções de potencial plástico

G - módulo cisalhante

$G_{\max }$ - módulo cisalhante máximo

Gsec - módulo de cisalhamento secante

$\mathrm{H}$ - profundidade focal

$H(x)$ - função Heaviside, função de grau

$\mathrm{K}$ - modulo de deformação volumétrica

K' - erro de aproximação das diferenças finitas

$\mathrm{K}_{2, \max }$ - constante da influência do índice de vazios

I - comprimento de onda

$\lambda \quad$ - probabilidade de ocorrência de sismos por unidade de tempo

$P^{*}(y>Y)$ - taxa anual de excedência do movimento $Y$ 


$$
\begin{aligned}
& \text { L - comprimento médio de ruptura da falha } \\
& \text { mo - magnitude mínima de referência } \\
& \mathrm{mb} \quad \text { - magnitude de ondas de corpo } \\
& \text { Mo - momento sísmico } \\
& \mathrm{ML} \quad \text { - magnitude local } \\
& \text { Ms - magnitude de ondas de superfície } \\
& \text { Mu - magnitude máxima } \\
& \text { Mw - magnitude momento } \\
& \text { [M] - matriz de massa } \\
& \mathrm{N} \quad \text { - número de sismos maiores ou iguais que certa magnitude } \\
& \mathrm{p}_{\mathrm{a}} \quad \text { - pressão atmosférica } \\
& P_{n} \quad \text { - probabilidade de ocorrência de sismos } \\
& P(y>Y) \text { - probabilidade de excedência de } Y \\
& \mathrm{P}\left(\mathrm{A} / \mathrm{E}_{\mathrm{i}}\right) \text { - probabilidade condicional } \\
& r(t) \quad \text { - ruído do registro sísmico } \\
& \text { rup, Dfalha - distância mais próxima ao área de ruptura } \\
& \rho \quad \text { - massa específica } \\
& \mathrm{s}(\mathrm{t}) \quad \text { - sinal do registro sísmico } \\
& \text { Sa,Y,y - aceleração espectral } \\
& \mathrm{S}_{\mathrm{i}} \quad \text { - fator solo nas relações de atenuação } \\
& \sigma_{i j} \quad \text { - componentes do tensor de tensões } \\
& \sigma^{\prime} m \text { - tensão efetiva média } \\
& \text { t } \quad \text { - tempo } \\
& \text { T - Taxa sísmica da fonte sismogênica } \\
& \mathrm{T}_{\mathrm{r}} \quad \text { - período de recorrência } \\
& \mathrm{Vi} \quad \text { - taxa anual de ocorrência de sismos da fonte i } \\
& v_{\mathrm{s}} \quad \text { - velocidade de ondas cisalhantes } \\
& V_{\mathrm{t}} \quad \text { - velocidade tangencial da partícula } \\
& \bar{v}_{s} \quad \text { - velocidade media das ondas cisalhantes } \\
& \Psi \quad \text { - ângulo de dilatância } \\
& W_{d} \text { - energia dissipada em um ciclo de histerese } \\
& W_{s} \quad \text { - energia de deformação máxima } \\
& x_{i} \quad \text { - componentes do vetor posição }
\end{aligned}
$$




\section{Lista de Abreviaturas}

ANSS - Advanced National Seismic System

CDA - Associação Canadense de Barragens

CERESIS - Centro Regional de Sismologia para América del Sur

CMT - Global Centroid-Moment-Tensor

FLAC - Fast Lagrangian Analysis of Continua

GSHAP - Global Seismic Hazard Assessment Program

IBC - International Building Code

ICOLD - International Commission on Large Dams

IGP - Instituto Geofísico do Peru

INDECI - Instituto Nacional de Defensa Civil (Peru)

ISC - International Seismological Centre

MCE - Maximum Credible Earthquake, Máximo sismo esperado

NEIC - National Earthquake Information Center

NGDC - National Geophysical Data Center

NOAA - National Oceanic and Atmospheric Administration

OBE - Operation Basis Earthquake, Sismo base de operação

OBSIS - Observatório Sismológico da Universidade de Brasília

PGA - Peak ground acceleration, aceleração máxima do solo

SBGf - Sociedade Brasileira de Geofísica

SEE - Safety Evaluation Earthquake, Sismo de avaliação de segurança

SISRA - Sismicidade da Região Andina

UHS - Uniform Hazard Spectra, Espectro de resposta uniformemente provável

UnB - Universidade de Brasília

USGS - United States Geological Survey 


\section{1 \\ Introdução}

1.1.

Relevância e justificativa da pesquisa

O cinturão do fogo é considerado como a região de maior atividade sísmica no planeta. Envolve uma grande quantidade de território continental e da plataforma oceânica, dentro do qual se encontra o Peru. Os terremotos registrados neste país têm origem na interação entre a placa Sul-Americana e a placa de Nazca, as quais interagem causando rupturas em falhas geológicas que dão origem a sismos, que podem apresentar diferentes mecanismos de ruptura: subducção, interface ou intraplaca.

Nas atividades de mineração os materiais gerados a partir da separação do mineral da matriz rochosa são chamados de rejeitos que, de acordo com o conteúdo de água, recebem diferentes nomes. O rejeito com grande quantidade de água é denominado polpa. Os rejeitos são geralmente depositados em locais que armazenam grande quantidade de material em pequena área, mas de grande altura nas estruturas conhecidas como barragens de rejeitos.

As rupturas das barragens de rejeitos de El Cobre (Chile, 1965), Buffalo Creek (Estados Unidos, 1972), Mochilcochi (Japão, 1978), Stava (Itália, 1985), Fundão (Brasil, 2015) e Brumadinho (Brasil, 2019) são exemplos de tragédias ambientais, econômicas, de perda de infraestrutura e de vidas humanas decorrentes do colapso de barragem de rejeitos.

As principais causas pelas quais a maioria das barragens de rejeitos rompeu foram:

- Terremotos na área da barragem de rejeitos;

- Deficiências no sistema de drenagem;

- Falta de controle e monitoramento dos trabalhos durante a construção;

- Alteamentos excessivos.

São listados abaixo alguns casos de barragens de rejeitos no Peru que romperam: 
- Casapalca CENTROMIN, altura: 60m, ano: 1952; consequências: numerosas mortes e contaminação do rio Rimac, Causa: terremoto.

- Milpo, altura: 60m, ano: 1956; consequências: numerosas mortes e interrupção da estrada Cerro de Pasco-Huanuco. Causa: terremoto.

- Almivirca QUIRUVILCA, altura: 40m, ano: 1962; consequências: danos na agricultura e obras de infraestrutura. Causa: terremoto $\mathrm{Mw}=6.7$.

- Yauli-Yacu CENTROMIN, altura: 80m, ano: 1968; consequências: interrupção da Rodovia Central e contaminação do Rio Rimac. Causa: terremoto.

- Almivirca QUIRUVILCA, altura: 40m, ano: 1970; consequências: poluição do Rio San Felipe. Causa: terremoto de 1970.

- Ticapampa ALIANZA, altura: 20m, ano: 1971; consequências: três mortos, destruição de casas e interrupção da rodovia Huaraz-Lima. Causa: terremoto.

No dia 25 de setembro de 2013, um sismo ocorrido em Acarí-Arequipa, Peru, de magnitude 6.9 na escala de Richter, atingiu a barragem de rejeitos de Otapara causando trincas no corpo da estrutura, recalques na crista e aparecimento de pequenos vulcões de areia (sand boils) que indicaram a redução dos parâmetros de resistência dos rejeitos devido à liquefação dinâmica.

\section{2.}

\section{Motivação e objetivos}

Esta dissertação tem como objetivo analisar o comportamento sísmico da barragem de rejeitos de Otapara, Peru, considerando os seguintes aspectos:

- Classificação da barragem mediante análise de risco;

- Estimar a ameaça sismica por métodos probabilísticos para obtenção do espectro de ameaça uniformemente provável;

- Determinação do sismo artificial de projeto por método de ajuste espectral;

- Análise pseudo-estática da estabilidade dos taludes da barragem por método do equilíbrio limite;

- Estimativa dos deslocamentos permanentes por método simplificado;

- Avaliação do potencial de liquefação por método simplificado considerando propagação unidimensional de ondas $S$; 
- Análise dinâmica do comportamento da barragem pelo método dos elementos finitos considerando o modelo constitutivo elastoplástico UBCSAND para carregamentos cíclicos.

\section{3.}

\section{Estrutura da dissertação}

A presente dissertação é composta por 8 capítulos, referências bibliográficas e anexos.

No capítulo 1 apresenta-se a relevância da pesquisa, a justificativa, motivação e seus principais objetivos, enquanto que o capítulo 2 é reservado para descrição de conceitos básicos de sismicidade, ameaça sísmica, geração de registros sísmicos e classificação de barragens quanto ao risco sísmico.

O capítulo 3 é dedicado à apresentação da barragem de rejeitos de Otapara e no capítulo 4 são discutidos os modelos constitutivos para comportamento cícilico, propriedades dos materiais e tipos de ensaios para sua obtenção.

O capítulo 5 descreve o modelo elastoplástico UBC3D-PLM, enquanto que no capítulo 6 são discutidos aspectos de modelagem sísmica.

No capítulo 7 são apresentados os resultados numéricos relativos ao comportamento estático e dinâmico da barragem e o capítulo 8 é dedicado para as conclusões da presente pesquisa e sugestões para o prosseguimento da mesma em trabalhos futuros.

\section{4. Histórico da linha de pesquisa}

A seguir, são apresentadas algumas pesquisas feitas na PUC-Rio, realaciodas a liquefação dinâmica, comportamento dinâmico de geoestrucutras (barragens), orientadas pelo professor Celso Romanel. Estas foram de grande importância para o entendimento dos conceitos do comportamento das estruturas diante das solicitações dinâmicas desenvolvidas nessa pesquisa.

Vilcahuamán Pinedo P. (2018) avaliou numérica o potencial de fiquefação induzido pelos terremotos na barragem de rejeitos o Provenir no Peru mediante o método de diferenças finitas empregando os modelos elastoplastico UBCSand e de Byrne com o programa FLAC 2D. 
Ccahuay Azurza M. (2018) analisou o comportamento sísmico da barragem de rejeitos de Chumpe no Peru, mediante as diretrizes de segurança de barragens da CDA e a ICOLD classificou o risco qual foi asosiado a um período de retorno, foi considerado o perigo sísmico determinístico e probabilístico, modelagem da barragem foi realizada com o software FLAC 2D.

Huaman Cabrera J. (2018) pesquisou sobre a previsão numérica do comportamento sísmico da barragem de rejeitos Alpamarca no Peru localizada em região sismicamente ativa, estudos probabilísticos de ameaça sísmica utilizando o software de código aberto Openquake, empregou o método de diferenças finitas com o programa FLAC 2D.

Velez Parra, D. (2017) estudou o comportamento dinâmico de duas geoestruturas no Equador: uma encosta de solo aluvial e a usina hidroelétrica Mazar (barragem de enrocamento); os estudos foram feitos mediante análises numéricas pelo método de diferenças finitas no programa FLAC 2D.

López Vásquez J. (2015) pesquisou a previsão da resposta dinâmica mediante análise numérica com o programa computacional FLAC 2D da barragem de terra Callazas, localizada no sul do Peru classificada como uma grande barragem pelas diretrizes de segurança de barragens. Foi realizado uma ameaça sísmica probabilística com leis de atenuação para solos e a geração de registros sísmicos artificiais. Os resultados obtidos foram deslocamentos permanentes, fatores de segurança e perfis de aceleração no solo de fundação e no corpo da barragem.

Contreras Fajardo R. (2014) estudou a previsão numérica do comportamento dinâmico da barragem de terra de Breapampa, situada no Peru em zona de atividade sísmica mediante o programa computacional FLAC 2D v.7 baseado no método das diferenças finitas. Foi simulada a construção, elevação do reservatório, estabelecida a linha freática; seleção do terremoto de projeto, filtragem de altas frequências, contorno silenciosas, modelo constitutivo MohrCoulomb e amortecimento histerético. Os resultados obtidos foram deslocamentos permanentes, história de deslocamentos, amplificações da aceleração horizontal, poropressões no corpo da barragem e potencial de ruptura cíclica. 
Perez Collantes F. (2013) investigou o comportamento dinâmico de uma barragem de rejeitos de bauxita localizado na Jamaica empregando método dos elementos finitos no programa PLAXIS 2D, foi considerado uma analise probabilística da ameaça sísmica. Os resultados de fator de segurança pelo método deredução de parâmetros, deslocamentos permanentes e relação tensãodeformação foram comparados com metodologias simplifadas como o método de estabilidade pseudo-estático e método de Newmark.

Castañeda Huertas J. (2012) pesquisou os procedimentos de análise nãolinear com as ferramentas computacionais FLAC e SHAKE para a previsão da resposta sísmica num projeto de cais nuclear, localizado no litoral do Rio de Janeiro, Brasil. Foi avaliada a vulnerabilidade de ocorrência de terremotos em regiões intraplaca com magnitudes menores, assim como o potencial de liquefação em solo tipo areia mediante o modelo constitutivo cíclico UBCSAND. Os resultados da resposta sísmica expressa em termos de história de acelerações, espectros de repostas, parâmetro $r_{u}$ de liquefação, e deslocamentos permanentes.

Loayza Herrea F. (2009) estudou a modelagem do comportamento póssismo de uma barragem de contenção de rejeitos de mineração localizada na Argentina pelo método das diferenças finitas no programa FLAC 2D. Foram feitos análise estática, avaliação dinâmica e a análise de estabilidade pós-sismo. Determinou-se o tipo de amortecimento e seus respetivos parâmetros, história no tempo de tensões, velocidades e deslocamentos logo ao término do sismo.

Hurtado Aquino G. (2009) estudou o fenômeno de liquefação na estabilidade de pilha de lixiviação de minério de cobre no Peru sob carregamento sísmico, foram empregados os modelos constitutivos de Finn quanto UBCSand no programa FLAC 2D.

Quispe Maldonado E. (2008) analisou a resposta sísmica do talude de um aterro reforçado com geossintéticos, localizada em zona de atividade sísmica, no Peru. As análises dinâmicas foram realizadas utilizando o programa computacional FLAC (ITASCA, 2005). O material de rejeito foi simulado através do modelo elastoplástico de Mohr-Coulomb e os reforços de geossintéticos como elementos de cabo. 
Morote Soto C. (2006) analisou a estabilidade e deformação dos taludes da estrutura de contenção dos resíduos de lixiviação de mineiro de uranio, na Bahia e dos taludes de bota-fora sul da mina de cobre Toquepala, no Peru, solo sob carregamento sísmico, foram realizadas análises pseudo-estática, métodos simplificados de deformações permanentes de Newmark e Makdisi-Seed, assim como modelos de elementos finitos mediante o programa GeoStudio (Slope/W, Sigma/W e Quake/W).

Estas pesquisas, orientadas pelo professor Celso Romanel, abrangendo a análise numérica do comportamento sísmico de uma barragem de rejeitos, alargaram as fronteiras de conhecimentos desses assuntos aos futuros pesquisadores. Permitindo informações mais sólidas e precisas às atuais pesquisas. 


\section{2 \\ Conceitos de sismologia e ameaça sísmica}

\section{1.}

\section{Conceitos de sismicidade}

\subsection{1.}

\section{Placas tectõnicas}

O círculo de fogo do Pacífico constitui a zona do globo terrestre que possui a maior tendência de ocorrência de eventos sísmicos, por se situar nos limites de placas tectônicas; nesta região, que abrange a costa sul-americana e chega até a Nova Zelândia, ocorrem aproximadamente $80 \%$ dos sismos mundiais (Erro! Fonte de referência não encontrada.).

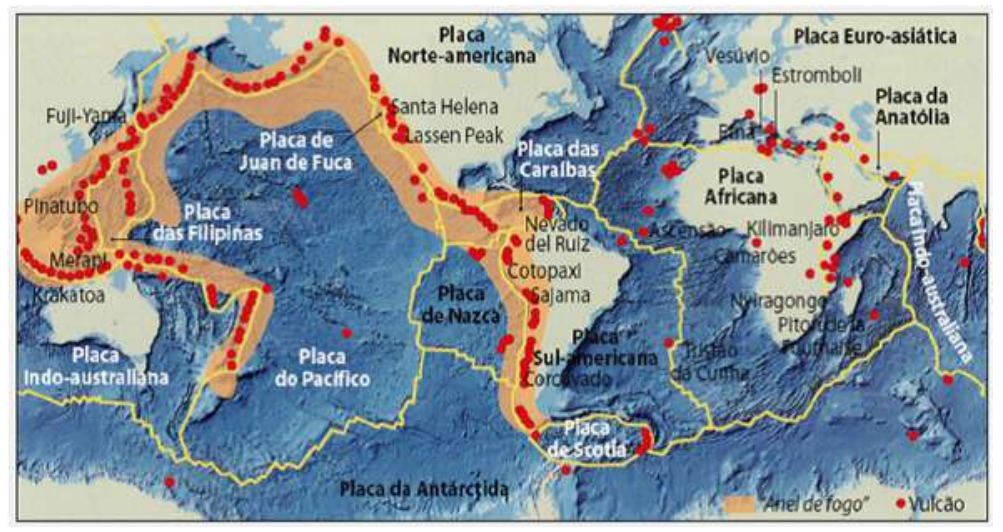

Figura 2.1- Distribuição de sismos e placas tectônicas (apud López, 2015).

Para estabelecer a localização de um sismo é necessária a definição de seu hipocentro e epicentro. O ponto onde o sismo tem sua origem é o hipocentro ou foco sísmico, enquanto que a interseção da linha vertical traçada pelo hipocentro com a superfície terrestre estabelece o epicentro (Figura 2.2). 


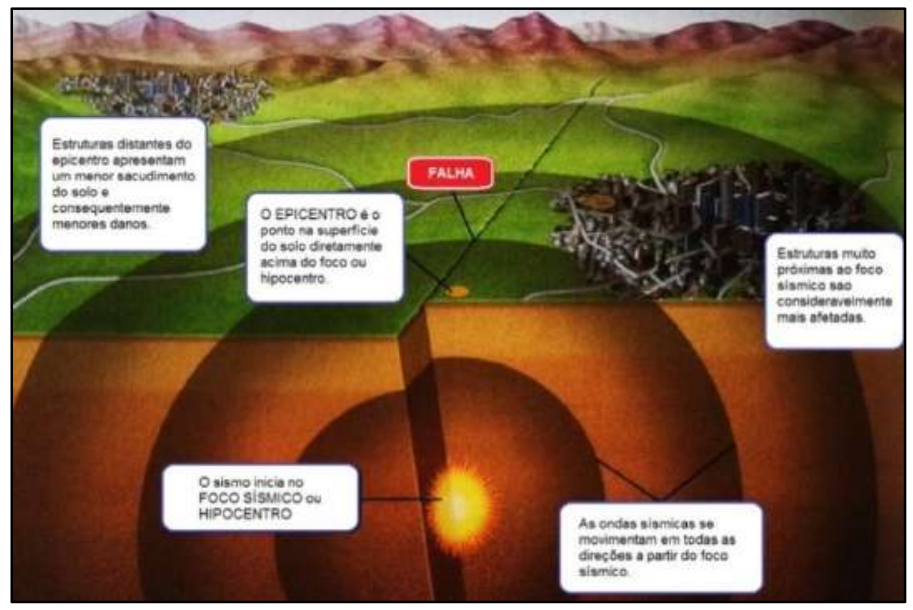

Figura 2.2- Localização do epicentro e do hipocentro (apud López, 2015).

\subsubsection{1. \\ Configuração tectónica do Peru}

A configuração tectônica do Peru é definida por tensões e deformações que ocorrem como resultado da interação da Placa de Nazca e da Placa Sul Americana. Esse processo de colisão e fricção originou diferentes estruturas tectônicas que modificam o comportamento da sismicidade no Peru (Figura 2.3).

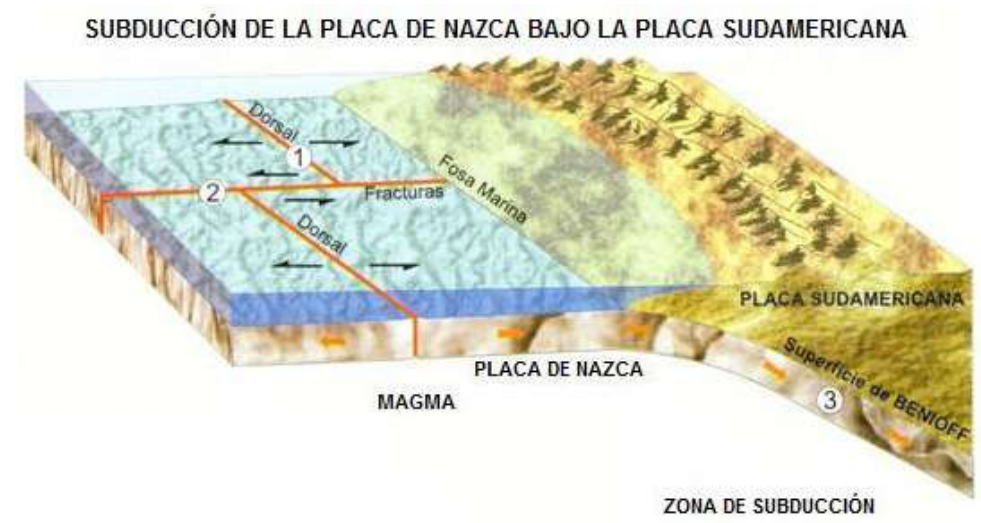

Figura 2.3- Processo de subducção da placa de Nazca sob a placa sul-americana (Kuroiwa, 2002).

A Placa de Nazca apresenta uma geometria heterogênea, caracterizada por dois diferentes modos de subducção (horizontal e normal ao norte e ao sul do Peru, respectivamente). A Placa de Nazca suporta várias contorções em toda a sua extensão, uma delas está localizada ao sul de Arequipa. As principais estruturas lineares da configuração geométrica da Placa de Nazca são a dorsal 
de Nazca, a dorsal de Sarmiento e Alvarado, a fratura de Mendaña, a fratura de Nazca, a fratura de Viru e a depressão submarina de Trujillo (Figura 2.4).

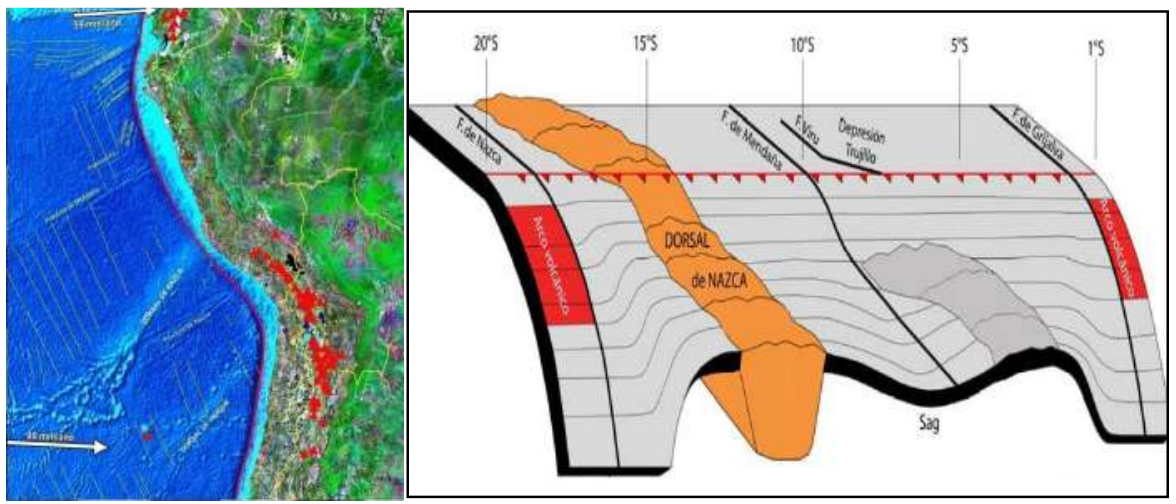

Figura 2.4- Configuração geométrica da placa nazca (Gamarra, 2009).

\subsection{2. \\ Registros sísmicos}

A engenharia sísmica tem como propósito aumentar a capacidade de resistência das estruturas e diminuir os danos gerados pela demanda sísmica. Os danos gerados pela demanda sísmica são estimados com base em registros sísmicos obtidos de instrumentação geofísica, como o sismógrafo e o acelerômetro. O sismógrafo tem a ventagem de possuir uma alta sensibilidade para registrar deslocamentos ou velocidades, mas a desvantagem de saturar o registro para sismos de grande magnitude que acontecem nas proximidades (Figura 2.5). O acelerômetro registra a aceleração do evento sísmico, sem saturação para eventos sísmicos mesmo com acelerações superiores à da gravidade, e por este motivo são os equipamentos mais usados.

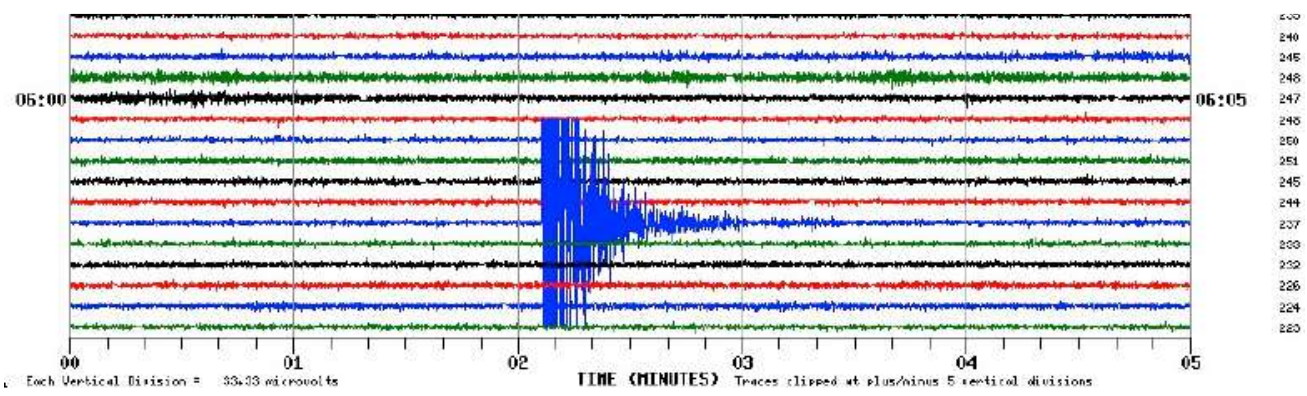

Figura 2.5- Saturação de um registro sísmico (sismograma) devido à proximidade de um grande evento (apud López, 2015). 
Para determinação mais exata dos valores de aceleração, velocidade ou deslocamento deve ser feito um processamento para correção da linha base e filtragem no domínio da frequência para eliminação de ruídos.

\subsubsection{1.}

\section{Correção da linha base}

A correção de linha base é executada pela aplicação de uma função, quadrática ou cúbica, conforme Equação (2.1):

$$
\ddot{y}_{c}(t)=\ddot{y}_{n}(t)+a+2 b t+3 c t^{2}
$$

onde o subscrito $c$ e $n$ indicam o registro sísmico corrigido e não corrigido, respectivamente, no tempo $t$. As constantes a, b e c são obtidas por meio da Equação (2.2) que estabelece uma operação de minimização do funcional $F\left(t, V_{0}\right.$, $a, b, c)$.

$$
\delta F\left(t, V_{0}, a, b, c\right)=\delta \int_{0}^{s} \dot{y}_{c}^{2} d t=0
$$

onde $s$ é a duração do terremoto e $\dot{y}_{c}(t)=\dot{y}_{n}(t)+V_{0}+a t+b t^{2}+c t^{2}$ é a velocidade no tempo $t$. Este ajuste é feito ponto a ponto da série discreta de valores do registro sísmico.

O efeito deste erro, que é usualmente pequeno em um acelerograma, resulta em um erro linear na velocidade e um erro quadrático no deslocamento, após as integrações no tempo do registro das acelerações (Figura 2.6). Corrigir tais erros é o que corresponde ao chamado ajuste de linha base (baseline adjustment).

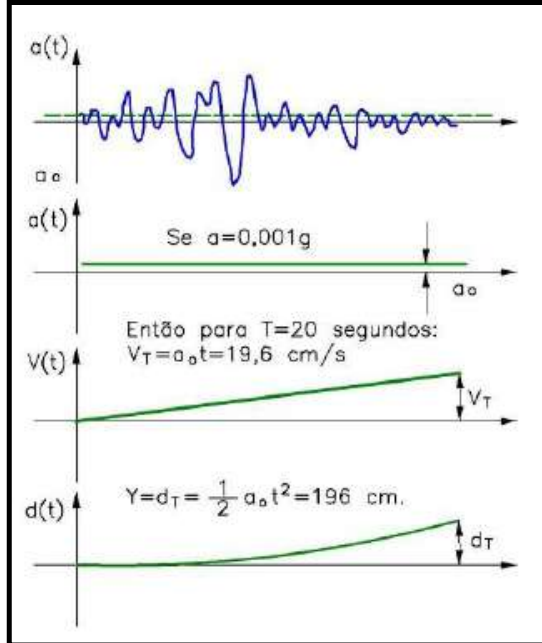

Figura 2.6- Ajuste de Linha base. (Carreño et al.,1999). 
O ajuste de linha base do registro sísmico deve ser feito após a filtragem (baseada na identificação da frequência de corte), já que após a filtragem o registro sísmico encontra-se com valores de aceleração, velocidade e deslocamentos finais diferentes de zero. Atualmente, alguns softwares realizam o processamento de registros sísmicos, e na presente pesquisa foi utilizado o programa computacional Seismosignal, 2018.

\subsubsection{2.}

\section{Porcesso de filtragem}

Pode-se considerar que o registro do acelerações é a soma do sinal do sismo e de ruídos, definido da seguinte forma:

$$
a(t)=s(t)+r(t)
$$

onde:

$a_{(t)}$ é o acelerograma sem correção,

$\mathrm{s}_{(\mathrm{t})}$ o sinal do sismo e

$r_{(t)}$ o ruído que afeta o acelerograma.

O sinal do acelerograma no tempo é levado para o domínio da frequência por meio da transformada de Fourier. O processo de filtragem consiste em eliminar, atenuar ou amplificar certas componentes de frequência do sinal, multiplicando por uma função que reduz o valor da amplitude do espectro de Fourier fora do intervalo de frequências desejado. Dependendo de sua aplicação, um filtro pode ser classificado como passa-baixa, passa-alta, passa-banda ou eliminador de banda.

Para eliminar os ruídos de altas frequências (high-cut filter) são utilizados filtros passa-baixa, pois esta componente do ruído pode prejudicar o processo de integração na obtenção das histórias de velocidade e de deslocamento (Figura 2.7). Os ruídos de altas frequências devem-se geralmente à aplicação de uma correção de instrumentos, como os requeridos em registros sobre sítios de rocha muito rígida.

Para eliminar os ruídos de baixas frequências (low-cut filter) são utilizados filtros passa-alta, pois estas componentes do ruído podem afetar os picos de aceleração (Figura 2.7). O processamento consiste em remover dos registros os ruídos de longos períodos e a seleção desse longo-período de corte (long-period cut-off) depende do que é considerado uma razão sinal-ruído aceitável. Uma vez 
definida a frequência de filtro, esta automaticamente define a faixa de períodos na qual a informação é aproveitável.
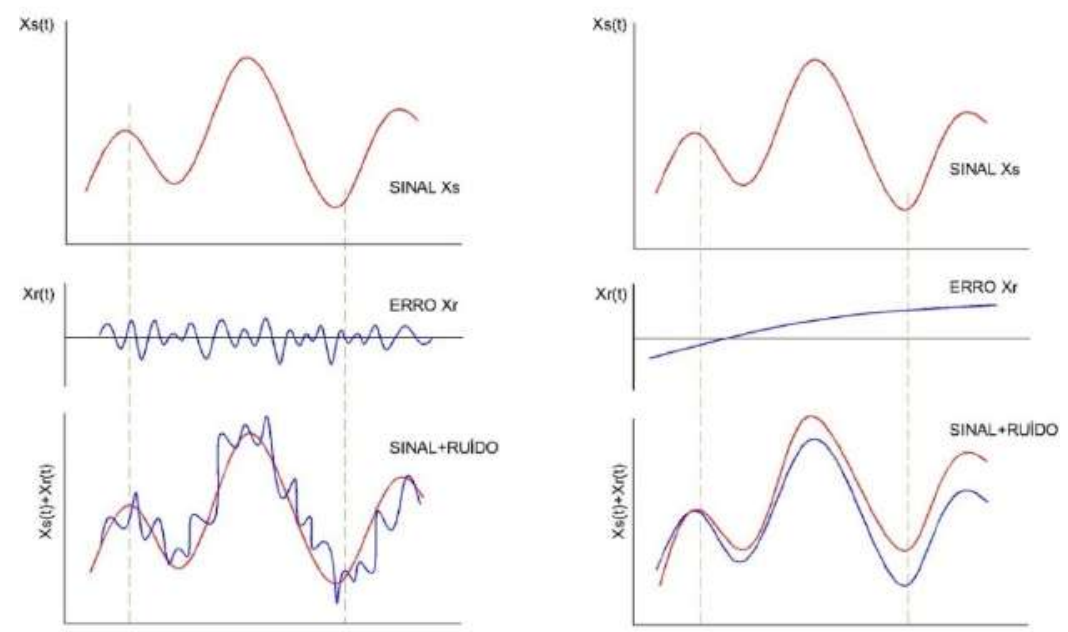

Figura 2.7- Efeitos de ruídos de alta (esquerda) e de baixa (direita) frequências (Hudson, 1979).

Por exemplo, a Figura 2.8(a)Figura 2.9 mostra um sinal naõ corrigido com ruído de baixa frequência, que deve ser tratado com um filtro de passa-alta para eliminar as correspondentes componentes de frequência. $O$ resultado da filtragem é o sinal apresentado na Figura 2.8(b) (Jiménez, 2007).

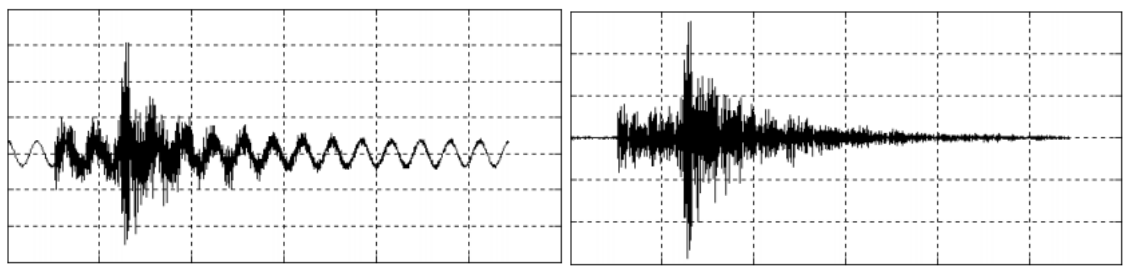

Figura 2.8- (a) Sinal sísmico naão corrigido, com ruído e (b) Sinal sísmico após filtragem (Jiménez, 2007).

Os filtros passa-banda podem eliminar conjuntamente ruídos de alta ou baixa frequências do registro sísmico. A faixa de freqüências de ruídos sísmico para terremotos de magnitude pequena e moderada situa-se entre $0,1 \mathrm{~Hz}$ e $1 \mathrm{~Hz}$. $\mathrm{Na}$ presente pesquisa foi empregado o programa computacional Seismosignal, 2018. 


\section{2.}

\section{Ameaça sísmica}

São definidos dois tipos de metodologia de ameaça sísmica: a análise determinística, que considera o mais catastrófico terremoto histórico para quantificar a sismicidade atual, e a análise probabilística, que estima o movimento sísmico em função de todos os terremotos já acontecidos na região, associandoos probabilidades de ocorrência no futuro.

\subsection{1.}

\section{Ameaça sísmica determinística}

Corresponde à estimativa de valores de aceleração considerando o terremoto de maior magnitude ocorrido em determinada área sísmica e sua distância até o local do projeto. Mediante uma lei de atenuação (equação matemática) se relaciona a aceleração com a distância e magnitude para estimar a resposta sísmica em termos de máximas acelerações ou de respostas espectrais.

Um resultado típico deste tipo de metodologia pode ser escrito como: "a ameaça sísmica tem um valor de PGA de 0,35g resultado de um terremoto de magnitude 6 sobre a Falha Balcones a uma distância de 12 milhas do local " (Meneses, 2009).

A ameaça sísmica determinística é um procedimento simples, que exige um grande histórico de terremotos regionais precedentes para a sua definição e que não fornece nenhuma informação sobre a probabilidade de ocorrência do sismo dominante, nem sobre os níveis de movimento sísmico em determinado período de tempo ou sobre as incertezas dos parâmetros assumidos na determinação da ameaça. Devido a estas características, por vezes é difícil que especialistas concordem com determinada estimativa de ameaça sísmica.

\subsection{2.}

\section{Ameaça sísmica probabilística}

Esta metodologia analítica estima a probabilidade que o nível de movimento do solo causado pelo terremoto seja ultrapassado, em um local determinado e em certo período de tempo. Os resultados dessa análise são expressos como 
probabilidades estimadas por unidade de tempo (número esperado de eventos por ano), mas as respostas calculadas da análise sísmica só podem ser alcançadas com incerteza significativa. Apesar dos grandes avanços no conhecimento sísmico nos últimos anos, ainda existem lacunas na compreensão dos mecanismos que causam terremotos e dos processos que governam a forma como a energia de um terremoto propaga-se desde a sua origem. Essas lacunas na compreensão significam que, quando uma análise de ameaça sísmica probabilística é realizada, há inevitavelmente incertezas significativas nos resultados numéricos e, portanto, a probabilidade de ocorrência é fornecida como parte da resposta (NUREG-6372, 1997).

Uma análise de ameaça sísmica probabilística envolve a interação com todo um conjunto de sismos. Estima-se a probabilidade estatística da ocorrência de certo parâmetro do movimento (por exemplo, a aceleração), em um determinado local, durante certo período de tempo. Um resultado típico deste tipo de metodologia pode ser escrito como: "um valor de PGA de 0,28g correspondente a $2 \%$ de probabilidade de ser excedido em 50 anos de exposição sísmica em um sitio dado" (Meneses, 2009).

Como pode ser percebido, a diferença entre as ameaças sísmicas determinística e probabilística é que a segunda faz menção da probabilidade de ocorrência de determinado valor de aceleração em certo tempo de vida útil da estrutura, além de considerar na sua formulação as incertezas inerentes e aleatórias dos parâmetros da análise.

\subsubsection{1.}

\section{Catálogo sísmico}

Para a identificação e cálculo dos parâmetros de sismicidade local das fontes sismogênicas é necessário compilar adequadamente catálogos sísmicos. Para a presente análise, a informação foi agrupada em três períodos de registro de dados sismológicos:

- Antes de 1900: dados históricos descritivos;

- 1900 - 1963: dados instrumentais aproximados;

- 1963 - 2015: dados instrumentais precisos. 
Para esta análise, foi utilizado o catálogo sísmico do Peru, compilado dos catálogos do Instituto Geofísico do Peru (IGP); o catálogo do Centro Sismológico Internacional (ISC); o catálogo do Centro Nacional de Informações sobre Terremotos (NEIC); o catálogo da Administração Nacional Oceânica e Atmosférica (NOAA) e o catálogo do Global Centroid Moment Tensor (CMT Global) para o período atualizado até $1^{\circ}$ de janeiro de 2016 , entre os meridianos $66^{\circ} \mathrm{W}$ e $84^{\circ} \mathrm{W}$ Greenwich e os paralelos 4ำ $\mathrm{N}$ e $23^{\circ} \mathrm{S}$ e magnitudes de momento $\mathrm{Mw} \geq 4,0 \mathrm{a} \mathrm{Mw}$ = 8.8. O catálogo sísmico foi analisado grafica e estatisticamente considerando o tempo, profundidade e magnitude dos eventos sísmicos registrados na área de estudo.

\subsubsection{2.}

\section{Padronização de magnitude}

Devido à grande importância de contar com um parâmetro uniforme e homogêneo para comparar o tamanho dos terremotos na avaliação da ameaça sísmica, as magnitudes do catálogo compilado foram padronizadas para a magnitude momento ( $\mathrm{Mw}$ ) e eliminando, ao mesmo tempo, os eventos registrados com magnitude zero ou sem magnitude.

Para converter magnitudes de diferentes escalas em Mw, foram utilizados as seguintes correlações:

a) Para eventos com magnitude $\mathrm{mb}$, a corresponde magnitude $\mathrm{Ms}$ foi calculada com as expressões recomendads pelo GSHAP (Global Seismic Hazard Assessment Program):

$$
\begin{array}{ll}
\mathrm{Ms}=1.644 \mathrm{mb}-3.753 & \mathrm{mb}<5.9 \\
\mathrm{Ms}=2.763 \mathrm{mb}-10.301 & \mathrm{mb} \geq 5.9
\end{array}
$$

b) Para eventos com magnitude Ms, a correspondente magnitude $\mathrm{Mw}$ foi determinada com as expressões recomendadas pelo ISC (International Seismological Center, Scordilis, 2006):

$$
\begin{array}{ll}
M w=0.67( \pm 0.005) M s+2.07( \pm 0.03) & 3.0 \leq M s \leq 6.1 \\
M w=0.99( \pm 0.02) M s+0.08( \pm 0.13) & 6.2 \leq M s \leq 8.2
\end{array}
$$




\subsubsection{3.}

\section{Depuração do catálogo sísmico}

Para atender os requisitos de uma distribuição de Poisson, assumida como representativa da distribuição do tempo da ocorrência de terremotos, foi realizada a depuração dos eventos sísmicos dependentes. Dado que a maioria dos eventos dependentes são réplicas, o algoritmo desenvolvido no projeto PILOT (Avaliação da Ameaça Sísmica no Norte dos Andes - GSHAP), baseado na correlação proposta por Maeda (1996), foi usado. As relações deste algoritmo, que estabelecem o critério espacial e temporal para eliminar réplicas do catálogo sísmico original, são:

$$
\begin{array}{ll}
\text { Quanto à distância: } & \mathrm{L} \leq 10^{(0.5 \mathrm{Mm}-1.8)} \\
\text { Em relação ao tempo: } & \mathrm{t} \leq 10^{(0.17+0.85(\mathrm{Mm}-4.0)) / 1.3}-0.3 \\
\text { Em relação à magnitude: } & \mathrm{Ma}<\mathrm{Mm}-1.0
\end{array}
$$

onde L, t, Mm e Ma representam a distância epicentral em relação ao evento principal, o tempo em dias em relação à ocorrência do evento principal, a magnitude de um evento principal e a magnitude de uma réplica, respectivamente. Essas relações foram derivadas de Utsu (1970) e consideram o decaimento exponencial em número e magnitude de réplicas (Annali di Geofísica, 1999).

\subsubsection{4.}

\section{Fontes sismogênicas e obtenção de parâmetros}

Normalmente as fontes sismogênicas são definidas seguindo um modelo de zonas sismogênicas que apresentam características de sismicidade bem definidas (Gamarra, 2009). As fontes sismogênicas podem ser falhas geológicas ou áreas extensas onde se admite uma sismicidade difusa distribuída uniformemente. A Figura 2.9(a) representa uma atividade sísmica cujo comportamento pode ser modelado como uma fonte pontual, enquanto a Figura 2.9(b) considera uma falha geológica superficial modelada como uma fonte linear. A Figura 2.9(c) mostra a modelagem mais utilizada considerando fonte tridimensional. Estabelecer as características de fontes pontuais ou lineares é mais complicado devido a pouca instrumentação existente para identificar as falhas adequadamente. 

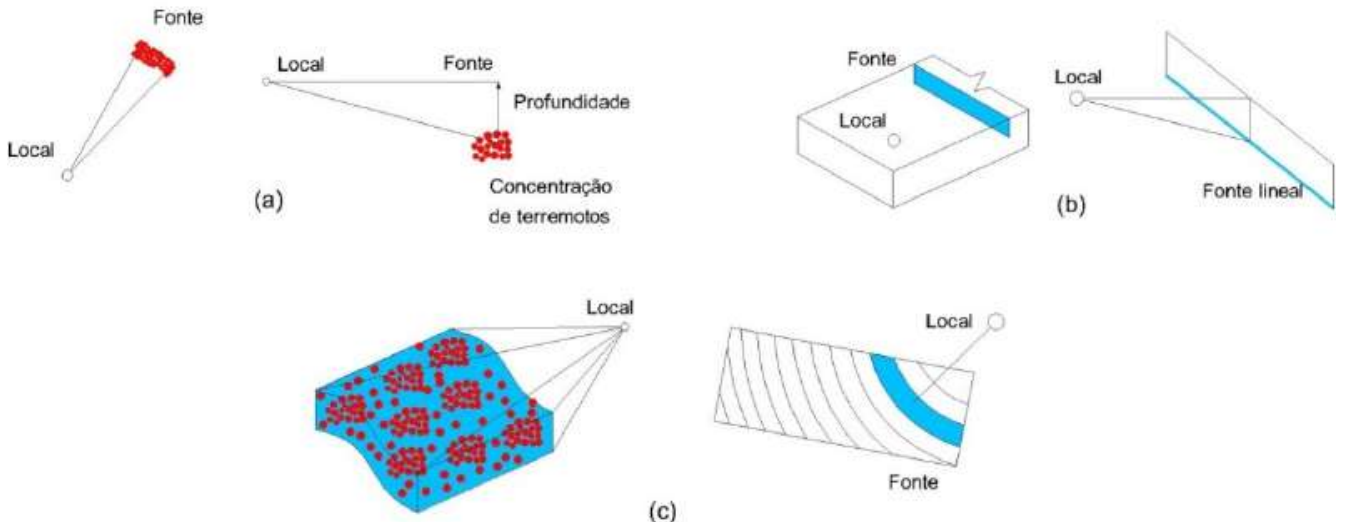

(c)

Figura 2.9- Geometria de fontes sismogênicas: (a) pontual; (b) linear; (c) tridimensional. Fontes: Kramer, 1996; Monroy e Bolaños, 2004.

Uma vez que as fontes sismogênicas tenham sido determinadas, as características da sismicidade de cada fonte devem ser estabelecidas em função de uma lei de recorrência, também chamada de distribuição temporal de magnitudes. Esta lei relaciona o tamanho dos sismos, em termos de magnitude ou intensidade, com sua frequência no tempo, tendo como hipótese que sismos passados podem ser utilizados para extrapolar a sismicidade da fonte sismogênica no futuro. A lei de recorrência mais utilizada é a de Gutenberg-Richter (1944), representada na Figura 2.10, que estabelece uma relação linear entre magnitude e o número de sismos em determinada fonte sismogênica.

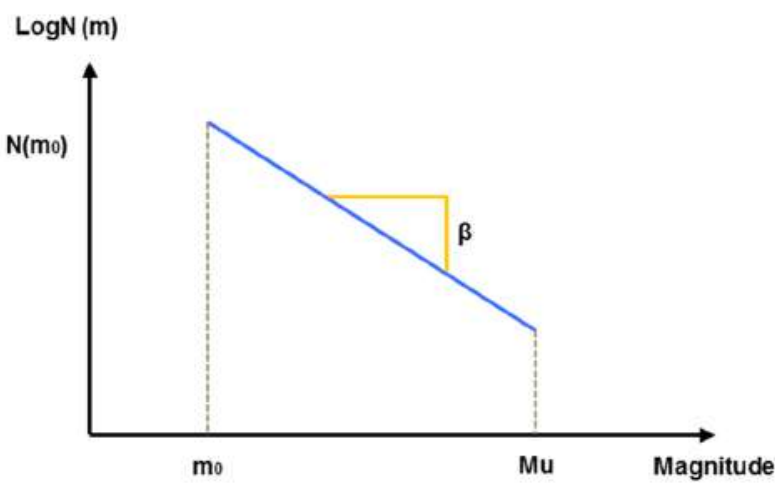

Figura 2.10- Representação do lei de Gutenberg-Richter com processo de Poisson duplamente truncado.

A lei de recorrência de Gutenberg-Richter é expressa por

$$
\log N=a-b M
$$

onde $\mathrm{M}$ é a magnitude, $\mathrm{N}$ o número médio de sismos com magnitude maior ou igual a M, o coeficiente a reflete a atividade sísmica e b indica a proporção de terremotos com pequenas e grandes magnitudes. 
Ao considerar eventos sísmicos, a lei de recorrência é escrita sob forma exponencial, em um intervalo de magnitude delimitado pela magnitude mínima de referencia $m_{0}$ e a magnitude máxima $M_{u}$ (duplo truncamento).

$$
T(m)=N \frac{\left(e^{-\beta m}-e^{-\beta M_{u}}\right)}{e^{-\beta m_{0}}-e^{-\beta M_{u}}}
$$

onde $\beta=\ln (10) \cdot b$

Embora a lei de Gutenberg-Richter seja amplamente utilizada, é também questionada quando aplicada na modelagem sísmica de falhas geológicas. Nesse caso o modelo do sismo característico (Schwartz e Coppersmith, 1984) é usado com melhores resultados. Este modelo sugere que em uma fonte isolada com boa quantidade de dados há um intervalo de magnitudes próximo à magnitude máxima $\left(\mathrm{M}_{\mathrm{u}}\right)$ com maior probabilidade de ocorrência do que as magnitudes intermediárias. Em outras palavras, a fonte libera sua energia em um evento de magnitude "característica" próximo à magnitude máxima $\left(\mathrm{M}_{\mathrm{u}}\right)$.

Os parâmetros que definem cada fonte sismogênica, necessários na avaliação da ameaça sísmica, são a magnitude mínima $\left(\mathrm{m}_{0}\right)$, a magnitude máxima $\left(\mathrm{M}_{\mathrm{u}}\right)$, a taxa do número acumulado de sismos que excedem a magnitude mínima (T) e a inclinação da curva ( $\beta$ ). Estes valores são chamados de parâmetros de sismicidade local.

A estimativa dos parâmetros $\beta$ e T é geralmente feita pelo método da máxima verossimilhança. Embora também seja possível usar uma regressão pelo método de mínimos quadrados, esta metodologia não fornece resultados adequados e atualmente não se recomenda sua utilização (McGuire, 2004; Monroy e Bolaños, 2004).

Segundo Monroy e Bolaños (2004) o método da máxima verossimilhança ajusta a distribuição dos sismos de uma determinada fonte de acordo com o valor médio mais provável do conjunto de dados. Quando usados os métodos da máxima verossimilhança e dos mínimos quadrados para a análise da mesma fonte sismogênica, como mostrado na Figura 2.11, os resultados indicam o melhor ajuste obtido pelo método da máxima verossimilhança. 

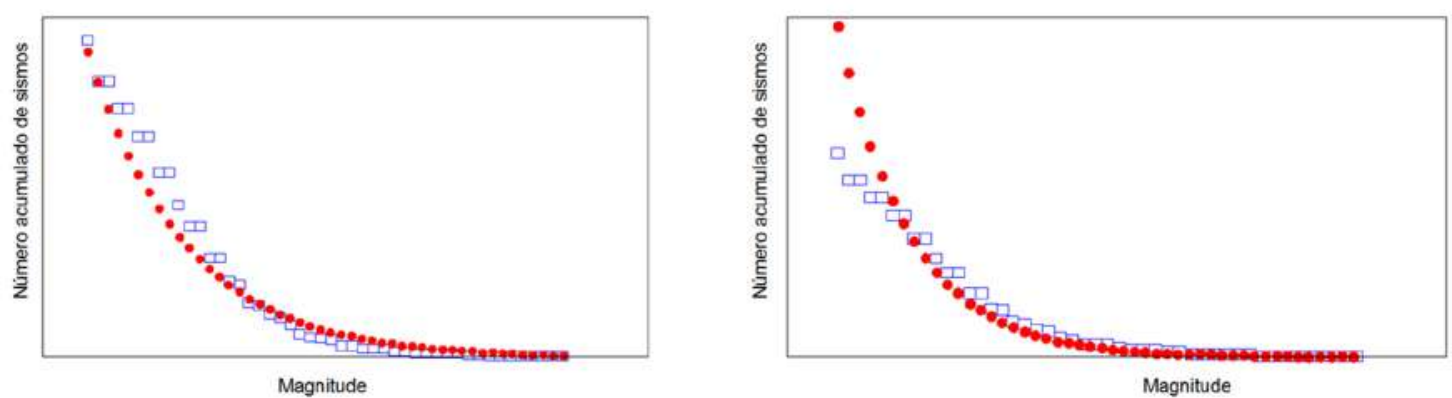

Figura 2.11- Ajuste pelo método da máxima verossimilhança (esquerda) e pelo método dos mínimos quadrados (direita) (Monroy e Bolaños, 2004).

De acordo com McGuire (2004) o valor do parâmetro $\beta$ pelo método de máxima verossimilhança é calculado pela seguinte equação:

$$
\frac{1}{\beta}=\bar{m}-m_{0}+\frac{\left(M_{u}-m_{0}\right) e^{-\beta\left(M_{u}-m_{0}\right)}}{1-e^{-\beta\left(M_{u}-m_{0}\right)}}
$$

onde $\bar{m}$ é a magnitude média considerando um modelo duplamente truncado.

Por outro lado, a estimativa da taxa $(\mathrm{T})$ do número acumulado de sismos que excedem a magnitude mínima, quando feita considerando intervalos de observação desiguais no catálogo sísmico (Weicher, 1980), é dada como uma soma de variáveis de uma distribuição de Poisson expressa por (McGuire, 2004),

$$
T=N \frac{\sum_{i} e^{-\beta m_{i}}}{\sum_{i} t_{i}^{*} e^{-\beta m_{i}}}
$$

onde $\mathrm{N}$ é o número acumulado de eventos, i representa o número de intervalos de observação e $t^{\star}$ o número de anos que cada incremento de magnitude $m_{i}$ foi observado.

A magnitude mínima é usualmente determinada pelo método de máxima curvatura (Wiemer et al,1999; Wiemer et al, 2000) como o ponto de inflexão da curva de recorrência sísmica. McGuire (2004) indica que esta magnitude deve considerar também critérios de risco sísmico (i.e. a magnitude mínima que pode causar danos em uma região).

Para cálculo da magnitude máxima considera-se a magnitude do maior evento sísmico acontecido na fonte sismogênica. Geralmente os dados recuperados de um catálogo sísmico não irão fornecer um valor correto da magnitude máxima, já que terremotos maiores e mais antigos podem ter ocorrido, 
sem registro nenhum. Então, considerações tectônicas, geofísicas e até um incremento da magnitude máxima podem ser introduzidas dependendo do julgamento profissional do analista (McGuire, 2004). No caso de falhas, a magnitude máxima está relacionada com as dimensões da ruptura e o deslocamento médio.

Uma das considerações feitas ao utilizar o modelo de recorrência de Gutenberg-Richter é assumir que todos os sismos seguem um processo de Poisson. Este processo, que permite estimar a sismicidade em um tempo futuro, pressupõe a verificação das seguintes hipóteses: a) independência - dados dois eventos sísmicos $\mathrm{A}$ e $\mathrm{B}$, a ocorrência do evento $\mathrm{A}$ não é afetada pela ocorrência do evento $B$, nem pelo momento em que ele ocorreu ou pela sua magnitude, 0 que significa que o processo não tem memória, pois os eventos do passado não afetam os eventos futuros; b) estacionaridade - dado um intervalo de tempo [t, $t+\Delta t$ ], a probabilidade de ocorrência de um evento em $\Delta t$ depende do número de eventos ocorridos em [t, $\mathrm{t}+\Delta \mathrm{t}]$ e do intervalo $\Delta \mathrm{t}$, porém não do tempo $\mathrm{t}$; $\mathrm{c}$ ) nãomultiplicidade - a probabilidade de dois ou mais eventos ocorrerem no intervalo de tempo $\Delta \mathrm{t}$ tende para zero à medida que o intervalo $\Delta \mathrm{t}$ também tende para zero, $\mathrm{o}$ que elimina a ocorrência de eventos simultâneos (Lomnitz, 1994).

Na sua forma mais geral, o processo de Poisson pode ser expresso como:

$$
P_{n}(t)=\frac{e^{-\lambda t}(\lambda t)^{n}}{n !}
$$

onde $\mathrm{P}_{\mathrm{n}}(\mathrm{t})$ é a probabilidade da ocorrência de sismos em um período de tempo $\mathrm{t}, \mathrm{n}$ corresponde ao número total de sismos e $\lambda$ é a probabilidade de ocorrência por unidade do tempo.

\subsubsection{5.}

\section{Relações de atenuação}

Uma vez que os parâmetros sismológicos de cada fonte tenham sido calculados, relações de atenuação adequadas devem ser selecionadas. As relações de atenuação são equações matemáticas que relacionam um parâmetro do movimento do terreno (normalmente a aceleração) com parâmetros que definem os sismos: magnitude ou intensidade sísmica, a distância entre a fonte sísmica e o sítio e uma dispersão estatística do modelo. Algumas relações consideram também outros fatores como o tipo de solo. Geralmente são 
desenvolvidas mediante análises de regressão de dados de registros sísmicos; portanto, mudam com o tempo à medida que a base de dados é incrementada (Kramer, 1996).

Em zonas de atividade sísmica moderada à baixa, os registros sísmicos disponíveis são limitados e menos representativos. Nos estudos de ameaça sísmica nestes locais é necessário, portanto, selecionar da literatura as relações de atenuação a serem empregadas na estimativa da ameaça sísmica como, por exemplo, aquelas mostradas na Figura 2.12. É importante saber que desta decisão dependerá em grande parte a confiabilidade da ameaça sísmica, pois as relações de atenuação têm uma influência crítica sobre os resultados.

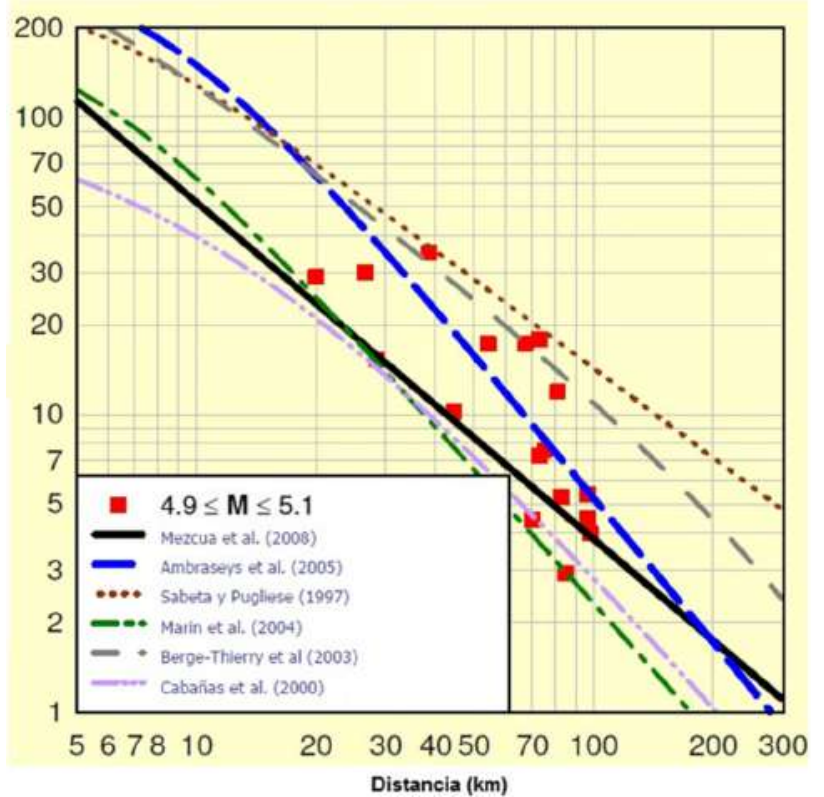

Figura 2.12- Comparação de diferentes relações de atenuação com registros sísmicos da Espanha (Mezcua et al, 2008).

\subsubsection{6.}

\section{Efeito do sítio}

As condições geológicas e geotécnicas do solo (efeito de sítio) controlam fortemente a amplitude e o conteúdo espectral das frequências do movimento. De modo geral, solos pouco rígidos tendem a amplificar o movimento em frequências baixas, sendo coincidente com as frequências fundamentais típicas de estruturas.

A consideração do fator solo nas relações de atenuação, assim como nas normas sísmicas, é feita considerando a velocidade média das ondas de 
cisalhamento (Vs) nos primeiros $30 \mathrm{~m}$ de profundidade do sítio. Este critério consta na norma International Building Code (IBC, 2012) que classifica o solo conforme Tabela 2.1.

A velocidade média $\bar{v}_{s}$ é calculada como:

$$
\bar{v}_{s}=\frac{\sum_{i=1}^{n} d_{i}}{\sum_{i=1}^{n} \frac{d_{i}}{v_{s i}}}
$$

Onde $d_{i}$ a espessura de cada camada de solo até $30 \mathrm{~m}$ de profundidade e $\mathrm{v}_{\mathrm{si}}$ a velocidade da onda $\mathrm{S}$ em cada camada $\mathrm{i}$.

Tabela 2.1- - Classificação de solos em função da velocidade de propagação da onda cisalhante (Vs) - IBC (2012), ASCE 7-10.

PROPRIEDADES MÉDIAS NOS 30 PRIMEIROS METROS

\begin{tabular}{|c|c|c|c|c|}
\hline \multirow[b]{2}{*}{$\begin{array}{l}\text { TIPO } \\
\text { DE } \\
\text { SOLO }\end{array}$} & \multirow[b]{2}{*}{$\begin{array}{l}\text { NOME DE } \\
\text { SOLO }\end{array}$} & \multicolumn{3}{|c|}{ PROPRIEDADES MÉDIAS NOS 30 PRIMEIROS METROS } \\
\hline & & $\begin{array}{l}\text { Velocidade de onda } \\
\text { cisalhante, } \bar{v}_{s}(\mathbf{m} / \mathbf{s})\end{array}$ & $\begin{array}{c}\text { Resistência à } \\
\text { penetração padrão } \\
\text { corrigida, } \bar{N}_{60}\end{array}$ & $\begin{array}{c}\text { Resistência ao } \\
\text { cisalhamento não } \\
\text { drenado, } \bar{S}_{u}(\mathrm{kPa})\end{array}$ \\
\hline A & Rocha sã & $\bar{v}_{s}>1500$ & $\mathrm{~N} / \mathrm{A}$ & $\mathrm{N} / \mathrm{A}$ \\
\hline B & Rocha dura & $760<\bar{v}_{s} \leq 1500$ & $\mathrm{~N} / \mathrm{A}$ & $\mathrm{N} / \mathrm{A}$ \\
\hline C & $\begin{array}{l}\text { Solo rijo ou } \\
\text { rocha } \\
\text { branda }\end{array}$ & $360<\bar{v}_{s} \leq 760$ & $\bar{N}_{60>50}$ & $\bar{s}_{u} \geq 100$ \\
\hline $\mathrm{D}$ & Solo médio & $180 \leq \bar{v}_{s} \leq 360$ & $15 \leq \bar{N}_{60} \leq 50$ & $50 \leq \bar{S}_{u} \leq 100$ \\
\hline$E$ & Solo mole & $\bar{v}_{s}<180$ & $\bar{N}_{60<15}$ & $\bar{S}_{u}<50$ \\
\hline$E$ & - & \multicolumn{3}{|c|}{$\begin{array}{l}\text { Qualquer perfil de solo com mais de } 3 \text { m de espessura que possua as } \\
\text { seguintes características: } \\
\text { 1. Índice de plasticidade (IP) }>20 \\
\text { 2. Teor de umidade (w) } \geq 40 \% \\
\text { 3. Resistência ao cisalhamento não drenado } \bar{S}_{u}<25 \mathrm{kPa}\end{array}$} \\
\hline $\mathrm{F}$ & - & 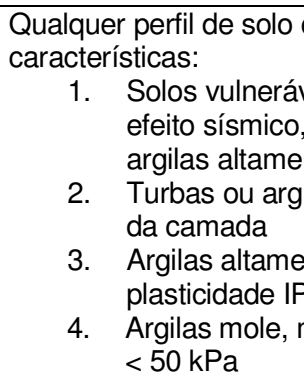 & $\begin{array}{l}\text { ie possua uma o mais } \\
\text { is a uma possível rupt } \\
\text { or exemplo: solos sus } \\
\text { e sensíveis e solos po } \\
\text { as altamente orgânicas } \\
\text { te plásticas ( } \mathrm{H}>7.6 \mathrm{~m} \\
75 \text { ) } \\
\text { édia ou rija muito espe }\end{array}$ & $\begin{array}{l}\text { s seguintes } \\
\text { ou colapso devido ao } \\
\text { íveis à liquefação, } \\
\text { cimentados. } \\
>3 \mathrm{~m}) \mathrm{H}=\text { espessura } \\
\text { m índice de } \\
\text { s }(\mathrm{H}>36 \mathrm{~m}) \text { com } \mathrm{S}_{u}\end{array}$ \\
\hline
\end{tabular}

\subsubsection{7.}

\section{Estimativa probabilística da ameaça sísmica}

Sismo é um evento aleatório ao qual a teoria de probabilidades pode ser aplicada para estimar sua ocorrência. De acordo com esta teoria se a ocorrência de um evento $A$ depende da ocorrência de outros eventos $E_{1}, E_{2}, \ldots, E_{n}$ então, pelo 
teorema da probabilidade total, a probabilidade de ocorrência de A tem a seguinte expressão:

$$
P(A)=\sum_{i}^{n} P\left(\frac{A}{E_{i}}\right) P\left(E_{i}\right)
$$

onde $\mathrm{P}\left(\mathrm{A} / \mathrm{E}_{\mathrm{i}}\right)$ é a probabilidade condicional que $A$ ocorra se acontecer $E_{i}$.

Pode-se considerar um parâmetro do sismo (designado por y) dependente da grandeza do sismo (magnitude ou intensidade) e da distância ao local de estudo. Caso a grandeza do sismo (M) e sua localização $(R)$ sejam considerados variáveis aleatórias contínuas e definidas por suas funções de densidade de probabilidade $f_{M}(m)$ e $f_{R}(r)$, respectivamente, então a ameaça sísmica definida pela probabilidade que o parâmetro do sismo (y) seja maior que certo valor $\mathrm{Y}$ será $P(y>Y)$ e terá a seguinte forma:

$$
P(y>Y)=\iint P[Y /(m, r)] f_{M}(m) f_{R}(r) d m d r
$$

A equação (2.11) resume a metodologia desenvolvida por Cornell (1968) para estimativa da ameaça sísmica.

A metodologia proposta por Cornell (1968) avalia a probabilidade de superação de um valor limite do movimento, como a aceleração, no local de estudo, devido à atividade de todas as fontes sismogênicas próximas e que possam contribuir ao movimento esperado (Climent et al, 2008). Considerando Ns fontes sismogênicas,

$$
\begin{aligned}
P^{*}(y>Y)=\sum_{i=1}^{N_{S}} P_{i}^{*}(y>Y) & \\
& =\sum_{i=1}^{N_{S}} v_{i} \iint P_{i}[y>Y / m, r] f_{M_{i}}(m) f_{R_{i}}(r) d m d r
\end{aligned}
$$

onde a dupla integral tem como limites as magnitudes e as distâncias mínimas e máximas da fonte. Neste ponto convém explicar o significado dos termos da equação (2.12):

$P^{*}(y>Y)$ : representa a taxa anual de excedência do movimento $\mathrm{Y}$, devido à ocorrência de sismos nas Ns fontes. A taxa anual é a soma das taxas anuais de excedência $P_{i}^{*}(y>Y)$ de cada fonte. Por sua vez, todas as fontes apresentam uma taxa anual de ocorrência de sismos $v_{i}$. 
$P_{i}[y>Y / m, r]$ : representa a probabilidade de excedência de $Y$ em função das variáveis $m$ (magnitude) e $r$ (distância).

$f_{M_{i}}(m)$ : função de densidade de probabilidade de magnitude.

$f_{R_{i}}(r)$ : função de densidade de probabilidade de distância.

Admitindo que a probabilidade de excedência de $Y$ só é função das variáveis $\mathrm{m}$ e r, então o termo $P_{i}[y>Y / m, r]$ só pode ter dois únicos valores: um e zero (Abrahamson, 2000). Quando é atingida a excedência do movimento, então os valores das variáveis $\mathrm{m}$ e $\mathrm{r}$ são tais que $\mathrm{y}>\mathrm{Y}$, portanto a probabilidade de excedência toma o valor de um. No caso que a excedência não seja atingida então o termo $P_{i}[y>Y / m, r]$ é igual à zero. Matematicamente, esse valor duplo é expresso por meio da função de Heaviside, também chamada de função de grau, que pode ser matematicamente escrita como H(Iny-InY). Quando Iny $>\ln Y$ o valor da função H é igual a unidade; para Iny<lnY seu valor é nulo.

Então, a equação (2.12) pode ser reescrita da seguinte forma:

$$
\begin{aligned}
P^{*}(y>Y)= & \sum_{i=1}^{N_{S}} P_{i}^{*}(y>Y) \\
& =\sum_{i=1}^{N_{S}} v_{i} \iint H(\ln y-\ln Y) f_{M_{i}}(m) f_{R_{i}}(r) d m d r
\end{aligned}
$$

A avaliação da integral depende das funções de densidade de probabilidade (PDF) $f_{M_{i}}(m)$ e $f_{R_{i}}(r)$, embora também possam ser usadas funções de distribuição $\mathrm{F}(\mathrm{x})$. A função de densidade de probabilidade de magnitude é calculada da lei de Gutenberg-Richter duplamente truncada.

$$
f_{M_{i}}(m)=\frac{\beta e^{-\beta\left(m-M_{0 i}\right)}}{1-e^{-\beta\left(M_{M i}-M_{0 i}\right)}} \text { com } \mathrm{M}_{\mathrm{oi}} \leq \mathrm{m} \leq \mathrm{M}_{\mathrm{Mi}}
$$

Onde $\mathrm{M}_{\mathrm{oi}}$ e $\mathrm{M}_{\mathrm{Mi}}$ são a mínima e máxima magnitude da fonte i.

A função de densidade de probabilidade de distância não tem uma expressão analítica e deve ser calculada numericamente. Para uma fonte sismogênica pontual $f_{R}(r)=1$ e para uma fonte circular de raio $\mathrm{R}_{\mathrm{MAX}}$, em cujo centro se determina a ameaça sísmica,

$$
f_{R}(r)=\frac{2 r}{R_{M A X}^{2}} \text { com } 0 \leq r \leq \mathrm{R}_{\mathrm{MAX}}
$$


A integral da equação 2.13 é resolvida de forma numérica considerando as funções de densidade de probabilidade $f_{M i}(m)$ e $f_{R i}(r)$ ou também através das funções de distribuição acumulativa $F(m)$ e $F(r)$. Geralmente se consideram intervalos discretos das variáveis $\Delta m$ e $\Delta r$ chamadas de zonas. Quando consideradas as funções de distribuição na resolução da equação, a diferença das funções de distribuição de cada variável nos extremos da correspondente zona (setor) fornece o valor da sua contribuição à ameaça. Tem-se então:

$$
\begin{gathered}
F_{i}\left(\mathrm{~m} / \text { setor }_{u, u+1}\right)=\frac{e^{-\beta\left(M_{u}-m_{0}\right)}-e^{-\beta\left(M_{u+1}-m_{0}\right)}}{1-e^{-\beta\left(M_{u}-m_{0}\right)}} \\
F_{i}\left(m / \text { setor }_{u, u+1}\right)=F\left(r_{v+1}\right)-F\left(r_{v}\right)=\left(r_{v+1}-r_{v}\right)\left(\frac{\Delta A_{v, v+1}}{A}\right)
\end{gathered}
$$

Onde $\mathrm{A}$ é dependente da área da zona considerada. Logo, substituindo na equação (2.13) obtém-se:

$$
\begin{aligned}
P^{*}(y>Y)= & \sum_{i=1}^{N_{s}} v_{i} \sum_{u=M_{\min }}^{M_{\max }} \sum_{v=R_{\min }}^{R_{\max }}\left(\frac { e ^ { - \beta ( M _ { u } - m _ { 0 } ) } - e ^ { - \beta ( M _ { u + 1 } - m _ { 0 } ) } } { 1 - e ^ { - \beta ( M _ { u } - m _ { 0 } ) } } \left(r_{v+1}\right.\right. \\
& \left.\left.-r_{v}\right)\left(\frac{\Delta A_{v, v+1}}{A}\right)\right)
\end{aligned}
$$

A equação (2.18) fornece a estimativa probabilística da ameaça sísmica devido à ação de Ns fontes sismogênicas como soma das contribuições das zonas $\Delta \mathrm{m}$ e $\Delta \mathrm{r}$. O programa CRISIS v.7 (Ordaz et al, 1999) foi utilizado nesta pesquisa para efetuar a avaliação desta equação.

\subsubsection{8.}

\section{Curva de ameaça sísmica}

Geralmente os resultados dos estudos de ameaça sísmica são apresentados por meio de curvas de ameaça e espectros de resposta uniformemente prováveis. As curvas de ameaça fornecem a probabilidade anual de excedência (nas ordenadas) de um determinado parâmetro do solo como a aceleração (nas abscissas) tal como mostra a Figura 2.13. Nesses gráficos, no caso de se desejar obter um determinado valor do período de retorno basta obter a inversa deste valor e ingressá-lo no eixo das ordenadas. 


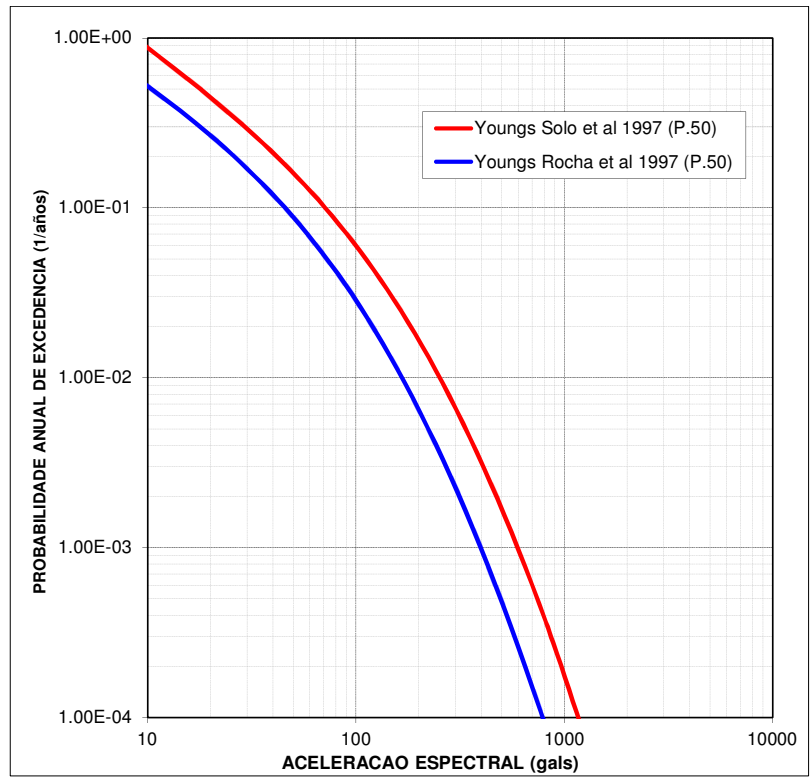

Figura 2.13- Curva de probabilidade de excedência utilizando duas relações de atenuação diferentes.

A partir das curvas de probabilidade de excedência obtidas para diferentes períodos estruturais é possível construir os espectros de resposta uniformemente provável (Figura 2.14) que apresentam valores com a mesma probabilidade de excedência em todos os períodos para um determinado tempo de vida útil da estrutura.

O espectro de resposta uniformemente provável fornece parâmetros de resposta que podem ser usados diretamente no cálculo das acelerações finais das estruturas, já que levam em conta as probabilidades de ocorrência de todos os sismos moderados próximos ao local de estudo, que tendem a produzir movimentos de alta frequência, bem como os sismos distantes de grande magnitude, que tendem a produzir movimentos de baixa frequência.

Deve ser mencionado que na prática é muito utilizado o valor do PGA (Peak Ground Acceleration - máxima aceleração do solo). Este valor é a aceleração que corresponde a um período estrutural $\mathrm{T}=0$, que representa uma estrutura infinitamente rígida, ou seja, correspondente à resposta do solo. No caso dos espectros de resposta uniformemente provável o valor do PGA é o ponto de início do espectro. Por exemplo, na Figura 2.14, o valor do PGA é aceleração do ponto A. O valor da máxima aceleração do solo obtido dos estudos de ameaça sísmica serve como parâmetro de entrada (coeficiente sísmico definido como o valor do 
PGA normalizado em relação à aceleração da gravidade) para análises de estabilidade de taludes pelo método pseudo-estático.
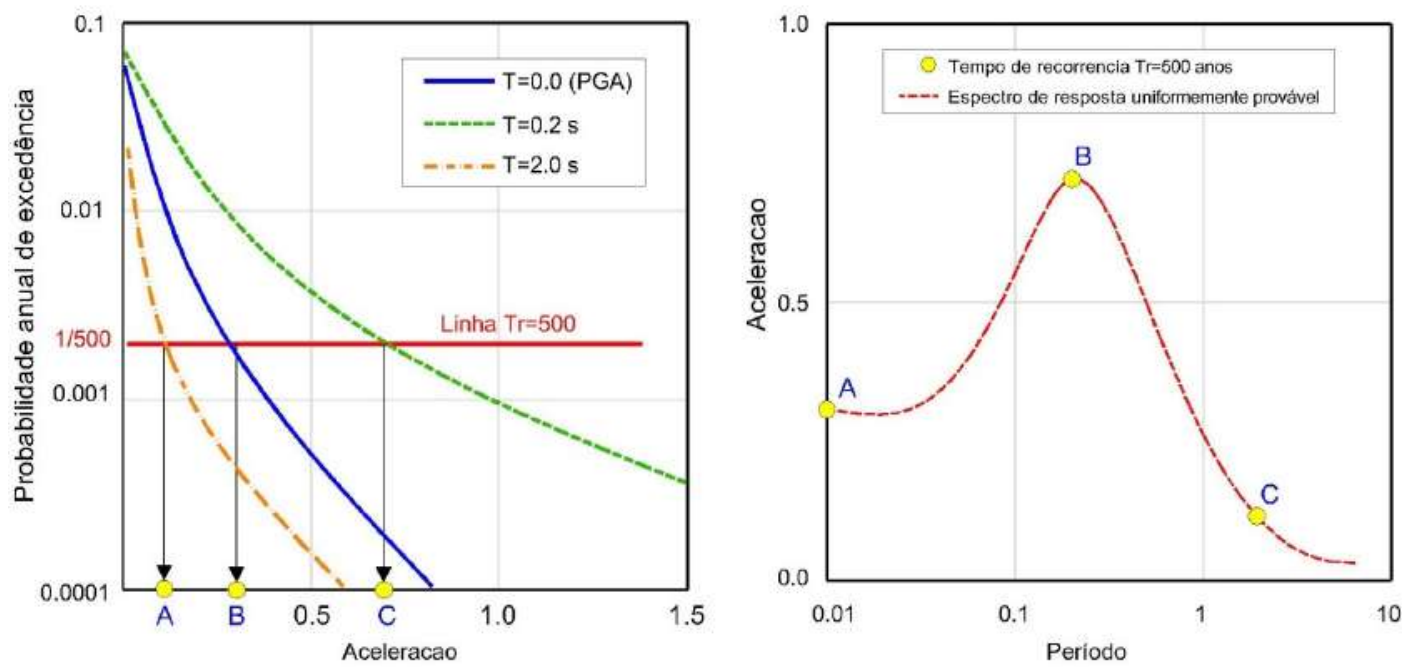

Figura 2.14- Obtenção do espectro de resposta uniformemente provável a partir das curvas de probabilidades de excedência (Meneses, 2009).

Como já indicado, a consideração da ocorrência de eventos sísmicos como uma distribuição de Poisson é um modelo bastante aceito, que permite calcular a probabilidade de um número de sismos acontecer em um intervalo de tempo conhecida a taxa média de ocorrência de eventos.

Da distribuição de Poisson obtém-se que a probabilidade de excedência $\mathrm{P}(\mathrm{y}>\mathrm{Y})$ em $t$ anos a partir do período de recorrência Tr é dada por,

$$
P(y>Y)=1-e^{-\frac{t}{T_{r}}}
$$

Por exemplo, um período de recorrência (ou período de retorno) $\operatorname{Tr}=500$ anos, tempo usado frequentemente em normas antissísmicas, é o resultado de uma probabilidade de excedência de $10 \%$ em $\mathrm{t}=50$ anos de vida útil da estrutura.

Estabelecidas as bases teóricas do método de ameaça sísmica, a seguir faz-se sua aplicação no projeto que é o objeto desta pesquisa. 


\subsection{3.}

\section{Desagregação da ameaça sísmica}

Análises de desagregação permitem investigar como as diferentes rupturas sísmicas, definidas em um modelo de fonte, contribuem para a probabilidade de exceder a certo nível de movimento do solo em um determinado lugar.

Dado o grande número de rupturas sísmicas associadas a um modelo de fonte, as contribuições não podem ser investigadas ruptura por ruptura, mas um esquema de classificação é usado. As rupturas são classificadas em termos de magnitude e distância no esquema de desagregação magnitude vs. Distância onde distância é medida de acordo com o conceito de distância Joyner Boore $\left(R_{J B}\right)$. Magnitude-Distancie desagregação:

$$
P\left(X>x / T, M, r_{j b}\right)=1-\prod_{\lambda} \prod_{\phi} \prod_{T R T} \prod_{\epsilon}(1-P(X>x / T, M))
$$

\section{3. \\ Geração de registros sismicos}

Em uma análise sísmica a definição das características do terremoto de projeto é fundamental. Um registro sísmico criteriosamente selecionado permite obter uma resposta da estrutura mais condizente com a realidade, fornecendo elementos para um dimensionamento que seja tanto técnica quanto economicamente adequados.

A seleção do terremoto de projeto, i.e., a escolha de um carregamento que não se sabe quando atuará, nem qual sua duração ou magnitude, é, portanto, tarefa complexa. Engenheiros geotécnicos tendem a caracterizar uma análise sísmica como uma estimativa do valor da aceleração horizontal de pico no terreno (PGA), provavelmente porque necessitam deste único valor para cálculo da estabilidade de taludes por métodos pseudo-estáticos, e tendem a esperar uma amplificação da aceleração máxima do terremoto pelas camadas do solo de fundação.

Ora, amplificações ocorrem para frequências próximas à frequência de ressonância das camadas de solo. Caso a frequência predominante do terremoto estiver nesta faixa de valores, então a aceleração horizontal do terremoto será 
forçosamente amplificada. Caso contrário, as acelerações em outras frequências o serão, gerando eventualmente complicações se estas forem as frequências que concentram a maior energia do terremoto.

Os métodos para seleção do registro sísmico de projeto são basicamente os seguintes (Aguilar, 2001):

- Método da utilização do histórico de registros sísmicos

- Método baseado no modelo de falha

- Método do espectro padrão

O primeiro método consiste de duas alternativas. Na primeira, dispõe-se de um registro sísmico histórico nas proximidades do local do projeto com níveis de aceleração compatíveis com aqueles determinados em estudos de ameaça sísmica regional. O registro sísmico é utilizado diretamente sem nenhuma modificação. Na segunda alternativa, as acelerações do registro sísmico histórico são multiplicadas por uma constante tal que a aceleração máxima coincida com a aceleração máxima prevista no estudo de ameaça sísmica; esta técnica foi muito utilizada no passado (técnica de escalonamento do registro sísmico).

O segundo método baseado no modelo de falha é utilizado para calcular teoricamente as representações da ruptura da falha e a irradiação de ondas sísmicas provocada por esta ruptura. Diversas alternativas de análise podem ser empregadas, baseadas em modelos de fonte sísmicas ou por meio de funções de Green.

O terceiro método, baseado em um espectro padrão, permite gerar registros sísmicos sintéticos por meio da superposição de ondas harmônicas (senoidais) que se ajustam a um espectro de acelerações pré-definido. Uma análise de regressão é usualmente feita baseada no conjunto de registros sísmicos gerados; a aplicabilidade deste método é dependente da quantidade e qualidade dos registros sintéticos assim obtidos.

Nesta pesquisa foi utilizada a segunda alternativa do primeiro método, utilizando registros sísmicos históricos para definição do terremoto de projeto, porém com uma importante modificação. Em vez de apenas fazer a normalização do registro em termos de acelerações máximas, é também feita uma análise de 
ajuste espectral para que o espectro de resposta do terremoto original esteja tão próximo quanto possível do espectro de resposta uniformemente provável obtido na análise de ameaça sísmica.

Quanto às denominações, Acevedo (2003) estabelece uma diferença nos acelerogramas que não são reais. Acelerogramas sintéticos são aqueles decorrentes dos modelos geológicos de ruptura de falhas, enquanto acelerogramas artificiais são aqueles obtidos pela estimativa no método de ajuste espectral. Portanto, os registros sísmicos considerados nesta investigação correspondem a acelerogramas artificiais.

\subsection{1.}

\section{Duração dos Registros Sísmicos}

A duração de um movimento forte do terremoto se torna um parâmetro significativo para o potencial de dano sísmico, o potencial destrutivo de um movimento de terremoto está intimamente relacionado ao seu conteúdo energético, que depende tanto da intensidade quanto da duração do movimento. Allem disso, uma caracterização completa do movimento do solo também deve incluir alguma medida da duração do sinal de movimento forte (Dobry et al., 1978).

Segundo Ghanat, as definições da duração do movimento do solo podem ser categorizadas em três tipos genéricos diferentes: duração bracketed, duração uniforme e duração significativa (Bommer e Martinez-Pereria, 1999). A duração bracketed mede a duração do movimento do solo desde a primeira até a última ocorrência de um valor limite de aceleração, excedendo a aceleração especificada do limiar. A duração uniforme é definida como a soma dos intervalos de tempo durante os quais a aceleração excede um valor limite. A duração significativa define a duração do movimento de solo como a duração do intervalo de tempo entre as acumulações de dois níveis especificados de energia de movimento de solo no local (conforme determinado pela integração do quadrado do histórico de tempo de aceleração).

Nesta dissertação foi utilizada a duração significativa, a definição mais usada pelos sismólogos de engenharia. Trifunac e Brady sugeriram que o intervalo entre $5 \%$ e 95\% da intensidade de Arias era uma escolha mais apropriada pela duração significativa (1975). Para a duração significativa do SD595, a duração da agitação 
forte é definida como a duração do intervalo de tempo entre a acumulação de $5 \%$ e $95 \%$ da energia de movimento do solo, em que a energia de movimento do solo é definida pelo Integral Arias. A definição de duração de Trifunac e Brady é ilustrada no gráfico de Husid na Figura 2.15. A intensidade de Arias normalizada varia de 0 a 1.

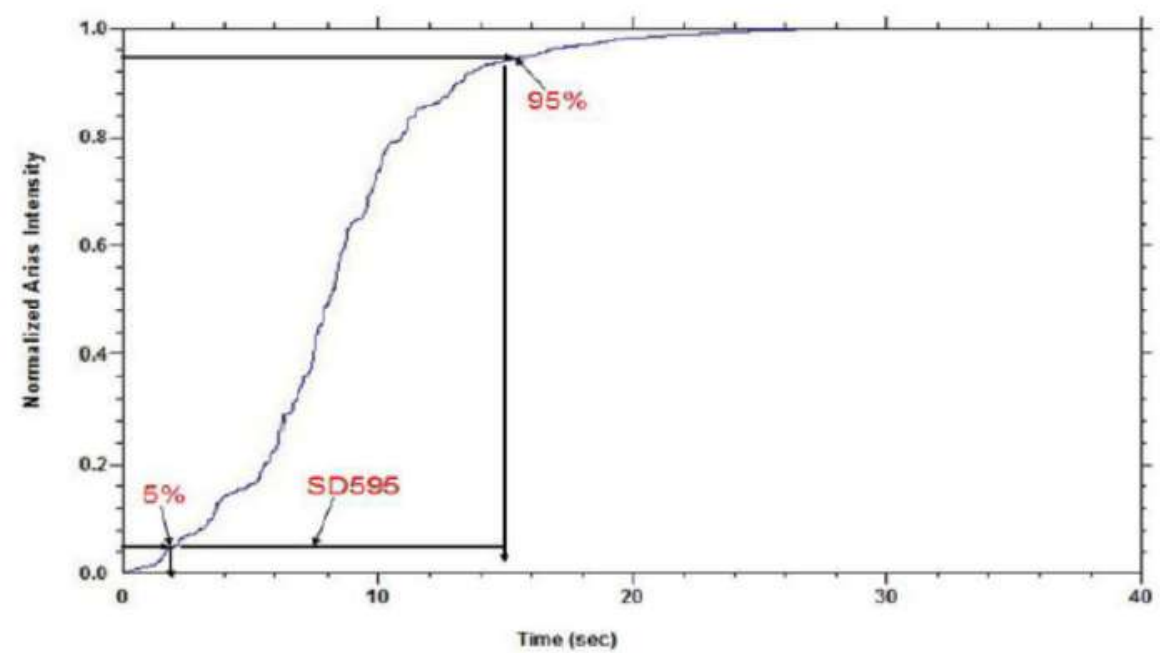

Figura 2.15 - Trifunac and Brady (1975) Duration of Strong Shaking (SD595) for Lake Hughes Acceleration Time History of 1994 Northrige Earthquake.

\subsection{2.}

Método de Ajuste Espectral

O método de ajuste espectral modifica o registro sísmico histórico no domínio do tempo procurando torna-lo compatível com o espectro de acelerações especificado pelo usuário. A metodologia foi baseada nas pesquisas de Lilhanand e Tseng (1987), dispondo-se de um código computacional originalmente escrito por Abrahamson (1993) e posteriormente atualizado por Hancock et al (2006). A modificação do conteúdo de frequências é feita através da adição de pequenas parcelas de onda (chamadas de wavelets) no domínio do tempo preservando a maior parte das características do registro original. Segundo Meneses (2009) podem acontecer dificuldades neste ajuste nos períodos longos do espectro. A Figura 2.16 mostra diferentes espectros de aceleração ajustados a um espectro padrão por meio deste método. A essência do método de ajuste espectral, relatado por Hancock et al (2006), é a seguinte:

- Calcula-se a resposta de um espectro com 1 grau de liberdade sob a ação de um registro de aceleração, para cada período e nível de amortecimento desejado; 
- Compara-se o pico da resposta do espectro 1D com a amplitude do espectro objetivo para determinar o erro;

- São adicionadas parcelas de ondas (wavelets) no registro da aceleração com amplitudes e fases apropriadas de modo que cada valor do espectro de resposta se ajuste à amplitude do espectro objetivo.

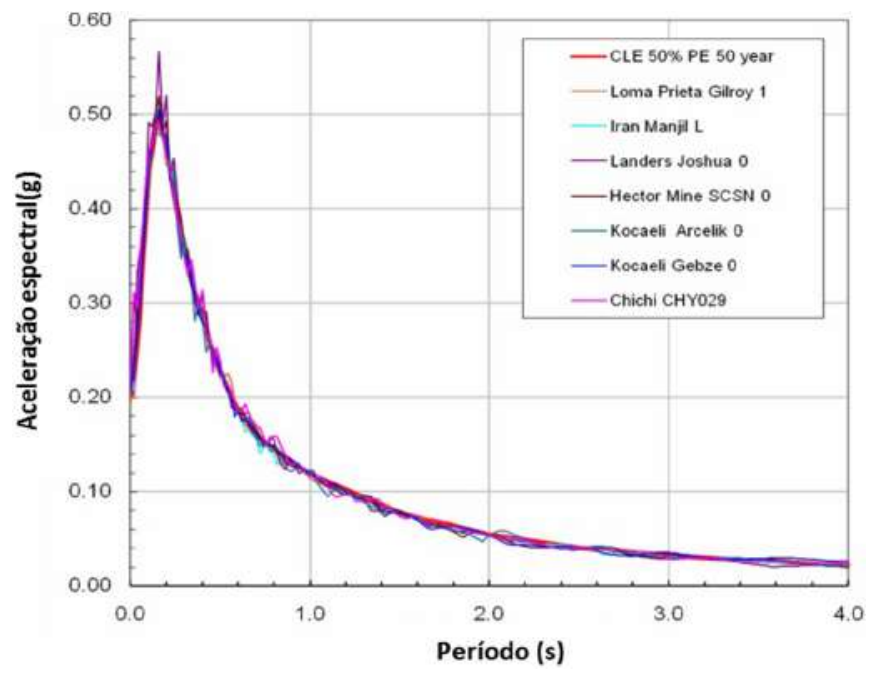

Figura 2.16- Espectros obtidos por meio do método de ajuste espectral (Meneses, 2009).

\section{4. \\ Classificação sismica das barragens}

A atividade econômica mineira em seu processo de extração gera resíduos; os quais são destinados às barragens de rejeitos. Tais barragens podem ser classificadas em função de sua altura, tipo de material do reservatório, danos pontenciais associados, categorias de risco, dentre outros.

Graças à classificação é possivel desenvolver um perfil do potencial de risco, que considera as consequências ao acontecer uma ruptura na barragem. O perfil baseia-se nas perdas (vidas, ambientais, culturais, econômicas) e população em risco; tal quantitativo é determinado usando uma aborgagem padrão. Há guias para classificar o potencial de risco das barragens como as propostas pela Associação Canadense de Barragens (CDA), pela Comissão Internacional de Grandes Barragens (ICOLD), entre outros. 


\subsection{1.}

\section{Associação canadense de barragens (CDA)}

A CDA fomenta o avanço do conhecimento e boas práticas relacionadas com a segurança das barragens mediante guias, boletins e publicações. São atualizadas quando são identificados problemas no conhecimento e prática.

Os casos recentes do rompimento da barragen de Fundão da Samarco (Brasil) e Mount Polley (Canadá), considerados como eventos catastróficos, fazem refletir sobre a necessidade de melhoria na segurança das barragens no futuro.

$\mathrm{Na}$ Tabela 2.2, apresenta-se as diretrizes que classificam a barragem de acordo com a CDA, a qual se baseia no potencial de perdas e na avaliação da popupação em risco. 
Tabela 2.2 - Classificação das barragens por níveis de perdas (adaptado CDA, 2013).

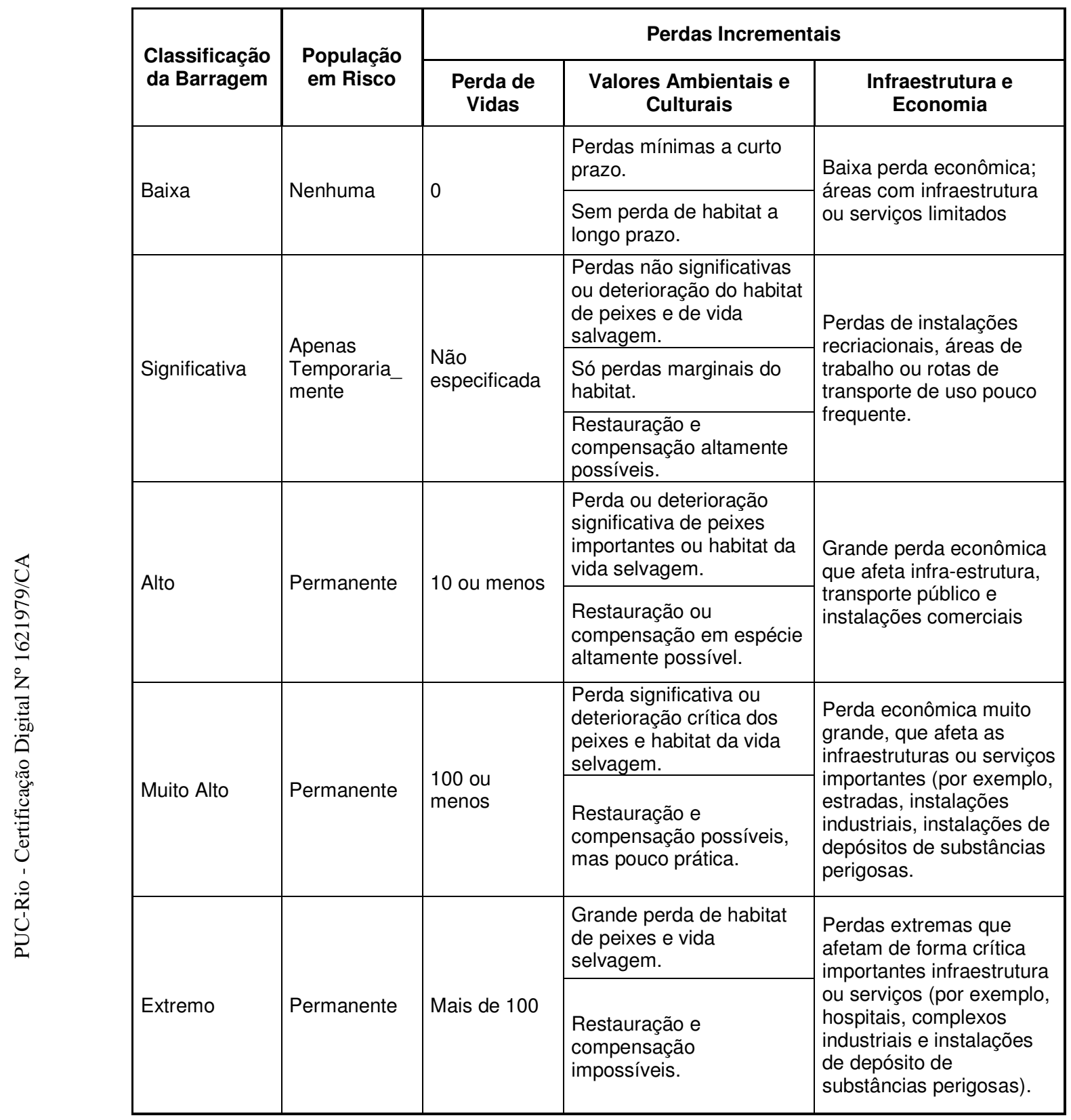

$\mathrm{Na}$ Tabela 2.3, aponta-se os níveis de terremoto para desenho de acordo com a CDA, a qual se basea na classe da barragem. 
Tabela 2.3 - Níveis Recomendados para o Terremoto de Desenho (adaptado CDA, 2013).

\begin{tabular}{|c|c|c|}
\hline Classe Barragem & $\begin{array}{c}\text { Mínima Probabilidade de Excedência } \\
\text { Anual dos perigos naturais }\end{array}$ & $\begin{array}{c}\text { Risco Social } \\
\text { Objetivo }\end{array}$ \\
\hline Baixo & $1 / 100$ & - \\
\hline Significativo & $1 / 1000$ & - \\
\cline { 1 - 3 } Alto & $1 / 2475$ & $(1 / \mathrm{N}) \times 10^{-3}$ \\
\hline Muito Alto & $1 / 10000$ & $(1 / \mathrm{N}) \times 10^{-3}$ \\
\cline { 1 - 2 } Extremo & \multicolumn{2}{|l}{} \\
\cline { 1 - 3 }
\end{tabular}

Onde:

$\mathrm{N}$, número de fatalidades

Na Tabela 2.4, mostra-se as condições de verificação de acordo com a CDA, a qual se basea nos níveis de risco potencial.

Tabela 2.4- Níveis de terremoto e inundação recomendada (adaptado CDA, 2013).

\begin{tabular}{|c|c|}
\hline Classe Barragem & $\begin{array}{c}\text { Probabilidade de Excedência Anual - } \\
\text { Terremotos }\end{array}$ \\
\hline Baixo & $1 / 100$ \\
\hline Significativo & Entre $1 / 100$ e $1 / 1000$ \\
\hline Alto & $1 / 2475$ \\
\hline Muito Alto & $1 / 2$ entre $1 / 2475$ e $1 / 10000$ ou MCE \\
\hline Extremo & $1 / 10000$ ou MCE \\
\hline
\end{tabular}

Onde:

AEP, a probabilidade de excedência anual;

MCE, terremoto máximo credível

\subsection{2.}

\section{Comissão internacional de grandes barragens (ICOLD, 2016)}

O ICOLD estabelece padrões e diretrizes para garantir que as barragens sejam construídas e operadas de maneira segura, eficiente, econômica, ambientalmente sustentável e socialmente justa.

$\mathrm{Na}$ Tabela 2.5, apresenta-se a quantificação dos fatores de risco para cada categoria de acordo com o ICOLD; baseado na capacidade de armazenamento, altura da barragem, requisitos de evacuação em função do número de pessoas e potencial de danos à jusante. 
Tabela 2.5- Quantificação do Fator de Risco (adaptado ICOLD, 2016).

\begin{tabular}{|c|c|c|c|c|}
\hline \multirow{2}{*}{ Fator de Risco } & Extremo & Grande & Moderado & Baixo \\
\hline \multirow{5}{*}{ Contribuição para Risco (Pontuação) } \\
\hline \multirow{2}{*}{ Capacidade (M-m $\left.{ }^{3}\right)$} & $>120$ & 120 a 1 & 1 a 0.1 & $<0.1$ \\
\cline { 2 - 5 } & 6 & 4 & 2 & 0 \\
\hline Altura (m) & $>45$ & 45 a 30 & 30 a 15 & $<15$ \\
\cline { 2 - 5 } & 6 & 4 & 2 & 0 \\
\hline \multirow{2}{*}{$\begin{array}{c}\text { Requisitos de evacuação } \\
\text { (Número de Pessoas) }\end{array}$} & $>1000$ & 1000 a 100 & 100 a 1 & Nenhum \\
\cline { 2 - 5 } & 12 & 8 & 4 & 0 \\
\hline \multirow{2}{*}{\begin{tabular}{c} 
Potencial de danos Jusante \\
\cline { 2 - 5 }
\end{tabular}} & Alto & Moderado & Baixo & Nenhum \\
\hline
\end{tabular}

Através da pontuação obtida pela Tabela 2.5 , obtem-se a classificação de risco da barragem, apresentada na Tabela 2.6.

Tabela 2.6- Classificação de Risco (adaptado ICOLD, 2016).

\begin{tabular}{|c|c|c|}
\hline Fator de Risco Total & \multicolumn{2}{|c|}{ Classificação de Risco } \\
\hline$(0$ a 6$)$ & I & Baixa \\
\hline$(7$ a 18$)$ & II & Moderado \\
\hline$(19$ a 30$)$ & III & Alto \\
\hline$(31$ a 36$)$ & IV & Extremo \\
\hline
\end{tabular}

\subsubsection{1. \\ Terminologia}

Para análise de comportamento sísmico de barragens é necessária a defição de critérios e tipos de terremotos. O ICOLD regulamenta da seguinte forma:

\subsubsection{1.}

\section{Sismo máximo provável}

O Sismo Máximo Provável, também conhecido como Maximum Credible Earthquake (MCE), é definido por uma análise determinística (percentil 84). É estabelecido como o movimento da média (percentil 50) mais um desvio padrão do sismo da maior magnitude para uma falha localizada numa região tectônica (ASCE/SEI 7-16, Minimum Design Loads and Associated Criteria for Buildings and other Structures). 
Os cenários MCE são movimentos de máximas solicitações sísmicas de uma análise determinística, quando comparados em termos de tempo de recorrência (período de retorno) com uma abordagem probabilística, correspondem a 10000 anos.

\subsubsection{2.}

\section{Sismo de avaliação de segurança}

O Sismo de Avaliação de Segurança, também conhecido como Safety Evaluation Earthquake (SEE), é definido como o movimento que gera danos sem atinguir o colapso. Para barragens que apresentam alto risco, o SEE poder ser substituído pelo MCE de uma análise determinística ou por um sismo, com um período de recorrência de 10000 anos da abordagem probabilística. Para fontes sísmicas, como os limites das placas, é mais apropriado trabalhar com um estudo determinístico. Para barragens que não apresentam um risco social pode se escolher um tempo de recorrência menor do SEE de uma análise probabilística.

\subsubsection{3. Sismo base de operação}

O Sismo Base de Operação, também conhecido como Operating Basis Earthquake (OBE), é definido como o movimento máximo que pode acontecer ao longo do tempo de construção. A atividade sísmica ocacionaria danos menores, fáceis de reparar, sem afetar a funcionabilidade da barragem e permaneceria em operação. Pode ser determinada a partir de uma avaliação de risco econômico, mas em geral escolhe-se um sismo para um tempo de recorrência de 150 anos ou de $50 \%$ de excedência em 100 anos.

\subsubsection{2.}

\section{Parâmetros de entrada sísmica para análise}

Um dos resultados obtidos pela ameaça sísmica, conhecido como Peak Ground Aceleration (PGA), é a aceleração pico do solo. $\mathrm{Na}$ abordagem determinística, esta solução existe em função da magnitude e localização do foco, enquanto que na abordagem probabilística, é em função da porcentagem a ser excedida e do tempo de exposição em anos. O resultado é introduzido como parâmetro para ajustar um sinal sísmico orginal, transfomando-o em um registro correspondente a nosso lugar de trabalho. 
$>$ Para uma classificação de perigo alto ou extremo da barragem, o sismo deve ser obtido pela SEE no nível do percentil 84 (abordagem determinística) ou por um sismo com probabilidade de excesso anual (AEP) de 10000 anos (abordagem probabilística).

$>$ Para uma classificação de perigo moderado da barragem, o sismo deve ser obtido pela SEE entre os níveis do percentil 50 até 84 (abordagem determinística) ou por um sismo com probabilidade de excesso anual (AEP) de 3000 anos (abordagem probabilística).

> Para uma classificação de perigo baixa da barragem, o sismo deve ser obtido pela SEE no nível do percentil 50 (abordagem determinística) ou por um sismo com probabilidade de excesso anual (AEP) de 1000 anos (abordagem probabilística).

$>$ O OBE corresponde a um sismo com probabilidade de excesso anual (AEP) de 150 anos (abordagem probabilística).

Existe uma ligação entre a magnitude e a duração do movimento sísmico, a qual tem importância significativa na avaliação do comportamento da barragem de rejeitos. Tanto a magnitude quanto a duração devem ser estimadas para o sismo do projeto.

O ICOLD sugere as acelerações verticais como os 2/3 das acelerações horizontais, considerando o tipo de falha. Os movimentos horizontais e verticais podem ser fornecidos pelas relações de atenuação.

\subsection{3.}

\section{Ministério de energia e minas do Peru (MEM, 1998)}

A guia apresentada do MEM considera uma aceleração pico do solo (PGA) para um tempo de recorrência de 500 anos na etapa de fechamento da barragem de rejeitos. Porém, não indica as consequências da ruptura da barragem, nem uma metodologia de classificação ou de pontencial de risco. 


\subsection{4.}

Associação brasileira de normas técnicas (ABNT, 2017)

A Associação Brasileira de Normas Técnicas (ABNT NBR 13028) recomenda que a avaliação sísmica deve ser feita no lugar da barragem tomando em conta com as normas existentes, registros passados e a bibliografia.

A ABNT sugere o empleo do MCE proposto pela CDA para os analises pseudo estáticos e analise de consequência de ruptura como critério sísmico conservador. 


\section{3 Avaliação da sísmicidade da barragem de rejeitos Otapara}

Este capitulo tem como objetivo avaliar a ameaça sísmica do sítio da barragem de rejeitos Otapara, localizada no Peru em região de alta atividade sísmica. São descritos os passos necessários para a realização do estudo, envolvendo desde a seleção do período de retorno, em função de diretrizes de segurança de barragens, identificação de fontes sismogênicas, tratamento de incertezas com a utilização de árvore lógica, determinação do espectro de resposta uniformemente provável, desagregação da ameaça sísmica e métodos para obter o sismo de projeto.

\section{1. \\ Localização da área do projeto}

A barragem de rejeitos Otapara está localizada em Arequipa, Peru, a uma elevação média de 430 metros, e com coordenadas UTM: Zona 18L, S 8.307.566 m, E 544.657 m. A Figura 3.1 indica a localização da barragem no Peru, a localização no estado de Arequipa e sua situação em relação ao rio Acari e a cidade de Otapara-Acari. 


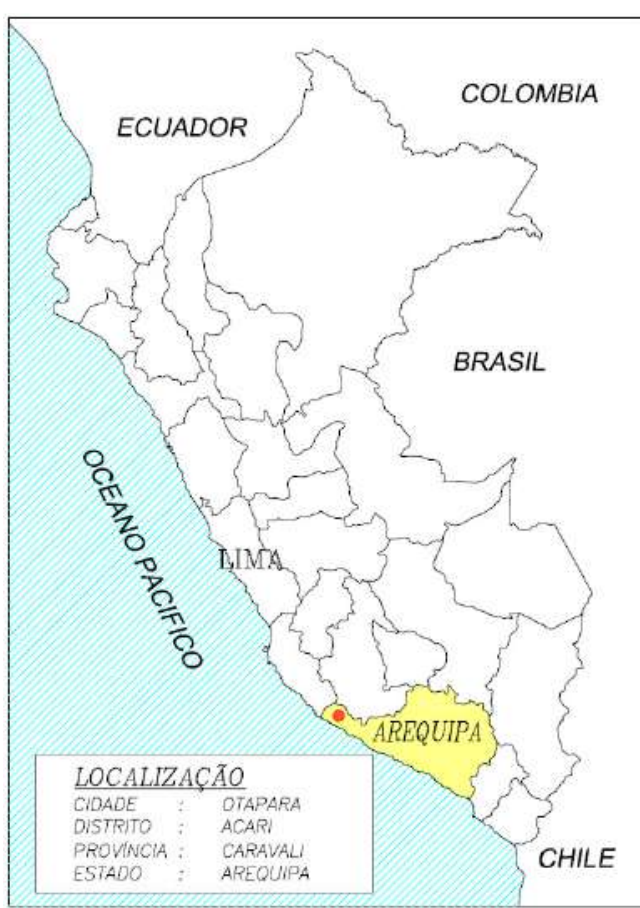

(a)

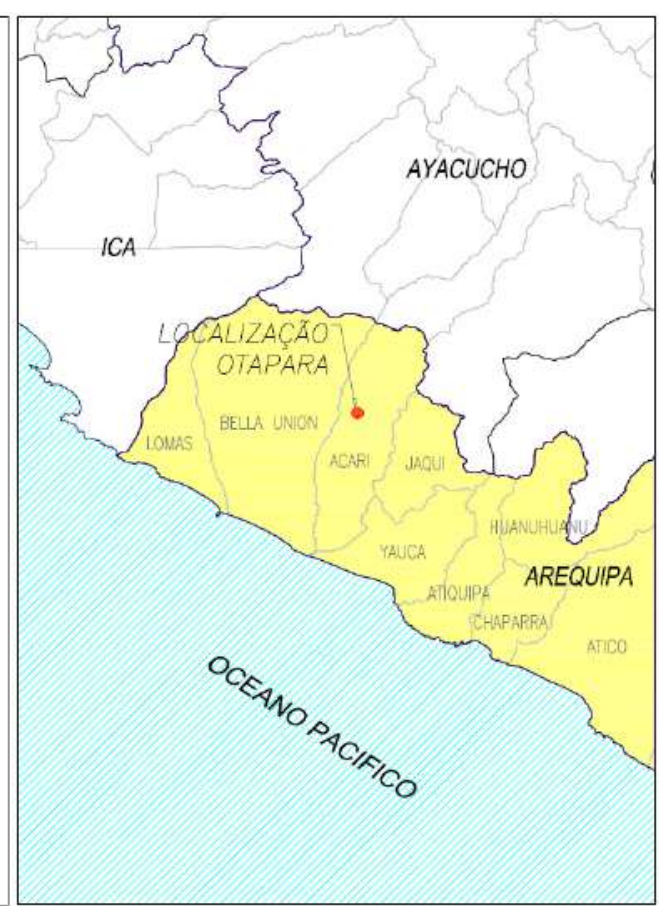

(b)

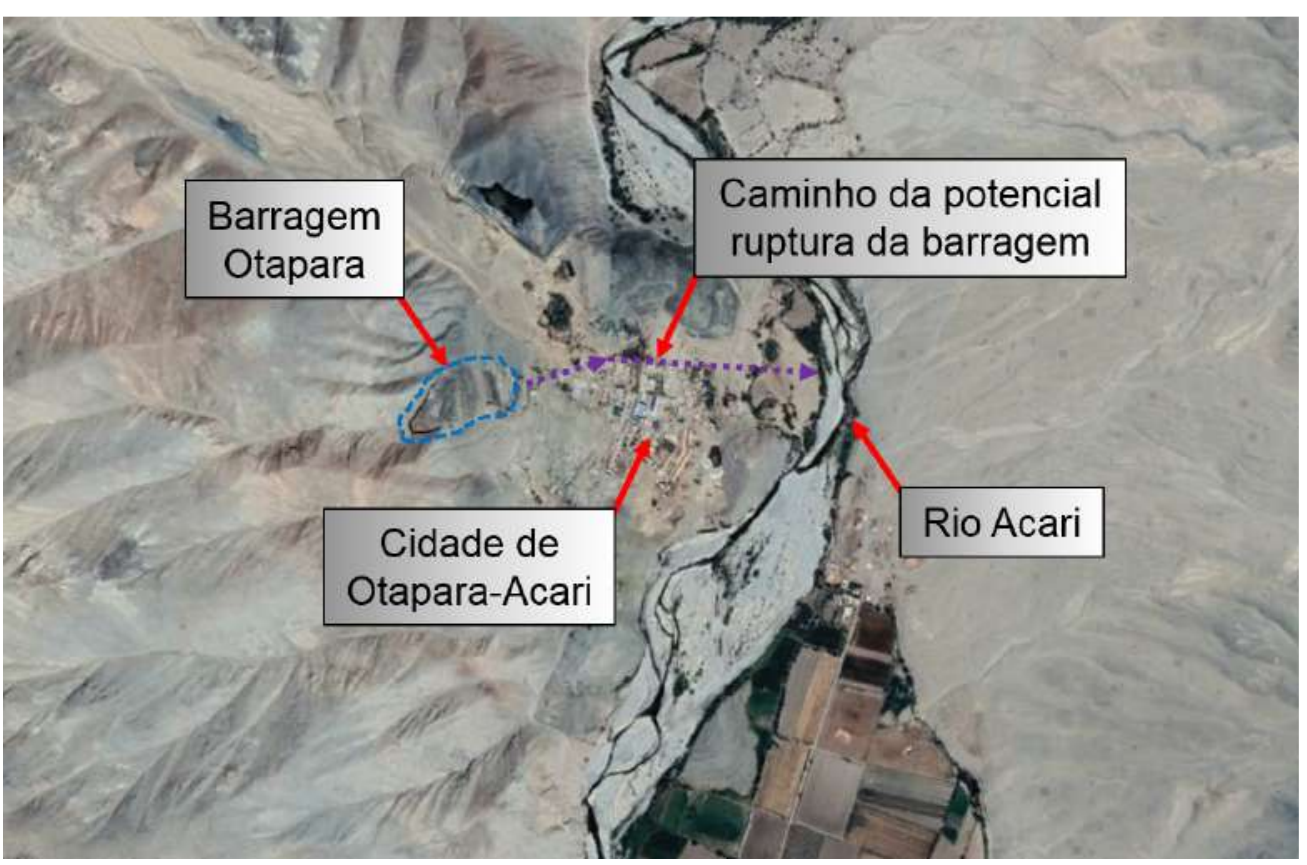

(c)

Figura 3.1 (a) Localização da barragem no Peru; (a) Localização no estado de Arequipa; (c) situação local. 


\section{2.}

\section{Introdução do projeto Otapara}

A barragem de rejeitos Otapara é formada por um dique de partida, construído com materiais de empréstimo, e posteriormente alteada pelo método de construção à montante, utilizando rejeitos ciclonados lançados a partir da crista. Na Figura 3.2 se apresenta a seção transversal crítica da barragem no final do alteamento.

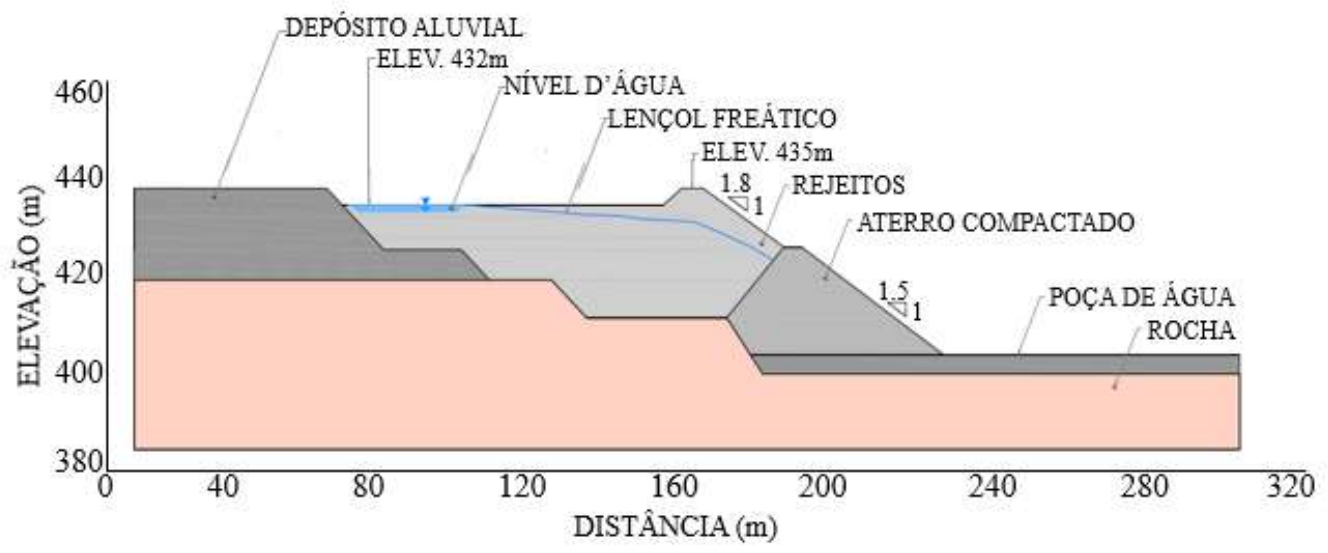

Figura 3.2- Seção transversal crítica da barragem Otapara.

Os rejeitos, tipo polpa, são transportados desde a usina de benefício por bombeamento mediante tubulações até a bacia de disposição, e descarregada ao longo do perímetro da crista do dique, formando uma praia. O ciclone, por efeito da força centrífuga, separa granulometricamente as partículas do rejeito em diferentes densidades e tamanhos. As partículas mais grossas e mais densas, saem pela parte inferior do ciclone (material de construção dos alteamentos), e as partículas mais finas e menos densas, escapam pela parte superior do ciclone.

O reservatório possui um revestimento impermeabilizante de geomembrana no fundo, um sistema de coleta da água superficial e profunda com elementos de drenagem, e poças para tratamento de percolados. Uma consideração adicional do reservatorio se refere à classificação de solos em função da velocidade de propagação da onda cisalhante (Vs), segundo a metodologia do IBC (2012), tipo de solo B. 


\subsection{1.}

Antecedentes do sísmo de 2013

$\mathrm{Na}$ quarta-feira do dia 25 de setembro de 2013, ocorreu um movimento sísmico, de 6.9 de magnitude em escala Richter (ML). O epicentro foi localizado a $112 \mathrm{~km}$ da cidade de Acarí, tendo gerado danos significativos que afetaram o funcionamento da barragem. Na Figura 3.3 é apresentada a localização do epicentro e os dados do sismo.

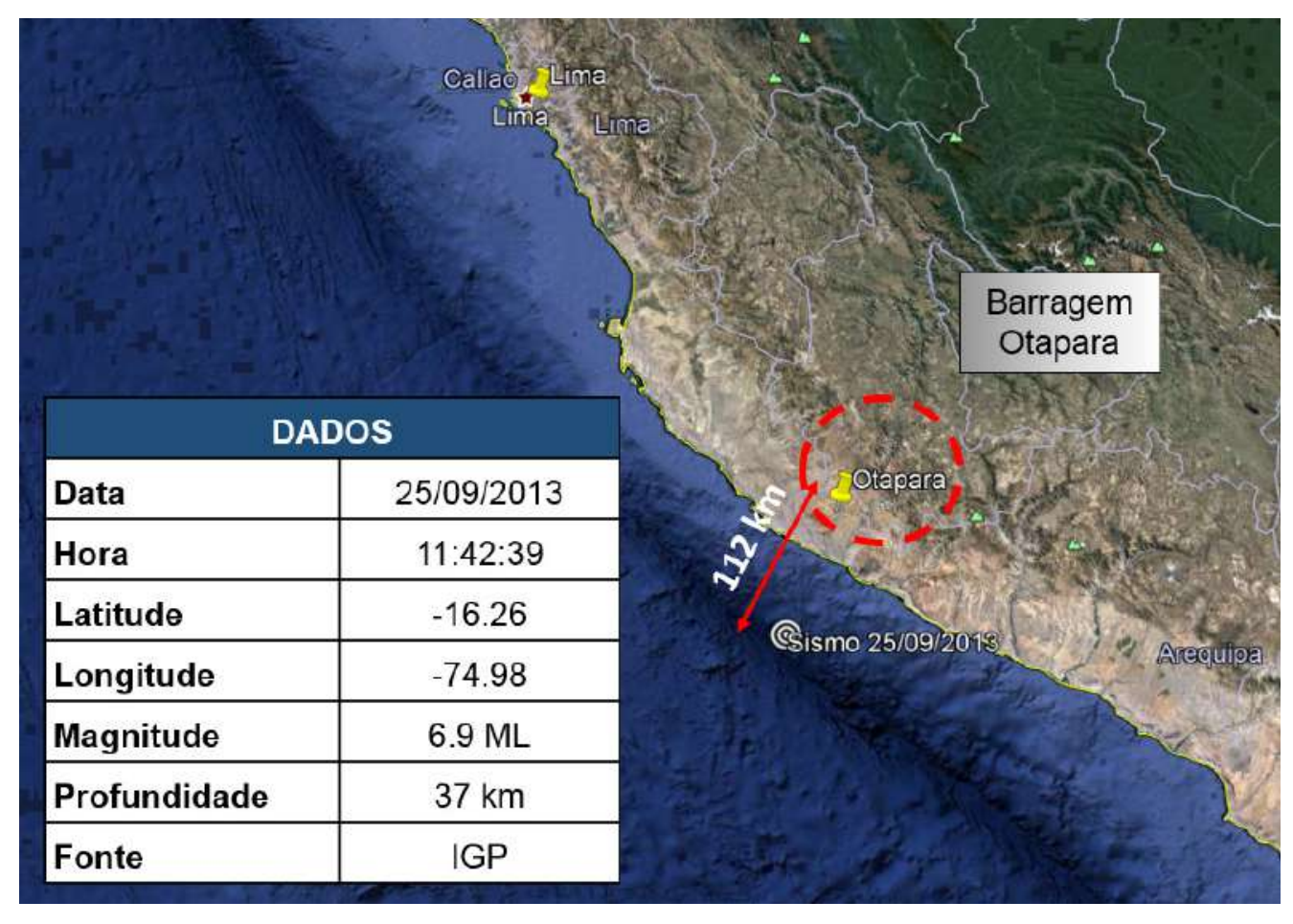

Figura 3.3- Localização e dados do sismo (CISMID).

Durante a avaliação das áreas afetadas da barragem, foram observadas trincas longitudinais e transversais em sua crista e nos taludes, variando de 3 até $10 \mathrm{~cm}$, deformações leves e deslizamentos locais. Além de sinais de liquefação nos resíduos (pequenos vulcões de areia) devido ao excesso de poropressão gerado pelo carregamento sísmico (Figura 3.4). 


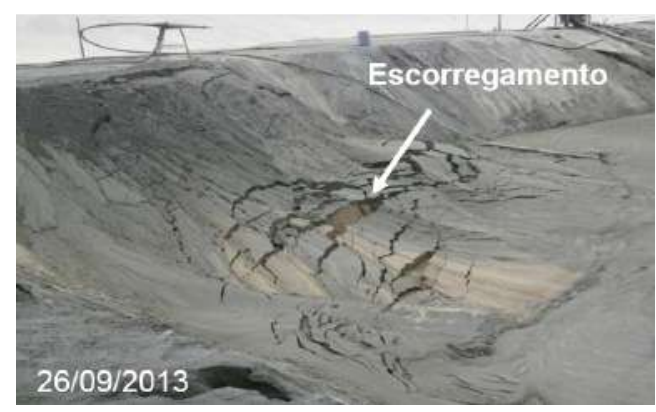

(a)

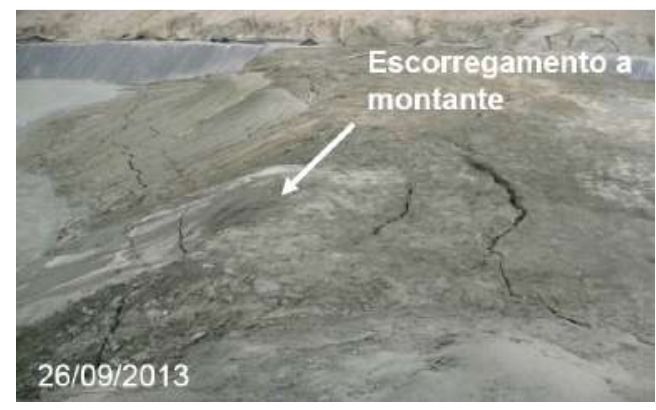

(c)

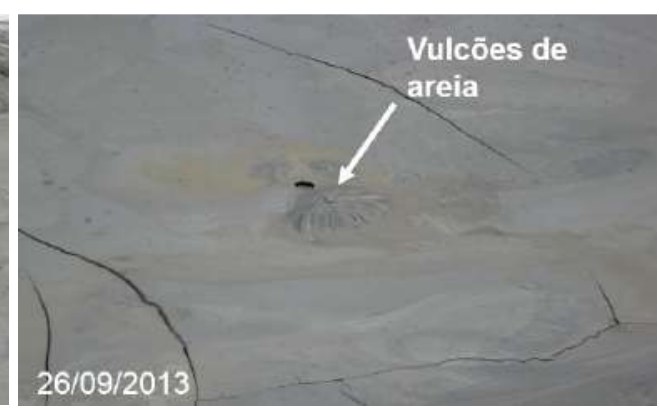

(b)

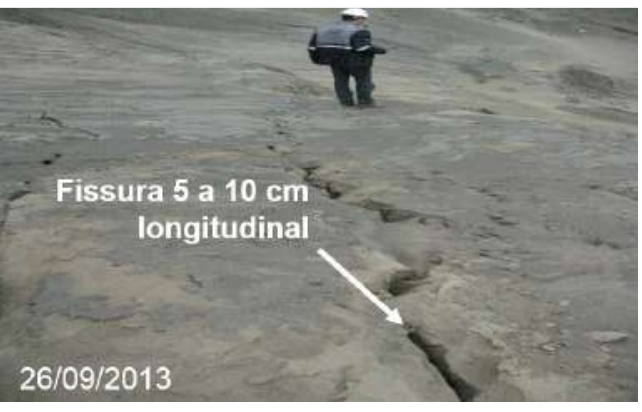

(d)

Figura 3.4- Consequências do sismo na barragem.

O sismo foi registrado em quatro (04) estações da rede de acelerógrafos do Peru, os quais foram calibrados para uma frequência de amostragem de $200 \mathrm{~Hz}$ ou 0.05 segundos. As acelerações máximas registradas pelas estações mostram valores pequenos da ordem de $0.003 \mathrm{~g}$ até $0.01 \mathrm{~g}$, devido à atenuação do movimento em relação à distância. Na Tabela 3.1, mostra-se a localização das estações e os valores máximos de acelerações registradas.

Tabela 3.1: Localização das estações e os valores máximos de acelerações.

\begin{tabular}{|c|c|c|c|c|c|c|c|}
\hline \multirow{2}{*}{$\mathbf{N}^{\circ}$} & \multirow{2}{*}{ Estação } & \multirow{2}{*}{$\begin{array}{c}\text { Elevação } \\
(\mathrm{m})\end{array}$} & \multirow{2}{*}{$\begin{array}{l}\text { Distância } \\
\text { (m) }\end{array}$} & \multicolumn{2}{|c|}{$\begin{array}{l}\text { Coordenadas } \\
\text { geográficas }\end{array}$} & \multicolumn{2}{|c|}{$\begin{array}{c}\text { Acelerações máximas } \\
(\mathrm{g})\end{array}$} \\
\hline & & & & Latitude & Longitude & PGA EW & PGA NS \\
\hline 1 & $\begin{array}{l}\text { Morro UNI } \\
(\text { LIM-SLP) }\end{array}$ & 134 & 521 & -12.02 & -77.05 & -0.0033 & -0.0028 \\
\hline 2 & $\begin{array}{l}\text { Decanato FIC-UNI } \\
\text { (LIM002) }\end{array}$ & 146 & 520 & -12.02 & -77.05 & 0.0036 & -0.0031 \\
\hline 3 & $\begin{array}{c}\text { Parque de la } \\
\text { Reserva (LIM005) }\end{array}$ & 130 & 516 & -12.07 & -77.04 & 0.0032 & -0.0025 \\
\hline 4 & $\begin{array}{l}\text { Villa El Salvador } \\
\text { (LIM007) }\end{array}$ & 167 & 947 & -12.21 & -76.94 & -0.0106 & -0.0100 \\
\hline
\end{tabular}

Foram executadas medidas de remediação como escavação manual ao longo das trincas, seguido do enchimento com o mesmo material escavado em camadas de 0,30 m, compactado com equipamento manual. Nas regiões do dique 
que apresentaram ruptura local, foram colocadas sacolas cheias de rejeito para controlar a filtração. Para o talude global, foi preciso fazer um retaludamento uniforme.

\section{3.}

\section{Classificação sísmica da barragem}

Para classificação de risco sísmico, normalmente são utilizadas as recomendações da Associação Canadense de Barragens - CDA (2014) ou do Comissão Internacional de Grandes Barragens - ICOLD (2016), que estabelecem critérios de risco e características dos terremotos para análise do comportamento sísmico destas estruturas. Na Figura 3.5 mostra-se o fluxograma dos passos empregados para obter o período de retorno do sismo de projeto associado à classificação do risco a partir das diretrizes de segurança de barragens.

Nesta pesquisa, o risco da barragem Otapara foi determinado com base nas recomendações da CDA (2014), recebendo a classificação de risco significativo, com recomendação de utilizar sismo de projeto com período de retorno de 1000 anos.

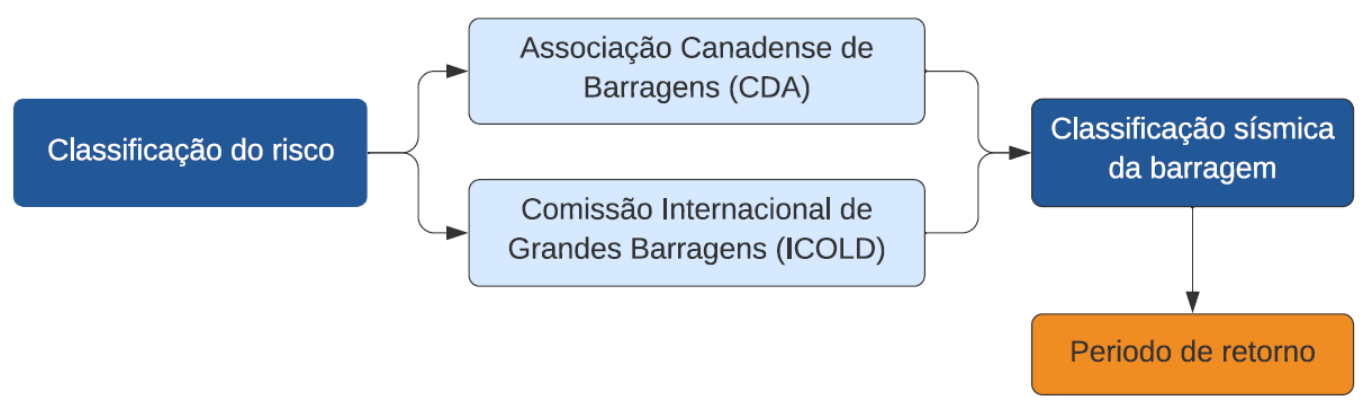

Figura 3.5- Fluxograma da classificação do risco na obtenção do período de retorno do simos de desenho.

\subsection{1.}

\section{Classificação sísmica pela CDA}

De acordo com a metodologia da CDA, a barragem de rejeitos Otapara é classificada como um risco potencial significativo. Através da Tabela 3.2, para este nível de risco potencial, é admitido o terremoto com um período de retorno de 1000 anos como sismo do projeto. 
Tabela 3.2- Níveis de terremoto (adaptado CDA, 2013).

\begin{tabular}{|c|c|}
\hline Classe Barragem & Probabilidade de Excedência Anual - Terremotos \\
\hline Baixo & $1 / 100$ \\
\hline Significativo & Entre $1 / 100$ e $1 / 1000$ \\
\hline Alto & $1 / 2475$ \\
\hline Muito Alto & $1 / 2$ entre $1 / 2475$ e $1 / 10$ 000 ou MCE \\
\hline Extremo & $1 / 10000$ ou MCE \\
\hline
\end{tabular}

\subsection{2.}

\section{Classificação sísmica pela ICOLD}

De acordo com a metodologia do ICOLD, o valor do fator de risco é de 18, de acordo com a Tabela 3.3, que a classifica como risco tipo II ou moderada.

Tabela 3.3- Estimativa do fator de risco da barragem de rejeitos.

\begin{tabular}{|c|c|c|c|c|c|}
\hline Fator de Risco & Extremo & Grande & Moderado & Baixo & \multirow{2}{*}{$\begin{array}{c}\text { Fator de } \\
\text { Risco }\end{array}$} \\
\hline \multicolumn{5}{|c|}{ Contribuição para Risco (Pontuação) } & \\
\hline \multirow{2}{*}{ Capacidade (M-m3) } & $>120$ & 120 a 1 & 1 a 0.1 & $<0.1$ & \multirow{2}{*}{2} \\
\hline & 6 & 4 & 2 & 0 & \\
\hline \multirow{2}{*}{ Altura (m) } & $>45$ & 45 a 30 & 30 a 15 & $<15$ & \multirow{2}{*}{4} \\
\hline & 6 & 4 & 2 & 0 & \\
\hline \multirow{2}{*}{$\begin{array}{l}\text { Requisitos de evacuação } \\
\text { (Número de Pessoas) }\end{array}$} & $>1000$ & 1000 a 100 & 100 a 1 & Nenhum & \multirow{2}{*}{4} \\
\hline & 12 & 8 & 4 & 0 & \\
\hline \multirow{2}{*}{$\begin{array}{l}\text { Potencial de danos } \\
\text { Jusante }\end{array}$} & Alto & Moderado & Baixo & Nenhum & \multirow{2}{*}{8} \\
\hline & 12 & 8 & 4 & 0 & \\
\hline \multicolumn{5}{|c|}{ TOTAL } & 18 \\
\hline
\end{tabular}

Conforme apresentado na Tabela 3.4, o sismo do projeto corresponde a um período de retorno de 3000 anos, segundo o ICOLD.

Tabela 3.4- Classificação de Risco (adaptado ICOLD, 2016).

\begin{tabular}{|c|c|c|}
\hline Fator de Risco Total & \multicolumn{2}{|c|}{ Classificação de Risco } \\
\hline$(0$ a 6$)$ & I & Baixa \\
\hline$(7$ a 18$)$ & II & Moderado \\
\hline$(19$ a 30$)$ & III & Alto \\
\hline$(31$ a 36$)$ & IV & Extremo \\
\hline
\end{tabular}


Nesta dissertação, foi escolhida a classificação sísmica da CDA, considerando um sismo para um período de retorno de 1000 anos, devido que o risco sísmico da barragem em estudo é melhor representado. Isso porque o risco sismico encontrasse associoado aos níveis de perdas e estar representados qualitativamente.

A classificação sísmica da ICOLD é conservadora para baixa produção mineira e barragem de rejeitos menores; no enquanto as duas tem semelhantes resultados para barragens maiores ou de grande produção mineira.

\section{4.}

Ameaça sísmica probabilística do projeto

Para obter a ameaça sísmica probabilística do projeto em função do espectro de resposta uniformemente provável e a desagregação da ameaça sísmica, foram seguidos os passos indicados no seguinte fluxograma (Figura 3.6).

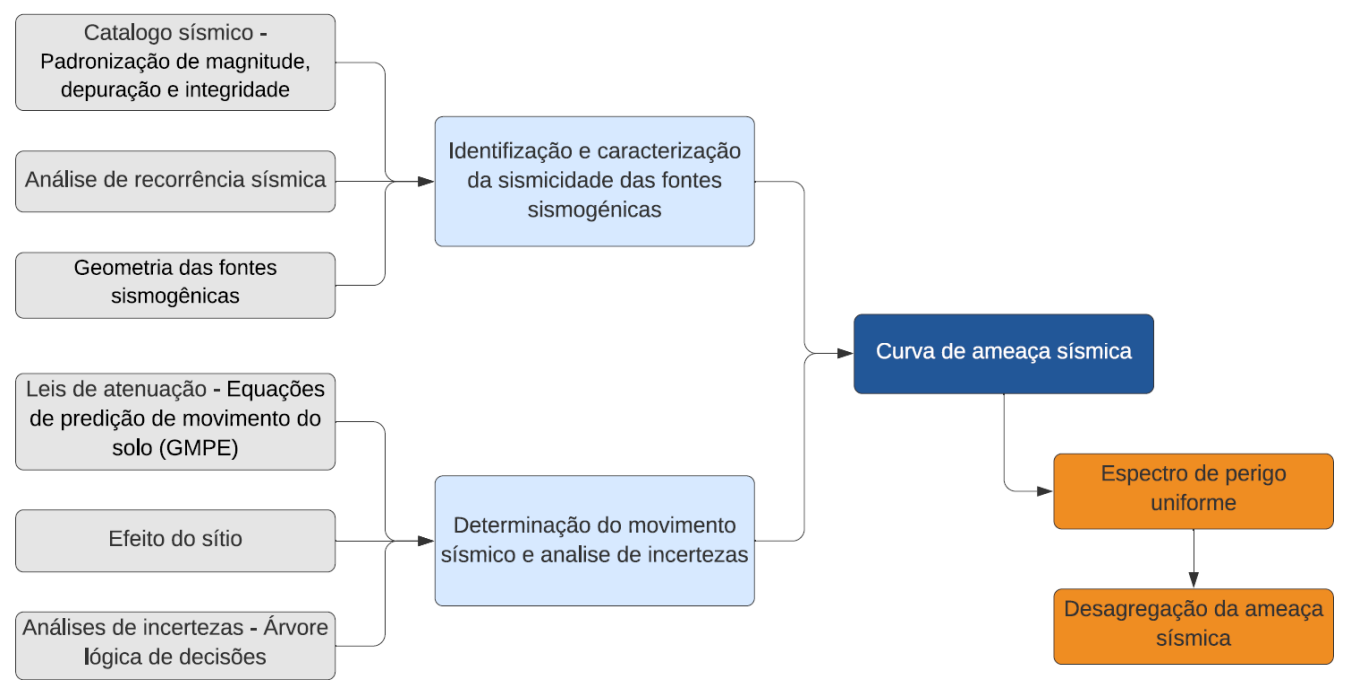

Figura 3.6- Fluxograma da a ameaça sísmica probabilística.

Nesta dissertação foi empregada apenas a análise probabilística; a justificativa está nas desvantagens da análise determinística. Esta análise não fornece informação sobre a probabilidade de ocorrência do sismo controlador nem da que o sismo ocorra onde é assumido que deva acontecer; tampouco produz resultados sobre o nível de vibração, esperado durante certo intervalo de tempo, 
ou sobre os efeitos das incertezas introduzidas nos vários passos necessários para calcular as características do movimento (Ccahuay, 2018).

A diferença entre as ameaças sísmicas determinística e probabilística é que a segunda faz menção da probabilidade de ocorrência de determinado valor de aceleração, em certo tempo de vida útil da estrutura; além disso considera, na sua formulação, as incertezas inerentes e aleatórias dos parâmetros das análises (Ccahuay, 2018).

\subsection{1.}

Identificação e caracterização das fontes sismogénicas

A identificação e carasterização das fontes sismogênicas assim como a análise de recorrência sísmica foi tomada da proposta por Roncal (2017).

\subsubsection{1. \\ Catálogo sísmico do Peru}

As informações sismológicas utilizadas nesta pesquisa foram tomadas do trabalho de Roncal (2017), no qual estão contidos os dados do catálogo sísmico do Instituto Geofísico do Peru (IGP, 2001). Essas informações foram complementadas até $1^{\circ}$ de janeiro de 2016 , usando informações compiladas de vários catálogos sísmicos das seguintes instituições: Centro Nacional de Informações sobre Terremotos (NEIC); Centro Sismológico Internacional (ISC); Pesquisa Geológica dos Estados Unidos (USGS); Administração Nacional Oceânica e Atmosférica (NOAA); e o Global Centroid Moment Tensor (CMT global). Ao mesmo tempo, o catálogo sísmico foi complementado com dados sísmicos históricos fornecidos pelo IGP, com os quais existe um catálogo sísmico compilado do ano de 1555 até o dia 01 de janeiro de 2016. A Figura 3.7 plota os eventos sísmicos considerados nas análises. 


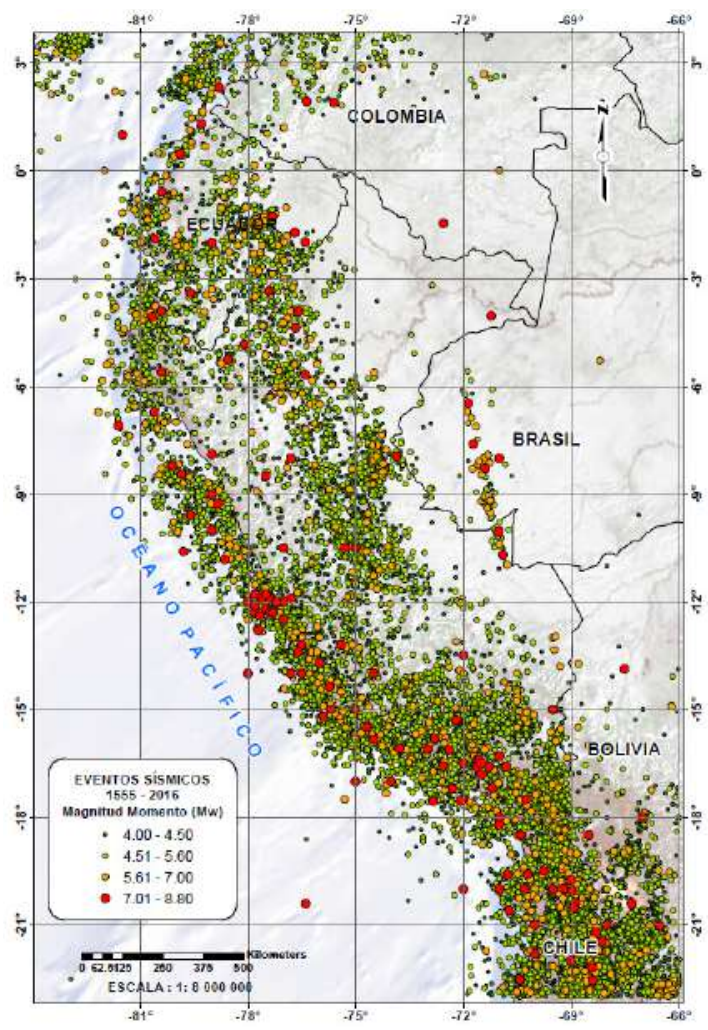

Figura 3.7- Eventos Sismicos Magnitude Momento (Mw) 1555-2016. (Roncal, 2017).

\subsubsection{2. \\ Integridade do catálogo sísmico}

Eventos com magnitude Mw maior ou igual a 4,0 são considerados na resposta das estruturas assim, o catálogo sísmico homogeneizado e depurado possui 12.919 eventos principais e independentes. A integridade do catálogo é apresentada na Figura 3.8, distribuída por sua frequência anual versus tempo antes do dia 1 de janeiro do 2016, agrupada por conjuntos de magnitude (Roncal, 2017). 


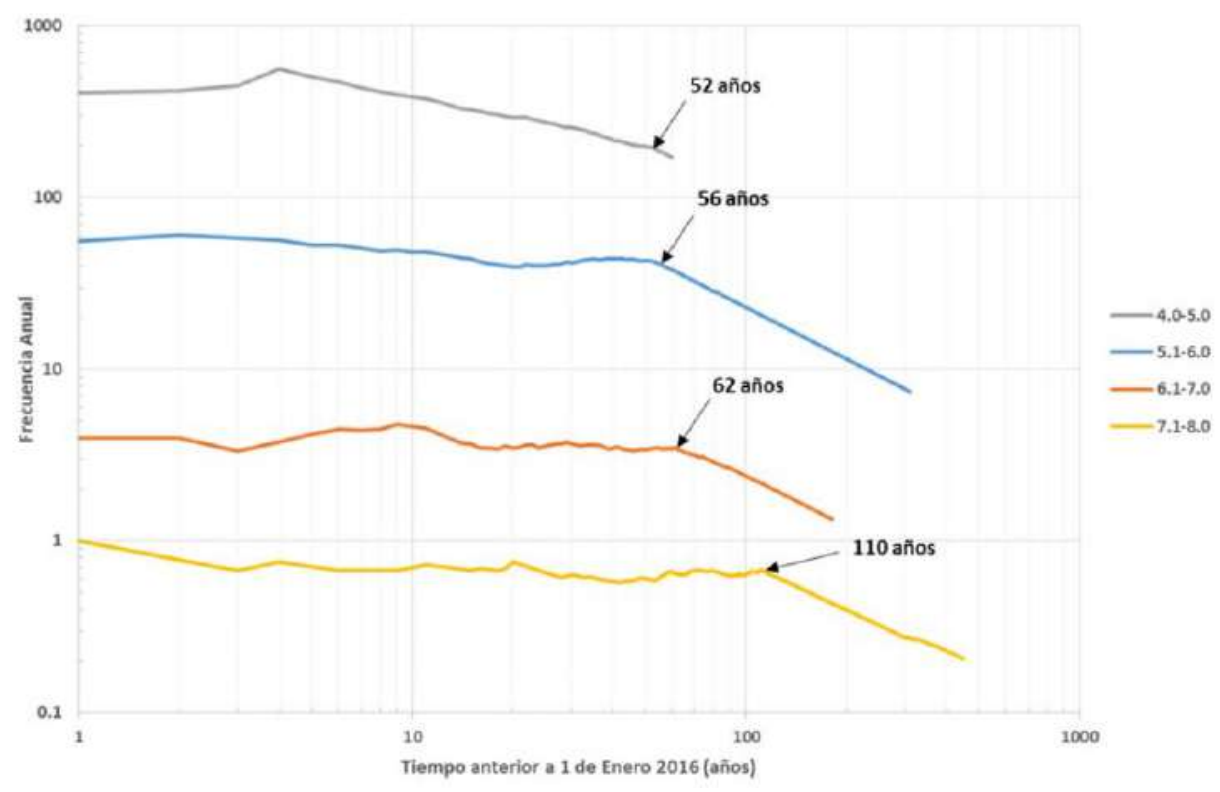

Figura 3.8- Análise de Completitude do Catálogo (Roncal, 2017).

\subsubsection{3. Geometria das fontes sismogênicas}

Foi feito uma distribuição espacial da sismicidade com base na localização dos hipocentros, para poder caracterizar os eventos sísmicos segundo seu mecanismo de ruptura; seja de subducção (onde os sismos interface e intraplaca são diferenciados) e sismos continentais ou crosta superficial. A determinação das fontes sismogênicas baseou-se no mapa de distribuição dos epicentros, bem como nas características tectônicas da área de influência, já que a atividade sísmica no Peru é o resultado da interação entre as placas de Nazca e Sulamericana, bem como o processo de reajustes tectônicos do sistema andino. Isto permite agrupar as fontes em continental e subducção.

As fontes sismogênicas definidas são 29, das quais 20 são de subducção e 9 fontes continentais. Das fontes 1 até 6 caracterizam a sismicidade de subducção interface, agrupam os sismos que ocorrem nas zonas de fronteira entre placas, em profundidades de até $75 \mathrm{~km}$ (Figura 3.9(a)); as fontes 7 até 20 caracterizam a sismicidade da subducção intraplaca, agrupam os sismos que ocorrem no interior de placas tectônicas, em profundidades maiores de $75 \mathrm{~km}$ (Figura 3.9 (b)) e as últimas 9 fontes caracterizam a sismicidade da crosta superficial, agrupam os sismos que não são produto direto do mecanismo de subducção, como os sismos 
produzidos por falhas geológicas ou vulcanismo. Tem profundidades máximas de 20 km (Figura 3.9(c)).

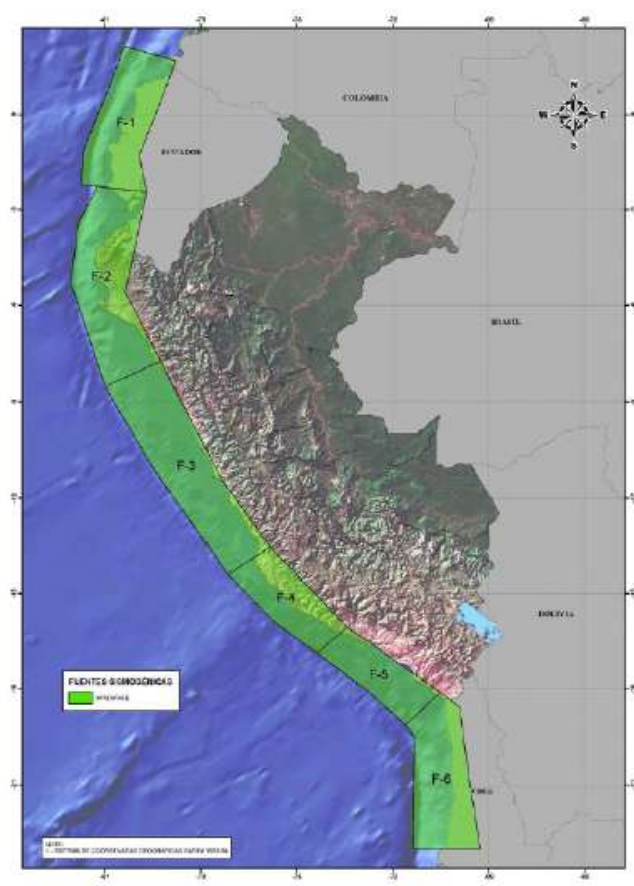

(a)

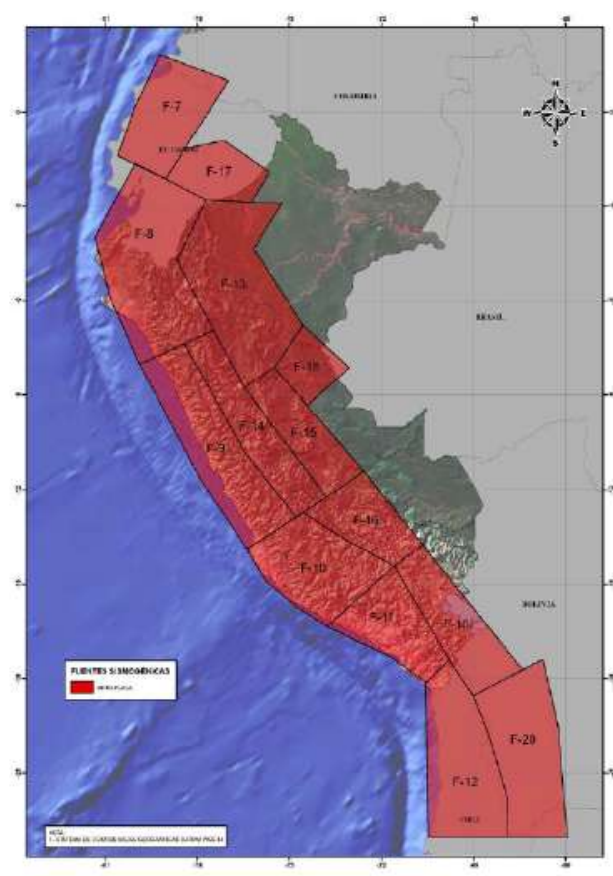

(b)

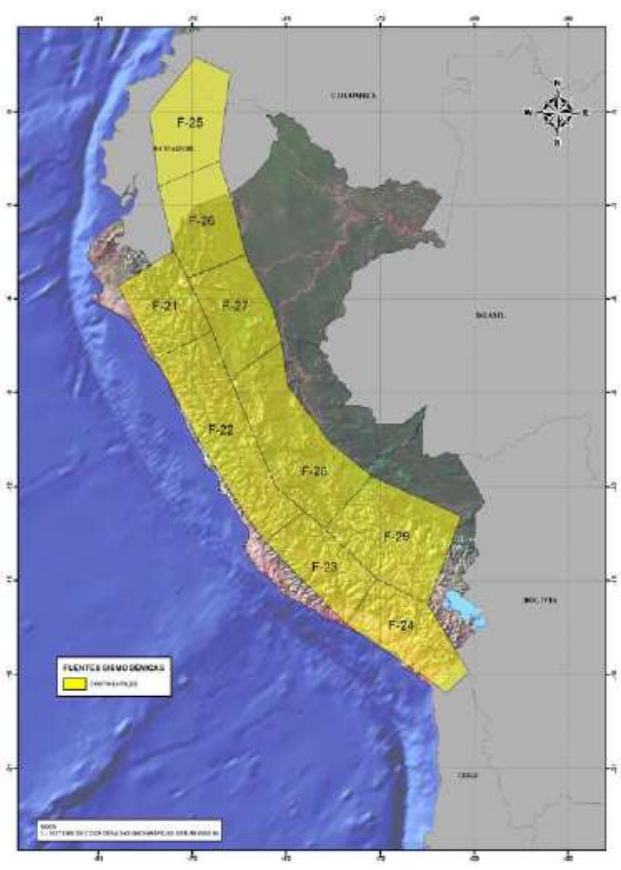

(c)

Figura 3.9- Fontes sismogênicas (a) subducção de interface (b) subducção intraplaca e (c) superfícial ou da crosta Continental (Roncal, 2017). 


\subsection{2.}

Caracterização da sismicidade ou distribuição temporal dos sismos Análise de recorrência sísmica

Para a determinação dos parâmetros sismológicos foi feita uma análise da recorrência sísmica mediante o modelo exponencial no truncado de Gutenberg e Richter, assim avalia-se a variação dos eventos sísmicos que cada fonte possa gerar.

Os parâmetros b e taxa são determinados pelo método de ajuste da máxima verossimilitude (Weichert 1980) considerando períodos de completitude do catálogo sísmico por intervalos de magnitude (Stepp 1972), como mostrado na Tabela 3.5.

Tabela 3.5- Integridade do catálogo sísmico (Roncal, 2017).

\begin{tabular}{|c|c|}
\hline $\begin{array}{c}\text { Faixa } \\
(\mathbf{M w})\end{array}$ & $\begin{array}{c}\text { Catálogo completo } \\
\text { desde }\end{array}$ \\
\hline$\leq 5.0$ & 1964 \\
\hline $5.1-6.0$ & 1960 \\
\hline $6.1-7.0$ & 1954 \\
\hline $7.1-8.0$ & 1906 \\
\hline$\geq 8.1$ & 1555 \\
\hline
\end{tabular}

Com essas considerações, na Tabela 3.6 são apresentados os parâmetros sismológicos de recorrência de fontes sismogênicas consideradas na análise. 
Tabela 3.6- Parâmetros sismológicos das fontes sismogênicas (Roncal, 2017).

\begin{tabular}{|c|c|c|c|c|}
\hline \multirow{2}{*}{ Fonte } & \multicolumn{5}{|c|}{ Parâmetros Sismológicos } \\
\cline { 2 - 5 } & Mmin & Mmax & $\boldsymbol{\beta}$ & Taxa \\
\hline F3 & 4,8 & 8,4 & 1,732 & 3,980 \\
\hline F4 & 4,4 & 8,4 & 1,730 & 6,620 \\
\hline F5 & 4,8 & 8,4 & 1,473 & 2,580 \\
\hline \multicolumn{5}{|c|}{ Mecanismo focal Interface } \\
\hline F9 & 4,5 & 7,9 & 1,939 & 6,510 \\
\hline F10 & 4,5 & 7,0 & 1,805 & 6,570 \\
\hline F11 & 4,8 & 7,8 & 2,251 & 4,850 \\
\hline F14 & 4,2 & 6,6 & 1,280 & 2,070 \\
\hline F15 & 4,6 & 6,0 & 2,334 & 2,520 \\
\hline F16 & 4,1 & 6,9 & 1,307 & 1,250 \\
\hline F19 & 4,8 & 7,0 & 2,307 & 2,920 \\
\hline \multicolumn{5}{|c|}{ Mecanismo focal Continentais } \\
\hline F22 & 4,1 & 7,2 & 1,068 & 1,320 \\
\hline F23 & 4,5 & 7,0 & 1,384 & 0,675 \\
\hline F24 & 4,4 & 7,4 & 1,314 & 1,280 \\
\hline F28 & 4,5 & 7,0 & 1,667 & 2,850 \\
\hline F29 & 4,3 & 7,1 & 1,259 & 1,420 \\
\hline
\end{tabular}

\subsection{3. \\ Determinação do movimento sísmico e analise de incertezas}

A avaliação dos movimentos do solo é atualmente obtida por uma função de distribuição de probabilidade de um parâmetro particular como a aceleração máxima do solo ou espectros de resposta que são definidos por parâmetros estatísticos (Roncal, 2017). Uma consideração adicional se refere à classificação de solos em função da velocidade de propagação da onda cisalhante (Vs) segundo a metodologia da IBC (2012), como indicado na seção do Capitulo 2.

Foram utilizadas relações de atenuação para solo tipo B (embasamento rochoso), pois foi detectada a existência de rocha superficial.

\subsubsection{1.}

\section{Leis de atenuação utilizadas na análise}

As equações de predição de movimento do solo (GMPE) ou também conhecidas como leis de atenuação estimam a propagação de ondas sísmicas de uma fonte até a área do projeto, são comumente baseadas na análise de 
magnitudes sísmicas, mecanismo focal, distâncias do evento a um ponto de análise e outros parâmetros sismológicos.

No caso de estudo foram consideradas as seguintes leis de atenuação, para os sismos de subducção Youngs et al. (1997), Zhao et al. (2006) e BC Hydro (2015), enquanto para os sismos continentales Sadigh et al. (1997) e Atkinson e Boore. (2003), essas leis foram selecionadas com base em sua aplicabilidade na área do projeto.

Equação de atenuação de Youngs et al. (1997):

Youngs et al. (1997) desenvolveram leis de atenuação para regiões de terremotos de subducção (interface e intraplaca), utilizando dados sísmicos registrados no Alasca, Chile, Japão, México, Peru (14 registros) e nas ilhas Salomão, para distâncias entre 10 e 500 km, levando em consideração as características regionais. A aplicação desta relação de atenuação é apropriada para terremotos de magnitude $5 \mathrm{Mw}$ ou superior. A relação de atenuação proposta por Youngs et al. (1997) para rocha, incluem amortecimento de 5\%.

Aqueles autores definiram as características geológicas regionais em três grupos: rocha, solo rígido pouco profundo e solo rígido profundo, considerando eventos em rocha para todos aqueles com velocidade de onda $S$ próximas a 750 $\mathrm{m} / \mathrm{s}$, eventos em solo profundo com profundidade de rocha superior a $20 \mathrm{~m}$, com velocidades de ondas S entre 180 e $360 \mathrm{~m} / \mathrm{s}$, e eventos em solo superficial, para profundidades de rocha inferior a $20 \mathrm{~m}$.

\section{Equação de atenuação de Zhao et al. (2006):}

Zhao et al. (2006) propuseram uma lei de atenuação para as regiões de subducção de terremotos de interface e intraplaca, utilizando dados de terremotos registrados basicamente no Japão (até 2003), Irã e na costa ocidental dos Estados Unidos, com um total de 4726 terremotos de subducção da crosta superficial, de interface e de intraplaca.

Usaram cinco classificações de sítios, classificados como SC, I, II, III e IV, correspondendo a quatro classes de materiais: rocha dura, rocha, solo compacto, solo medianamente compacto e solo fofo, conforme Molas \& Yamazaki (1995). Os eventos de rocha foram considerados para todos aqueles com velocidade de onda 
$\mathrm{S}$ superior a $600 \mathrm{~m} / \mathrm{s}$, eventos em solos compacto com velocidade entre $300 \mathrm{~m} / \mathrm{s}$ e $600 \mathrm{~m} / \mathrm{s}$, em solos medianamente compactos com velocidade entre $200 \mathrm{~m} / \mathrm{s} 300$ $\mathrm{m} / \mathrm{s}$ e eventos em solos fofos com velocidade de onda $S$ inferior a $200 \mathrm{~m} / \mathrm{s}$.

\section{Equação de atenuação de BC Hydro (2015):}

Em 2007, a BC Hydro, principal proprietária de barragens na Colúmbia Britânica, Canadá, iniciou uma atualização da avaliação de ameaça sísmica nas áreas de barragens. Uma questão chave foi o movimento de terremotos na zona de subducção de Cascadia, Canadá. Novas equações de previsão do movimento (GMPE) foram desenvolvidas por Abrahamson et al. (2015).

Os dados iniciais de movimento foram retirados de Atkinson e Boore (2003, 2008), que incluem uma compilação referente às leis de atenuação de Crouse et al. (1988), Crouse (1991) e Youngs et al. (1997). Adicionalmente, foram consideradas informações sobre movimentos de solo provocados por terremotos de subducção ocorridos no Japão (Zhao, 2008), Taiwan (Cheng, 2008), América do Sul e América Central (Pacific Engineering, 2008) e México (Macías - Carrasco, 2008).

\section{Equação de atenuação de Sadigh et al. (1997):}

Sadigh et al. (1997) desenvolveram leis de atenuação para acelerações máximas do solo e acelerações espectrais de resposta horizontal (5\% de amortecimento) para terremotos continentais. Essas relações baseiam-se principalmente em dados de fortes eventos sísmicos na Califórnia, terremotos de Gazli (Rússia, 1976) e Tabas (Irã, 1978). A GMPE foi desenvolvida para rocha, considerando 121 acelerogramas, para terremotos com magnitude $\mathrm{Mw} \geq 4 \mathrm{e}$ distâncias de até $100 \mathrm{~km}$.

Sadigh et al. (1993) indicaram que, dentro dos $10 \mathrm{~km}$ de superfície de ruptura, existem diferenças sistemáticas entre as componentes de falha normal e falha paralela nos movimentos de longo período. Especificamente, recomendam que a componente de falha normal seja aumentada em $20 \%$ em relação aos valores geométricos médios para períodos espectrais de 2.0 segundos ou superiores, e a componente de falha paralela seja $20 \%$ menor do que o valor médio. 
Em relação à classificação do site, Sadigh et al. (1993) usaram duas categorias gerais de classificação: rocha e solos profundos, com base em estudos de velocidade de onda $S$. Rocha é caracterizada por $V S_{30} \geq 750 \mathrm{~m} / \mathrm{s}$ e solos profundos quando o embasamento rochoso se situa a profundidades maiores do que $20 \mathrm{~m}$.

\subsubsection{2.}

Árvore lógica

Para reduz as incertezas epistêmicas inerentes aos modelos de sismicidade, foi empregado a metodologia da árvore lógica para considerar ponderação das leis de atenuação aplicáveis as fontes de subducção e continentais. Nesta pesquisa foi atribuindo o peso de 0,32 para Youngs et al (1997); 0,32 para Zhao et al (2006); 0,16 para BC Hydro (2015); 0,12 para Sadigh et al. (1997) e 0,08 para Atkinson e Boore (2003) na árvore lógica, como apresentados na Figura 3.10.

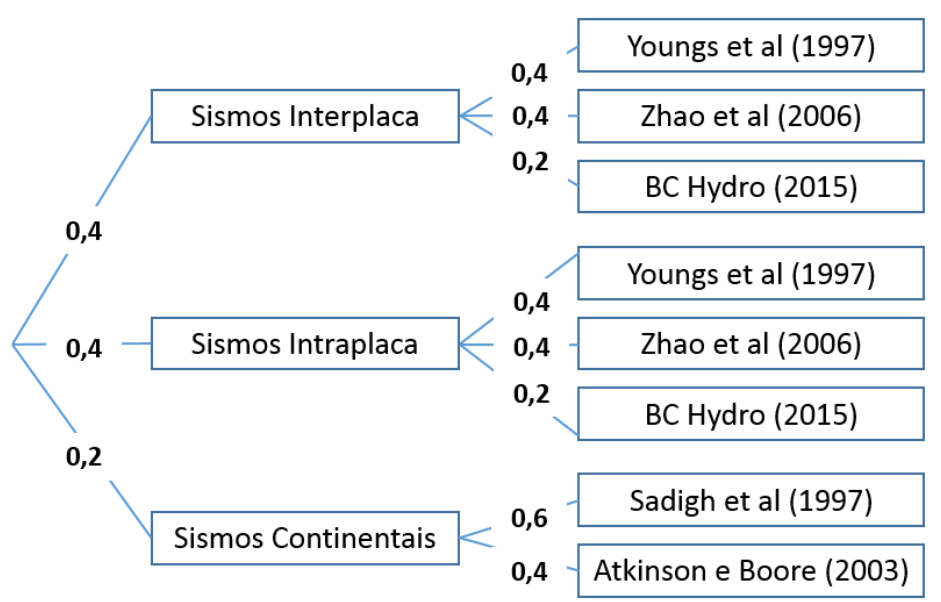

Figura 3.10- Árvore Lógica usada na barragem de rejeitos Otapara.

\subsection{4.}

Estimação da probabilidade de excedencia do nível de movimento sísmico determinado em um período de tempo

Os resultados obtidos a partir da avaliação da ameaça sísmico probabilístico são expressos em termos da probabilidade de ocorrência, curvas de ameaça e espectro de resposta uniformemente provável. 
A Tabela 3.7 apresenta a aceleração máxima (g), comparando-a com valores obtidos em pesquisas anteriores, observando-se variação nos resultados dependente das leis de atenuação consideradas, principalmente. Em comparação com os trabalhos prévios o resultado mostra-se conservador, as variações podem ser devidas à base de dados, o software utilizado, as relações de atenuação e da analise considerada. O trabalho de Castillo e Alva (1993) considerou como base de dados o Projeto SISRA (Sismicidade da Região Andina), a ISC (International Seismological Center), o IGP (Instituto Geofísico do Peru) e o NEIC (National Earthquake Information Center) com informação entre os anos 1900 até 1990; o software empregado foi o RISK; as relações de atenuação empregadas foram Casaverde e Vargas (1980) para as fontes de subducção baseada em 10 registros sismicos e para fontes corticais McGuire (1974), na análise foram identificadas 27 fontes sismogênicas e os sismos de subducção não foram diferenciados entre interface e intraplaca. O trabalho de Gamarra e Aguilar (2009) considerou como base de dados o IGP (Instituto Geofísico do Peru), o NEIC (National Earthquake Information Center) com informação entre os anos 1471 até 2009; o software empregado foi o CRISIS2007, as relações de atenuação empregadas foram Youngs et al (1997) - Solo para fontes de subducção e Sadigh et al (1997) para fontes corticais; na análise foi definido 20 fontes sismogênicas (subducção e corticais) e seus respectivos parâmetros de sismicidade para resultados de aceleração em solo tipo D. O trabalho de IGP (2014) considerou como base de dados o IGP (Instituto Geofísico do Peru), o Engdahl e Villaseñor (2002), o USGS (United States Geological Survey) com informação entre os anos 1500 até 2011; o software empregado foi o CRISIS2007; as relações de atenuação empregadas foram Youngs et al (1997) - Rocha para fontes de subducção e Sadigh et al (1997) para fontes corticais; na análise foi definido 33 fontes sismogênicas de diferentes mecanismos de falha para resposta em rocha. No trabalho do Roncal e Aguilar feito para SENCICO (2016), obtendo-se um valor de aceleração similar para um período de retorno de 1000 anos. 
Tabela 3.7- Valores de aceleração máxima do solo (PGA) para solo tipo B.

\begin{tabular}{|l|c|c|}
\hline \multirow{2}{*}{ Estudo } & \multicolumn{2}{c|}{$\mathbf{a}_{\max }(\mathbf{g})$ para $\operatorname{Tr}(\mathbf{a n ̃ o s})$} \\
\cline { 2 - 3 } & $\mathbf{5 0 0}$ & $\mathbf{1 0 0 0}$ \\
\hline Salvador (2019) & 0.510 & 0.610 \\
\hline SENCICO (2016) & 0.500 & 0.612 \\
\hline IGP (2014) & 0.420 & 0.520 \\
\hline Gamarra e Aguilar (2009) & 0.540 & - \\
\hline Castillo e Alva (1993) & 0.450 & 0.520 \\
\hline
\end{tabular}

A curva de ameaça sísmica proporciona a probabilidade de excedência anual respecto de um determinado parâmetro do movimento do solo, nesse caso a aceleração. Na Figura 3.11 é apresentada a curva de ameaça sísmica para solo tipo B (NEHRP, 2015) considerando 5\% de amortecimento critico.

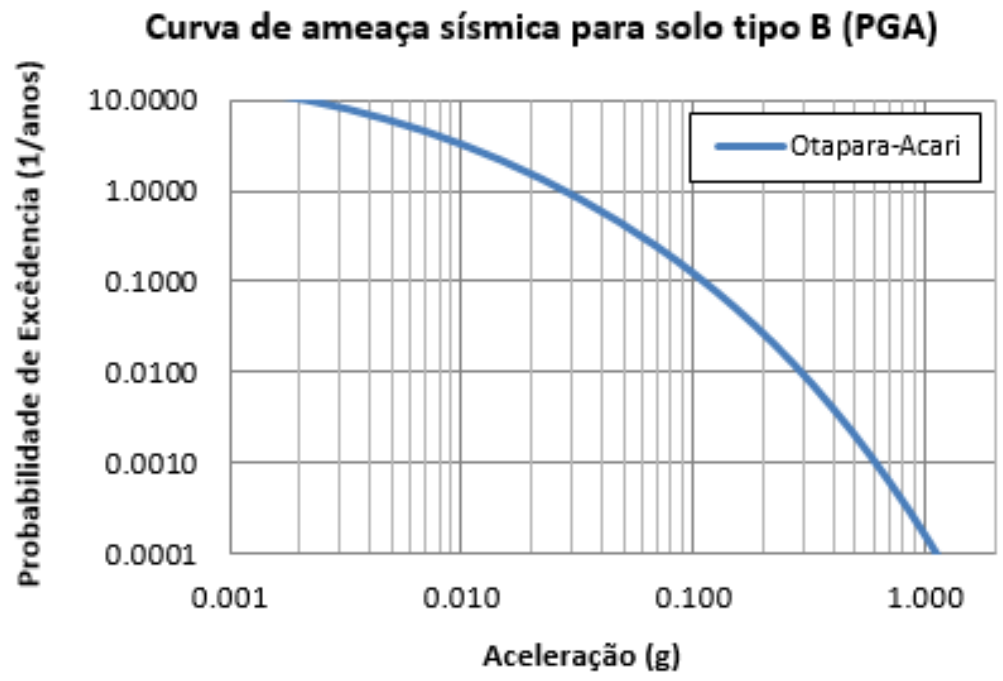

Figura 3.11- Curva de ameaça sísmica para solo tipo B com 5\% de amortecimento crítico.

A partir das curvas de ameaça sísmica obtidas para diferentes períodos estruturais é possível construir os espectros de resposta uniformemente provável, as quais apresentam valores de aceleração em diferentes períodos estruturais para a mesma probabilidade anual de excedência considerando um tempo de exposição da estrutura. Na Figura 3.12 mostra-se o espectro do projeto para uma probabilidade de excedência de 5\% em 50 anos, que corresponde a 1000 anos de período de recorrência. Os valores de aceleração e a definição do espectro de resposta uniformemente provável constituem informações básicas para a análise do comportamento sísmico da barragem de rejeitos Otapara. 


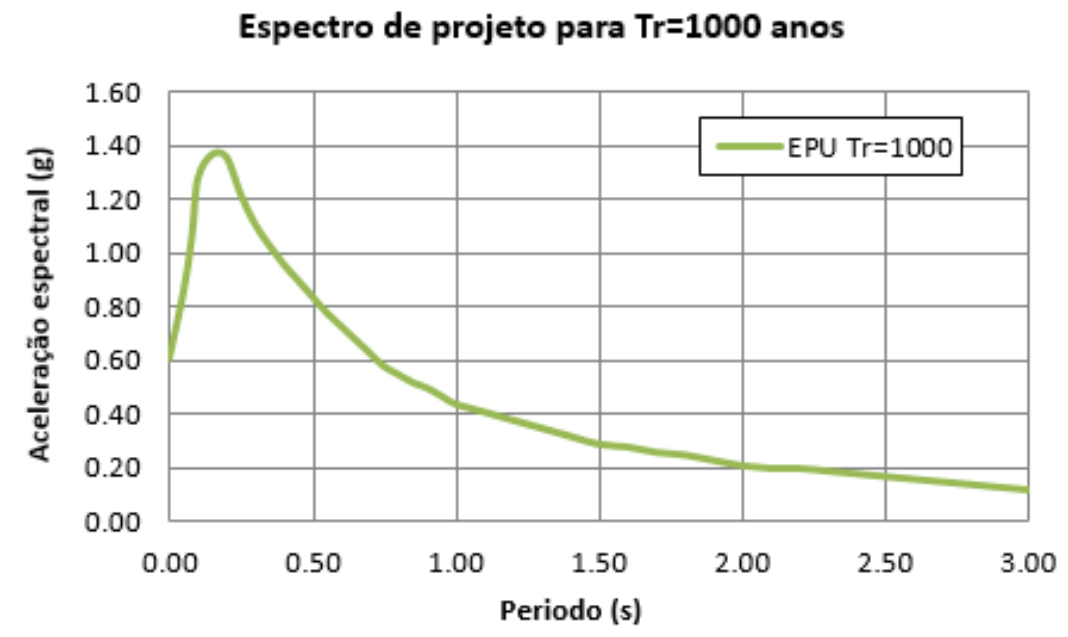

Figura 3.12- Espectro do projeto para 1000 anos de período de recorrência.

O PSHA foi realizado usando a teoria proposta por Cornell (1968) e usando o programa de computador CRISIS 2018 (Ordaz et al., 2018). Decidiu-se avaliar a ameaça sísmica para uma probabilidade de excedência de 5\% em 50 anos correspondente a um período de retorno de 1000 anos. O cálculo da aceleração máxima do solo (PGA) foi calculado para a área de estudo usando uma malha regular de $0,1^{\circ}$ geográficos em longitude e latitude.

\subsection{5.}

Desagregação da ameaça sísmica

Pelo processo de desagregação da ameaça sísmica, é possível estimar a fração de contribuição de diferentes parâmetros (magnitude e distância) para a ameaça sísmica total, como também identificar as fontes sísmogênicas mais influentes (Abrahamson, 2006).

$\mathrm{Na}$ Tabela 3.8 mostram-se os resultados da análise de desagregação magnitude - distância para um tempo de retorno de 1000 anos, probabilidade de excedência de $5 \%$ e 50 anos de vida útil. 
Tabela 3.8- Desagregação de Ameaça Sísmica PGA para Rocha, $\operatorname{Tr}=1000$ anos, $P E=5 \%$ em 50 anos.

\begin{tabular}{|c|c|c|c|c|c|c|c|c|c|c|c|}
\hline & & \multicolumn{10}{|c|}{ Distância } \\
\hline & & 0,0 & 22,2 & 44,4 & 66,7 & 88,9 & 111,1 & 133,3 & 155,6 & 177,8 & 200,0 \\
\hline \multirow{10}{*}{ 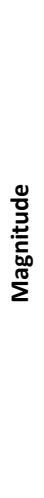 } & 4,1 & $0,0 \mathrm{E}+00$ & $0,0 E+00$ & $0,0 \mathrm{E}+00$ & $0,0 E+00$ & $0,0 \mathrm{E}+00$ & $0,0 E+00$ & $0,0 E+00$ & $0,0 E+00$ & $0,0 E+00$ & $0,0 \mathrm{E}+00$ \\
\hline & 4,5 & $0,0 \mathrm{E}+00$ & $0,0 \mathrm{E}+00$ & $3,1 \mathrm{E}-04$ & $1,9 \mathrm{E}-03$ & $7,4 \mathrm{E}-04$ & $1,1 \mathrm{E}-04$ & 2,1E-05 & $1,4 \mathrm{E}-06$ & $0,0 \mathrm{E}+00$ & $0,0 \mathrm{E}+00$ \\
\hline & 5,0 & $0,0 \mathrm{E}+00$ & $0,0 E+00$ & 4,4E-04 & $1,8 \mathrm{E}-03$ & $6,6 \mathrm{E}-04$ & $1,1 \mathrm{E}-04$ & $2,8 \mathrm{E}-05$ & $5,8 \mathrm{E}-06$ & 4,1E-07 & $0,0 E+00$ \\
\hline & 5,4 & $0,0 \mathrm{E}+00$ & $0,0 \mathrm{E}+00$ & $5,9 \mathrm{E}-04$ & $4,3 E-03$ & $2,6 \mathrm{E}-03$ & $6,1 \mathrm{E}-04$ & $1,8 \mathrm{E}-04$ & $4,5 \mathrm{E}-05$ & $7,2 \mathrm{E}-06$ & $0,0 \mathrm{E}+00$ \\
\hline & 5,8 & $0,0 \mathrm{E}+00$ & $0,0 \mathrm{E}+00$ & 7,1E-04 & $3,4 \mathrm{E}-03$ & $2,0 \mathrm{E}-03$ & $5,7 \mathrm{E}-04$ & $2,1 \mathrm{E}-04$ & $6,7 \mathrm{E}-05$ & $1,9 \mathrm{E}-05$ & $0,0 \mathrm{E}+00$ \\
\hline & 6,3 & $0,0 E+00$ & $0,0 \mathrm{E}+00$ & 7,7E-04 & $6,5 \mathrm{E}-03$ & $5,2 \mathrm{E}-03$ & $1,8 \mathrm{E}-03$ & $7,8 \mathrm{E}-04$ & $2,9 \mathrm{E}-04$ & $9,6 \mathrm{E}-05$ & $0,0 E+00$ \\
\hline & 6,7 & $0,0 E+00$ & $0,0 \mathrm{E}+00$ & $7,3 \mathrm{E}-04$ & $4,4 \mathrm{E}-03$ & $3,6 \mathrm{E}-03$ & $1,4 \mathrm{E}-03$ & $6,9 \mathrm{E}-04$ & $2,9 \mathrm{E}-04$ & $1,1 \mathrm{E}-04$ & $0,0 \mathrm{E}+00$ \\
\hline & 7,1 & $0,0 \mathrm{E}+00$ & $0,0 \mathrm{E}+00$ & $6,0 \mathrm{E}-04$ & $1,9 \mathrm{E}-03$ & $9,5 \mathrm{E}-04$ & $2,8 \mathrm{E}-04$ & $8,2 \mathrm{E}-05$ & $6,2 \mathrm{E}-05$ & $2,2 \mathrm{E}-05$ & $0,0 \mathrm{E}+00$ \\
\hline & 7,6 & $0,0 \mathrm{E}+00$ & $0,0 \mathrm{E}+00$ & 4,4E-04 & $1,7 \mathrm{E}-03$ & $1,3 \mathrm{E}-03$ & $5,1 \mathrm{E}-04$ & $1,9 \mathrm{E}-04$ & $1,4 \mathrm{E}-04$ & $5,2 \mathrm{E}-05$ & $0,0 E+00$ \\
\hline & 8,0 & $0,0 \mathrm{E}+00$ & $0,0 \mathrm{E}+00$ & $0,0 E+00$ & $0,0 \mathrm{E}+00$ & $0,0 E+00$ & $0,0 E+00$ & $0,0 E+00$ & $0,0 E+00$ & $0,0 E+00$ & $0,0 \mathrm{E}+00$ \\
\hline
\end{tabular}

Pode-se observar na Figura 3.13 que o sismo de maior contribuição para o período estrutural de 0 s (PGA) tem magnitude $M w=6.3$, distância epicentral de $65 \mathrm{~km}$, com mecanismo focal de interface. Também é importante notar que há outro pico de menor contribuição, de magnitude $\mathrm{Mw}=5.4 \mathrm{Mw}$, distância epicentral de $65 \mathrm{~km}$, com mecanismo focal de intraplaca.

\section{Desagregacão da Ameaca Sismica PGA}

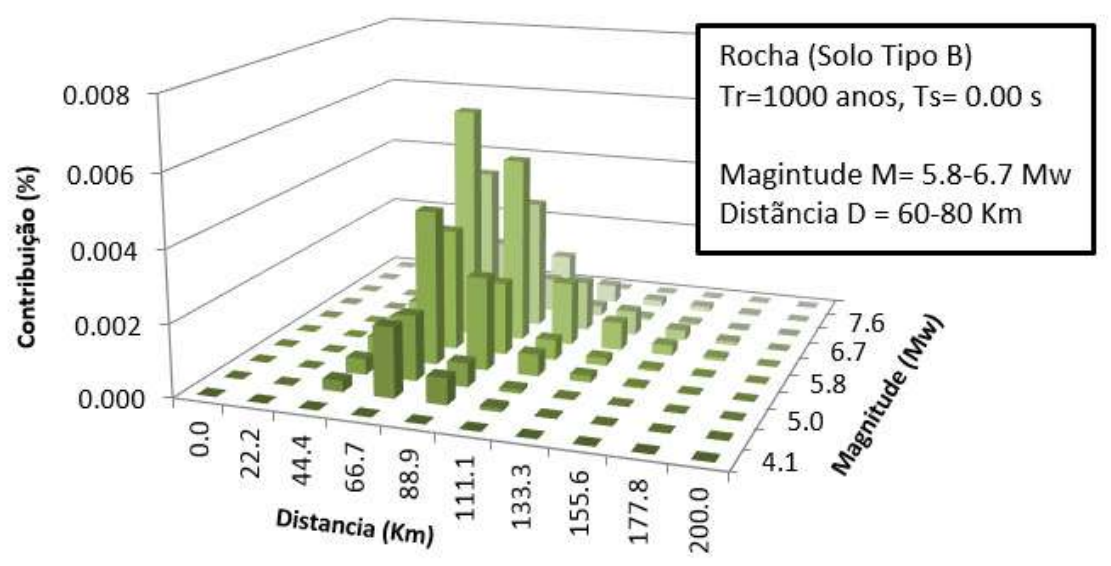

Figura 3.13 - Desagregação da ameaça sísmica para PGA considerando $T r=1000$ anos, probabilidade de excedência de $5 \%$ em 50 anos de exposição. 


\section{5.}

\section{Registros sismos empregados na analise}

Uma recomendação importante na seleção dos registros sísmicos utilizados para definição do sismo de projeto é considerar o conteúdo espectral, magnitude, distância epicentral e mecanismo focal semelhantes aos identificados no processo de desagregação da ameaça sísmica.

A base de dados sísmicos do Pacific Earthquake Engineering Research Center (PEER) permite seleção de sismos reais que satisfazem estas caracteristicas mediante processo de escalonamento de acelerogramas reais que poderiam ser considerados na modelagem sísmica da barragem de rejeitos Otapara por meio de métodos numéricos (elementos finitos, diferenças finitas).

A metodologida para construção do sismo de projeto usada no presente estudo é mediante o método do ajuste espectral com base no algoritmo proposto por Al Atik e Abrahamson (2010), que adiciona ou subtrai wavelets nas partes das histórias de aceleração cujas frequências não apresentam ajuste satisfatório entre o espectro de resposta de aceleração e o espectro-alvo. Este tipo de ajuste é geralmente aplicado quando se dispõe de poucos terremotos registrados por estações sismográficas localizadas nas proximidades da obra. Na Figura 3.14 é apresentado o fluxograma dos passos para obter os sismos de desenho em função do método de ajuste espectral.

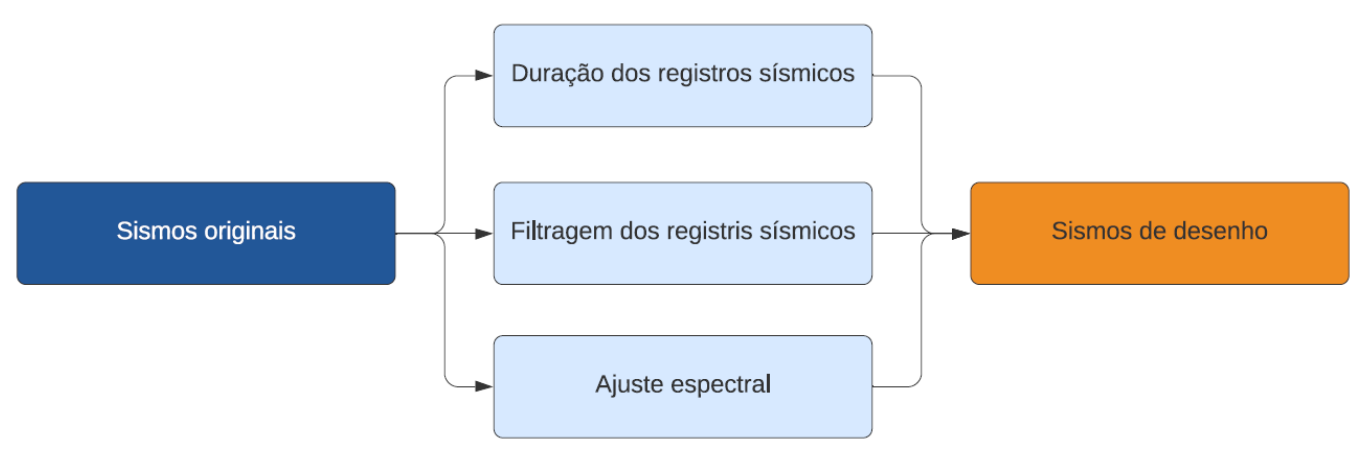

Figura 3.14-Fluxograma para cpmstrução do sismo de projeto.

$\mathrm{Na}$ presente pesquisa foram considerados registros sísmicos de Atico (2001), Lima (1974) e Maule (2010) e na Tabela 3.9 mencionam-se as características originais dos terremotos (prévio ao ajuste) considerados para a modelagem sísmica. 
Tabela 3.9- Registros sísmicos considerados no ajuste espectral.

\begin{tabular}{|c|c|c|c|c|c|c|c|}
\hline Sismo & Data & $\begin{array}{c}\text { Magnitude } \\
(\mathbf{M w})\end{array}$ & $\begin{array}{c}\text { Mecanismo } \\
\text { Focal }\end{array}$ & $\begin{array}{c}\text { Prof. } \\
\mathbf{( k m )}\end{array}$ & Estação & $\begin{array}{c}\text { Duração } \\
\text { original } \\
(\mathbf{s})\end{array}$ & $\begin{array}{c}\text { Aceleração } \\
\mathbf{( g )}\end{array}$ \\
\hline $\begin{array}{c}\text { Atico, } \\
\text { Moquegua } \\
\text { Peru }\end{array}$ & $\begin{array}{c}23 \text { junho } \\
2001\end{array}$ & 8.2 & $\begin{array}{c}\text { Subducção } \\
\text { interface }\end{array}$ & 33 & $\begin{array}{c}\text { Moquegua } \\
\text { (CISMID) }\end{array}$ & 198.92 & 0.30 \\
\hline $\begin{array}{c}\text { Lima } \\
\text { Peru }\end{array}$ & $\begin{array}{c}03 \\
\text { outubro } \\
1974\end{array}$ & 7.5 & $\begin{array}{c}\text { Subducção } \\
\text { interface }\end{array}$ & 13 & Lima (PRQ) & 97.96 & 0.20 \\
\hline $\begin{array}{c}\text { Maule, } \\
\text { Concepción } \\
\text { Chile }\end{array}$ & $\begin{array}{c}27 \\
\text { fevereiro } \\
2010\end{array}$ & 8.8 & $\begin{array}{c}\text { Subducção } \\
\text { interface }\end{array}$ & 31 & $\begin{array}{c}\text { Concepción } \\
\text { (VII Região) }\end{array}$ & 201.99 & 0.40 \\
\hline
\end{tabular}

A coleta dos dados do acelerograma compreendeu três registros na direção horizontal EW, horizontal NS e vertical UD; trabalhou-se com os registros de maior aceleração horizontal EW como é apresentado na Tabela 3.10.

Tabela 3.10- Direções e acelerações máximas dos registros.

\begin{tabular}{|c|c|c|c|c|c|c|c|c|c|}
\cline { 2 - 10 } \multicolumn{1}{c|}{} & \multicolumn{3}{c|}{ Atico 2001 } & \multicolumn{3}{c|}{ Lima 1974 } & \multicolumn{3}{c|}{ Maule 2010 } \\
\hline Orientação & EW & NS & UD & EW & NS & UD & EW & NS & UD \\
\hline $\begin{array}{l}\text { Aceleração } \\
\text { máxima (g) }\end{array}$ & 0.301 & 0.224 & 0.164 & 0.198 & 0.184 & 0.102 & 0.402 & 0.397 & 0.285 \\
\hline
\end{tabular}

O sismo de Atico de 2001 foi muito significativo pois mais de 100 pessoas faleceram e danos materiais ocorreram em mais de 60000 casas, muitas das quais devido ao tsunami acontecido após o terremoto. A estação mais próxima que registrou o sismo está localizada em Moquegua em uma fundação de solo areno-argiloso com os registros na direção EW apresentando os maiores valores de aceleração horizontal. Na Figura 3.15 mostra-se o registro sísmico orginal de Atico. 


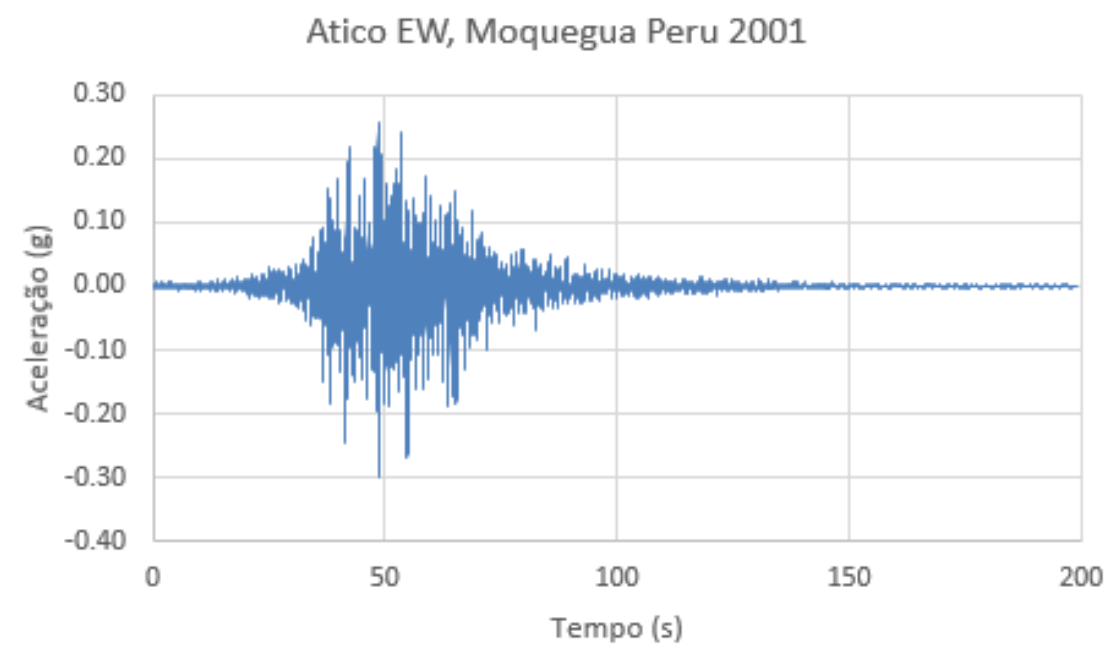

Figura 3.15- Registro sísmico de Atico, na direção EW.

O sismo de Lima do 1974 foi um dos primeiros registrados no Peru, sendo um dos mais importantes devido que a estação que o registrou está localizada em Lima, onde o tipo de solo de fundação (pedregulho) apresenta comportamento semelhante ao de rocha branda com valor de $P G A=0.20 \mathrm{~g}$. Quase 100 pessoas morreram, mais de 2400 resultaram feridas e a perdas econômicas foram de aproximadamente 700 milhões de dólares. Na Figura 3.16 mostra-se o registro sísmico orginal de Lima.

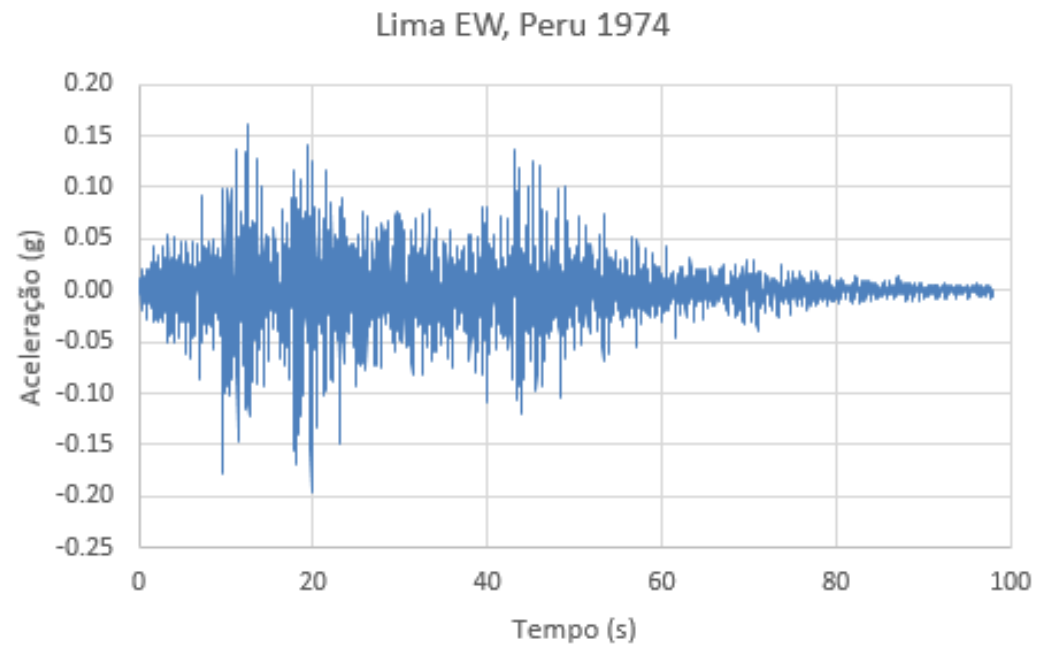

Figura 3.16- Registro sísmico de Lima, na direção EW. 
O sismo de Maule do 2010 apresentou uma grande magnitude de $8.8 \mathrm{Mw}$ e foi registrado pela rede de acelerogramas de Chile em 22 estações, tendo em uma delas alcançado a aceleração máxima $P G A=0,92 \mathrm{~g}$. O sismo de Maule foi catastrófico, com morte de mais de 500 pessoas, além de 1400 feridos e 2500000 edificações afetadas. Na Figura 3.17 mostra-se o registro sísmico orginal de Maule.

\section{Maule EW, Concepción Chile 2010}

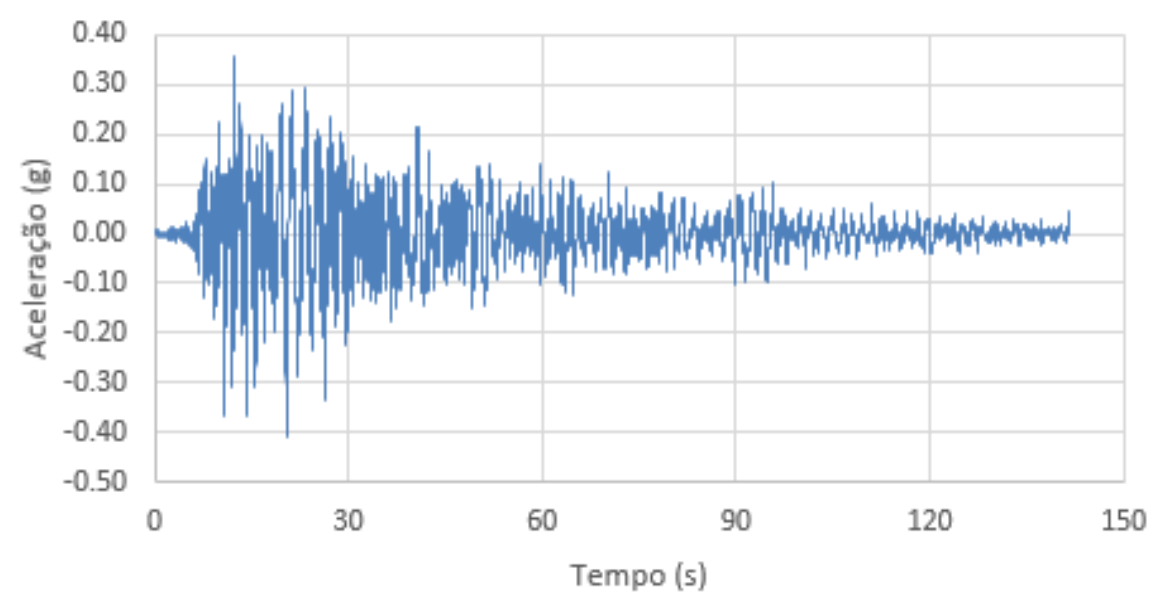

Figura 3.17- Registro sísmico de Maule, na direção EW.

\subsection{1.}

\section{Duração dos registros sísmicos}

A duração do registro é um aspecto importante considerado na avaliação, associado ao tempo de computação requerido para a execução da análise numérica. A presente pesquisa considerou o critério de Trifunac e Brady (1975) que estabelece a duração entre o $5 \%$ e $95 \%$ da intensidade Arias, com perda de energia no registro sísmico menor do que $5 \%$.

A Figura 3.18 mostram a intensidade de Arias e os limites de 5\% (limite inferior da duração, t1) e 95\% (limite superior da duração, t2) da intensidade Arias para os sismos de Atico (2001). 


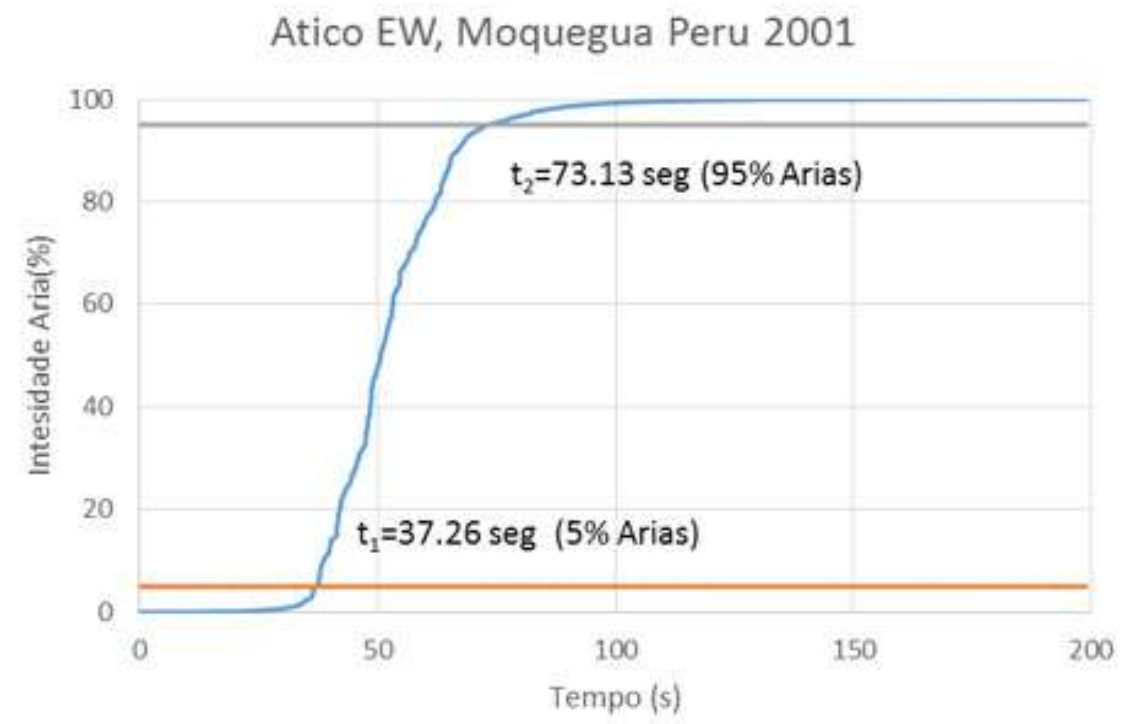

Figura 3.18- Critério de Trifunac e Brady para o sismo de Atico EW (2001).

$\mathrm{Na}$ Tabela 3.11 mostra-se a energia do sismo para um tempo de duração e a escolha do tempo com menor perda de energia.

Tabela 3.11- Tentativas de duração do registro sísmico conservando sua energia, sismo de Atico EW.

\begin{tabular}{|c|c|c|c|c|c|}
\hline \multirow{5}{*}{ 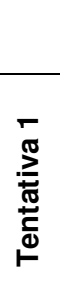 } & \multicolumn{2}{|c|}{ Tempo (s) } & \multirow{2}{*}{$\begin{array}{c}\text { Intensidade } \\
\text { Arias (\%) }\end{array}$} & \multirow{2}{*}{$\begin{array}{c}\begin{array}{c}\text { Fluxo Energia } \\
\left(\mathbf{c m}^{2} / \mathbf{s}\right)\end{array} \\
95.91\end{array}$} & \multirow{2}{*}{$\begin{array}{c}\begin{array}{c}\text { Fluxo Energia } \\
(\%)\end{array} \\
4.64\end{array}$} \\
\hline & $t_{1}$ & 37.26 & & & \\
\hline & $t_{2}$ & 73.13 & 95.00 & 1876.83 & 90.76 \\
\hline & $\mathrm{t}_{\text {final }}$ & 198.91 & 100.00 & 2067.98 & 100.00 \\
\hline & $\Delta \mathrm{t}$ & 35.87 & 90.00 & 1780.92 & 86.12 \\
\hline \multirow{4}{*}{ 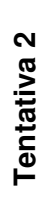 } & $t_{1}$ & 20.00 & 0.11 & 1.91 & 0.09 \\
\hline & $t_{2}$ & 120.00 & 99.77 & 2050.23 & 99.14 \\
\hline & $t_{\text {final }}$ & 198.91 & 100.00 & 2067.98 & 100.00 \\
\hline & $\Delta \mathrm{t}$ & 100.00 & 99.66 & 2048.31 & 99.05 \\
\hline
\end{tabular}

A seguir apresenta-se as faixas de duração do registro sísmico com base na conservação da energia para o sismo de Atico 2001 (Figura 3.19). 
Atico EW, Moquegua Peru 2001

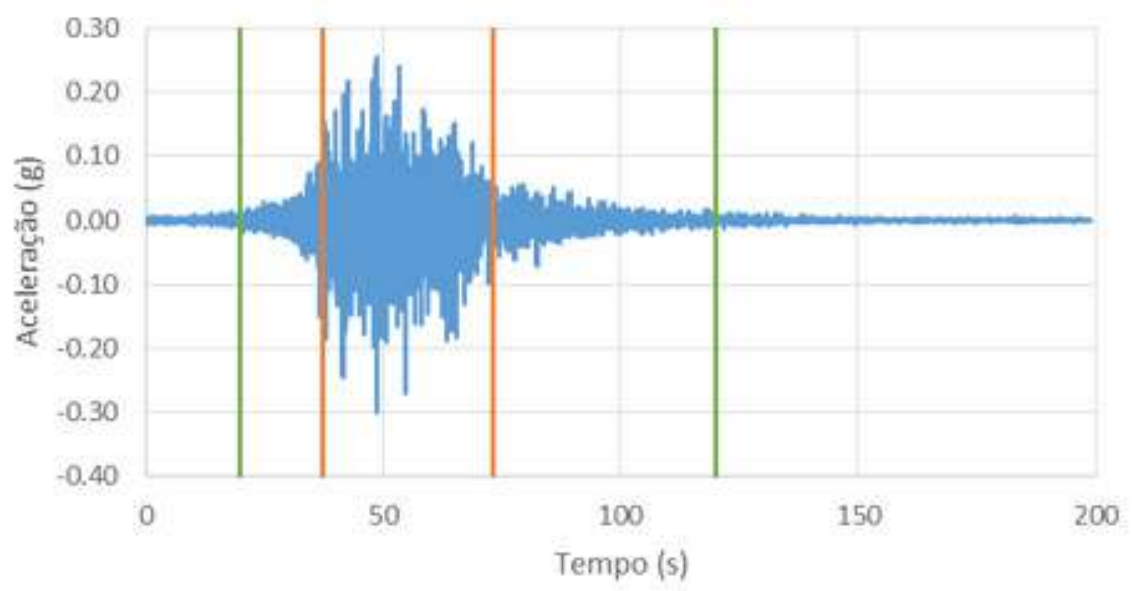

Figura 3.19- Duração do registro sísmico com base na conservação da energia Atico EW (2001).

A Figura 3.20 mostram a intensidade Arias e os limites de 5\% (limite inferior da duração, t1) e 95\% (limite superior da duração, t2) da intensidade de Arias para os sismos de Lima (1974).

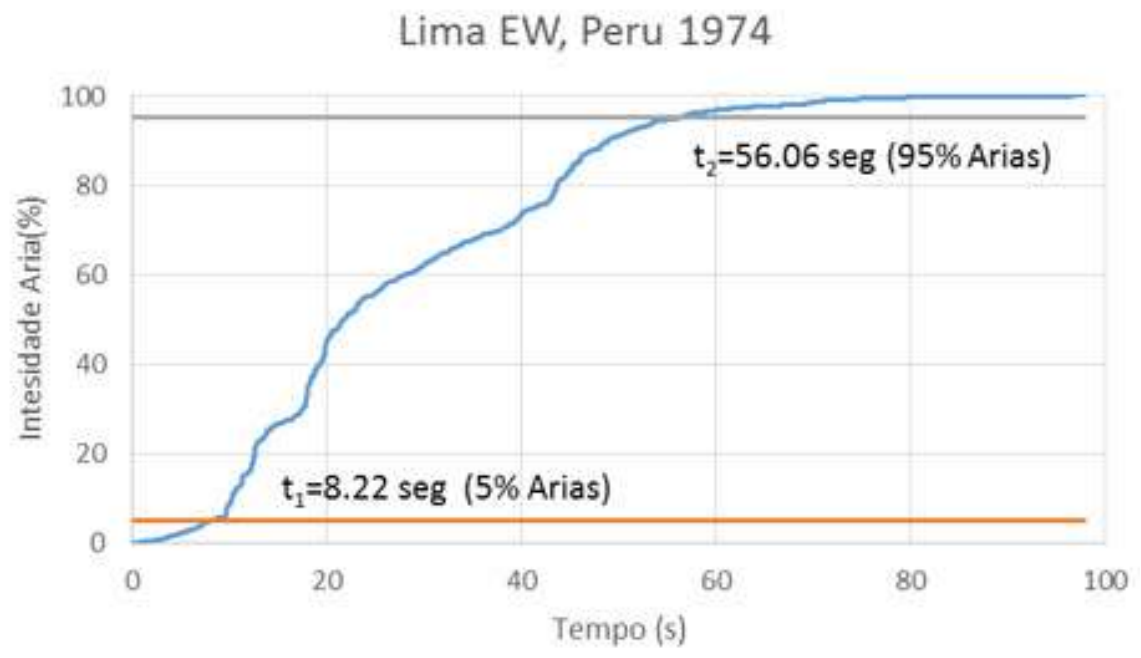

Figura 3.20- Critério de Trifunac e Brady para o sismo de Lima EW (1974).

Na Tabela 3.11 mostra-se a energia do sismo para um tempo de duração e a escolha do tempo com menor perda de energia. 
Tabela 3.12- Tentativas de duração do registro sísmico conservando sua energia, sismo de Lima EW.

\begin{tabular}{|c|c|c|c|c|c|}
\hline & \multicolumn{2}{|c|}{ Tempo (s) } & $\begin{array}{c}\text { Intensidade Arias } \\
(\%)\end{array}$ & $\begin{array}{c}\text { Fluxo Energia } \\
\left(\mathrm{cm}^{2} / \mathrm{s}\right)\end{array}$ & $\begin{array}{c}\text { Fluxo Energia } \\
(\%)\end{array}$ \\
\hline \multirow{4}{*}{ 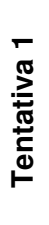 } & $t_{1}$ & 8.22 & 5.00 & 83.61 & 12.45 \\
\hline & $t_{2}$ & 56.06 & 95.00 & 603.22 & 89.79 \\
\hline & $t_{\text {final }}$ & 97.94 & 100.00 & 671.82 & 100.00 \\
\hline & $\Delta \mathrm{t}$ & 47.84 & 90.00 & 519.60 & 77.34 \\
\hline \multirow{4}{*}{ } & $t_{1}$ & 0.00 & 0.00 & 0.00 & 0.00 \\
\hline & $t_{2}$ & 80.00 & 99.64 & 661.78 & 98.51 \\
\hline & $t_{\text {final }}$ & 97.94 & 100.00 & 671.82 & 100.00 \\
\hline & $\Delta \mathrm{t}$ & 80.00 & 99.64 & 661.78 & 98.51 \\
\hline
\end{tabular}

Também se apresenta as faixas de duração do registro sísmico, com base na conservação da energia, para o sismo de Lima 1974 (Figura 3.21).

\section{Lima EW, Peru 1974}

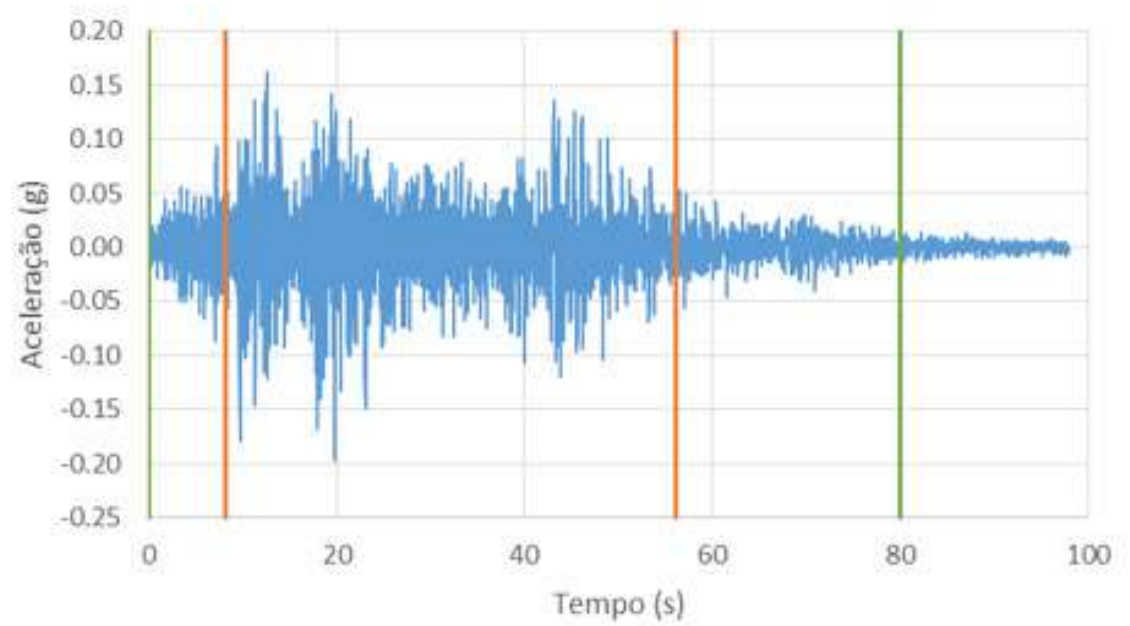

Figura 3.21- Duração do registro sísmico com base na conservaçãoda energia Lima EW (2001).

A Figura 3.22 mostra a intensidade Arias e os limites de 5\% (limite inferior da duração, t1) e 95\% (limite superior da duração, t2) da intensidade Arias para os sismos de Maule (2010). 
Maule, Concepción Chile 2010

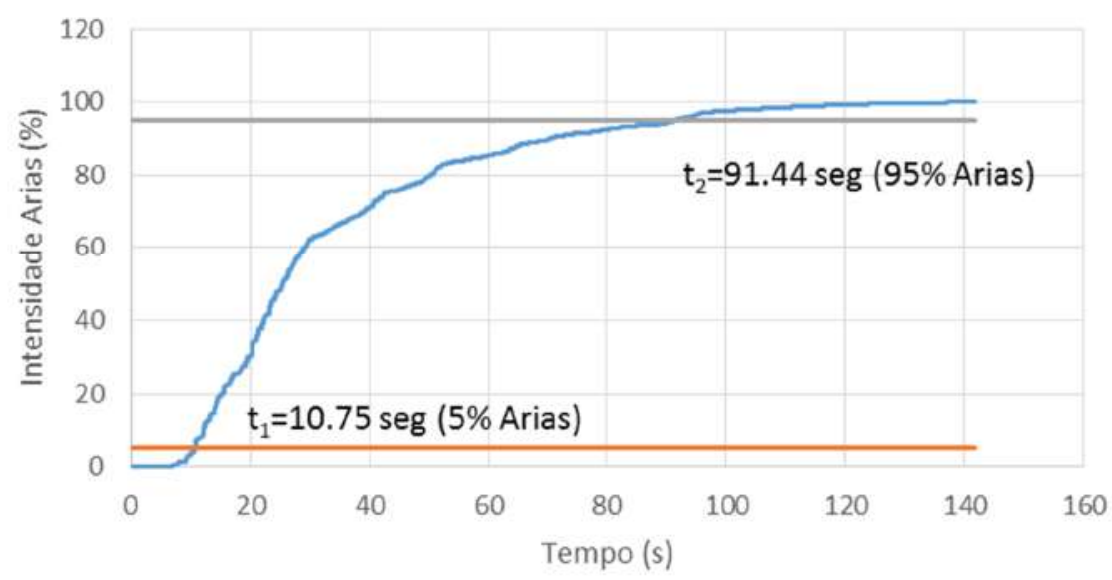

Figura 3.22- Critério de Trifunac e Brady para o sismo de Maule EW (2010).

Na Tabela 3.11 mostra-se a energia do sismo para um tempo de duração e a escolha do tempo com menor perda de energia.

Tabela 3.13- Tentativas de duração do registro sísmico conservando sua energia, sismo de Maule EW.

\begin{tabular}{|c|c|c|c|c|c|}
\hline & \multicolumn{2}{|c|}{ Tempo (s) } & $\begin{array}{c}\text { Intensidade } \\
\text { Arias (\%) } \\
\end{array}$ & $\begin{array}{c}\text { Fluxo Energia } \\
\left(\mathrm{cm}^{2} / \mathrm{s}\right)\end{array}$ & $\begin{array}{c}\text { Fluxo Energia } \\
(\%)\end{array}$ \\
\hline \multirow{4}{*}{ 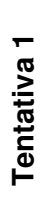 } & $t_{1}$ & 10.75 & 5.00 & 541.80 & 2.15 \\
\hline & $t_{2}$ & 91.44 & 95.00 & 23897.01 & 94.62 \\
\hline & $t_{\text {final }}$ & 141.68 & 100.00 & 25256.61 & 100.00 \\
\hline & $\Delta t$ & 80.70 & 90.00 & 23355.21 & 92.47 \\
\hline \multirow{4}{*}{ 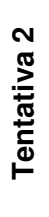 } & $t_{1}$ & 5.00 & 0.04 & 3.87 & 0.02 \\
\hline & $t_{2}$ & 100.00 & 97.57 & 24598.00 & 97.39 \\
\hline & $t_{\text {final }}$ & 141.68 & 100.00 & 25256.61 & 100.00 \\
\hline & $\Delta \mathrm{t}$ & 95.00 & 97.53 & 24594.13 & 97.38 \\
\hline
\end{tabular}

A Figura 3.23 indica as faixas de duração do registro sísmico, com base na conservação da energia para o sismo de Maule 2010. 


\section{Maule EW, Concepción Chile 2010}

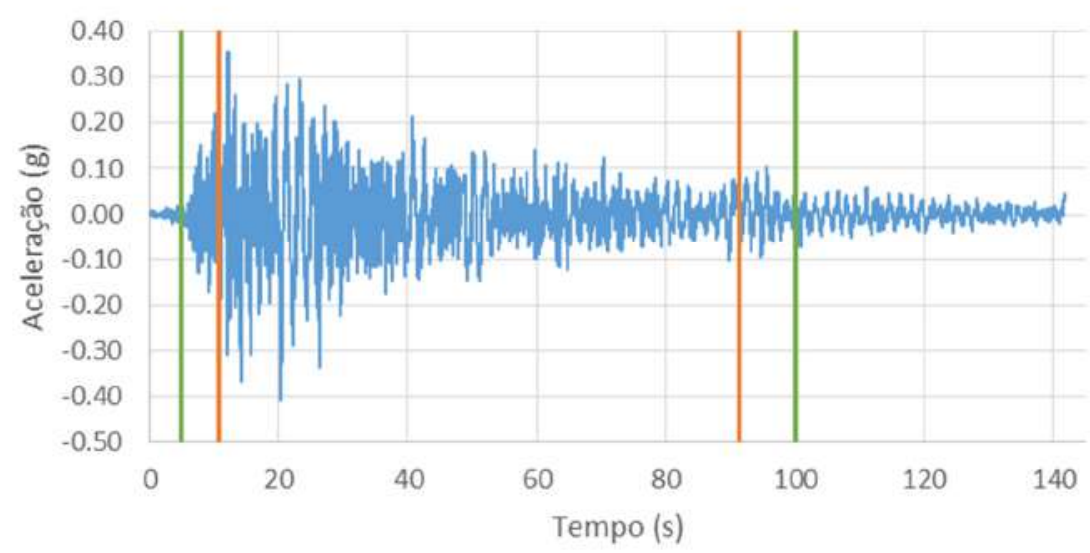

Figura 3.23- Duração do registro sísmico com base na conservaçãoda energia Maule EW (2010).

\subsection{2.}

Filtragem dos registros sismicos

Todos os registros indicados foram previamente tratados através da aplicação de um filtro passa-banda de tipo Butterworth no intervalo de $0.1 \mathrm{~Hz}$ a 10 $\mathrm{Hz}$, faixa de frequências usualmente considerada em análises sísmicas. $\mathrm{O}$ software utilizado no tratamento dos sinais sísmicos foi o SeismoSignal (SeismoSoft, 2016). A seguir, são apresentados registros de aceleração, velocidade e deslocamento dos sismos de Atico 2001 (Figura 3.24), Lima 1974 (Figura 3.25) e Maule 2010 (Figura 3.26) respectivamente com a duração indicada anteriormente. 


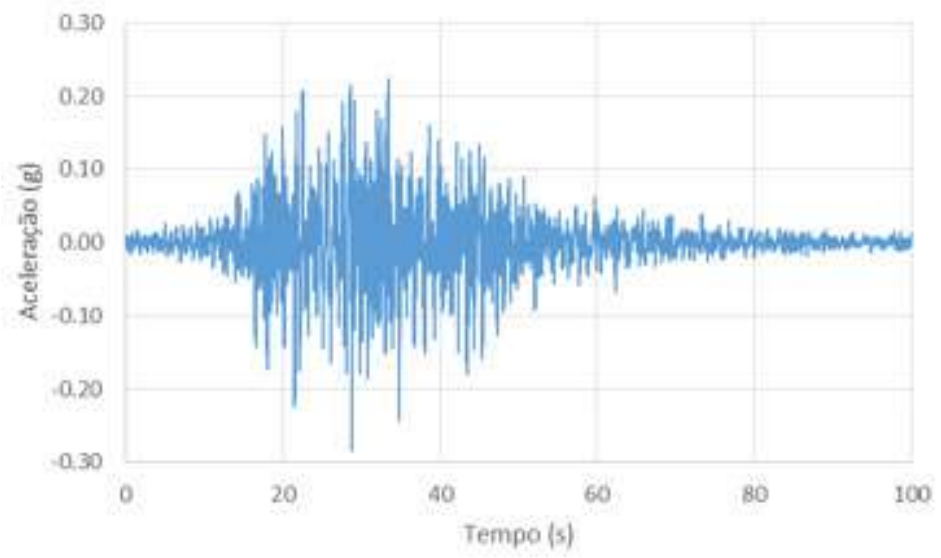

(a)

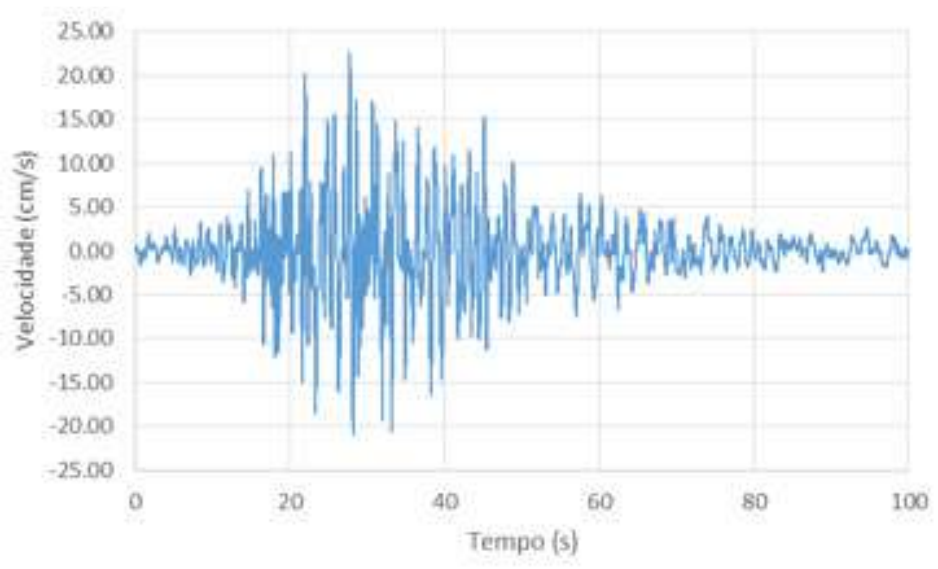

(b)

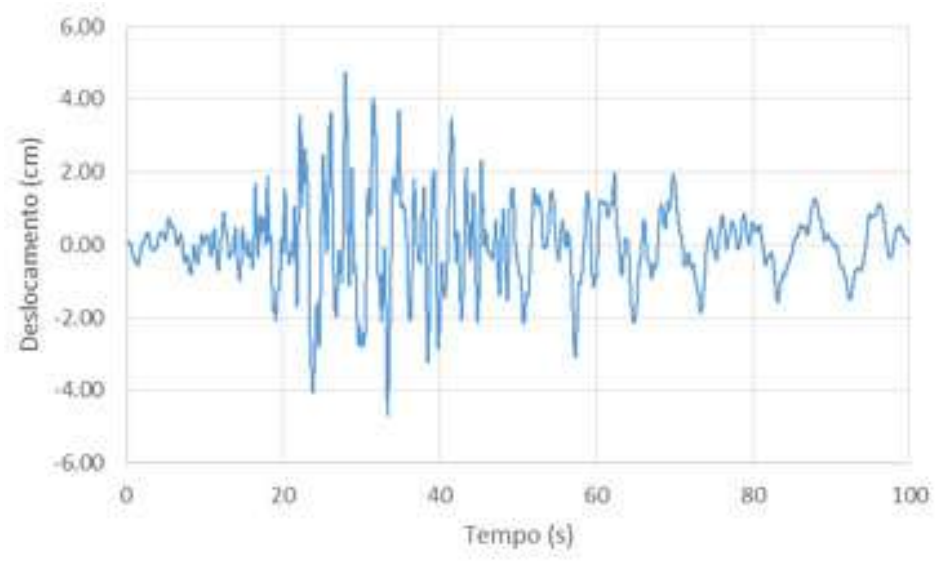

(c)

Figura 3.24- Registro de (a) aceleração (b) velocidade (c) deslocamento do sismo de Atico (2001) prévio ao ajuste espectral. 


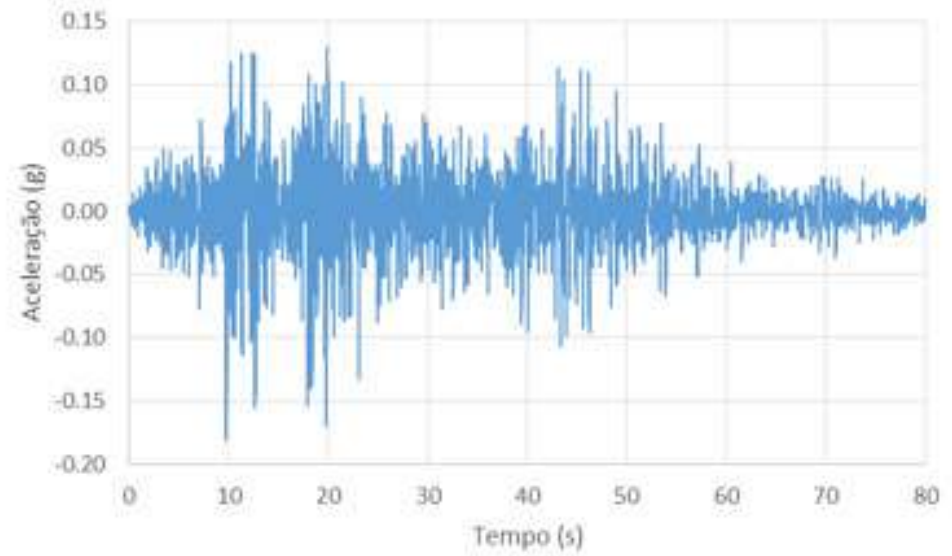

(a)

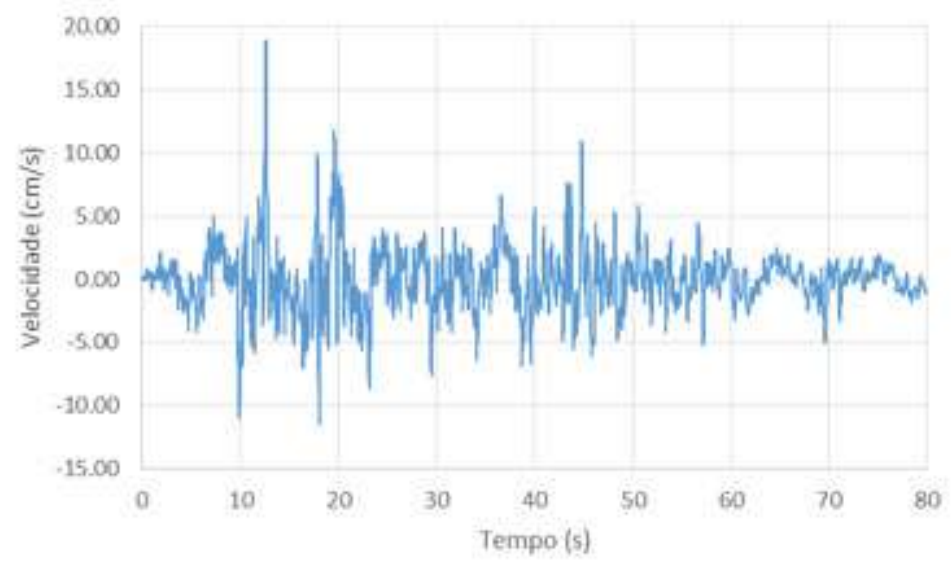

(b)

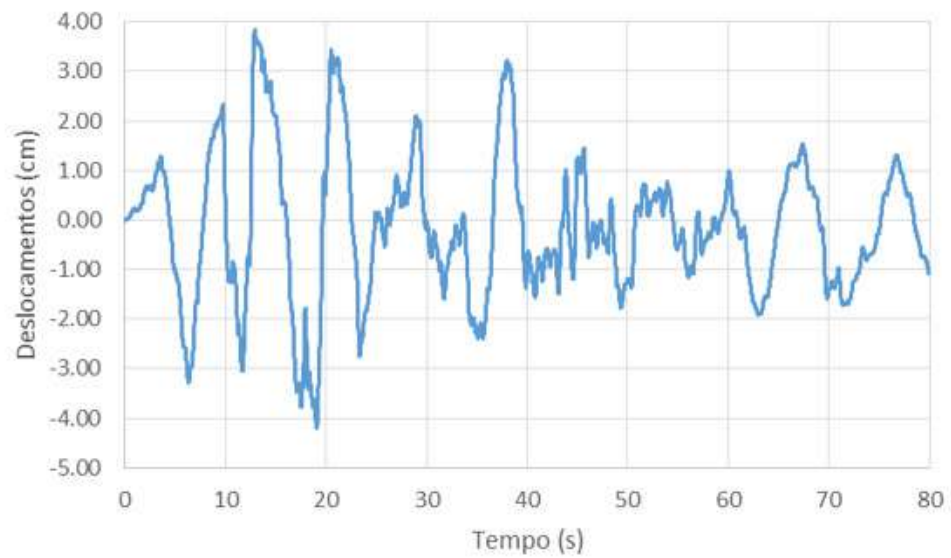

(c)

Figura 3.25- Registro de (a) aceleração (b) velocidade (c) deslocamento do sismo de Lima (1974) prévio ao ajuste espectral. 


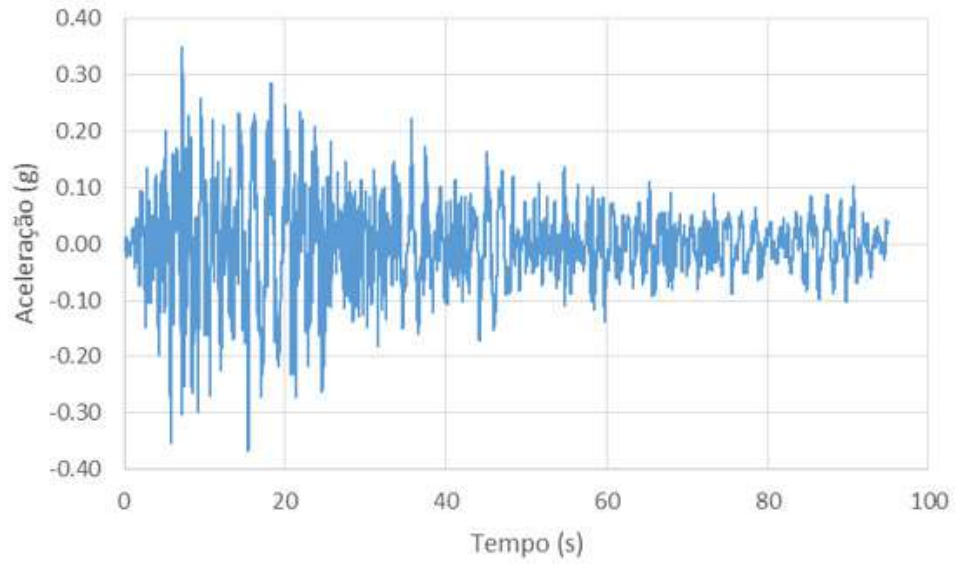

(a)

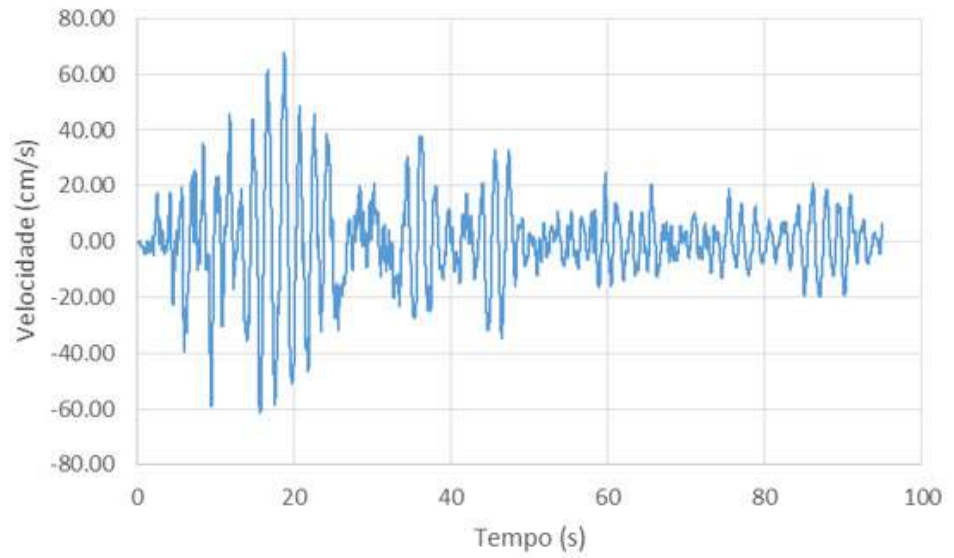

(b)

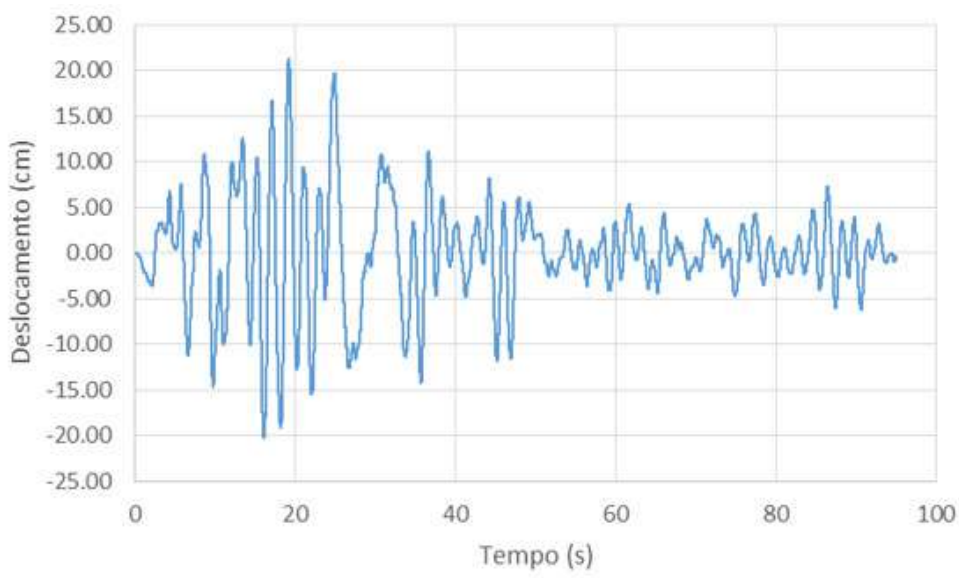

(c)

Figura 3.26- Registro de (a) aceleração (b) velocidade (c) deslocamento do sismo de Maule (2010) prévio ao ajuste espectral. 


\subsection{3.}

\section{Ajuste espectral}

Quanto às denominações, Acevedo (2003) estabelece uma diferença nos acelerogramas que não são reais. Acelerogramas sintéticos são aqueles decorrentes dos modelos geológicos de ruptura de falhas, enquanto acelerogramas artificiais são aqueles obtidos pela estimativa no método de ajuste espectral. Portanto, os registros sísmicos considerados nesta investigação correspondem a acelerogramas artificiais.

Da desagregação se tem valores de magnitude, distância e tipo de mecanismo focal do sismo com maior contribuição da ameaça sísmica, estes dados são empregados na seleção dos registros originais para que depois sejam ajustados a um espectro objetivo. Segundo a ASCE 7-16, recomenda-se trabalhar pelo menos com 5 registros sísmicos com o mesmo mecanismo focal obtido da desagregação; os registros poderão ser fornecidos por redes de acelerogramas de outros países, mas devem cumprir com os valores de magnitude e distância da desagregação. Outra recomendação para a escolha dos registos sísmicos é que seus espectros de resposta deveram ser semelhantes com o espectro objetivo com uma variação de $10 \%$ no PGA com a finalidade de ter convergência no momento do ajuste espectral. Na Figura 3.27 são apresentados os espectros de resposta dos registos antes do ajuste espectral.

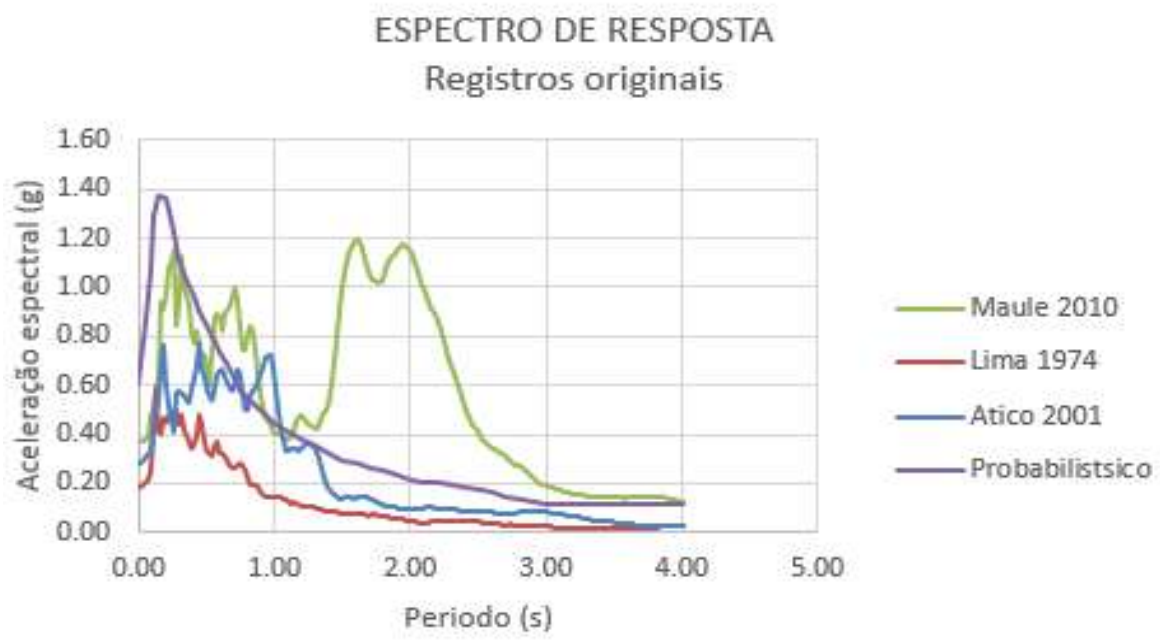

Figura 3.27- Espectros de resposta originais dos registros sísmicos considerados. 
Será utilizado o método de ajuste espectral (Abrahamson, 1993; Hancock et al, 2006) para geração de acelerogramas artificiais cujos espectros de resposta sejam consistentes com os espectros obtidos no estudo de ameaça sísmica. $\mathrm{Na}$ Figura 3.28 são apresentados os espectros de resposta dos registros após do ajuste espectral.

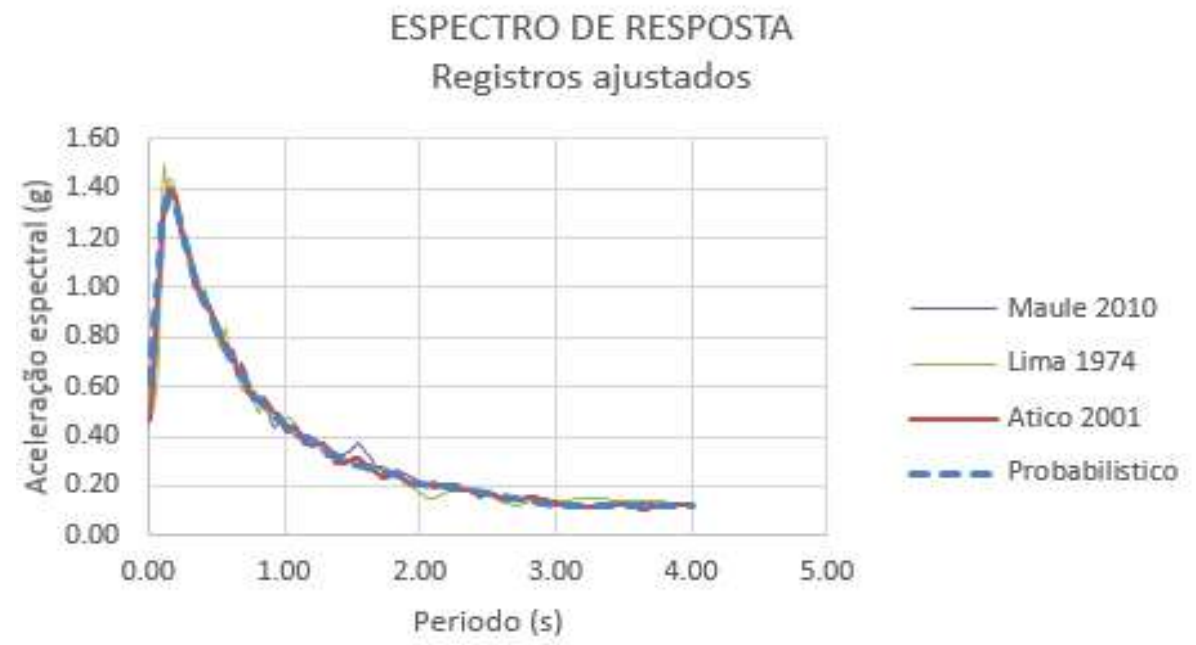

Figura 3.28- Processo de ajuste espectral dos registros sísmicos.

A seguir, são apresentados os registros de aceleração, velocidade e deslocamento dos sismos ajustados de Atico 2001 (Figura 3.29), Lima 1974 (Figura 3.30) e Maule 2010 (Figura 3.31). 


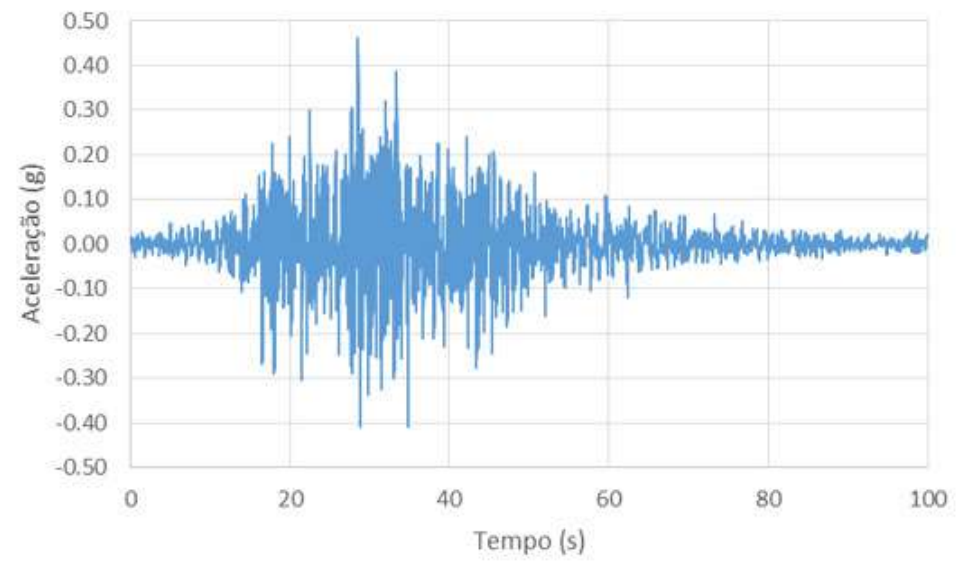

(a)

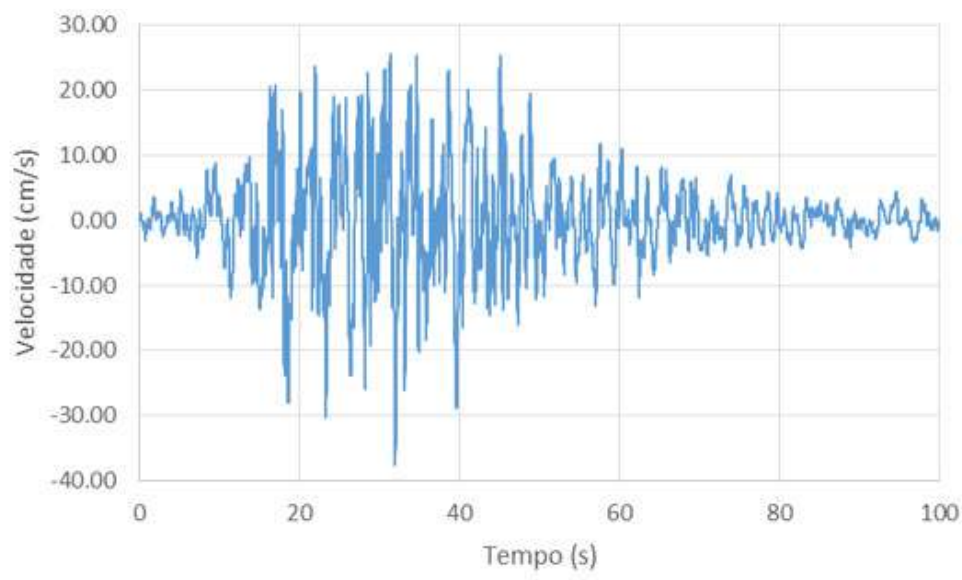

(b)

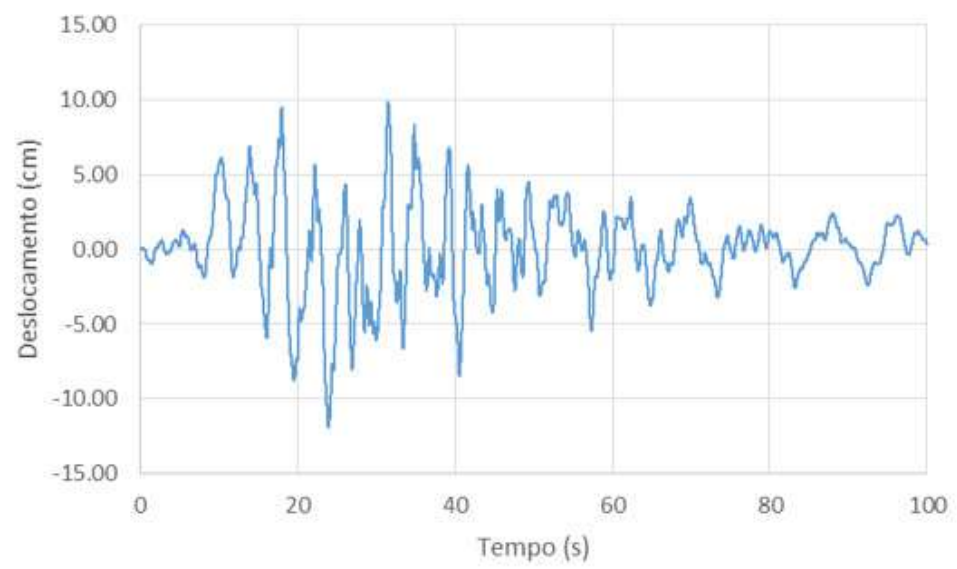

(c)

Figura 3.29- Registro de (a) aceleração (b) velocidade (c) deslocamento do sismo de Atico (2001) após o ajuste espectral. 


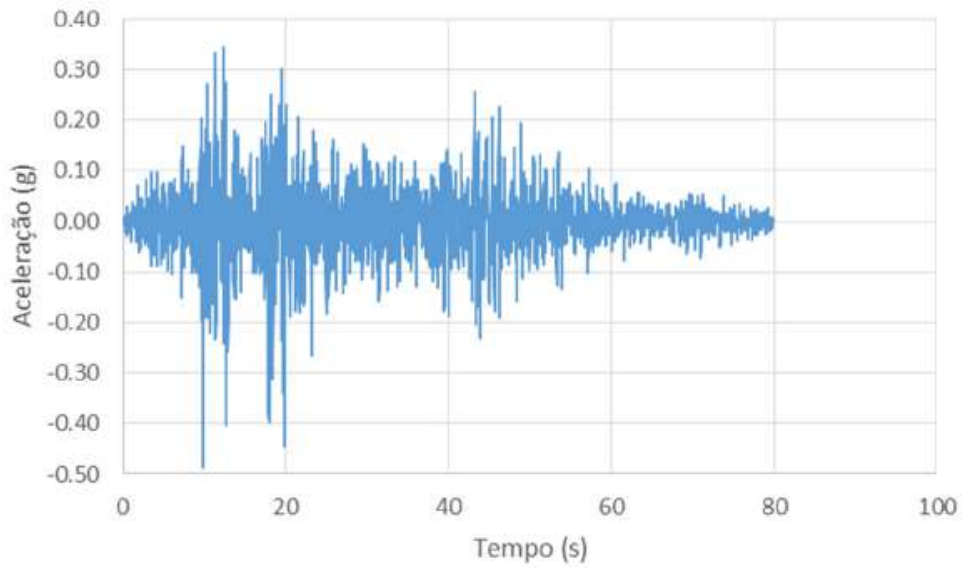

(a)

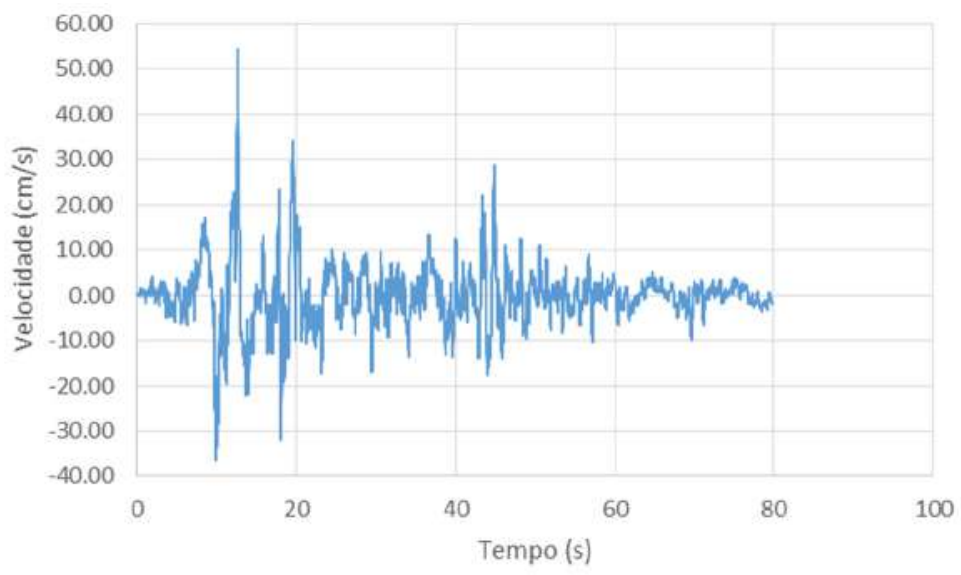

(b)

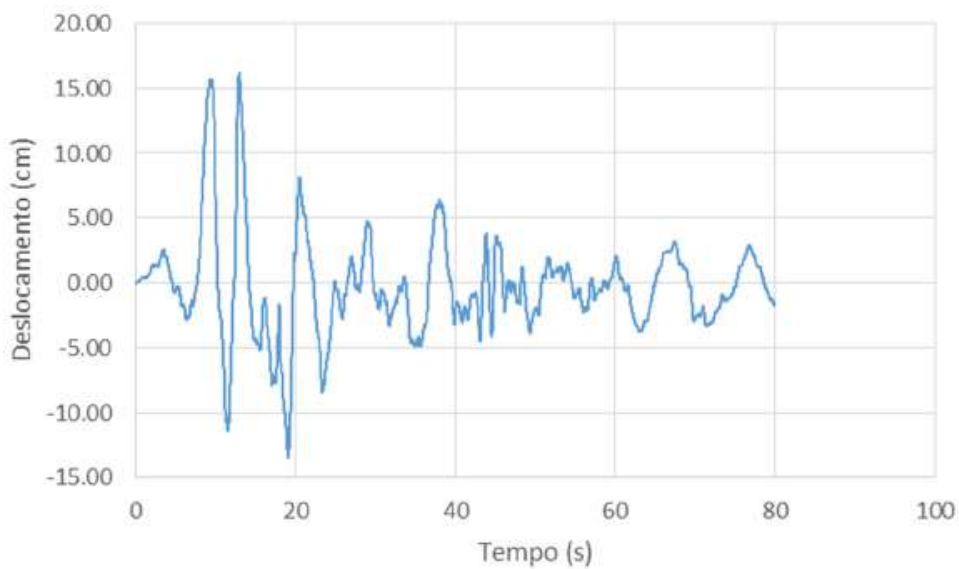

(c)

Figura 3.30- Registro de (a) aceleração (b) velocidade (c) deslocamento do sismo de Lima (1974) após o ajuste espectral. 


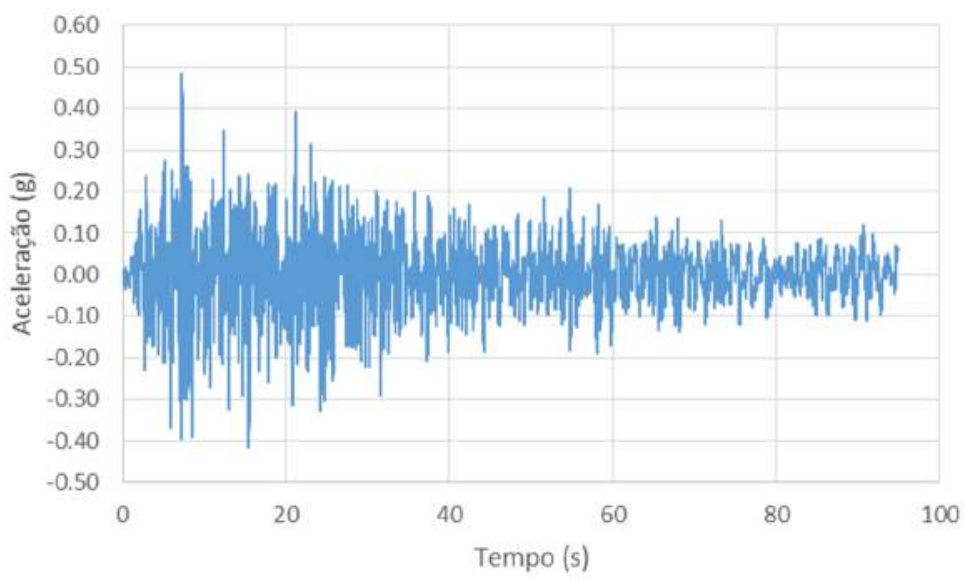

(a)

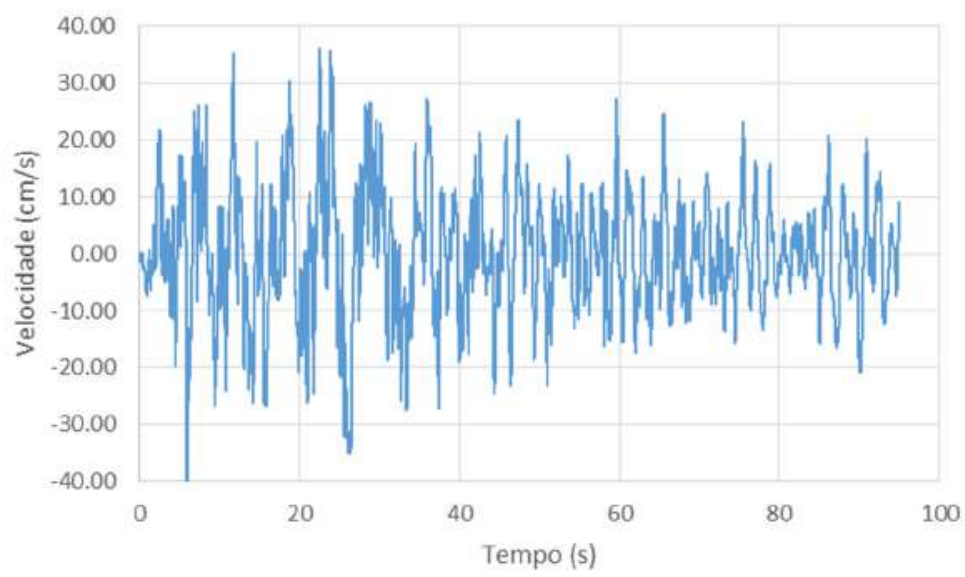

(b)

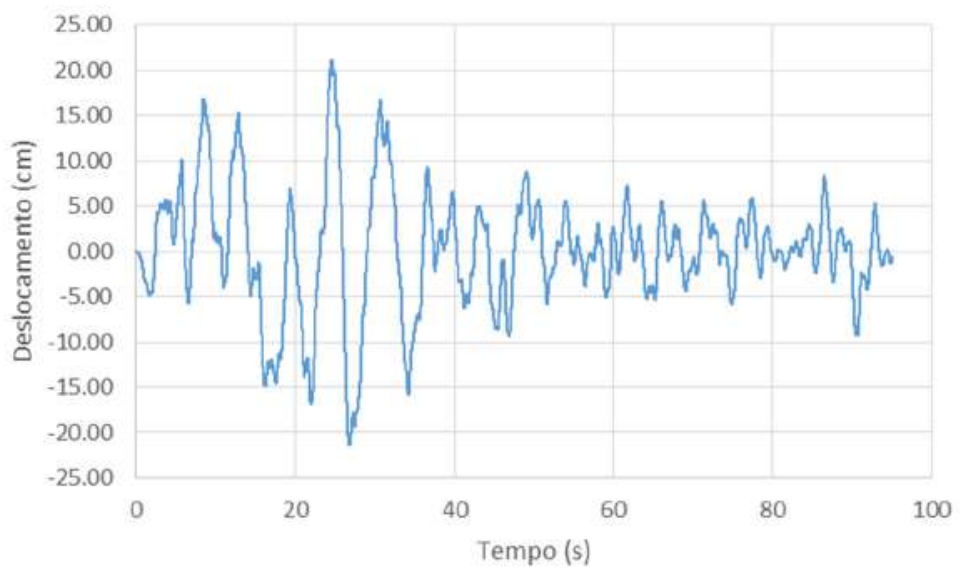

(c)

Figura 3.31- Registro de (a) aceleração (b) velocidade (c) deslocamento do sismo de Maule (2010) após o ajuste espectral. 


\section{4 Comportamento dinâmico do solo e fenômeno de liquefação}

\section{1. Caracterização das propriedades dinâmicas}

Os solos exibem um comportamento tensão-deformação não-linear, sendo geralmente inelástico sob condições de carregamento cíclico. Em nível de pequenas deformações, a rigidez do material é muito grande e o amortecimento muito pequeno. Em altos níveis de deformações, os efeitos da não-linearidade e inelasticidade incrementam resultando em baixa rigidez e grande amortecimento. Uma caracterização completa desse comportamento é muito complicada.

\subsection{1. Módulo de cisalhamento}

Ensaios de laboratório têm mostrado que a rigidez do solo é influenciada pela amplitude da deformação cíclica, índice de vazios, tensão principal efetiva média, índice de plasticidade, razão de pré-adensamento e número de ciclos.

O módulo de cisalhamento secante, $G_{s e c}$, de um elemento de solo varia com a amplitude da deformação cisalhante cíclica, decrescendo com o incremento das amplitudes das deformações (Figura 4.1 (a)).

A inclinação da curva cruzando a origem representa o maior valor do módulo cisalhante, $G_{\max }$ (Figura 4.1 (b)). A normalização do módulo secante pelo seu máximo valor $G_{s e d} / G_{\max }$ pode ser representada em uma curva para caracterização seu comportamento cíclico. A variação da razão de módulos $G / G_{\max }$ com a deformação cisalhante é descrita graficamente pela "curva de redução do modulo de cisalhamento". 


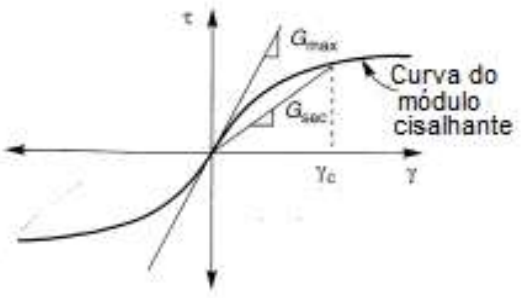

(a)

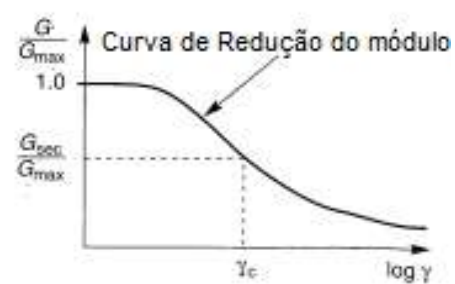

(b)

Figura 4.1- (a) Módulo de cisalhamento secante, $\mathrm{G}_{\mathrm{sec}}$, (b) módulo de cisalhamento tangente, $\mathrm{G}_{\mathrm{tan}}$. (Kramer, 1996).

O módulo de cisalhamento máximo, $G_{\max }$, pode ser obtido através de medições de velocidade da onda cisalhante, $v_{s}$, para baixos níveis de deformação (aprox. $3 \times 10^{-4 \%}$ ) a partir de ensaios geofísicos, como indicado na expressão (4.1), ou quando as medidas da velocidade de onda cisalhante não são conhecidas, o $G_{\max }$ pode ser estimado através da relação proposta por Kramer (1996), indicado na expressão (4.2):

$$
\begin{gathered}
G_{\max }=\rho \mathrm{v}_{\mathrm{s}}^{2} \\
G_{\max }=625 F(e)(O C R)^{\mathrm{k}} P_{a}^{1-n}\left(p^{\prime}\right)^{n}
\end{gathered}
$$

onde $F(e)$ é uma função do índice de vazios; OCR é a razão de préadensamento; $k$ é o exponente da razão de pré-adensamento (Tabela 4.1); $p^{\prime}$ é a tensão principal efetiva média $\left[p^{\prime}=\left(\sigma_{1}^{\prime}+\sigma_{2}^{\prime}+\sigma_{3}^{\prime}\right) / 3\right] ; n$ é o exponente da tensão; e Pa é a pressão atmosférica nas mesmas unidades da $p^{\prime}$ e $G_{\max }$.

Tabela 4.1 - Exponente da razão de pre-adensamento, k. (adaptado Hardin \& Drnevich (1972)).

\begin{tabular}{|c|c|}
\hline Índice de Plasticidade (IP) & $\mathbf{k}$ \\
\hline 0 & 0,00 \\
\hline 20 & 0,18 \\
\hline 40 & 0,30 \\
\hline 60 & 0,41 \\
\hline 80 & 0,48 \\
\hline$\geq 100$ & 0,50 \\
\hline
\end{tabular}

Hardin (1978) propôs que $F(e)=1 /\left(0,3+0,7 e^{2}\right)$ enquanto que Jamiolkowski et al. (1991) sugeriu que $F(e)=1 / e^{1,3}$. O exponente da tensão é frequentemente tomado como $n$ igual a 0,5 , mas este pode ser calculado para cada solo a partir 
de resultados de ensaios de laboratório a diferentes níveis de tensões de confinamento efetiva.

O $G_{\max }$ também pode ser obtido a partir de relações empíricas, como a proposta por Seed \& Idriss (1970):

$$
\begin{aligned}
& G_{\text {max }}=1000 K_{2, \max }\left(p^{\prime}\right)^{0,5} \quad \text { em psf } \\
& G_{\max }=21,7 K_{2, \max } P_{a}\left(\frac{p^{\prime}}{P_{a}}\right)^{0,5} \quad \mathrm{em} \mathrm{Pa}
\end{aligned}
$$

onde $k_{2, \max }$ (no intervalo entre 40 a 70) é obtido da Tabela 4.2 (Seed \& Idriss, 1970 ) em função do índice de vazios (e) ou densidade relativa $(D R)$ e p'. Para o caso de solos granulares (pedregulhos) os valores de $K_{2, \max }$ estão tipicamente na faixa de 80 a 180 (Seed et al., 1984).

Tabela 4.2 - Estimação de K2,max. (adaptado Seed \& Idriss (1970)).

\begin{tabular}{|c|c|}
\hline$e$ & $k_{2, \max }$ \\
\hline 0,4 & 70 \\
\hline 0,5 & 60 \\
\hline 0,6 & 51 \\
\hline 0,7 & 44 \\
\hline 0,8 & 39 \\
\hline 0,9 & 34 \\
\hline
\end{tabular}

\begin{tabular}{|c|c|}
\hline$D R(\%)$ & $k_{2, \max }$ \\
\hline 30 & 34 \\
\hline 40 & 40 \\
\hline 45 & 43 \\
\hline 60 & 52 \\
\hline 75 & 59 \\
\hline 90 & 70 \\
\hline
\end{tabular}

Para o caso de solos granulares com presença de finos, estimativas preliminares do $G_{\max }$ pode ser obtidas a partir do Índice de Plasticidade (IP), razão de pré-adensamento (OCR) e resistência não drenada ${ }^{1}$ (Tabela 4.3).

${ }^{1}$ Devido a que a resistência não drenada é altamente variável e que o módulo cisalhante para uma resistência não drenada varia diferentemente com a tensão confinante efetiva, os resultados devem ser usados cuidadosamente. 
Tabela 4.3 - Valores de $G_{m a x} / S_{u}^{a}($ Kramer, 1996).

\begin{tabular}{|c|c|c|c|}
\hline \multirow{2}{*}{ Índice de Plasticidade (IP) } & \multicolumn{3}{|c|}{ Razão de pré-adensamento, OCR } \\
\cline { 2 - 4 } & $\mathbf{1}$ & $\mathbf{2}$ & $\mathbf{3}$ \\
\hline $15-20$ & 1100 & 900 & 600 \\
\hline $20-25$ & 700 & 600 & 500 \\
\hline $35-45$ & 450 & 380 & 300 \\
\hline
\end{tabular}

Fonte: After Weiler (1988); ${ }^{a}$ Resistência não drenada medida em ensaio triaxial de compressão CU.

O módulo cisalhante máximo pode ser estimado, também, a partir de parâmetros de ensaios de campo, como as relações empíricas listadas na Tabela 4.4, limitadas a uma estimativa preliminar ${ }^{2}$ do $G_{\max }$.

Tabela 4.4 - Relações empíricas de correlação entre $G_{\max }$ e parâmetros de ensaios in situ (adaptado a partir de Kramer, 1996).

\begin{tabular}{|c|c|l|l|l|}
\hline $\begin{array}{c}\text { Ensaio } \\
\text { in situ }\end{array}$ & \multicolumn{1}{|c|}{ Relação } & $\begin{array}{c}\text { Tipo de } \\
\text { solo }\end{array}$ & \multicolumn{1}{c|}{ Referências } & Comentários \\
\hline \multirow{3}{*}{ SPT } & $G_{\max }=20000\left(N_{1-60}\right)^{0,333}\left(p^{\prime}\right)^{0,5}$ & Areia & $\begin{array}{l}\text { Ohta \& Goto (1976); } \\
\text { Seed et al. (1986) }\end{array}$ & Gmax e $p^{\prime}{\mathrm{em} \mathrm{lb} / \mathrm{ft}^{2}}^{2}$ \\
\cline { 2 - 5 } & $G_{\max }=325(N)_{60}^{0,68}$ & Areia & $\begin{array}{l}\text { Imai \& Tonouchi } \\
(1982)\end{array}$ & Gmax em kips/ $\mathrm{ft}^{2}$ \\
\hline
\end{tabular}

A avaliação do módulo cisalhante pode tornar-se mais complexa devido aos efeitos de tempo e taxa de deformação. Os efeitos de taxa podem causar um aumento no $G_{\max }$ com o incremento da taxa de deformação e a influência da taxa de deformação no $G_{\max }$ incrementa com o incremento da plasticidade do solo.

A curva de redução dos módulos de cisalhamento, $\mathrm{G} / \mathrm{G}_{\max }$, é caracterizada para avaliar o comportamento de redução dos módulos cisalhantes. Esta caracterização das curvas de redução dos módulos é extremadamente importante por poder influenciar grandemente na resposta ou na forma com um depósito de solo amplificará ou atenuará. Inicialmente, as curvas de redução dos módulos foram tratadas separadamente para solos arenosos e pedregulhos como as

${ }^{2}$ Kramer (1996) indica que existe uma grande variabilidade na correlação dos resultados devido à dificuldade de correlacionar o $G_{\max }$ de pequenas deformações com ensaios de penetração de grandes deformações. 
desenvolvidas por Seed \& Idriss (1970). Todavia, a partir da década de 1980, Vucetic \& Dobry (1991), Darendeli (2001), Menq (2003), Roblee e Chiou (2004), entre outros, concluíram que há uma transição gradual entre o comportamento de materiais granulares e coesivos, sendo que a forma das curvas de redução de módulo de cisalhamento é mais afetada pelo índice de plasticidade do que pelo índice de vazios (Dobry \& Vucetic, 1987 e Sun et al., 1988). Os autores apresentaram os tipos de curvas como visto na Figura 4.2, deixando em evidencia que a deformação cisalhante cíclica de início não linear (threshold shear strain), $\gamma_{t}$, é maior para solos altamente plásticos do que para solos de baixa plasticidade.

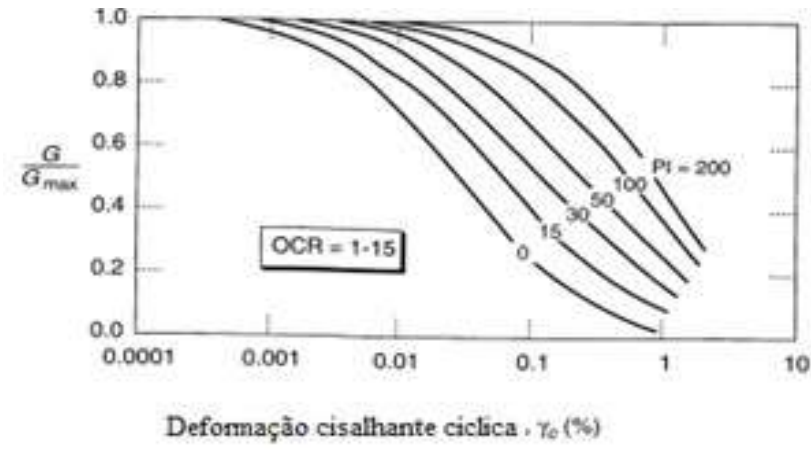

Figura 4.2 - Curvas de redução de módulos para solos granulares finos de diferentes plasticidades (After Vucetic \& Dobry, 1991).

Na Figura 4.2 a curva de redução do modulo para PI igual a 0 é muito semelhante à curva média de redução do módulo usada comumente para areias de Seed \& Idriss (1970). Kramer (1996) sugere que essa semelhança das curvas de redução dos módulos (Figura 4.2) recomendaria a sua aplicabilidade a ambos os solos granulares (arenosos e pedregulhos ${ }^{3}$ ).

A pesquisa de Menq (2003) concluiu que, para solos granulares, a curva de redução do módulo de cisalhamento $\left(\mathrm{G} / \mathrm{G}_{\max }\right)$ é principalmente uma função da tensão efetiva de confinamento $\left(\sigma_{0}\right)$, do índice de vazios $(e)$, do tamanho médio dos grãos $\left(D_{50}\right)$ e do coeficiente de uniformidade $\left(c_{u}\right)$. A curva $G / G_{\max }$ diminui com o aumento de $D_{50}, C_{u}$ e $\sigma_{0}$ e com a diminuição de e. À medida que a deformação

3 Para pedregulhos, apesar da dificuldade experimental da execução de ensaios em laboratório, algumas evidências indicam que a curva média de degradação de $G$ tem forma similar, porém mais achatada, do que a curva média das areias (Seed et al., 1986). 
de cisalhamento aumenta, o módulo de cisalhamento se torna mais dependente desses parâmetros (Figura 4.3).

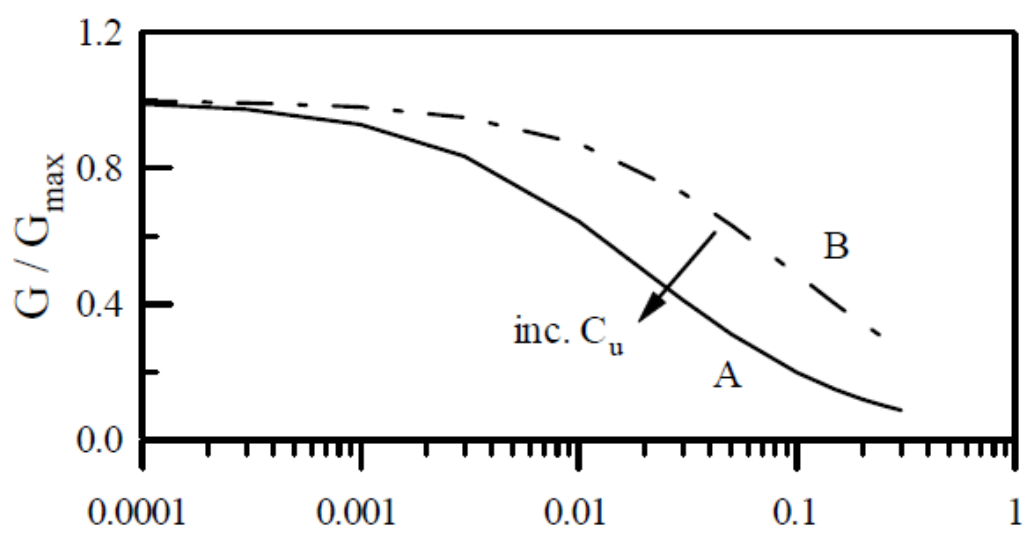

Shear Strain, $\gamma, \%$

Figura 4.3- Comparação das curvas de redução do módulo de corte para areia pouco graduada (SP) e cascalho bem graduada (GW) (Menq, 2003).

A pesquisa de Roblee e Chiou (2004) apresenta o desenvolvimento empírico de um novo modelo hiperbólico dependente da profundidade e do tipo de solo. $\mathrm{O}$ modelo fornece uma ferramenta de fácil implementação que se baseia em conceitos desenvolvidos por Darendelli e Stokoe. A curva $G / G_{\max }$ aumenta com a profundidade (Figura 4.4) e com o incremento da porcentagem de finos (Figura 4.5).

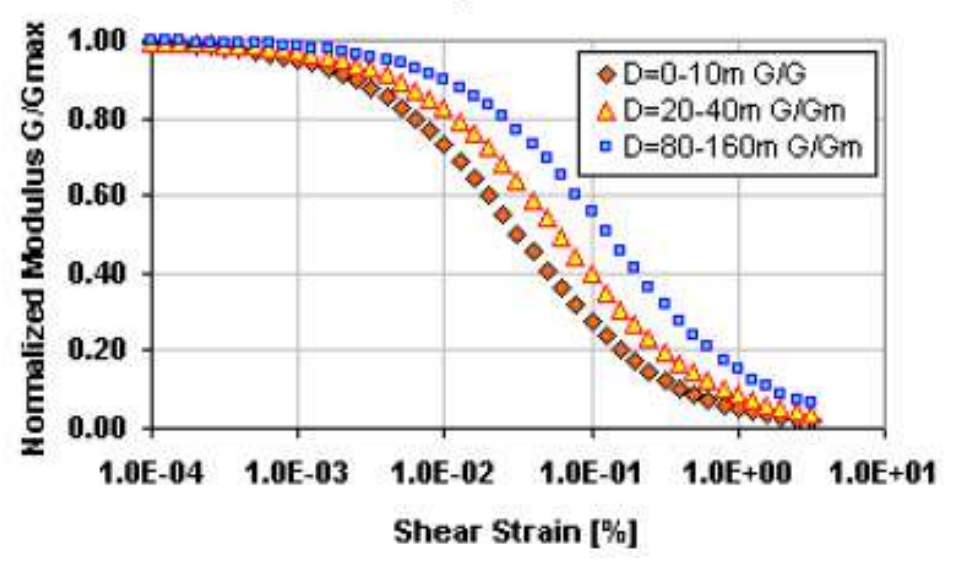

Figura 4.4- Efeito na curva de redução do módulo de cisalhamento pelo aumento da profundidade no solo 1-PCA (Roblee e Chiou, 2004). 


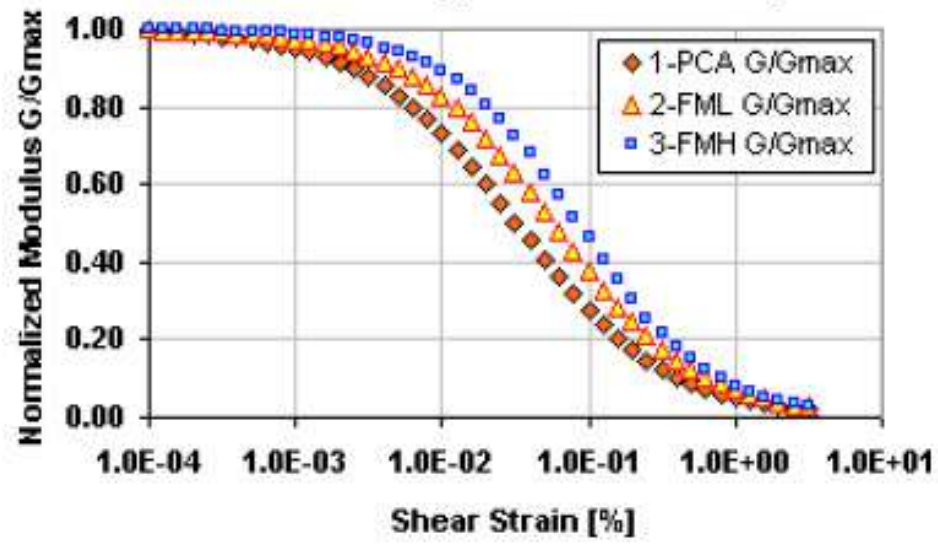

Figura 4.5- Efeito na curva de redução do módulo de cisalhamento pelo do tipo de solo para profundidade superficial (Roblee e Chiou, 2004).

\subsection{2.}

Razão de amortecimento

Durante o carregamento cíclico ocorrerá dissipação de energia mesmo para baixos níveis de deformação de modo que a razão de amortecimento nunca é zero. Acima da deformação $\gamma_{t /}$ a largura do laço de histerese exibida pelo solo carregado ciclicamente incrementará com o incremento das amplitudes das deformações cisalhantes cíclicas, o que indica que a razão de amortecimento incrementa com o incremento das amplitudes das deformações.

Da mesma forma que o comportamento de redução dos módulos é influenciado pelas características de plasticidade, o comportamento de amortecimento também é influenciado pelo índice de plasticidade do material, constatado por Kokushu et al. (1982), Dobry \& Vucetiic (1987), Sun et al. (1988), Vucetic \& Dobry (1991) entre outros. Razões de amortecimento de solos altamente plásticos são menores do que aqueles de baixa plasticidade (ou solos granulares) na mesma amplitude de deformação cíclica (Figura 4.6). Da Figura 4.6, a curva de amortecimento para um IP igual a 0 é bastante próxima da curva de amortecimento média usada para areias proposta por Seed \& Idriss (1970). De acordo com Seed et al. (1984) o comportamento de amortecimento de pedregulhos é muito similar aos dos arenosos. 


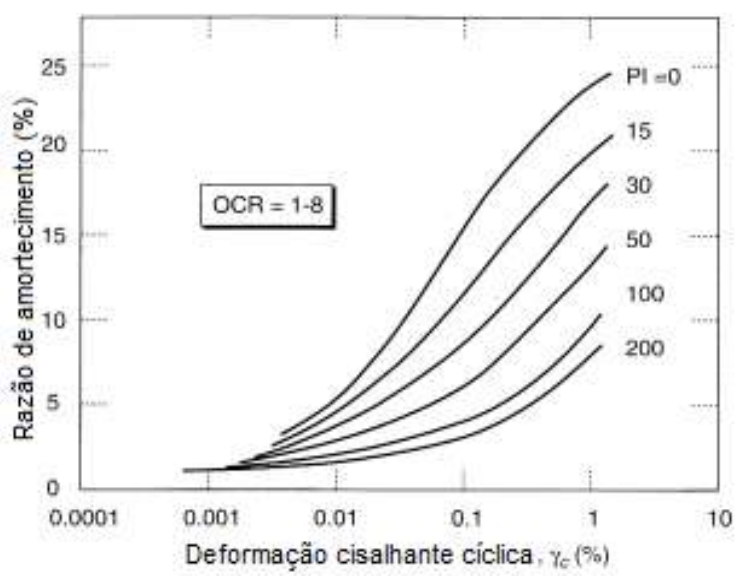

Figura 4.6- Variação da razão de amortecimento de solos granulares finos com a amplitude de deformação cisalhante cíclica e o índice de plasticidade (After Vucetic \& Dobry,1991).

Na pesquisa de Menq (2003) a curva de amortecimento (Ds) diminui com o aumento de $D_{50}$ e $\sigma_{0}$, mas aumenta com o aumento de $c_{u}$ e a medida que a deformação de cisalhamento aumenta a curva de amortecimento se torna mais dependente (ver Figura 4.7).

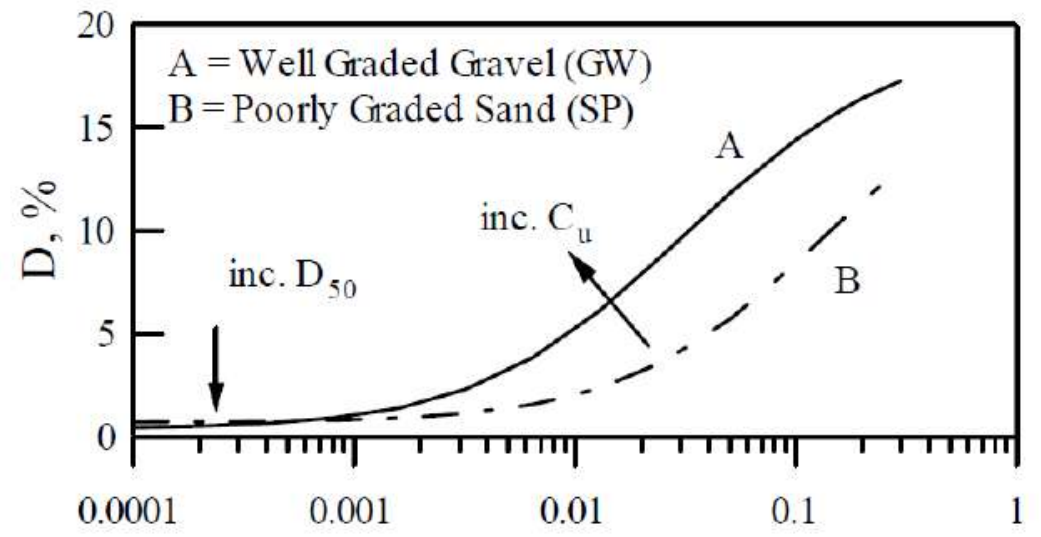

Shear Strain, $\gamma, \%$

Figura 4.7- Comparação das curvas de amortecimento para areia pouco graduada (SP) e cascalho bem graduada (GW) (Menq, 2003).

Na pesquisa de Roblee e Chiou (2004) a curva de amortecimento (Ds) diminui com o aumento da profundidade (Figura 4.8) 


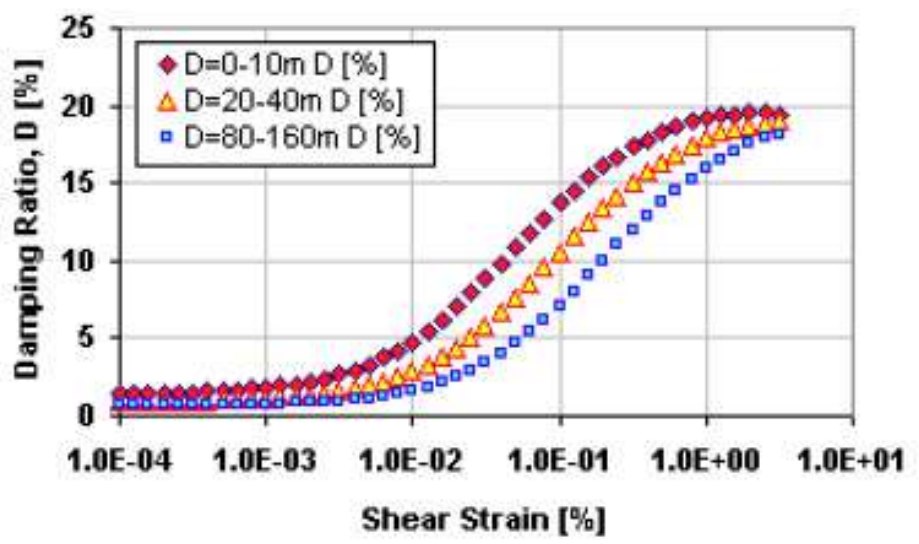

Figura 4.8- Efeito na curva de amortecimento da profundidade no solo 1-PCA. (Roblee e Chiou, 2004).

\section{2.}

\section{Ensaios para a obtenção das propriedades dinâmicas}

O comportamento dos solos sujeitos a carregamentos dinâmicos é governado, especificamente, pelas propriedades dinâmicas dos solos.

Existe uma grande incerteza na medição das propriedades dos solos, muitas dessas incluem a inerente variabilidade dos solos (sua formação geológica que depende da forma a qual foram depositados), a anisotropia inerente (uma função da estrutura do solo), anisotropia induzida (causada pelas condições de tensões anisotrópicas), alteração do estado de tensões no solo (tensões iniciais) no momento da amostragem em campo, limitações dos equipamentos de ensaios, erros na execução do ensaio e erros de interpretação. Porém, muitas destas fontes de incerteza podem ser minimizadas com o devido cuidado dos procedimentos na execução dos ensaios principalmente, mas também quando se faz uma boa escolha do tipo de ensaio a ser realizado que seja indicado com as condições do material, do terreno e do problema específico a ser analisado. Por exemplo, em problemas dominados pelos efeitos de propagação de ondas somente baixos níveis de deformações são induzidos no solo, enquanto que para outros problemas, tais como estabilidade de massas de solo, grandes deformações serão induzidas no solo.

As propriedades dos solos que influenciam na propagação das ondas e outros fenômenos a pequenas deformações incluem a rigidez, o amortecimento, o coeficiente de Poisson e o peso específico, sendo que, os mais importantes 
devido a sua influência, são a rigidez e o amortecimento. As características de amortecimento e rigidez dos solos sob carregamentos cíclicos são muito importantes para a avaliação de muitos problemas em geoestruturas submetidas a terremotos, não somente quando avaliados a pequenas deformações, mas também a médias ou grandes deformações, quando a influência do número de ciclos de carregamento sobre a resistência cisalhante é mais significativa. Existe uma ampla variedade de métodos e técnicas para medir as propriedades dinâmicas dos solos a pequenas e grandes deformações tanto no campo quanto no laboratório.

A capacidade dos ensaios de laboratório em avaliar medições mais exatas das propriedades dos solos dependerá da alta qualidade das amostras e da capacidade dos ensaios replicarem o melhor possível tanto as condições iniciais quanto as condições de carregamento.

Os ensaios de campo permitem que as propriedades do solo sejam medidas in situ, no seu estado atual (isto é, conservando o estado de tensões, condições estruturais, químicas, termais, etc.) que refleta nas características medidas. Estas respostas são obtidas de relativamente grandes volumes de solo, minimizando, desta forma, o potencial de avaliação de resultados vindos de pequenas amostras não representativas. Os ensaios de campo podem ser usados para medir as características dos solos a pequenas ou a grandes deformações, a seleção do(s) método(s) dependerá do parâmetro requerido, principalmente. Ensaios de campo que medem características e propriedades mecânicas dos solos a grandes deformações, tais como resistência ao cisalhamento, resistência ao cisalhamento residual, módulo cisalhante e amortecimento têm sido correlacionados a propriedades a pequenas deformações. Ensaios SPT, CPT, BPT e LPT tamém têm sido amplamente usados como índices para avaliar as características de liquefação.

\subsection{1.}

\section{Ensaio geofísicos}

Técnicas geofísicas representam uma classe importante dos ensaios de campo para a determinação das características e propriedades dinâmicas do solo a pequenas deformações ou variações a pequena escala. Estes procedimentos, considerados como métodos ativos, abrangem a geração de ondas de tensão em 
regime permanente e/ou transiente e a interpretação do comportamento a partir de sinais de retorno medidos em lugares específicos, com informações sobre parâmetros elásticos, medição de velocidades de ondas de corpo (S e P) e/ou de superfície $(R)$, frequência, forma e comprimento de ondas, os quais podem ser relacionados com estimativas de amortecimento e do módulo de cisalhamento a pequenas deformações (tipicamente abaixo de $0.001 \%$ ) baseado na teoria de propagação da onda para materiais lineares. Dentre os métodos sísmicos de maior uso encontram-se os ensaios up-hole e down-hole, cone sísmico, análise espectral para ondas de superfície (SASW).

Em 1999 foi introduzido o método de análise de multicanais para ondas de superfície (MASW) resultado de inúmeros estudos feitos na Kansas Geological Survey (Park et al., 1999) para solucionar problemas associados com o SASW. Porém, os ensaios MASW tem a vantagem que explora produtivamente técnicas de processamento e de registro multicanais que são similares àquelas usadas nas técnicas de reflexão sísmicas e em que o método consegue identificar e separar ondas de superfície de vários modos de vibração. Uma vez que a onda de superfície foi corretamente identificada, procede-se à extração da componente de velocidade da onda $S$ (que está relacionada à frequência do sinal), para obter como resultado final uma curva de variação de velocidade de onda $S$ a diversas profundidades.

A interpretação de parâmetros elásticos, tal como, amortecimento e módulo cisalhante a pequenas deformações in situ pode ser determinado por meio da velocidade da onda cisalhante, $v_{s}$, medida em campo.

\subsection{2.}

\section{Ensaio de laboratório}

\section{Ensaio de coluna ressonante e cisalhamento torcional}

Este teste é realizado para obter o módulo de cisalhamento e a razão de amortecimento histerético. Neste ensaio, vibrações forçadas senoidais são impostas na parte superior da amostra por meio de um atuador e, posteriormente, a freqüência do vibrador (atuador) é ajustada, a fim de medir a freqüência de ressonância e a velocidade de vibração. Este processo é repetido para diferentes 
forças excitantes, a fim de obter as características de deformação dinâmica para vários níveis de deformação.

\section{Ensaio triaxial cíclico}

Os ensaios triaxiais cíclicos são comumente utilizados para obter as propriedades dinâmicas dos solos a grandes níveis de deformação, além de também conseguirem simular o fenómeno de liquefação em solos saturados sob carregamentos cíclicos cisalhantes em condições não drenadas (Daftari, 2015).

Os primeiros pesquisadores em avaliar o fenómeno de liquefação em ensaios triaxiais cíclicos foram See e Lee (1966), em areias fofas e densas com baixos e altos índices de vazios. Em sequência, vários outros pesquisadores continuaram avaliando a liquefação em ensaios triaxiais cíclicos como Castro (1969), Mohamad e Dobry (1986), Sitharam et al. (2004), Ghionna e Porcino (2006), Rangaswamy et al. (2010), Sesov et al. (2012) e Liu e Chang (2017).

\section{Ensaio de cisalhamento direto cíclico}

De acordo com Daftari (2015), o ensaio de cisalhamento direto cíclico reproduz melhor as condições de tensão de um terremoto melhor que um ensaio triaxial cíclico. Este ensaio é comunmente utilizado na avaliação do potencial de liquefação dinâmica em solos. Neste ensaio, uma amostra de solo cilíndrica é restringida contra expansão lateral por placas rígidas e a amostra é envolvida por uma membrana. Ao aplicar tensões de cisalhamento horizontais cíclicas na parte superior ou inferior da amostra, a amostra é deformada da mesma maneira que um elemento de solo submetido a ondas $\mathrm{S}$ de propagação vertical.

Peacock e Seed (1968) foram um dos primeiros pesquisadores em trabalhar com ensaios de cisalhamento cíclico para estudar o fenómeno de liquefação. Anos recentes foram publicados trabalhos desenvolvidos pelos seguintes autores: Finn (1985), Sivathayalan (1994), Kammerer et al. (2001) e Wijewickreme e Sanin (2004).

\section{Ensaio em centrifuga}

De acordo com Daftari (2015), o ensaio centrifuga tenta reproduzir a condição de contorno e propriedades do material no campo por um modelo físico de pequena escala. Pode ser usado para avaliar o desempenho de um protótipo 
ou verificar teorias preditivas (modelos constitutivos). Este ensaio é um método útil para estudar o comportamento dinâmico das estruturas de terra e fundações. O objetivo do ensaio é submeter a estrutura de solo a pequena escala a uma aceleração centrifuga típica entre 30-200g.

De acordo com Bertalot (2012), a modelagem de terremotos pelo ensaio centrifuga começou no final dos anos 70s na Inglaterra por Morris (1979). Anos mais recentes, os pesquisadores utilizam este ensaio na avaliação do fenómeno de liquefação: Scott (1986), Hushmand et al. (1988), Gutierrez (1998), Sharp et al. (2000), Adalier e Elgamal (2005) e Madabhushi et al. (2016).

\section{3. \\ Modelos constitutivos}

Solos são materiais deformáveis, podendo apresentar comportamento tensão-deformação altamente não linear quando experimentan carregados estáticos ou dinamicos como sismos. A utilização de métodos numéricos para análise da resposta da barragem dependerá da etapa do analise seja estático ou dinâmico para empregar os modelos constitutivos adecuados.

\subsection{1. Modelo elástico}

O uso da teoria de elasticidade é a abordagem mais tradicional para representar o comportamento tensão-deformação. No contexto de modelos constitutivos, a definição clássica de Cauchy é a mais precisa. Ela descreve que, em um material elástico, o estado de tensão é função apenas do estado de deformação, ou "vice-versa", e compreende-se que as trajetórias de carregamento, descarregamento ou recarregamento são coincidentes neste tipo de material. Em outras palavras, o modelo elástico é conservativo, liberando no descarregamento toda a energia interna armazenada durante a fase de carregamento.

A teoria de elasticidade é freqüentemente empregada em modelos constitutivos onde o descarregamento, recarregamento ou carregamento reverso (no caso de carregamento cíclico) são lineares; aplicando-se a lei generalizada de Hooke de forma incremental com parâmetros elásticos variáveis a cada incremento, (Ibañez, 2003). 
A lei constitutiva para materiais linearmente elásticos e isotrópicos, conhecida como lei de Hooke generalizada, é expressa por:

$$
\sigma_{i j}=\lambda \varepsilon_{k k} \delta_{i j}+2 \mu \varepsilon_{i j}
$$

onde $\lambda$ e $\mu$ são as constantes de Lamé.

A equação (4.2) é melhor expressa em termos da deformação volumétrica $K(\lambda=$ $K-2 / 3 G)$ e do módulo de cisalhamento $G(\mu=G)$.

Uma propriedade importante para um solo isotrópico elástico é demonstrada na lei generalizada de Hooke, onde os incrementos de deformações estão direitamente relacionados com os incrementos de tensões efetivas. Quando as invariantes de deformação estiverem corretamente associadas com as invariantes de tensão, os incrementos de deformação de cisalhamento $\Delta \mathcal{E}_{s}$ serão dependentes somente dos incrementos das correspondentes invariantes de tensão $\Delta q$ '. Além disso, os incrementos de deformação volumétrica $\Delta \varepsilon_{v}$ são dependentes somente dos incrementos das correspondentes invariantes de tensão $\Delta p$ '.

$$
\begin{gathered}
\Delta \varepsilon_{v}=\frac{1}{K} \Delta p^{\prime}+0 . \delta q^{\prime} \\
\Delta \varepsilon_{s}=0 . \Delta p^{\prime}+\frac{1}{3 G^{\prime}} \Delta q^{\prime}
\end{gathered}
$$

sendo $K$ o módulo de compressão volumétrica elástico e $G$ o módulo de cisalhamento elástico.

Mesmo que estas equações sejam derivadas da condição $\sigma_{2}^{\prime}=\sigma_{3}$, elas são válidas para estados gerais de tensões para materiais isotrópicos elásticos lineares.

Para o caso de carregamento não-drenado de um solo saturado, se $\Delta \varepsilon_{v}=0$, da equação (4.4) tem-se que:

$$
\Delta p^{\prime}=0
$$


A magnitude da poropressão é ajustada para manter $\Delta p^{\prime}=0$ e pode ser relacionada com os incrementos das invariantes das tensões de acordo com a equação (4.5).

$$
\Delta u=b(\Delta p+a \Delta q)
$$

em que a e b são parâmetros empíricos.

As relações entre os incrementos das invariantes de tensões totais e efetivas podem ser obtidas das equações (4.6) e (4.7).

$$
\begin{gathered}
\Delta p^{\prime}=\Delta p-\Delta u \\
\Delta q^{\prime}=\Delta q
\end{gathered}
$$

Considerando a equação (4.5) e comparando com as equações (4.6) e (4.7) tem-se:

$$
\Delta u=\Delta p
$$

Portanto, para o caso de um carregamento drenado, $b=1,0$ e $a=0$.

A técnica de análise de carregamento não-drenado em termos de tensões totais, anteriormente mostrada, é simples, mas devem-se considerar as condições nas quais devem ser usadas. O comportamento do solo é, ainda, dependente das tensões efetivas, porém estas são controladas pela condição de volume constante. É importante ressaltar que a técnica das tensões totais só é válida quando o solo for saturado e não-drenado, conseqüentemente, a deformação volumétrica é igual a zero. Em outros casos, a análise de tensões totais não é válida, e o cálculo em termos de tensões efetivas deve ser efetuado. 


\subsection{2.}

\section{Modelo HSM - Hardening Soil Model}

A idéia básica para a formulação do modelo Hardening soil é a relação hiperbólica entre a deformação axial $\left(\varepsilon_{a}\right)$ e a tensão de desvio q, mostrada na Figura 4.9. Nos ensaios triaxiais adensados drenados esta relação pode ser descrita pela seguinte expressão:

$$
\text { Para } q<q_{f}
$$

$$
\varepsilon_{a}=\frac{1}{2 E_{50}} \frac{q}{1-\frac{q}{q_{a}}}
$$

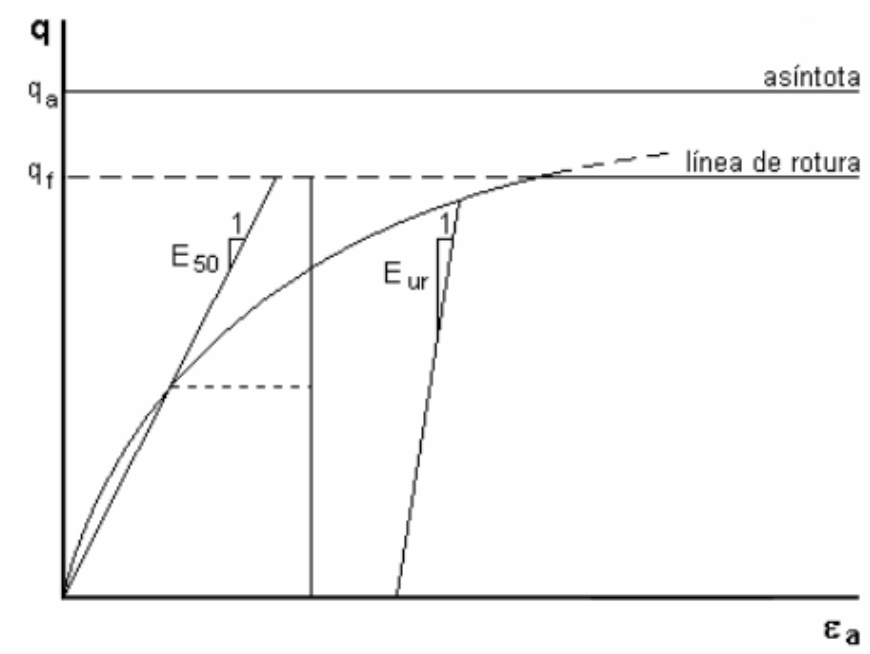

Figura 4.9- Relação tensão-deformação hiperbólica para testes triaxiais adensados drenados.

$\mathrm{Na}$ expressão anterior $q_{a}$ é o valor de resistência assintótica e $E_{50}$ é o módulo de Young correspondente quando atinge $50 \%$ da tensão de ruptura $\left(q_{f}\right)$. A expressão para determinar a tensão de ruptura $\left(q_{f}\right)$ é derivada do critério de ruptura de Mohr-Coulomb, o que implica os valores de resistência de c 'e $\varphi$ ', enquanto $q_{a}$ é uma fração de $q_{f}$, como mostrado na seguinte expressões:

$$
\begin{gathered}
q_{f}=\left(p+c^{\prime} \cot \varphi^{\prime}\right) \frac{6 \sin \varphi^{\prime}}{3-\sin \varphi^{\prime}} \\
q_{a}=\frac{q_{f}}{R_{f}}
\end{gathered}
$$


Quando $\mathrm{q}=\mathrm{q}_{\mathrm{f}}$, o critério de quebra é satisfeito e a perfeita plasticidade ocorre de acordo com o critério de Mohr-Coulomb.

$\mathrm{Na}$ expressão (4.9), o valor de $E_{50}$ é dependente da tensão da câmara $\sigma_{3}^{\prime}$ de acordo com a seguinte expressão, onde $E_{50}^{\text {ref }}$ é o módulo de rigidez de referência correspondente à tensão da câmara de referência $\sigma_{\text {ref. }}^{\prime}$

$$
E_{50}=E_{50}^{r e f}\left(\frac{\sigma_{3}^{\prime}+c^{\prime} \cot \varphi^{\prime}}{\sigma_{r e f}^{\prime}+c^{\prime} \cot \varphi^{\prime}}\right)^{m}
$$

A dependência potencial da rigidez na tensão é uma característica básica do modelo Hardening soil. Além disso, para descrever a rigidez do solo muito mais precisamente do que o modelo de Mohr-Coulomb, o endurecimento do solo leva em conta a rigidez do solo nas trajetórias de descarga-recarga usando o módulo elástico $\mathrm{E}_{\mathrm{ur}}$.

$$
E_{u r}=E_{u r}^{r e f}\left(\frac{\sigma_{3}^{\prime}+c^{\prime} \cot \varphi^{\prime}}{\sigma_{r e f}^{\prime}+c^{\prime} \cot \varphi^{\prime}}\right)^{m}
$$

Os componentes elásticos das deformações axiais $\varepsilon_{a}$ e radial $\varepsilon_{r}$, são calculados pelas seguintes expressões, onde $v_{u r}$ é o coeficiente de Poisson para a recarga de descarga.

$$
\begin{gathered}
\varepsilon_{a}^{e}=\frac{q}{E_{u r}} \\
\varepsilon_{r}^{e}=v_{u r} \frac{q}{E_{u r}}
\end{gathered}
$$

A mesma dependência potencial é apresentada novamente para obter rigidez em relação às compressões unidimensionais usando o módulo edeométrico de $\mathrm{E}_{\mathrm{oed}}$, como mostrado abaixo, onde deve ser notado que a variável $\sigma_{1}{ }_{1}$ é usada em vez de $\sigma_{3}^{\prime}$, por isso em um teste oedométrico esta é a tensão conhecida. O valor do parâmetro $E_{o e d}^{\text {ref }}$, conforme mostrado na Figura 4.10, é o inclinação da linha tangente à curva $\sigma^{\prime}{ }_{1}-\varepsilon_{a}$ para uma tensão de $\sigma^{\prime}$ ref.

$$
E_{\text {oed }}=E_{\text {oed }}^{r e f}\left(\frac{\sigma_{1}^{\prime}+c^{\prime} \cot \varphi^{\prime}}{\sigma_{\text {ref }}^{\prime}+c^{\prime} \cot \varphi^{\prime}}\right)^{m}
$$




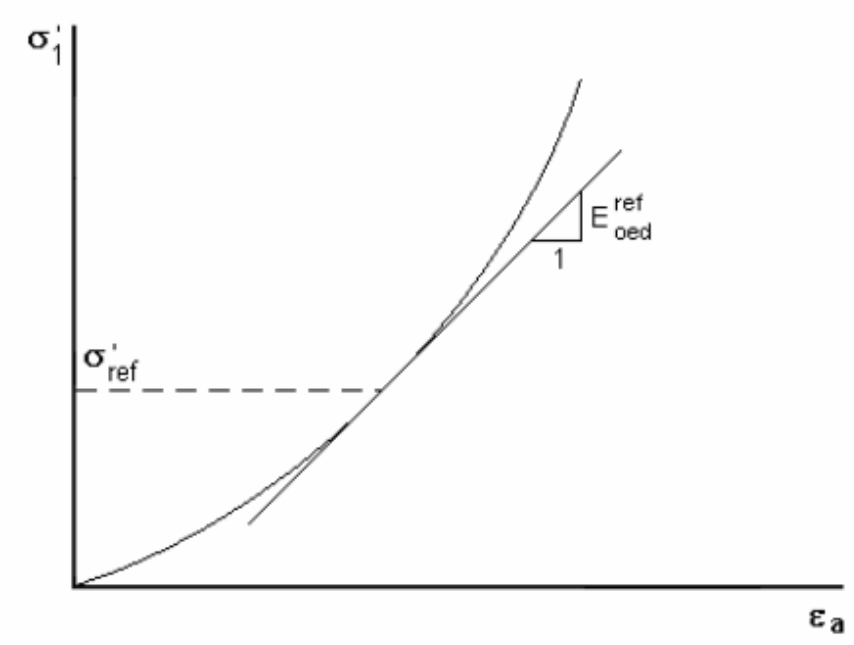

Figura 4.10- Determinação do valor de $\mathrm{E}_{\mathrm{oed}}{ }^{\text {ref }}$ em testes oedométricos.

Como valores médios típicos em vários solos, as seguintes relações orientativas entre $E_{50}$, $E_{u r}$ e $E_{o e d}$ estão disponíveis, embora solos muito rígidos ou muito moles possam ter outras relações.

$$
\begin{aligned}
& E_{\text {ur }} \approx 3 E_{50} \\
& E_{\text {oed }} \approx E_{50}
\end{aligned}
$$

Como nos outros modelos de plasticidade, o Hardening soil mantém uma relação entre a deformação plástica volumétrica $\partial \varepsilon_{p}^{p}$ e a deformação de corte plástica $\partial \varepsilon_{q}{ }^{p}$, por meio da lei de fluência. Esta relação entre implica um ângulo de dilatação $\psi$ que é determinado pela seguinte expressão:

$$
\sin \psi=\frac{\sin \varphi_{m}-\sin \varphi_{c s}}{1-\sin \varphi_{m} \sin \varphi_{c s}}
$$

Um parâmetro final dentro do modelo Hardening-Soil é o coeficiente de pressão lateral do solo para solos $\mathrm{K}_{0}{ }^{\mathrm{nc}}$ consolidados normalmente cujo valor é estimado em 0,5 .

Os parâmetros de entrada do Hardening soil estão resumidos na Tabela 4.5. 
Tabela 4.5- Parâmetros Hardening soil.

\begin{tabular}{|c|l|}
\hline$c$ & Coesão \\
\hline$\varphi$ & Ângulo de atrito interno \\
\hline$\psi$ & Ângulo de dilatação \\
\hline$E_{50}^{r e f}$ & Rigidez de secagem em ensaios triaxiais \\
\hline$E_{\text {oed }}^{r e f}$ & Rigidez da tangente em cargas oedométricas \\
\hline$m$ & Poder de dependência do stress na rigidez \\
\hline$E_{u r}^{r e f}$ & Rigidez na recarga de descarga \\
\hline$v_{u r}$ & Coeficiente de Poisson na recarga de descarga \\
\hline$\sigma_{r e f}^{\prime}$ & Tensão de referência para rigidez \\
\hline$K_{0}^{n c}$ & Coeficiente de pressão no lado do solo \\
\hline$R_{f}$ & Relação entre qf e qa \\
\hline
\end{tabular}

\subsection{3.}

\section{Modelo hardening soil small}

Em geral, a rigidez do solo é caracterizada por um comportamento não linear, dependente de tensão e deformação, isto é, mesmo em um depósito litológico homogêneo do solo, a rigidez do solo varia com a profundidade e seu valor decai com o nível de deformação induzido pelo carregamento. A tensão máxima em que o comportamento do solo pode ser considerado puramente elástico é muito pequena (na ordem de $10^{-6}$ ). A rigidez do solo associada a essa faixa de deformação é indicada como rigidez inicial e seu valor decai aumentando a amplitude de deformação de acordo com a Figura 4.11. 


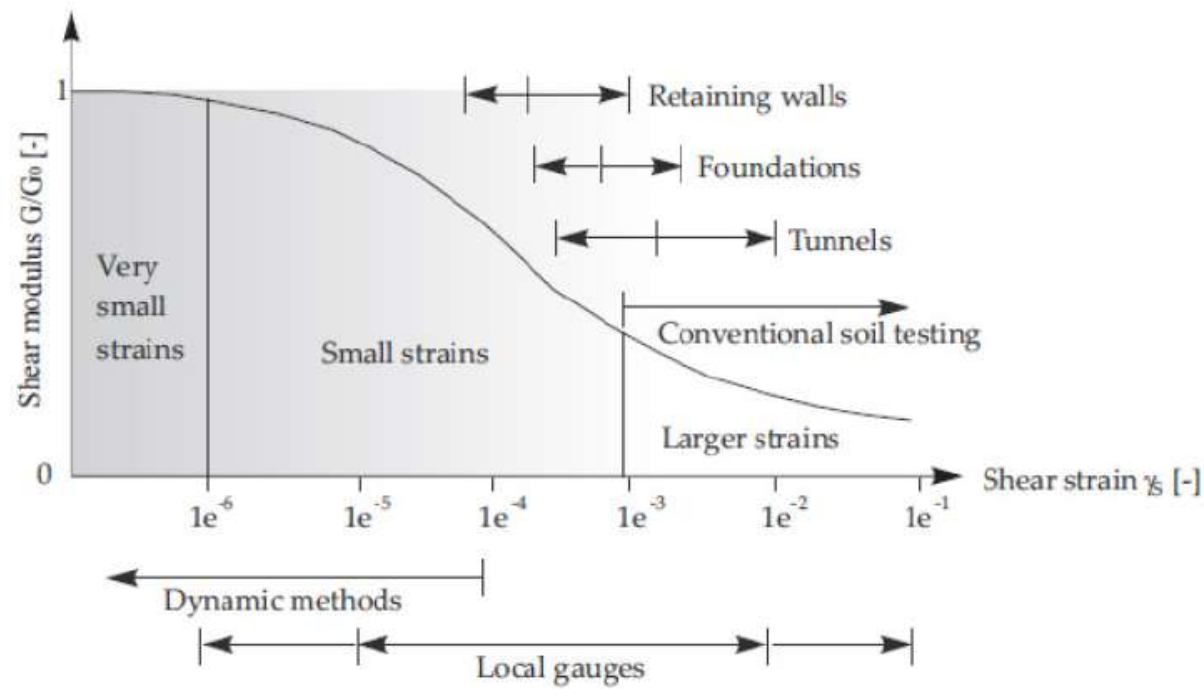

Figura 4.11- Comportamento de rigidez-deformação.

Em condições dinâmicas, o solo é submetido a cargas de cisalhamento cíclico, mostrando não apenas um comportamento não linear, mas também dissipativo. O laço histerético gerado durante o carregamento de cisalhamento cíclico consiste em uma seqüência de carregamento e descarregamento, devido ao comportamento irreversível do solo. Em geral, foi observado que os terremotos induzem um pequeno nível de deformação no solo, que exibe uma alta rigidez de cisalhamento $\mathrm{G}_{0}$, e que $\mathrm{G}$ diminui enquanto a quantidade de energia dissipada aumenta, aumentando a magnitude da deformação de cisalhamento $r$. O modelo Hardening soil já é responsável pela dependência da rigidez de acordo com uma lei de potência expressa pelo parâmetro m.

Comparado ao modelo Hardening soil, o modelo HS small é estendido introduzindo dois parâmetros adicionais que são mantidos também no modelo GHS: a alta rigidez a um pequeno nível de deformação $\left(G_{0}\right)$ e a tensão de cisalhamento na qual $\mathrm{G}$ reduziu para $70 \%$ o inicial $\mathrm{G}_{0}\left(\Upsilon_{0,7}\right)$.

A dependência do estresse é expressa pela seguinte equação:

$$
G_{0}=G_{0}^{r e f}\left(\frac{c \cos \varphi-\sigma_{3}^{\prime} \sin \varphi}{c \cos \varphi+p^{r e f} \sin \varphi}\right)^{m}
$$


onde a rigidez inicial de cisalhamento $\mathrm{G}_{0}$ é uma função da tensão efetiva, dos parâmetros de resistência (c e $\phi$ ) e o parâmetro $m$ que depende do tipo de solo (geralmente varia entre 0,5 e 1 , de acordo com o tipo de solo). O típico comportamento histerético é mostrado na Figura 4.12. A rigidez inicial e a rigidez secante da curva de carga inicial coincidem com a rigidez máxima de cisalhamento $\mathrm{G}_{0}$. Ao aumentar a tensão de cisalhamento, a rigidez decai. Quando a direção da carga é invertida, a rigidez começa a partir do mesmo $\mathrm{G}_{0}$ e diminui até a próxima inversão de carga.

A relação tensão-deformação é dada por:

$$
\tau=G_{S} Y
$$

onde $\mathrm{G}_{\mathrm{s}}$ representa a rigidez de cisalhamento secante.

O módulo de cisalhamento secante dependente de tensão é expresso por:

$$
G_{S}=\frac{G_{0}}{1+0.385 \frac{\gamma}{Y 0.7}}
$$

A razão de amortecimento histerético local é descrita pela seguinte fórmula:

$$
\xi=\frac{E_{D}}{4 \pi E_{S}}
$$

onde $E_{D}$ representa a energia dissipada, dada pela área do circuito fechado (áreas amarelas e verdes), e Es é a energia acumulada na máxima deformação de cisalhamento $\Upsilon_{C}$ (áreas verde e azul). A razão de amortecimento $(\xi)$ se aplica até que o comportamento do material permaneça elástico e o módulo de cisalhamento diminua com a deformação. 


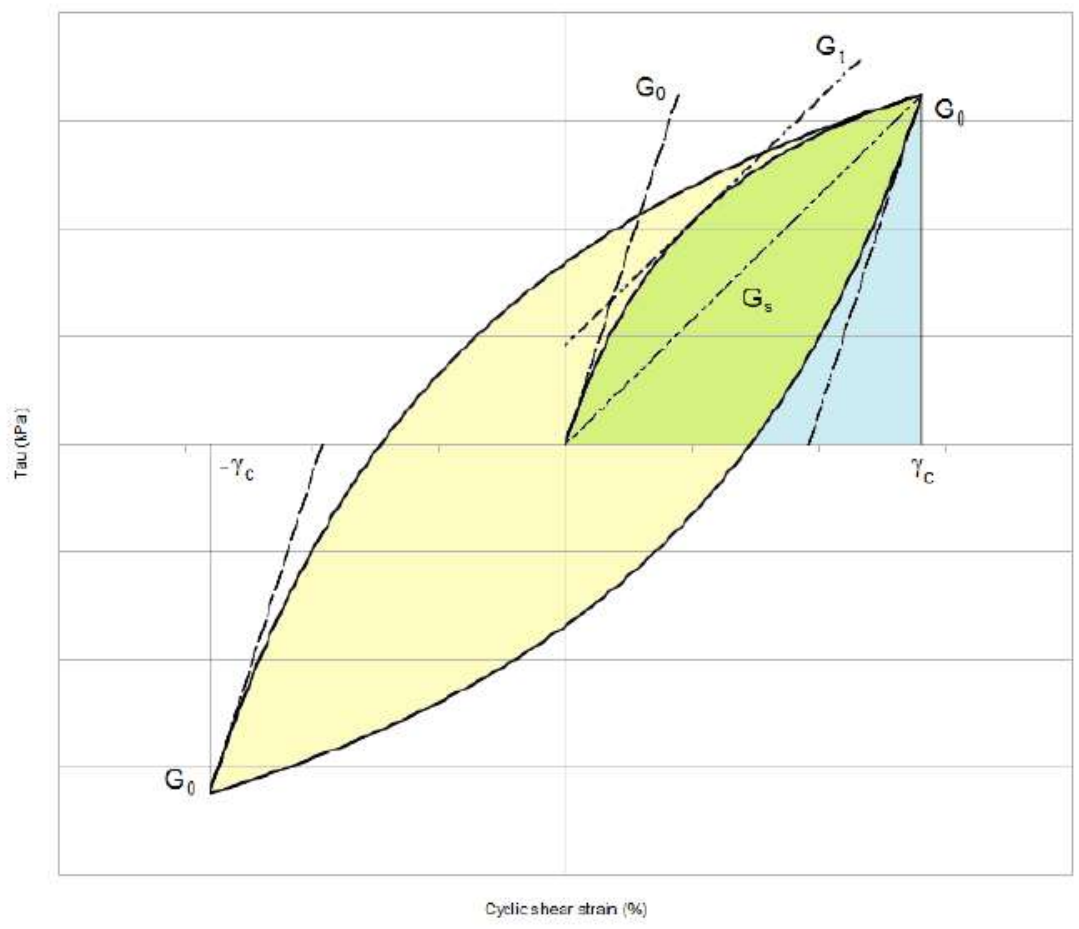

Figura 4.12- Comportamento histerético.

No modelo HS small, o módulo de cisalhamento tangente é limitado por um limite inferior, $\mathrm{G}_{\mathrm{ur}}$, para voltar ao modelo original Hardening soil em níveis mais altos de deformação. Gur está relacionado com $\mathrm{E}_{\mathrm{ur}} \mathrm{e} \mathrm{v}_{\mathrm{ur}}$ de acordo com a seguinte expressão:

$$
G_{u r}=\frac{E_{u r}}{2\left(1+v_{u r}\right)}
$$

A deformação de cisalhamento que corresponde ao ponto em que a rigidez de cisalhamento secante $G_{t}$ atinge o valor de $G_{u r}$ representa a deformação de cisalhamento de corte $\gamma_{\text {cut-off, }}$ isto é, o limite acima do qual a rigidez de cisalhamento não pode diminuir mais do que o valor de $\mathrm{G}_{\mathrm{ur}}$ atingido.

$$
\Upsilon_{c u t-o f f}=\frac{Y_{0.7}}{0.385}\left(\sqrt{\frac{G_{0}}{G_{u r}}}-1\right)
$$

Os parâmetros de entrada do Hardening soil estão resumidos na Tabela 4.6. 
Tabela 4.6- Parâmetros adicionais HS small.

\begin{tabular}{|c|l|}
\hline$Y_{0.7}$ & Coeficiente de Poisson na recarga de descarga \\
\hline$G_{0}^{r e f}$ & Tensão de referência para rigidez \\
\hline$v_{u r}^{\prime}$ & Coeficiente de pressão no lado do solo \\
\hline
\end{tabular}

\subsection{4.}

\section{Modelo UBC3D-PLM (Petalas e Galavi, 2013)}

O modelo UBC3D-PLM foi desenvolvido por Tsegaye (2010) e implementado como um modelo definido pelo usuário no PLAXIS. Está intimamente baseado no modelo theUBCSAND introduzido por Puebla et al. (1997), Beaty e Byrne (1998).

Similarmente ao modelo original da UBCSAND, o UBC3D-PLM é um modelo de tensões efetivas baseado na teoria da plasticidade clássica com uma regra de endurecimento hiperbólico (Figura 4.13). A regra de endurecimento relaciona 0 ângulo de atrito mobilizado com a deformação de cisalhamento plástico para uma determinada tensão. A principal diferença entre o modelo UBCSAND é que o modelo UBC3D-PLM usa o criterio de rendimento de Mohr-Coulomb (Figura 4.16) em um espaço de tensões principais 3D. Além disso, é utilizada uma função de potencial plástico não-associado modificada, baseada no critério de DruckerPrager. Na versão atual uma regra de densificação do solo foi adicionada para prever uma evolução mais realista do excesso de poropressão durante 0 carregamento cíclico. Isso permite o aumento das deformações volumétricas com uma taxa decrescente durante o cisalhamento. Além disso, o módulo volumetrico da água é dependente do grau de saturação que é especificado via entrada PLAXIS.

O modelo UBC3D-PLM foi desenvolvido para simular o comportamento dinâmico de solos não-coesivos e é particularmente adequado para analisar os problemas envolvendo a geração de poropressão em comportamento nãodrenado e liquefação. Pelo mesmo motivo, é menos adequado para uso em análise estática. Embora seja um modelo avançado, é relativamente simples de aplicar, pois possui um número razoável de parâmetros que podem ser extraídos de testes laboratoriais ou in situ. 


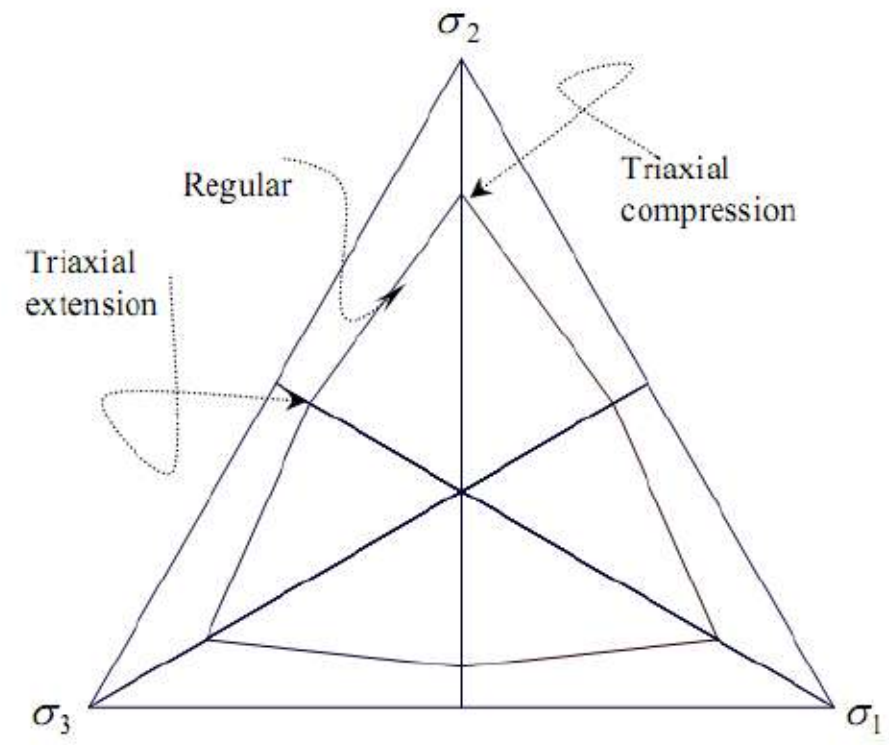

Figura 4.13- Projeção da superfície de escoamento no plano do desvio. Depois de Tsegaye (2010) (Petalas e Galavi, 2013).

O primeiro passo que deve ser feito pelo modelo é calcular as tensões principais do tensor de tensão. Isso é feito depois de resolver o problema do autovalor. Os autovalores fornecem as tensões principais e os autovetores serão suas direções. No que diz respeito ao comportamento isotrópico, as direções das tensões principais são xed (a rotação das tensões principais não é incluída no UBC3D-PLM), de modo que a resposta do material não é dependente da orientação. Após a determinação das três tensões principais, a superfície de produção deve ser definida. Considerando qualquer trajetória de tensão no espaço generalizado de tensão 3-D visualizado no plano de desvio, a superfície de rendimento que será ativada é dada pela equação na qual a diferença máxima entre duas tensões principais está sendo usada. A superfície de rendimento crítico no modelo é dada pela Equação 4.26:

$$
f_{m}=\frac{\sigma_{\max }^{\prime}-\sigma_{\min }^{\prime}}{2}-\left(\frac{\sigma_{\max }^{\prime}-\sigma_{\min }^{\prime}}{2}+c^{\prime} \cot \varphi_{P}^{\prime}\right) \sin \varphi_{m o b}
$$

onde $\sigma_{\max }^{\prime}$ e $\sigma_{\text {min }}^{\prime}$ são as tensões principais máximas e mínimas, $\phi_{p}^{\prime}$ e $\phi_{\text {mob }}$ são os ângulos de atrito máximos e mobilizados respectivamente e c' é a coesão. 
O comportamento elástico é assumido como isotrópico e expresso em termos de volume elástico e módulo de cisalhamento, conforme descrito pelas seguintes equações:

$$
\begin{aligned}
& K_{B}^{e}=k_{B}^{e} P_{A}\left(\frac{p^{\prime}}{P_{A}}\right)^{m e} \\
& K_{G}^{e}=k_{G}^{e} P_{A}\left(\frac{p^{\prime}}{P_{A}}\right)^{n e}
\end{aligned}
$$

onde $K_{B}^{e}$ e $K_{G}^{e}$ são o volume e o módulo de cisalhamento, respectivamente, em um nível de tensão de referência. Os fatores ne e me são parâmetros de ne taxa de dependência de tensão de rigidez. Na literatura, o nível de estresse de referência $\left(p_{\text {ref }}\right)$ é comumente tomado como a pressão atmosférica $(P A=100 \mathrm{kPa})$. O comportamento elástico puro é previsto pelo modelo durante o processo de descarga.

A regra de endurecimento hiperbólico (Beaty e Byrne, 1998) é apresentada esquematicamente na Figura 4.14. Relaciona o incremento do seno do ângulo de atrito mobilizado ao incremento da tensão de cisalhamento de plástico como segue (Puebla et al., 1997):

$$
\begin{gathered}
\delta_{Y}^{p}=\frac{1}{G^{*}} \delta \sin \varphi_{m o b} \\
G^{*}=k_{G}^{p}\left(\frac{p^{\prime}}{P_{A}}\right)^{n p}\left\{\left(1-\frac{\sin \varphi_{m o b}}{\sin \varphi_{P}^{\prime}}\right) R_{f}\right\}^{2}
\end{gathered}
$$

onde $k_{G}^{p}$ é o número do módulo de cisalhamento de plástico; np é o expoente do módulo de cisalhamento de plástico; $\phi_{\text {mob }}$ é o ângulo de atrito mobilizado, que é definido pela razão de tensão; $\phi_{\text {peak }}$ é o ângulo de atrito do pico; e $R_{f}$ é a razão de falha $n_{f} / n_{\text {ult, }}$ variando de 0.5 a 1.0 , onde $n_{f}$ é a razão de tensão na falha e nult é a razão de tensão assintótica da hipérbole de melhor ajuste.

A regra de endurecimento reformulada por Tsegaye (2010) no modelo UBC3D-PLM é dada como: 


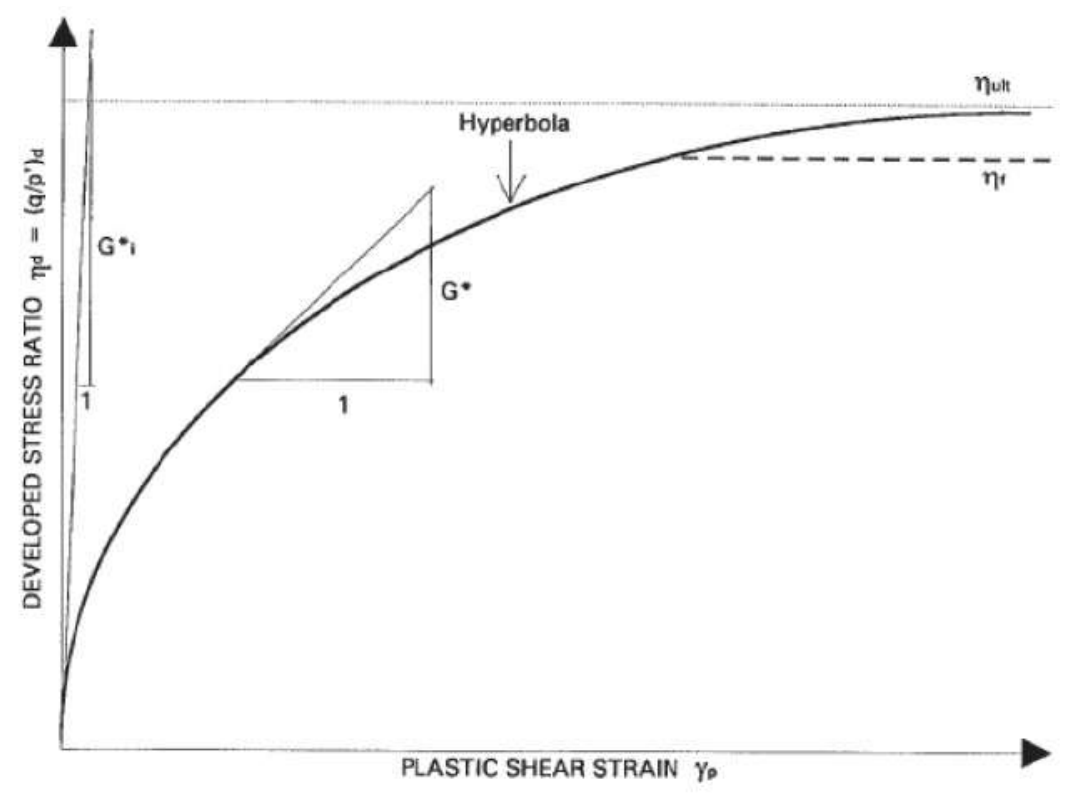

Figura 4.14- Regra de endurecimento da UBCSAND original de Beaty e Byrne (1998) (Petalas e Galavi, 2013).

A função potencial plástica é baseada em Drucker Prager e é formulada como:

$$
\begin{gathered}
g=q-\alpha\left(p^{\prime}+c \cot \varphi_{p}\right) \\
\alpha=\frac{\sqrt{3} \sin \psi_{m}}{\cos \theta+\frac{\sin \theta \sin \psi}{\sqrt{3}}}
\end{gathered}
$$

Onde $\theta$ é igual a $30^{\circ}$ porque a superfície de Drucker-Prager é fixada no ponto de compressão.

A regra de fluxo é dada pela seguinte equação:

$$
\begin{aligned}
d \varepsilon_{v} & =\sin \psi_{m} d Y_{p} \\
\sin \psi_{m} & =\sin \varphi_{m}-\sin \varphi_{p}
\end{aligned}
$$

onde, $d \varepsilon_{v}^{p}$ é o incremento de tensão volumétrica de plástico e $\phi_{\mathrm{p}}$ é o ângulo de atrito máximo. 
A regra de densificação é implementada em UBC3D por uma superfície de rendimento secundário para a qual uma regra simplificada de endurecimento cinemático é usada. Para carregamento secundário, o módulo de cisalhamento de plástico é aumentado após cada ciclo de carga de acordo com a seguinte regra de densificação:

$$
K_{G}^{p}=K_{G}^{p}\left(4+\frac{n_{\text {cross }}}{2}\right) \text { hard fac } \text { hard }_{\text {in }}
$$

onde $\mathrm{n}_{\text {cross }}$ é o número de reversões de tensão de cisalhamento de carga para descarga ou vice-versa, hard é um fator que está corrigindo a regra de densidade para solos soltos e fachard é um multiplicador que é um parâmetro de entrada do usuário para ajustar a regra de densidade.

O UBC3D-PLM é um modelo descritivo, portanto seus parâmetros são derivados por ajuste de curva a partir de testes de laboratório no mesmo material. A calibração do caminho de tensão adequado é de grande importância, a fim de obter uma solução precisa. Neste caso, os testes mais adequados são drenados testes de cisalhamento simples. No entanto, os resultados dos testes DSS para os mesmos materiais nem sempre são possíveis de encontrar. Nesse caso, existem várias correlações para a aquisição dos parâmetros de entrada, seja de resultados de testes triaxiais ou de resultados de SPT.

Os parâmetros de entrada do UBC3D-PLM estão resumidos na Tabela 4.7. 
Tabela 4.7- Parâmetros UBC3D-PLM.

\begin{tabular}{|c|l|}
\hline$\varphi_{C V}$ & o ângulo de atrito de volume constante \\
\hline$\varphi_{P}$ & o ângulo de atrito máximo \\
\hline$c^{\prime}$ & a coesão do solo \\
\hline$K_{B}^{e}$ & o módulo volumetrico elástico do solo no nível de referência PA = 100kPa \\
\hline$K_{G}^{e}$ & o módulo elástico de cisalhamento no nível de referência PA = 100kPa \\
\hline$K_{G}^{p}$ & o módulo de cisalhamento de plástico drenado \\
\hline$m e$ & o expoente do módulo volumétrico elástico \\
\hline$n e$ & o expoente do módulo elástico de cisalhamento \\
\hline$n p$ & o expoente do módulo de cisalhamento de plástico \\
\hline$R_{f}$ & a relação de falha \\
\hline$f a c_{h a r d}$ & o fator de densificação \\
\hline$\left(N_{1}\right)_{60}$ & o valor do SPT corrigido \\
\hline$f a c_{p o s t}$ & $\begin{array}{l}\text { um fator que determina o valor mínimo do módulo de cisalhamento durante a } \\
\text { degradação da rigidez }\end{array}$ \\
\hline$P_{A}$ & a tensão de referência que é igual à pressão atmosférica \\
\hline
\end{tabular}

\subsection{5.}

\section{Correlações de SPT com parâmetros UBCSAND}

Da mesma forma que a maioria dos modelos de liquefação, o UBC3D-PLM é um modelo descritivo e os parâmetros do modelo são determinados por ajuste de curva, preferencialmente a partir de testes de cisalhamento direto não drenado cíclico (DSS). No entanto, em muitos casos, esses testes não estão disponíveis e existem dados de testes in situ, como testes de Penetração Padrão (SPT) ou de Cone Penetration (CPT). Parâmetros para o modelo UBC3D-PLM podem ser determinados a partir de testes SPT de acordo com as seguintes correlações (Beaty e Byrne, 2011) onde $\left(N_{1}\right)_{60}$ é a contagem de sopro normalizada a uma pressão de aproximadamente $100 \mathrm{kPa}$ e uma eficiência de martelo de $60 \%$.

Essas correlações são as seguintes:

$$
\begin{gathered}
k_{G}^{e}=21.7 * 20.0 *\left(N_{1}\right)_{60}^{0.333} \\
k_{B}^{e}=k_{G}^{e} * 0.7 \\
k_{G}^{p}=k_{G}^{e} *\left(N_{1}\right)_{60}^{2} * 0.003+100.0
\end{gathered}
$$




$$
\varphi_{p}=\varphi_{c v}+\frac{\left(N_{1}\right)_{60}}{10.0}
$$

onde $\varphi_{p}$ é o ângulo de atrito máximo para $\left(\mathrm{N}_{1}\right)_{60}$ valores menores que 15 , enquanto para maiores é sugerido um acréscimo adicional como descrito pela relação (4.43):

$$
\varphi_{p}=\varphi_{p i}+\max \left(0.0, \frac{\left(N_{1}\right)_{60}-15}{5}\right)
$$

Os valores em me e ne são considerados iguais a 0,5 e o valor de $\mathrm{np}$ igual a 0,4 por padrão. Para a taxa de falha, aplica-se a seguinte correlação:

$$
R_{f}=1.1\left(N_{1}\right)_{60}^{-0.15}
$$

contanto que o valor de ocorrência seja menor que 0,99, caso contrário, um valor de 0,99 é usado. Em relação ao fator de densificação (fachard), o valor sugerido para o UBCSAND é 1.0 .

A partir da equação (4.3), uma relação direta entre o cisalhamento elástico e o módulo volumetrico é derivada, o que corresponde a uma razão de Poisson de 0,02 da teoria da elasticidade. Esse índice é muito baixo para cálculos estáticos e levaria a resultados irrealistas. No entanto, foi demonstrado (Hardin 1978, Negussey, 1984) que a razão de Poisson varia com a deformação e que, para as pequenas deformações, seu valor pode variar entre 0,0 e 0,2. Por essa razão, para cálculos dinâmicos, uma proporção de Poisson muito menor pode ser usada, da mesma forma que o módulo de tensão de cisalhamento pequena é usado. Ainda assim, a hipótese está no lado baixo, uma vez que a suposição usual para as areias é de aproximadamente 0,1 (Byrne et al, 1987). Para resolver os problemas que podem ocorrer nas análises estáticas, sugere-se usar uma calibragem diferente do modelo ou um modelo constitutivo diferente para eles.

Embora existam semelhanças significativas entre o modelo UBCSAND e o UBC3D-PLM, os modelos não são idênticos e essas correlações não podem ser usadas diretamente para o UBC3D-PLM sem validação. No entanto, eles constituem um ponto de partida muito bom para determinar as correlações adequadas para o UBC3D-PLM. 


\section{4.}

\section{Fenómeno de Liquefação}

O primeiro pesquisador em usar o termo liquefação foi Hazen (1920) para descrever a falha da barragem Calaveras, Califórnia. Porém, segundo o Kramer (1996), expressa que foram Mogami e Kubo (1953) os primeiros em falar de liquefação. Este fenómeno começou a ser estudado profundamente por os engenheiros geotécnicos a partir do terremoto que aconteceu no Alaska ( $\mathrm{Mw}=9.2)$ em 1964 (Kramer, 1996).

De acordo com Kramer (1996) o termo liquefação está associado a deformações do solo causadas por perturbações monotônicas, transitórias ou repetidas de solos saturados sem coesão sob condições não drenadas. A geração de excessos de poropressão sob carregamento em condições não drenadas é selho distintivo do fenómeno de liquefação. De acordo com Jefferies e Been (2006), a liquefação do solo é um fenómeno em que o solo perde grande parte de sua resistência ou rigidez por um curto período de tempo, mas ainda assim é tempo suficiente para que a liquefação seja a causa de muitos fracassos, mortes e perdas financeiras.

\subsection{1.}

\section{Suscetibilidade à liquefação}

De acordo com Kramer (1996), para avaliar o potencial de liquefação em um solo, deve primeiro ser avaliado a suscetibilidade desse a liquefaçer. Se o solo não é suscetível a avaliação finaliza, mas se existe suscetibilidade então deve avaliar-se o inicio da liquefação e seus possíveis efeitos.

Existem critérios de para avaliar a suscetibilidade à liquefação dos solos, estos critérios estão baseados em observações de campo e ensaios de laboratório. A continuação são apresentados os mais conhecidos:

- Critério histórico fundamentado nos casos históricos que podem ajudar a identificar áreas específicas que apresentam evidências de fenômenos de liquefação anteriores.

- Critério geológico, que avalia o ambiente de deposição, o ambiente hidrogeológico e a idade do depósito do solo. 
- Critério de composição, pelo qual se analisa a forma, o tamanho e a gradação das partículas que conformam o solo.

- Critérios de estado, onde se especifica o estado inicial do depósito de solo, podendo-se avaliar por meio do índice de vazios crítico, o estado permanente de deformação ou o parâmetro de estado.

\subsubsection{Parâmetro de estado}

A natureza de SSL amostra aplicabilidade na caracterização do potencial de liquefação com medições de densidade, índice de vazios e densidade relativa. Para o caso de um elemento de solo com específico índice de vazios (i.e. de terminada densidade relativa) pode ser suscetível à liquefação sob altas tensões confinantes mas não suscetível caso estas sejam baixas (Kramer, 1996; Cárdenas, 2008).

Been e Jefferies (1985), definiram o conceito de parâmetro de estado, sendo definido por:

$$
\psi=e_{0}-e_{s s}
$$

Onde $e_{S S}$ é o índice de vazios na condição de estado permanente sob a tensão de confinamento efetiva de interesse (Figura 4.15).

De acordo com Kramer (1996), quando $\psi$ for positivo, o solo exibe comportamento contrativo e pode ser suscetível à liquefação, enquanto que para valores negativos de $\psi$ a variação volumétrica é negativa (dilatação) e o solo não é considerado suscetível ao fluxo por liquefação. 


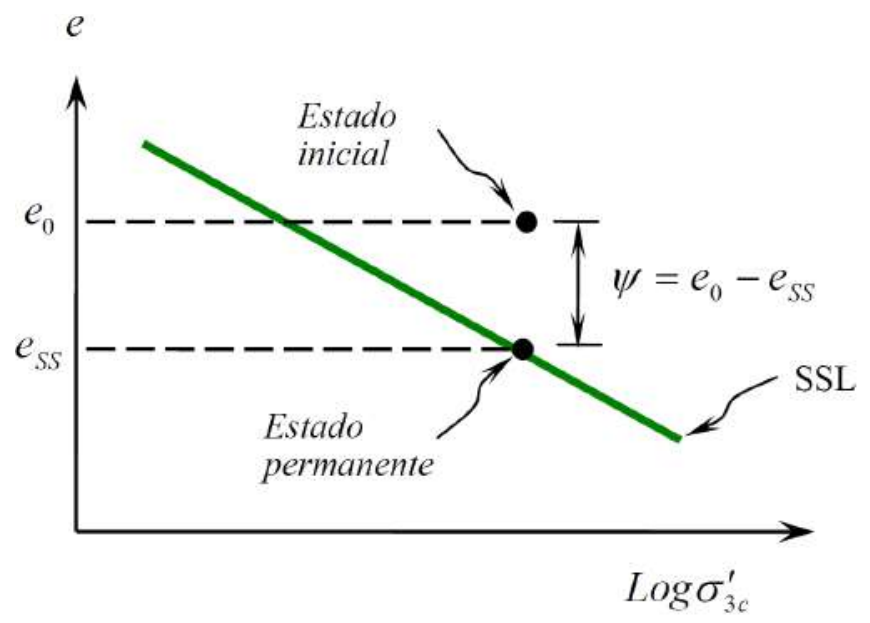

Figura 4.15- Definição do parâmetro de estado $\psi$ (adaptado Kramer, 1996).

\subsection{3.}

\section{Avaliação do potencial de liquefação}

O potencial de liquefação é uma medida quantitativa da susceptibilidade à liquefação e pode ser calculado como a razão entre a solicitação de carregamento cíclico e a resistência cíclica. Em outras palavras, é o inverso do fator de segurança $\left(F S_{L}\right)$ que pode ser estimado como:

$$
F S_{L}=\frac{\text { Tensão cisalhante requerida para causar liquefação }}{\text { Tensão cisalhante cíclica equivalente induzida pelo sismo }}=\frac{C R H}{C S H}(4.43
$$

Portanto, este fenômeno só ocorrerá para um potencial de liquefação maior que 1.

Poulos et al. (1985) afirmam que a determinação do potencial de liquefação é uma análise de estabilidade que requer dados da resistência ao cisalhamento e as tensões de cisalhamento in situ.

\subsubsection{1.}

\section{Métodos de campo}

De acordo com Daftari (2015), o uso de ensaios de campo é o principal método na prática de engenharia comum na avaliação do potencial de liquefação. O cálculo de duas variáveis é necessário para avaliar a resistência a liquefação dos solos. Eles são os siguentes: CSR (razão de tensão cíclica) e CRR (razão da 
resistência cíclica). Na Tabela 4.8 é apresentado uma comparação entre as vantagens e desvantagens dos ensaios de campo para avaliar liquefação.Os principais métodos de campo são apresentados a continuação:

\section{Métodos baseados em SPT}

O ensaio SPT (standard penetration test) é um dos mais usados na mecânica dos solos e engenharia geotécnica. Este ensaio é utilizado para avaliar a resistência à penetração de solos. A partir dos resultados deste ensaio, muitos pesquisadores estabeleceram correlações com outros parâmetros dos solos. Os números de golpes $(\mathrm{N})$ é normalizado para sobrecarregamento de $100 \mathrm{kPa}$ e eficiência da energia do martelo a $60 \%$. Em consequência é necessário fazer correções em função do FC (fração fina) e para areias limpas equivalentes. De acordo com Youd et al. (2001), as correções são dadas pelas equações (4.44).

Tabela 4.8- Comparação das vantagens e desvantagens de vários testes de campo para avaliação da resistência à liquefação (Hurtado, 2009).

\begin{tabular}{|c|c|c|c|c|}
\hline \multirow{2}{*}{ Característica } & \multicolumn{4}{|c|}{ Tipo de Teste } \\
\hline & SPT & CPT & Vs & BPT \\
\hline $\begin{array}{l}\text { Medições passadas em } \\
\text { zonas com liquefação }\end{array}$ & Abundante & Abundante & Limitado & Escasso \\
\hline $\begin{array}{l}\text { Tipo do comportamento } \\
\text { tensão-deformação } \\
\text { influenciando o teste }\end{array}$ & $\begin{array}{l}\text { Parcialmente } \\
\text { drenado, } \\
\text { grandes } \\
\text { deformações }\end{array}$ & $\begin{array}{c}\text { Drenado, } \\
\text { grandes } \\
\text { deformações }\end{array}$ & $\begin{array}{l}\text { Pequenas } \\
\text { deformações }\end{array}$ & $\begin{array}{l}\text { Parcialmente } \\
\text { drenado, grandes } \\
\text { deformações }\end{array}$ \\
\hline $\begin{array}{l}\text { Controle da qualidade e } \\
\text { repetibilidade }\end{array}$ & Pobre a boa & Muito boa & Boa & Pobre \\
\hline $\begin{array}{l}\text { Detecção da variabilidade } \\
\text { do depósito de solo }\end{array}$ & $\begin{array}{c}\text { Boa para testes } \\
\text { pouco } \\
\text { espaçados } \\
\end{array}$ & Muito boa & Aceitável & Aceitável \\
\hline $\begin{array}{l}\text { Tipo de solo na qual o } \\
\text { teste é recomendado }\end{array}$ & Não gravoso & Não gravoso & Todos & $\begin{array}{l}\text { Principalmente } \\
\text { gravoso }\end{array}$ \\
\hline $\begin{array}{c}\text { Toma das amostras de } \\
\text { solo }\end{array}$ & Sim & Não & Não & Não \\
\hline $\begin{array}{c}\text { Medição de propriedades } \\
\text { índice ou de engenharia }\end{array}$ & Índice & Índice & Engenharia & Índice \\
\hline
\end{tabular}

$$
\left(\mathrm{N}_{1}\right)_{60 \mathrm{cs}}=\alpha+\beta \times\left(\mathrm{N}_{1}\right)_{60}
$$

Onde:

$\alpha=0$ for $F C \leq 5 \%$

$\alpha=\operatorname{Exp}\left[1,76-\left(190 / \mathrm{FC}^{2}\right)\right]$ for $5 \%<\mathrm{FC}<35 \%$

$\alpha=5$ for $\mathrm{FC} \geq 35 \%$

$\beta=1$ for $\mathrm{FC}_{\leq} \mathrm{5} \%$ 
$\beta=\left[0,99+\left(\mathrm{FC}^{1,5} / 1000\right)\right]$ for $5 \%<\mathrm{FC}<35 \%$

$\beta=1,2$ for $F C \geq 35 \%$

Os principais métodos utilizados na atualidade são os siguentes:

\section{a) Método Youd et al. (2001):}

A metodologia de Youd et al. (2001) consiste em avaliar o potencial de liquefação com base em resultados de ensaios de campo (SPT), em função dos valores de $\left(N_{1}\right)_{60}$, com correção da porcentagem de finos. As equações (4.45) a (4.48) permitem calcular o fator de segurança contra a ruptura por liquefação $\mathrm{FS}_{\mathrm{CL}}$.

$$
\begin{aligned}
& \operatorname{CSR}=\left(\frac{\tau_{\mathrm{av}}}{\sigma_{\mathrm{vo}}^{\prime}}\right)=0,65 \times\left(\frac{\mathrm{a}_{\mathrm{max}}}{\mathrm{g}}\right) \times\left(\frac{\sigma_{\mathrm{vo}}}{\sigma_{\mathrm{vo}}^{\prime}}\right) \times \mathrm{r}_{\mathrm{d}} \\
& \mathrm{CRR}_{7,5}=\frac{1}{34-\left(\mathrm{N}_{1}\right)_{60}}+\frac{\left(\mathrm{N}_{1}\right)_{60}}{135}+\frac{50}{\left[10 \times\left(\mathrm{N}_{1}\right)_{60}+45\right]^{2}}-\frac{1}{200} \\
& \mathrm{MSF}=\frac{10^{2,24}}{\mathrm{M}_{\mathrm{w}}^{2,56}} \\
& \mathrm{FS}_{\mathrm{CL}}=\left(\frac{\mathrm{CRR}_{7,5}}{\mathrm{CSR}}\right) \times \mathrm{MSF}
\end{aligned}
$$

Onde CSR é a razão de tensão cíclica, $\tau_{a v}$ a tensão cisalhante cíclica média, $a_{\max }$ a aceleração horizontal máxima, $\sigma_{\mathrm{vo}}$ e $\sigma^{\prime}$ vo as tensões verticais iniciais total e efetiva, respectivamente, $r_{d}$ um coeficiente de redução de CSR com a profundidade, CRR a razão de resistência cíclica, $\left(\mathrm{N}_{1}\right)_{60}$ o número de golpes corrigido do ensaio de simples reconhecimento SPT, MSF o fator de escala de magnitude, $M_{w}$ a magnitude momento e $F S_{C L}$ o fator de segurança contra a ruptura por liquefação.

\section{b) Método Boulanger e Idriss (2014):}

Boulanger e Idriss (2014) desenvolveram um método simplificado similar ao método de Youd et al. (2001), expresso pelas equações (4.49) a (4.53), com o objetivo de também determinar o fator de segurança contra a ruptura por liquefação, baseado nos valores de $\left(\mathrm{N}_{1}\right)_{60}$ do ensaio de simples reconhecimento SPT. 


$$
\begin{aligned}
& \mathrm{CRR}_{7,5}=\exp \left[\frac{\left(\mathrm{N}_{1}\right)_{60 \mathrm{cs}}}{14,1}+\left(\frac{\left(\mathrm{N}_{1}\right)_{60 \mathrm{cs}}}{126}\right)^{2}-\left(\frac{\left(\mathrm{N}_{1}\right)_{60 \mathrm{cs}}}{23,6}\right)^{3}+\left(\frac{\left(\mathrm{N}_{1}\right)_{60 \mathrm{cs}}}{25,4}\right)^{4}-2,8\right] \\
& \mathrm{MSF}=1+\left(\mathrm{MSF}_{\max }-1\right) \times\left[8,64 \exp \left(\frac{-\mathrm{M}_{\mathrm{w}}}{4}\right)-1,325\right] \\
& \mathrm{C}_{\sigma}=\frac{1}{18,9-2,55 \times \sqrt{\left(\mathrm{N}_{1}\right)_{60 \mathrm{cs}}}} \leq 0,3 \\
& \mathrm{~K}_{\sigma}=1-\mathrm{C}_{\sigma} \times \ln \left(\frac{\sigma_{\mathrm{v}}^{\prime}}{\mathrm{P}_{\mathrm{a}}}\right) \leq 1,1 \\
& \mathrm{FS}_{\mathrm{CL}}=\left(\frac{\mathrm{CRR}}{\mathrm{CSR}}\right) \times \mathrm{MSF} \times \mathrm{K}_{\sigma}
\end{aligned}
$$

Onde $\left(\mathrm{N}_{1}\right)_{60 \text { cs }}$ é o número de golpes do ensaio SPT ajustado ao equivalente em areia limpa e $\mathrm{K}_{\sigma}$ um fator de correção devido ao carregamento do solo. $\mathrm{C}_{\sigma}$ é um coeficiente em função de $\left(\mathrm{N}_{1}\right)_{60 c s}$. $\mathrm{MSF}_{\max }$ para areia é 1,8. Na Figura 4.16 é apresentado resultados de casos históricos de liquefação na qual relaciona $\left(\mathrm{N}_{1}\right)_{60}$ com o valor de CSR.

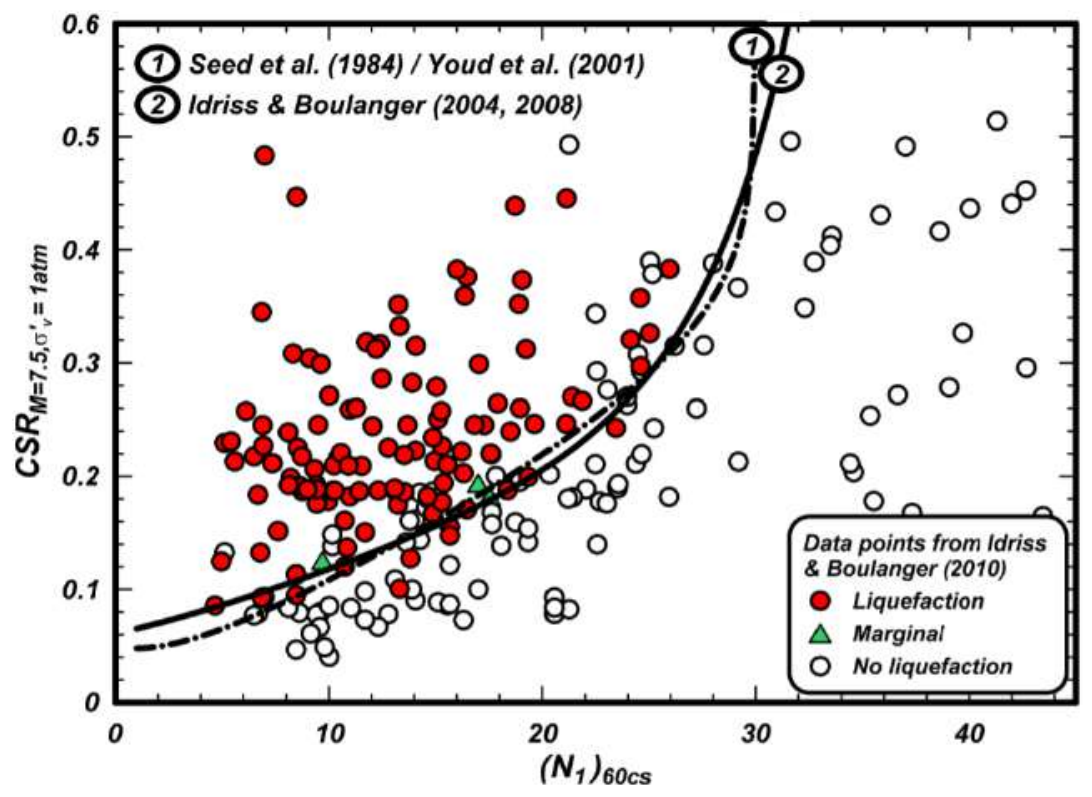

Figura 4.16- Exemplos de curvas de inicio de liquefação baseadas em SPT, inclui os resultados de Youd et al. (2001). (Idriss e Boulanger, 2014). 


\subsubsection{2. \\ Métodos de laboratório}

\section{Ensaio triaxial cíclico}

Os ensaios triaxiais cíclicos são comunmente utilizados para obter as propriedades dinâmicas dos solos a grandes níveis de deformação. Além também estos ensaios conseguem simular o fenómeno de liquefação em solos saturados ante carregamentos cíclicos cisalhantes em condições não drenadas (Daftari, 2015).

Os primeiros pesquisadores em avaliar o fenómeno de liquefação em ensaios triaxiais cíclicos foram See e Lee (1966), avaliaram areias fofas e densas para índice de vazios altos e baixos. Em consequência, pesquisadores continuaram avaliando a liquefação em ensaios triaxiais cíclicos: Castro (1969), Mohamad e Dobry (1986), Sitharam et al. (2004), Ghionna e Porcino (2006), Rangaswamy et al. (2010), Sesov et al. (2012) e Liu e Chang (2017).

\section{Ensaio de cisalhamento direto cíclico}

De acordo com Daftari (2015), o ensaio de cisalhamento direto cíclico reproduz melhor as condições de tensão de um terremoto melhor que um ensaio triaxial cíclico. Este ensaio é comunmente utilizado na avaliação do potencial de liquefação dinâmica em solos. Neste ensaio, uma amostra de solo cilíndrica é restringida contra expansão lateral por placas rígidas e a amostra é envolvida por uma membrana. Ao aplicar tensões de cisalhamento horizontais cíclicas na parte superior ou inferior da amostra, a amostra é deformada da mesma maneira que um elemento de solo submetido a ondas $S$ de propagação vertical.

Peacock e Seed (1968) foram um dos primeiros pesquisadores em trabalhar com ensaios de cisalhamento cíclico para estudar o fenómeno de liquefação. Anos recentes foram publicados trabalhos desenvolvidos pelos seguintes autores: Finn (1985), Sivathayalan (1994), Kammerer et al. (2001) e Wijewickreme e Sanin (2004).

\section{Ensaio centrifuga}

De acordo com Daftari (2015), o ensaio centrifuga tenta reproduzir a condição de contorno e propriedades do material no campo por um modelo físico de pequena escala. Pode ser usado para avaliar o desmpenho de um protótipo ou 
verificar teorias preditivas (modelos constitutivos). Este ensaio é um método útil para estudar o comportamento dinâmico das estruturas de terra e fundações. objetivo do ensaio é submeter a estrutura de solo a pequena escala a uma aceleração centrifuga típica entre 30-200g.

De acordo com Bertalot (2012), a modelagem de terremotos pelo ensaio centrifuga começou no final dos anos 70s na Inglaterra por Morris (1979). Anos mais recentes, os pesquisadores utilizam este ensaio na avaliação do fenómeno de liquefação: Scott (1986), Hushmand et al. (1988), Sharp et al. (2000), Adalier e Elgamal (2005) e Madabhushi et al. (2016).

\subsection{4.}

\section{Resistência cisalhante não drenada residual}

Olson \& Stark (2002) definem a resistência ao cisalhamento do solo liquefeito (liquefied shear strength, $s_{u}(L I Q)$ ) como a resistência ao cisalhamento mobilizada a grandes deformações depois que o solo arenoso, contráctil e saturado se liqüefaz, sendo diferente da resistência ao cisalhamento de um solo no início da liquefação, a qual é chamada de resistência ao cisalhamento na etapa de escoamento (yield shear strength).

A $s_{u}(L I Q)$ foi citada por Poulos et al. (1985) como a resistência cisalhante não drenada no estado permanente $S_{u s}$ (undrained steady-state shear strength). Stark \& Mesri (1992) nomearam-na de resistência ao cisalhamento não drenada crítica $s_{u}$ (critical) (undrained critical shear strength) e de acordo com Olson \& Stark (2002), Seed (1987) a define como a resistência ao cisalhamento não drenada residual $s_{r}$ (undrained residual shear strength).

\subsubsection{1.}

\section{Idriss \& Boulanger (2007)}

A Figura 4.17 mostra dois relacionamentos diferentes para estimar $S$ no design. Eles são essencialmente os mesmos para valores de (N1) 60cs-Sr menores que cerca de 12, onde ambos são restringidos pelos dados disponíveis. No entanto, é necessário estimar as resistências residuais para solos com valores de (N1) 60cs-Sr maiores que 14 e, portanto, a extrapolação da correlação de resistência residual além dos limites dos dados disponíveis é inevitável. As duas 
relações mostradas na Figura 89 fornecem orientação sobre essa extrapolação para duas condições.

A relação superior na Figura 4.17 corresponde a uma condição na qual os efeitos da redistribuição de vazios podem ser julgados confidencialmente como insignificantes. Esta condição pode incluir locais onde a estratigrafia não impediria a dissipação pós-terremoto das pressões de excesso de água, portanto a dissipação das pressões de poros em excesso seria acompanhada pela densificação dos solos em todas as profundidades. Neste caso, os dados experimentais disponíveis e as correlações entre DR e $\left(N_{1}\right)_{60}$ para areias limpas e areias com finos indicam que a resistência ao cisalhamento não-drenada aumentaria rapidamente à medida que o valor $\left(\mathrm{N}_{1}\right)_{60 c s-s r}$ se aproximasse 15 . Essa relação pode ser representada pela seguinte equação:

$$
\begin{gathered}
\frac{S_{r}}{\sigma_{v 0}^{\prime}}=\exp \left(\frac{\left(N_{1}\right)_{60 C S-S r}}{16}+\left(\frac{\left(N_{1}\right)_{60 C S-S r}-16}{21.2}\right)^{3}-3.0\right)(1 \\
\left.+\exp \left(\frac{\left(N_{1}\right)_{60 C S-S r}}{2.4}-6.6\right)\right) \leq \tan \varphi^{\prime}
\end{gathered}
$$

A relação mais baixa na Figura 4.17 corresponde às condições em que os efeitos da redistribuição de vazios podem ser significativos. Isso incluiria locais com camadas relativamente espessas de solos liquefiáveis que são superpostos por solos de baixa permeabilidade que impediriam a dissipação pós-terremoto das pressões de água porosas induzidas por terremotos. Essa relação pode ser representada pela seguinte equação:

$$
\frac{S_{r}}{\sigma_{v 0}^{\prime}}=\exp \left(\frac{\left(N_{1}\right)_{60 C S-S r}}{16}+\left(\frac{\left(N_{1}\right)_{60 C S-S r}-16}{21.2}\right)^{3}-3.0\right) \leq \tan \varphi^{\prime}
$$




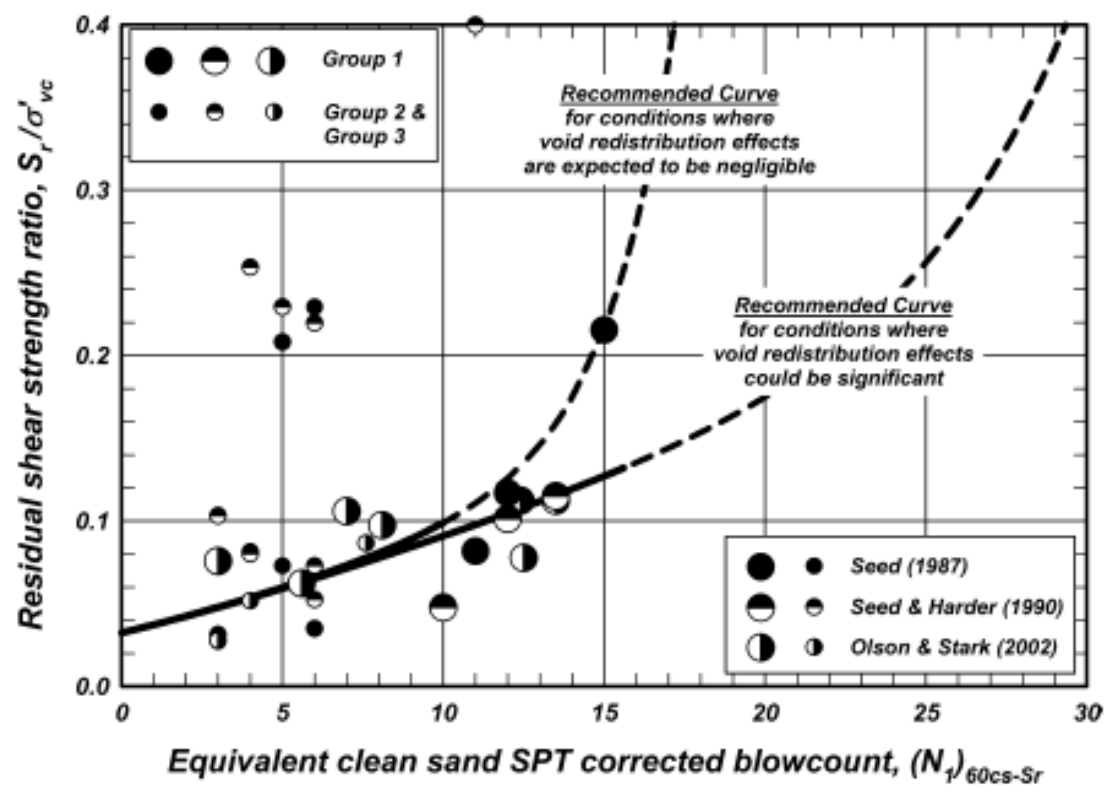

Figura 4.17-. Relação de resistência ao cisalhamento residual normalizada de areia liquefeita versus contagem de sopro corrigida SPT de areia limpa equivalente para $\sigma_{\mathrm{vc}}^{\prime}<400 \mathrm{kPa}$, usando as histórias de casos publicadas por Seed (1987), Seed e Harder (1990) e Olson e Stark (2002). 


\section{5 Avaliação da liquefação dos rejeitos da barragem Otapara}

Este capitulo tem como objetivo avaliar o potencial de liquefação dinâmica do depósito de rejeitos da barragem localizada em Arequipa, Peru, em região de alta atividade sísmica. A análise do potencial de liquefação é feita por meio de método empírico determinístico baseado nos resutados de ensaios de simples reconhecimento SPT. Na Figura 5.1 mostra-se o fluxograma dos passos empregados para obter o fator de segurançã contra inicio da liquefação associado ao potencial de liquefação.

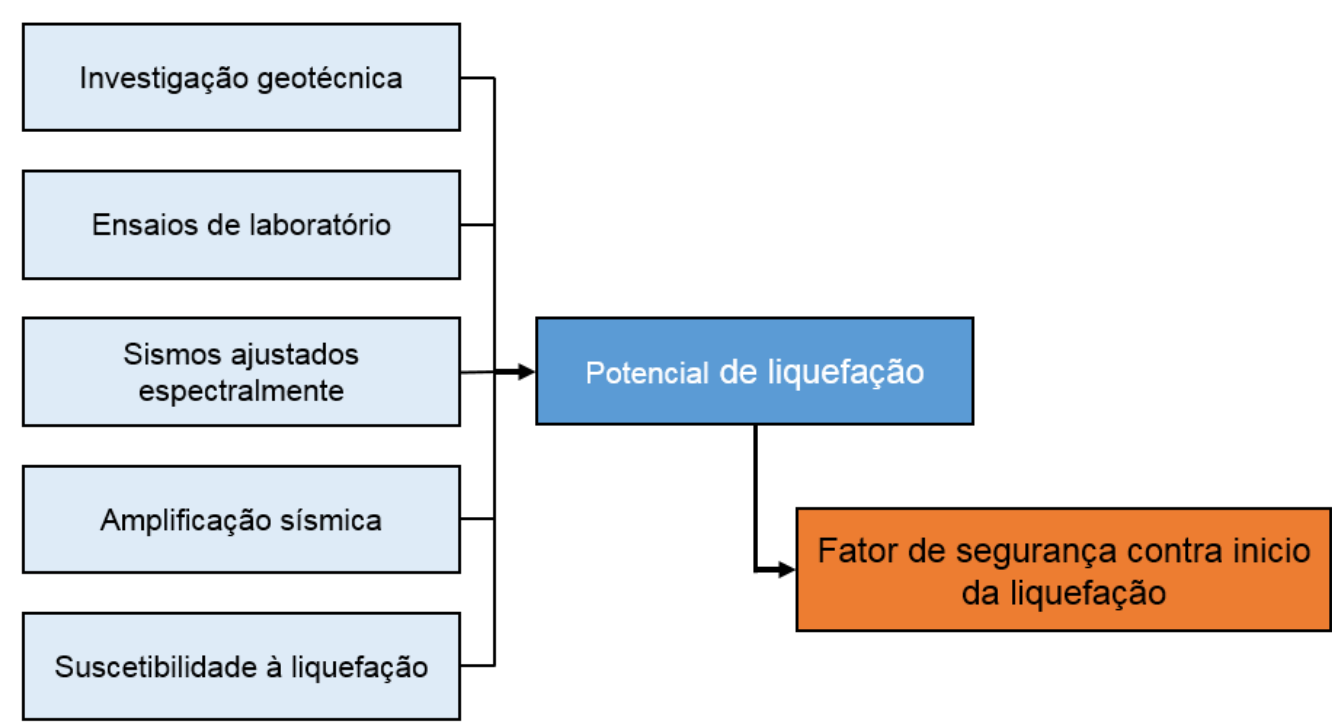

Figura 5.1- Fluxograma da avaliação do potencial de liquefação.

Os rejeitos de mineração tipo polpa, normalmente são depositados nas bacias de barragem de rejeitos completamente saturados e com baixa densidade relativa. Estes materiais muitas vezes são aproveitados na construção dos alteamentos durante a operação da barragem até o fechamento do mesmo. Dentro dos tipos de alteamento encontra-se o método a montante, a linha central e a jusante; o método a montante resulta sendo o mais econômico, e mais inseguro enquanto a estabilidade. Em países com alta atividade sísmica realizar 
avaliações do potencial a liquefação dos rejeitos, resulta de grande importância na toma de decisões das análises de risco.

\section{1.}

Caracterização geotécnica dos materiais

A caracterização geotécnica dos materiais foi mediante ensaios in-situ e testes no laboratório, a continuação mostra resultados mais relevantes para a avaliação da liquefação dos rejeitos e resultados de outros materiais empregados na análise da resposta dinâmica da barragem.

\subsection{1.} Investigação geotécnica

Realizou-se 04 perfurações geotécnicas, nas quais foram realizados 58 ensaios SPT no total e 10 ensaios de Cone Peck, as perfurações foram distribuídas de forma adequada sobre a área de interesse, a fim de avaliar indiretamente a resistência e determinar a consistência e / ou compactação dos materiais que compõem o depósito de rejeitos.

O teste de penetração padrão SPT (ASTM D 1586) consiste basicamente em contar o número de golpes $(\mathrm{N})$ que são necessários para introduzir uma camada de solo, uma amostragem (colher partida) de $30 \mathrm{~cm}$ de comprimento em diferentes profundidades (geralmente com variação de metro em metros). 0 tomador da amostra é espancado sob potência constante, com um peso de 140 libras em queda livre. $(33,5 \mathrm{~kg})$ e uma altura de queda de 30 polegadas $(76,2 \mathrm{~cm})$. A Tabela 5.1 apresenta a relação entre o N do SPT e a compacidade/consistência. 
Tabela 5.1- Relação entre NSPT com compacidade e consistência (ABNT - NBR 6484).

\begin{tabular}{|c|c|}
\hline Compacidade & Intervalo do NSPT \\
\hline Areia fofa & $\mathrm{N}_{\mathrm{SPT}} \leq 4$ \\
\hline Areia pouco compacta & $4<\mathrm{N}_{\mathrm{SPT}} \leq 8$ \\
\hline Areia medianamente compacta & $8<\mathrm{N}_{\mathrm{SPT}} \leq 18$ \\
\hline Areia compacta & $18<\mathrm{N}_{\mathrm{SPT}} \leq 40$ \\
\hline Areia muito compacta & $\mathrm{N}_{\mathrm{SPT}}>40$ \\
\hline Consistência & Intervalo do NSPT \\
\hline Argila muito mole & $\mathrm{N}_{\mathrm{SPT}} \leq 2$ \\
\hline Argila mole & $2<\mathrm{N}_{\mathrm{SPT}} \leq 5$ \\
\hline Argila média & $5<\mathrm{N}_{\mathrm{SPT}} \leq 10$ \\
\hline Argila rija & $10<\mathrm{N}_{\mathrm{SPT}} \leq 19$ \\
\hline Argila dura & $\mathrm{SPT}>19$ \\
\hline
\end{tabular}

O teste dinâmico de ausculta do cone consiste na introdução contínua de uma ponta cônica do tipo Peck. O equipamento usado para introduzir a ponta cônica no solo é o mesmo usado para realizar o teste de penetração padrão; em que a colher padrão é substituída por um cone de $6,35 \mathrm{~cm}$ (2,5 ") de diâmetro e ângulo de $60^{\circ}$ na ponta. Este cone é continuamente direcionado para o solo. A gravação da auscultação é feita contando o número de golpes (Cn) para introduzir a ponta cônica a cada $15 \mathrm{~cm}$. Considera-se que o Cn é o número de golpes para cada $30 \mathrm{~cm}$ de penetração com o cone Peck, além disso o resultado é apresentado em forma gráfica indicando o número de golpes correspondentes.

A Figura 5.2 apresenta a localização dos ensaios SPT feitos na área de estudo, dos quais os SPT 1 e SPT-2 foram realizados antes do evento sísmico e o SPT 3 e SPT-4 foram efetuados posterior ao sismo do 2013 descrito anteriormente. 


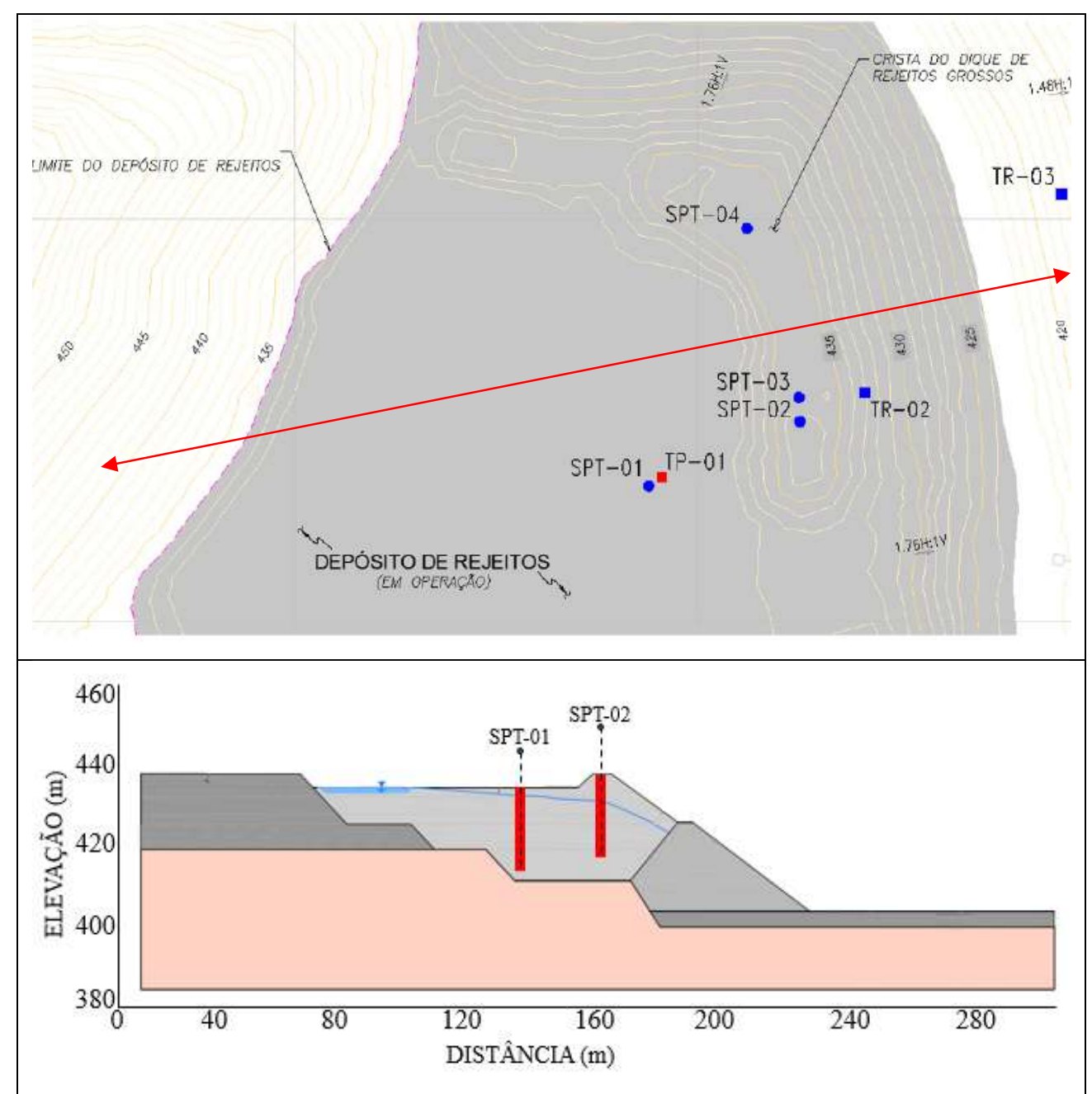

Figura 5.2 - Localização dos ensaios SPT e outras sondagens realizadas no projeto.

As Tabela 5.2 a Tabela 5.3 apresentam um resumo dos testes realizados a cada furo de sondagem SPT. Os resultados destes testes mostram uma tendência clara para aumentar a consistência ou compacidade dos rejeitos em relação à profundidade. Assim, na área da bacia na sondagem SPT-01 encontramos areias siltosas fofas ( $N \leq 4$ golpes) e pouco compactas ( $N \leq 8$ golpes) ate uma profundidade de $10,00 \mathrm{~m}$, seguidas de siltes de baixa plasticidade de compacidade medianamente compactas ( $N \leq 18$ golpes) e compactas ( $N \leq 40$ golpes), o nível do lençol freático foi encontrado a uma profundidade de 2,0 m próximo à superfície. Na sondagem foi encontrada uma lente de argila de consistência dura ( $\mathrm{N} \leq 18$ golpes) entre os 12,00 e 12,50 m de profundidade, a qual vai ser considerada como uma camada de areia siltosa de forma conservadora. 
$\mathrm{Na}$ zona correspondente à crista do dique de rejeitos grossos na sondagem SPT-02, encontramos areias siltosas fofas ( $\mathrm{N} \leq 4$ golpes) e pouco compactas ( $\mathrm{N}$ $\leq 8$ golpes) até uma profundidade $10,00 \mathrm{~m}$, seguidas de areias de compacidade medianamente compactas ( $\mathrm{N} \leq 18$ golpes) a compactas ( $\mathrm{N} \leq 40$ golpes) até uma profundidade $20,00 \mathrm{~m}$. O nível do lençol freático foi encontrado a uma profundidade de $7,0 \mathrm{~m}$.

Para correlacionar os resultados da execução do teste de Cone Peck com o ensaio SPT, utilizou-se a calibração investigada por Romero (2007), que indica que para solos tipo SP pode se considerar $0.5 \mathrm{Cn}=\mathrm{N}$. Esta formulação resulta conservadora para solos tipo SM e ML com $\mathrm{N}<30$ golpes onde pode se considerar $2,3923 \mathrm{Cn}^{0,5883}=\mathrm{N}$.

Tabela 5.2- Resumo dos Ensaios SPT 1 y CP - Antes do Sismo.

\begin{tabular}{|c|c|c|c|c|c|c|}
\hline Área & $\begin{array}{l}\text { Seção do } \\
\text { teste }(m)\end{array}$ & $\begin{array}{c}\text { Elevação } \\
\text { (m) }\end{array}$ & $\begin{array}{c}\text { Tipo } \\
\text { de } \\
\text { solo }\end{array}$ & $\mathbf{N}$ & $C_{n}$ & $\begin{array}{l}\text { Compacidade / } \\
\text { Consistência }\end{array}$ \\
\hline \multirow{19}{*}{ Bacia } & $1.00-1.45$ & 432 & SM & 2 & - & Fofa \\
\hline & $2.00-2.45$ & 431 & SM & 2 & - & Fofa \\
\hline & $3.00-3.45$ & 430 & SM & 2 & - & Fofa \\
\hline & $4.00-4.45$ & 429 & SM & 6 & - & Pouco compacta \\
\hline & $5.00-5.45$ & 428 & SM & 3 & - & Fofa \\
\hline & $6.00-6.45$ & 427 & SM & 3 & - & Fofa \\
\hline & $7.00-7.45$ & 426 & SM & 6 & - & Pouco compacta \\
\hline & $8.00-8.45$ & 425 & SM & 8 & - & Pouco compacta \\
\hline & $9.00-9.45$ & 424 & SM & 9 & - & Medianamente compacta \\
\hline & $10.00-10.45$ & 423 & SM & 13 & - & Medianamente compacta \\
\hline & $11.00-11.45$ & 422 & SM & 9 & - & Medianamente compacta \\
\hline & $12.00-12.45$ & 421 & $\mathrm{CL}$ & 21 & - & Consistência dura \\
\hline & $13.00-13.45$ & 420 & ML & 22 & - & Compacta \\
\hline & $14.00-14.45$ & 419 & $\mathrm{ML}$ & 29 & - & Compacta \\
\hline & $15.15-15.45$ & 417.5 & - & 19 & 32 & Compacta \\
\hline & $16.20-16.50$ & 416.5 & - & 21 & 38 & Compacta \\
\hline & $17.10-17.40$ & 415.5 & - & 25 & 53 & Compacta \\
\hline & $18.15-18.45$ & 414.5 & - & 26 & 56 & Compacta \\
\hline & $18.75-19.05$ & 413.5 & - & 26 & 56 & Compacta \\
\hline
\end{tabular}


Tabela 5.3- Resumo dos Ensaios SPT 2 y CP - Antes do Sismo.

\begin{tabular}{|c|c|c|c|c|c|c|}
\hline Área & $\begin{array}{l}\text { Seção do } \\
\text { teste }(m)\end{array}$ & $\begin{array}{c}\text { Elevação } \\
\text { (m) }\end{array}$ & $\begin{array}{c}\text { Tipo } \\
\text { de } \\
\text { solo }\end{array}$ & $\mathbf{N}$ & $C_{n}$ & $\begin{array}{l}\text { Compacidade / } \\
\text { Consistência }\end{array}$ \\
\hline \multirow{19}{*}{$\begin{array}{c}\text { Crista do } \\
\text { dique de } \\
\text { rejeitos } \\
\text { grossos }\end{array}$} & $1.00-1.45$ & 436 & SM & 3 & & Fofa \\
\hline & $2.00-2.45$ & 435 & SM & 4 & & Fofa \\
\hline & $3.00-3.45$ & 434 & SM & 4 & & Fofa \\
\hline & $4.00-4.45$ & 433 & SM & 4 & & Fofa \\
\hline & $5.00-5.45$ & 432 & SM & 6 & & Pouco compacta \\
\hline & $6.00-6.45$ & 431 & SM & 6 & & Pouco compacta \\
\hline & $7.00-7.45$ & 430 & SM & 4 & & Fofa \\
\hline & $8.00-8.45$ & 429 & SM & 4 & & Fofa \\
\hline & $9.00-9.45$ & 428 & SM & 7 & & Pouco compacta \\
\hline & $10.00-10.45$ & 427 & SM & 12 & & Medianamente compacta \\
\hline & $11.00-11.45$ & 426 & SM & 18 & & Medianamente compacta \\
\hline & $12.00-12.45$ & 425 & SM & 21 & & Compacta \\
\hline & $13.00-13.45$ & 424 & SM & 22 & & Compacta \\
\hline & $14.00-14.45$ & 423 & SM & 27 & & Compacta \\
\hline & $15.00-15.45$ & 422 & - & 15 & 22 & Medianamente compacta \\
\hline & $16.05-16.50$ & 420.5 & - & 17 & 26 & Medianamente compacta \\
\hline & $17.25-17.55$ & 419.5 & - & 19 & 32 & Medianamente compacta \\
\hline & $18.15-18.45$ & 418.5 & - & 19 & 34 & Compacta \\
\hline & $18.75-19.05$ & 417.5 & - & 23 & 46 & Compacta \\
\hline
\end{tabular}

Nas sondagens SPT-3 e SPT-4 feitas após do sismo perto da posição do SPT-2 na crista do dique de rejeitos grossos, é mostrado que os testes realizados acima do lençol freático têm um número de golpes $(\mathrm{N})$ maiores do que aqueles feitos antes do sismo. Porém abaixo do lençol freático, é mostrado que o número de golpes foi reduzido em aproximadamente $30 \%$, o que indica que o material saturado de rejeitos provavelmente sofreu perda de resistência devido à carga sísmica (ver Tabela 5.4 e Tabela 5.5). 
Tabela 5.4- Resumo dos Ensalos SPT 3 - Após do Sismo.

\begin{tabular}{|c|c|c|c|c|c|c|}
\hline Área & $\begin{array}{l}\text { Seção do } \\
\text { teste (m) }\end{array}$ & $\begin{array}{c}\text { Eleva } \\
\text { ção } \\
\text { (m) }\end{array}$ & $\begin{array}{c}\text { Tipo } \\
\text { de } \\
\text { solo }\end{array}$ & $\mathbf{N}$ & $C_{n}$ & $\begin{array}{l}\text { Compacidade / } \\
\text { Consistência }\end{array}$ \\
\hline \multirow{15}{*}{$\begin{array}{l}\text { Crista do } \\
\text { dique de } \\
\text { rejeitos } \\
\text { grossos }\end{array}$} & $1.00-1.45$ & 436 & SM & 9 & - & Medianamente compacta \\
\hline & $2.00-2.45$ & 435 & SM & 7 & - & Pouco compacta \\
\hline & $3.00-3.45$ & 434 & SM & 6 & - & Pouco compacta \\
\hline & $4.00-4.45$ & 433 & SM & 8 & - & Pouco compacta \\
\hline & $5.00-5.45$ & 432 & SM & 12 & - & Medianamente compacta \\
\hline & $6.00-6.45$ & 431 & SM & 9 & - & Medianamente compacta \\
\hline & $7.00-7.45$ & 430 & SM & 9 & - & Medianamente compacta \\
\hline & $8.00-8.45$ & 429 & SM & 11 & - & Medianamente compacta \\
\hline & $9.00-9.45$ & 428 & SM & 12 & - & Medianamente compacta \\
\hline & $10.00-10.45$ & 427 & SM & 8 & - & Pouco compacta \\
\hline & $11.00-11.45$ & 426 & SM & 13 & - & Medianamente compacta \\
\hline & $12.00-12.45$ & 425 & SM & 13 & - & Medianamente compacta \\
\hline & $13.00-13.45$ & 424 & SM & 8 & - & Pouco compacta \\
\hline & $14.00-14.45$ & 423 & SM & 9 & - & Medianamente compacta \\
\hline & $15.00-15.45$ & 422 & $\mathrm{ML}$ & 15 & - & Medianamente compacta \\
\hline
\end{tabular}

Tabela 5.5- Resumo dos Ensaios SPT 4 - Após do Sismo.

\begin{tabular}{|c|c|c|c|c|c|c|}
\hline Área & $\begin{array}{l}\text { Seção do } \\
\text { teste (m) }\end{array}$ & $\begin{array}{c}\text { Eleva } \\
\text { ção } \\
\text { (m) }\end{array}$ & $\begin{array}{c}\text { Tipo } \\
\text { de } \\
\text { solo }\end{array}$ & $\mathbf{N}$ & $C_{n}$ & $\begin{array}{l}\text { Compacidade / } \\
\text { Consistência }\end{array}$ \\
\hline \multirow{15}{*}{$\begin{array}{l}\text { Crista do } \\
\text { dique de } \\
\text { rejeitos } \\
\text { grossos }\end{array}$} & $1.00-1.45$ & 436 & SM & 6 & - & Pouco compacta \\
\hline & $2.00-2.45$ & 435 & SM & 6 & - & Pouco compacta \\
\hline & $3.00-3.45$ & 434 & SM & 10 & - & Medianamente compacta \\
\hline & $4.00-4.45$ & 433 & SM & 10 & - & Medianamente compacta \\
\hline & $5.00-5.45$ & 432 & SM & 6 & - & Pouco compacta \\
\hline & $6.00-6.45$ & 431 & SM & 9 & - & Medianamente compacta \\
\hline & $7.00-7.45$ & 430 & SM & 10 & - & Medianamente compacta \\
\hline & $8.00-8.45$ & 429 & SM & 9 & - & Medianamente compacta \\
\hline & $9.00-9.45$ & 428 & SM & 9 & - & Medianamente compacta \\
\hline & $10.00-10.45$ & 427 & SM & 9 & - & Medianamente compacta \\
\hline & $11.00-11.45$ & 426 & $\mathrm{ML}$ & 9 & - & Medianamente compacta \\
\hline & $12.00-12.45$ & 425 & $\mathrm{ML}$ & 11 & - & Medianamente compacta \\
\hline & $13.00-13.45$ & 424 & $\mathrm{ML}$ & 9 & - & Medianamente compacta \\
\hline & $14.00-14.45$ & 423 & $\mathrm{ML}$ & 9 & - & Medianamente compacta \\
\hline & $15.00-15.45$ & 422 & $\mathrm{ML}$ & 9 & - & Medianamente compacta \\
\hline
\end{tabular}




\subsection{2.}

\section{Ensaios do laboratório}

Nas amostras selecionadas, obtidas na primeira campanha geotécnica, foram realizados testes laboratoriais para identificação e classificação de acordo com o Sistema Único de Classificação de Solos (SUCS). As propriedades do índice de solo, granulometria, limites de consistência e teor de umidade estão resumidas na Tabela 5.6.

Tabela 5.6- Resumo de ensaios de Clasificação de solos.

\begin{tabular}{|c|c|c|c|c|c|c|c|c|}
\hline \multirow[b]{2}{*}{ Sondagem } & \multirow{2}{*}{$\begin{array}{l}\text { Prof. } \\
\text { (m) }\end{array}$} & \multirow{2}{*}{$\begin{array}{l}\text { Clasif. } \\
\text { SUCS }\end{array}$} & \multicolumn{3}{|c|}{ D. Granulométrica } & \multicolumn{2}{|c|}{$\begin{array}{l}\text { Límites de } \\
\text { Atterberg }\end{array}$} & \multirow{2}{*}{$\begin{array}{l}\text { Teor de. } \\
\text { Umidade } \\
\text { (w\%) }\end{array}$} \\
\hline & & & $\begin{array}{c}\text { Pedreg } \\
\text { ulho } \\
(\%)\end{array}$ & $\begin{array}{c}\text { Areia } \\
(\%)\end{array}$ & $\begin{array}{c}\text { Finos } \\
(\%)\end{array}$ & LL & IP & \\
\hline TP-01 & $0.00-1.50$ & SM & 0 & 78.0 & 22.0 & -- & - & 8.2 \\
\hline TP-03 & $0.00-1.10$ & SM & 20.5 & 60.5 & 19.0 & -- & -- & 5.8 \\
\hline TP-03 & $1.10-1.60$ & GM & 57.5 & 29.8 & 12.6 & -- & -- & 7.7 \\
\hline TR-02 & $0.30-3.50$ & SM & 0 & 50.4 & 49.6 & -- & -- & 4.1 \\
\hline TR-03 & $0.30-2.50$ & GM & 44.2 & 43.4 & 12.4 & -- & -- & 1.7 \\
\hline TR-05 & $0.30-2.00$ & GW-GM & 47.5 & 42.5 & 10 & -- & -- & 0.5 \\
\hline SPT-01 & $12.00-12.45$ & $C L$ & 0 & 17.0 & 83.0 & -- & -- & 23.0 \\
\hline
\end{tabular}

Onde:

SUCS: Sistema Unificado de Classificação de Solos.

LL: Limite de Liquidez

IP: Índice de Plásticidade

Para determinar as propriedades de resistência, um ensaio de cisalhamento direto foi realizado em uma amostra obtida a partir da trincheira TR-02, que é um material representativo do rejeito grosso que forma a inclinação superior da barragem do reservatório. Para a execução do teste foram seguidos os procedimentos da norma ASTM D-3080 (Cizalhamento direto). Os resultados desses testes são apresentados na Tabela 5.7. 
Tabela 5.7- Resumo do Ensaio de Corte Direto.

\begin{tabular}{|c|c|c|c|c|c|}
\hline \multirow[b]{2}{*}{ Sondagem } & \multirow[b]{2}{*}{ Amostra } & \multirow{2}{*}{$\begin{array}{l}\text { Prof. } \\
\text { (m) }\end{array}$} & \multirow{2}{*}{$\begin{array}{l}\text { Clasif. } \\
\text { sucs }\end{array}$} & \multicolumn{2}{|c|}{ Parâmetros de resistência } \\
\hline & & & & $\begin{array}{c}\text { Coesão } \\
\text { (kPa) }\end{array}$ & $\begin{array}{c}\text { Ângulo de } \\
\text { atrito }\left(^{\circ}\right)\end{array}$ \\
\hline TR-02 & $M-1$ & $0.30-3.50$ & SM & 0.14 & 37.5 \\
\hline
\end{tabular}

SUCS: Sistema Unificado de Classificação de Solos.

Durante a campanha geotécnica, amostras de rejeitos frescos obtidos antes (rejeitos globais) foram coletadas e após atingirem o hidrociclone (rejeitos grossos e finos. Nestas amostras, testes laboratoriais foram realizados para identificação e classificação de acordo com o Sistema Unificado de Classificação de Solos (SUCS - Unified Soil Classification System). As propriedades do índice dos solos testados em termos de granulometria, limites de consistência e teor de umidade estão resumidas na Tabela 5.8 .

Tabela 5.8- Resumo de ensaios de clasificação de solos do rejeito.

\begin{tabular}{|c|c|c|c|c|c|c|c|}
\hline \multirow{2}{*}{ Amostra } & \multirow{2}{*}{$\begin{array}{l}\text { Clasif. } \\
\text { sucs }\end{array}$} & \multicolumn{3}{|c|}{ D. Granulométrica } & \multicolumn{2}{|c|}{$\begin{array}{l}\text { Límites de } \\
\text { Atterberg }\end{array}$} & \multirow{2}{*}{$\begin{array}{c}\text { Teor de. } \\
\text { Umidade } \\
\text { (w\%) }\end{array}$} \\
\hline & & $\begin{array}{c}\text { Pedregulho } \\
\text { (\%) }\end{array}$ & $\begin{array}{c}\text { Areia } \\
\text { (\%) }\end{array}$ & $\begin{array}{c}\text { Finos } \\
(\%)\end{array}$ & LL & IP & \\
\hline Rejeito Global & $M L$ & 0 & 36.6 & 63.4 & -- & -- & 30.7 \\
\hline Rejeito Grosso & SM & 0 & 60.6 & 39.4 & -- & -- & 28.4 \\
\hline Rejeito Fino & $\mathrm{CL}$ & 0 & 0.3 & 99.7 & 30.4 & 9.8 & 77.4 \\
\hline
\end{tabular}

Os dados de densidade úmida dos rejeitos globais (polpa), rejeitos grossos e rejeitos finos, que são mostrados na Tabela 5.9.

Tabela 5.9- Resumo de densidade promedio de rejeito.

\begin{tabular}{|c|c|}
\hline Amostra & Densidade $\left(\mathbf{g r} / \mathbf{c m}^{3}\right)$ \\
\hline Rejeito Global & 1.20 \\
\hline Rejeito Grosso & 2.08 \\
\hline Rejeito Fino & 1.10 \\
\hline
\end{tabular}

A gravidade específica de um solo é definida como o peso unitário do material dividido pelo peso unitário da água destilada a uma temperatura de $4^{\circ} \mathrm{C}$. 
Os procedimentos da ASTM D-854 foram seguidos e os resultados destes testes são apresentados na Tabela 5.10 .

Tabela 5.10- Resumo de ensaios de gravedade específica.

\begin{tabular}{|c|c|c|}
\hline Área & $\begin{array}{c}\text { Clasif. } \\
\text { SUCS }\end{array}$ & $\begin{array}{c}\text { Grav. Sólidos } \\
\text { (Mat. < No4) }\end{array}$ \\
\hline Rejeito Global & $\mathrm{ML}$ & 3.375 \\
\hline Rejeito Grosso & $\mathrm{SM}$ & 3.154 \\
\hline Rejeito Fino & $\mathrm{CL}$ & 2.994 \\
\hline
\end{tabular}

Onde:

SUCS: Sistema Unificado de Classificação de Solos.

Um teste de compressão simples foi realizado em amostras de rocha obtidas durante o mapeamento geológico, a fim de obter sua resistência à compressão não confinada. Este teste segue os procedimentos da ASTM D-5731, e um resumo dos resultados do teste de carga pontual é apresentado na Tabela 5.11, em termos da resistência à compressão não confinada equivalente $a \sigma_{c}$ e a resistência da rocha.

Tabela 5.11- Resumo do Ensaios de Compressão Simples.

\begin{tabular}{|c|c|c|c|c|c|}
\hline \multirow{2}{*}{ Localização } & \multirow{2}{*}{ Litologia } & \multirow{2}{*}{$\begin{array}{l}\text { Prof. } \\
\text { (m) }\end{array}$} & \multicolumn{2}{|c|}{$\begin{array}{c}\text { Compressão } \\
\text { Simples }\end{array}$} & \multirow{2}{*}{$\begin{array}{c}\text { Grau de } \\
\text { dureza } \\
\text { ISMR }\end{array}$} \\
\hline & & & $\begin{array}{l}\text { Is (50) } \\
\text { (MPa) }\end{array}$ & $\begin{array}{c}\sigma_{\circ} \\
(\mathrm{MPa})\end{array}$ & \\
\hline $\begin{array}{c}\text { Montante da } \\
\text { bacia }\end{array}$ & Granito & Superficial & 8.3 & 201 & R5 \\
\hline
\end{tabular}

Is (50): Índice de compressão simples corregido; бo: Resistência da compressão não confinada

Com a amostra de rocha extraída, os respectivos testes foram realizados para determinar as propriedades físicas da rocha intacta, como; Gravidade específica, absorção (ASTM C-9783) e densidade de rochas (ASTM D-2937), seguindo os padrões recomendados para o teste. A Tabela 5.12 abaixo mostra um resumo dos resultados obtidos. 
Tabela 5.12- Resumo de ensaios de propriedades fisicas em rocha.

\begin{tabular}{|c|c|c|c|}
\hline Localização & $\begin{array}{c}\text { Densidade } \\
\text { da rocha } \\
\left(\mathbf{g r} / \mathbf{c m}^{3}\right)\end{array}$ & $\begin{array}{c}\text { P.A. } \\
(\%)\end{array}$ & $\begin{array}{c}\text { PEA } \\
\left(\mathbf{g r} / \mathbf{c m}^{3}\right)\end{array}$ \\
\hline $\begin{array}{c}\text { Montante da } \\
\text { bacia }\end{array}$ & 2.69 & 0.11 & 2.72 \\
\hline
\end{tabular}

Onde:

PEA: Peso específico aparente; PA: Porcentagem de absorção

Para entender o comportamento dinâmico dos materiais tipo rejeitos, estão sendo considerados ensaios triaxial cíclico feito na pesquisa do Soto (2002).

$\mathrm{Na}$ investigação feita por Soto (2002) foram avaliadas as propriedades dinâmicas dos rejeitos como a resistência cíclica e o modulo deYoung do material para tensões de confinamento de $100 \mathrm{kPa}$ e $200 \mathrm{kPa}$. Na Tabela 5.13 são apresentados a lista de ensaios de liquefação para os rejeitos em condições saturadas (Soto 2002).

Tabela 5.13-. Resumo dos testes de liquefação (adaptado Soto, 2002).

\begin{tabular}{|c|c|c|c|c|c|c|}
\hline Teste & Rejeito & SUCS & DR (\%) & $\begin{array}{c}Y_{d} \\
\left(\mathrm{gr}_{\mathrm{cm}}{ }^{3}\right)\end{array}$ & $\begin{array}{c}\text { Saturação } \\
(\%)\end{array}$ & $\begin{array}{c}\text { Tensão } \\
\text { confinante } \\
\left(\mathrm{kg} / \mathrm{cm}^{2}\right)\end{array}$ \\
\hline 1 & Fino & $\mathrm{ML}$ & - & 1.56 & 100 & 1.0 \\
\hline 2 & Fino & $\mathrm{ML}$ & - & 1.56 & 100 & 2.0 \\
\hline 5 & Grosso & $\mathrm{SM}$ & 40.0 & - & 100 & 1.0 \\
\hline 6 & Grosso & $\mathrm{SM}$ & 40.0 & - & 100 & 2.0 \\
\hline 9 & Grosso & $\mathrm{SM}$ & 60.0 & - & 100 & 1.0 \\
\hline 10 & Grosso & $\mathrm{SM}$ & 60.0 & - & 100 & 2.0 \\
\hline
\end{tabular}

Na Figura 5.3 são apresentados os resultados dos ensaios triaxiais cíclicos de liquefação para os rejeitos feitos pelo Soto (2002), onde pode se observar a influencia da tensão confinante na resistência cíclica. 
(a)

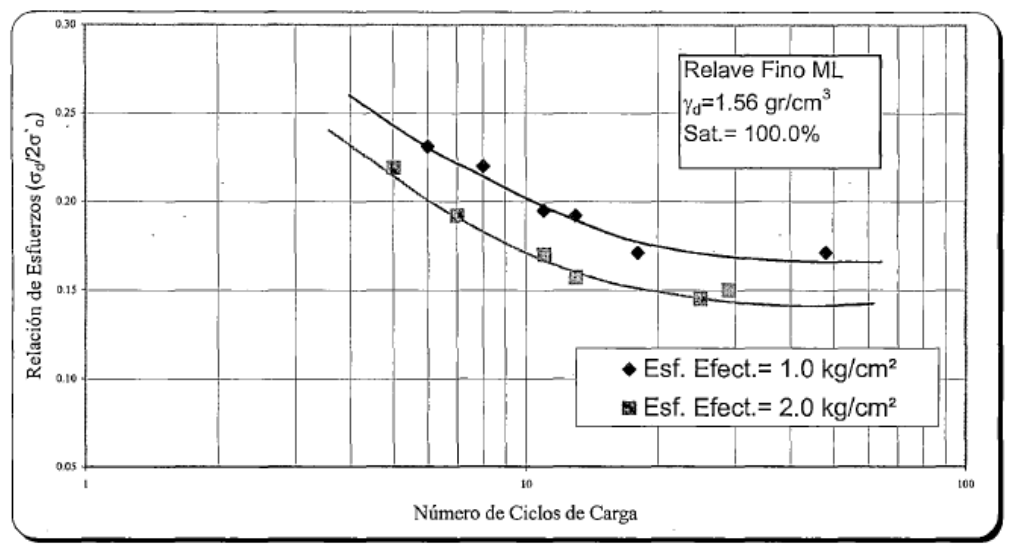

(b)

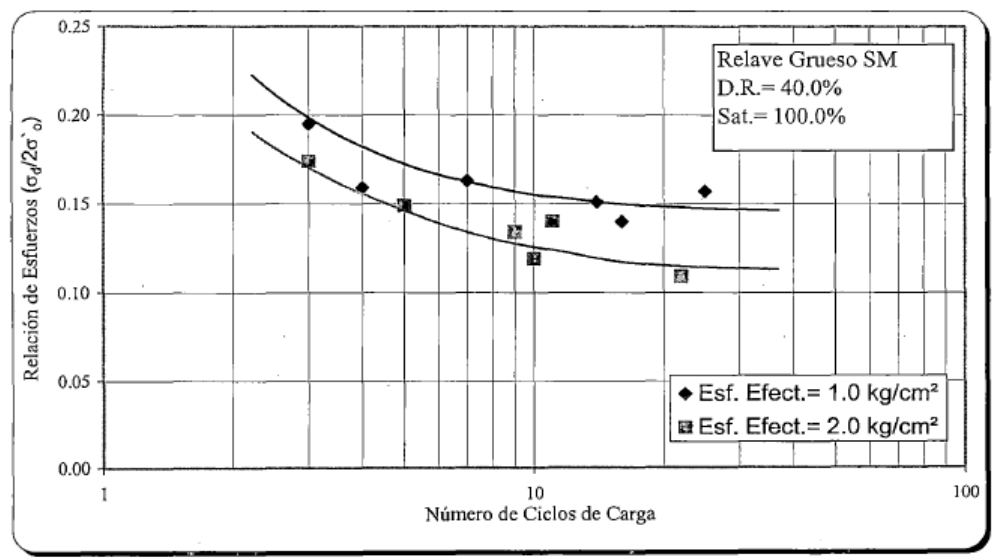

(c)

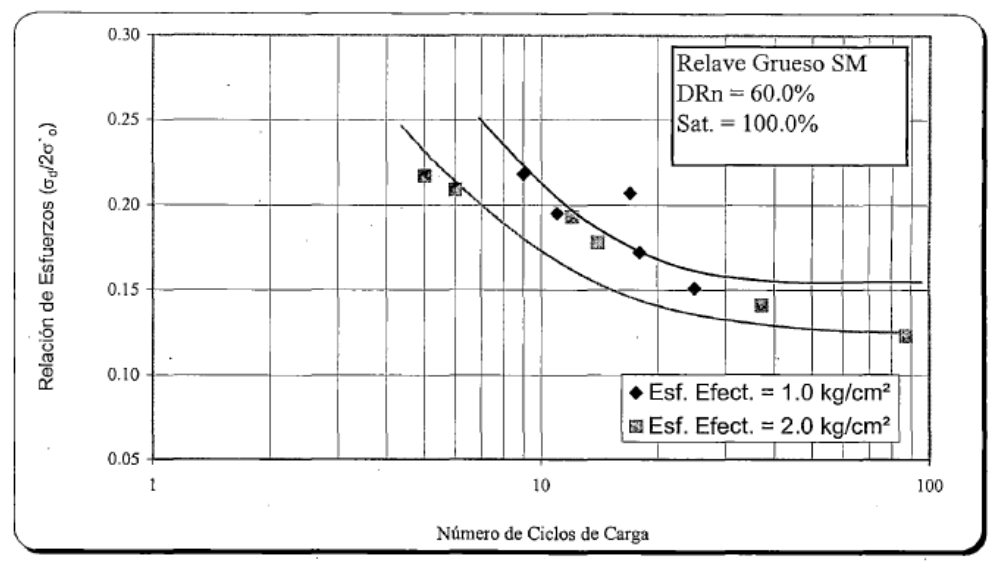

Figura 5.3- Influência na resistência cíclica dos rejeitos (a) Fino $M L Y_{d}=1.56 \mathrm{gr} / \mathrm{cm}^{3}$, (b) Grosso SM $\mathrm{DR}=40.0 \%$ e (c) Grosso SM DR=60.0\% (Soto 2002).

Na Figura 5.4 é apresentado os resultados dos ensaios triaxiais cíclicos de deformação dinâmica para rejeitos grossos (SM), pode-se observar as curvas de degradação do modulo de Young e amortecimento. 
ENSAYO DE DEFORMACIÓN DINÁMICA
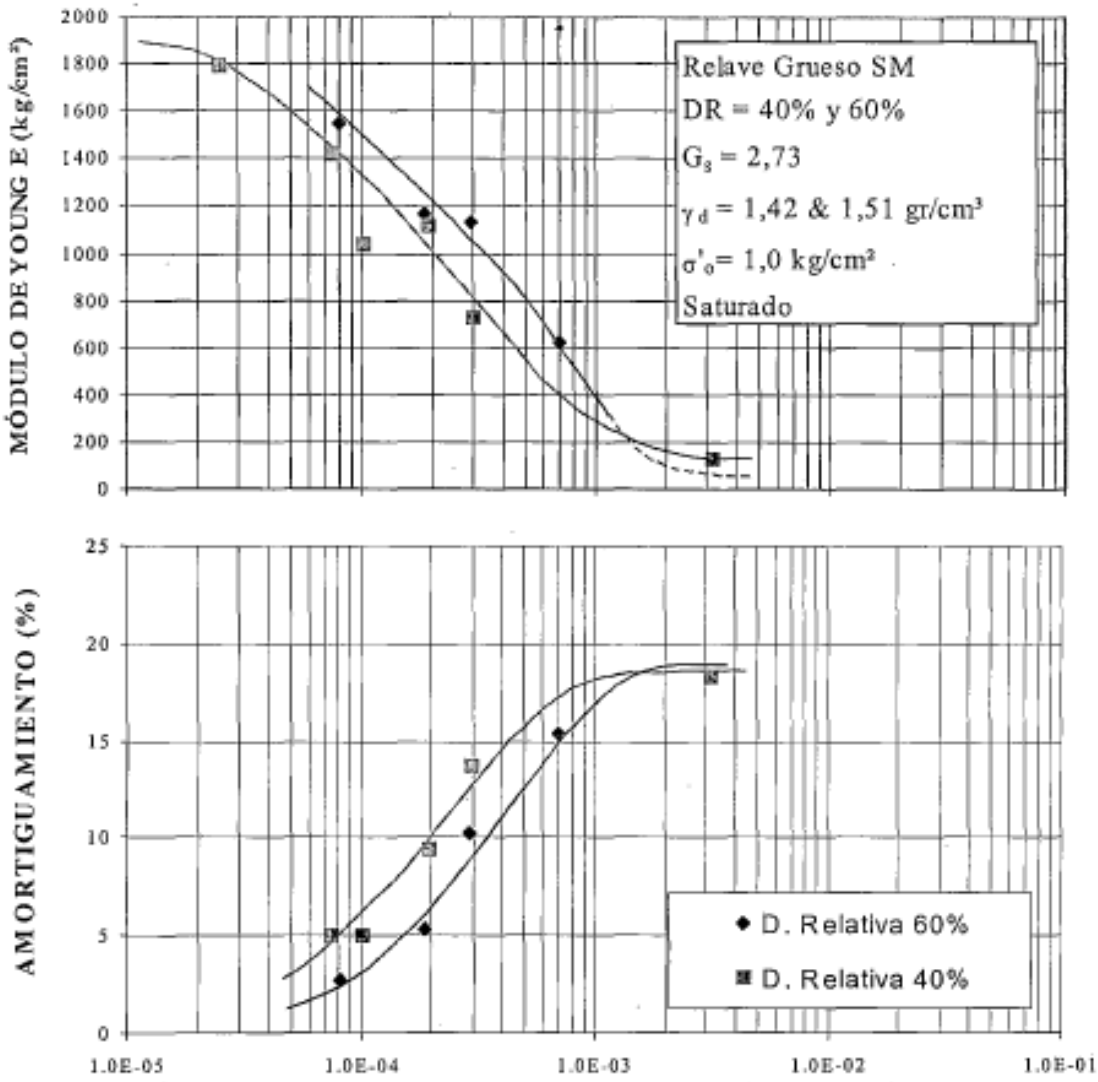

DEFORMACIÓN AXIAL

Figura 5.4- Curva de degradação do modulo de Young e amortecimento para os rejeitos grossos. (Soto 2002).

\section{2.}

\section{Suscetibilidade à liquefação}

Da caracterização geotécnica dos rejeitos da barragem de Otapara, e considerando os critérios de Bray e Sancio (2006) e Boulanger e Idriss (2008), conclui-se que os rejeitos grossos $(\mathrm{SM})$ e finos $(\mathrm{ML})$ são materiais suscetíveis à liquefação dinâmica. 


\section{3.}

\section{Avaliação do potencial de liquefação}

Uma vez confirmada a suscetibilidade à liquefação dinâmica, uma análise do início de liquefação (liquefaction triggering) deve ser executada, considerando como ferramenta principal de engenharia a utilização de resultados de ensaios de campo (CPT, SPT, velocidade de ondas S). Nos métodos empíricos de Boulanger e Idriss (2014) e NCEER - National Center for Earthquake Engineering Research (Youd e Idriss, 2001), requer-se para estimativa do início de liquefação a determinação de duas variáveis normalizadas: a razão de resistência cíclica CRR (cyclic resistance ratio), associada à capacidade do solo em resistir à liquefação, e a razão de tensão cíclica CSR (cyclic stress ratio), associada à demanda sísmica no sítio do projeto.

O fator de segurança contra início da liquefação $\mathrm{FS}_{\llcorner}$, em um ponto sob tensão vertical efetiva $\sigma_{v}^{\prime}$ situado na profundidade $z$, devido a um terremoto de magnitude momento $\mathrm{M}$, é determinado por:

$$
\mathrm{FS}_{\mathrm{L}}=\frac{\mathrm{CRR}_{\mathrm{M} \sigma^{\prime}{ }_{v}(z)}}{\operatorname{CSR}_{(z)}}
$$

No caso de ensaios SPT, a razão de resistência cíclica pode ser estimada por meio de gráficos ou correlações que relacionam valores de CRR, determinados em sítios onde houve ou não ocorrência de liquefação, em função do número de golpes $\left(\mathrm{N}_{1}\right)_{60}$ normalizados em relação à tensão vertical efetiva, à porcentagem de finos, ao comprimento das hastes de ensaio, ao diâmetro do furo, ao tipo de amostrador e à eficiência de energia do martelo. Como as correlações foram desenvolvidas para terremotos de magnitude $M_{w}=7,5$ e tensão vertical efetiva de referência de 1 atm (aproximadamente 100 kPa), a razão de resistência cíclica $\mathrm{CRR}_{\mathrm{M}}$ óv da Eq. 1 deve ser corrigida para a magnitude particular do terremoto $\mathrm{M}_{\mathrm{w}}$, em função de um fator de escala MSF (magnitude scaling factor), e da tensão vertical efetiva $\sigma_{v}^{\prime}$ atuante na profundidade $z$.

Idriss e Boulanger (2010) compararam os valores de CRR com aqueles obtidos pelo método NCEER (Youd e Idriss, 2001), concluindo que para profundidades $\mathrm{z} \leq 12 \mathrm{~m}$ as estimativas produzidas por ambos os métodos empíricos são razoáveis, com diferenças de no máximo $\pm 10 \%$. Para z $>12 \mathrm{~m}$, o 
método de Idriss e Boulanger (2010) prevê resultados que são mais próximos dos observados em campo e em ensaios de laboratório.

A razão de tensão cíclica $\operatorname{CSR}_{(z)}$ é determinada pela Equação 5.2 proposta por Seed e Idriss (1971), expressa em termos de um valor uniforme equivalente a $65 \%$ da máxima razão de tensão cisalhante cíclica:

$$
\operatorname{CSR}_{(z)}=0,65 \frac{\tau_{\max }}{\sigma_{v}^{\prime}}
$$

onde $\tau_{\max }$ é a máxima tensão cisalhante cíclica induzida pelo terremoto na profundidade $z$ e $\sigma_{v}^{\prime}$ é a correspondente tensão vertical efetiva in situ. A escolha do nível de tensão de referência (fator 0,65) foi proposta por Seed e Idriss (1967), sendo comumente adotada na prática da engenharia.

\subsection{1. Amplificação sísmica}

$\mathrm{Na}$ presente pesquisa, os valores de $\tau_{\max }$ nas diversas profundidades foram calculados utilizando o programa Deepsoil v7 (Hashash et al., 2018), considerando o modelo não linear para simulação da resposta das diferentes camadas de solo ao longo dos furos SPT-1 e SPT-2 no depósito de rejeitos.

Os valores das velocidades $\mathrm{V}_{\mathrm{s}}$ de propagação de onda $\mathrm{SH}$ ao longo dos furos de sondagem foram determinados por meio de correlações com o número de golpes N do ensaio SPT, propostas por Hasançebi e Ulusay (2007): para areias $V_{s}=90,82 N^{0,319}$, para argilas $V_{s}=97,89 N^{0,269}$ e para solos em geral $V_{s}=90 N^{0,309}$. $\mathrm{Na}$ Figura 5.5 se apresenta as velocidades das ondas cisalhantes (Vs) a longo da sondagem SPT-1 e SPT-2. 


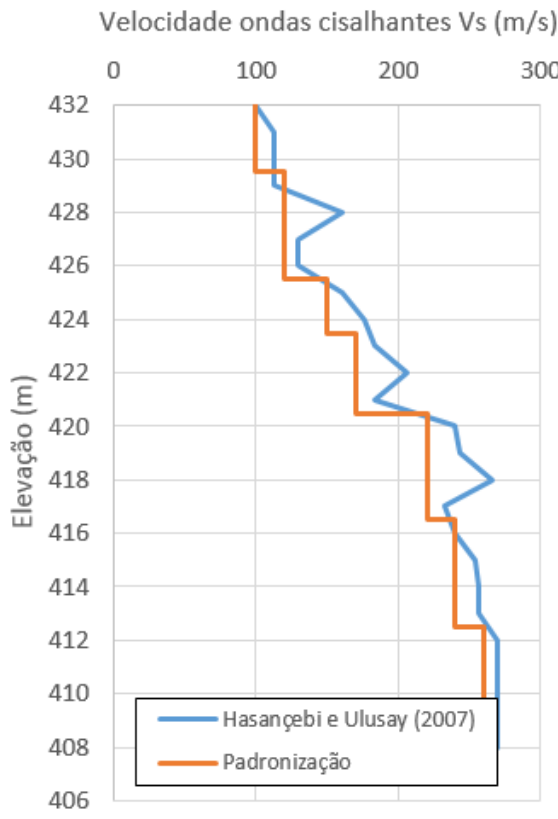

(a)

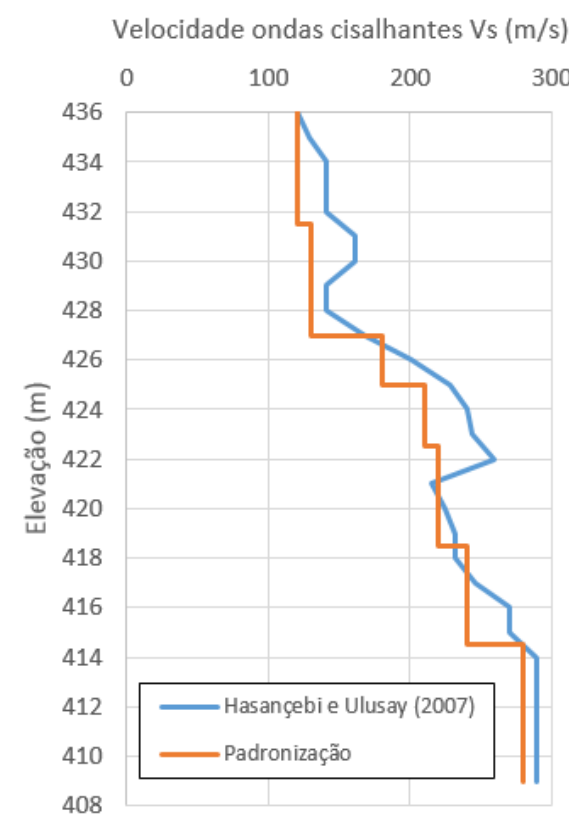

(b)

Figura 5.5- Velocidade de ondas cisalhantes na sondagem (a) SPT-1 e (b) SPT-2.

Depois da padronização da velocidade de ondas de cisalhantes, foi feita uma discretização do rejeito em camadas tendo em conta a densidade e ângulo atrito. Na Figura 5.6 se apresenta uma discretização dos rejeitos em camadas a longo da sondagem SPT-1 e SPT-2. 


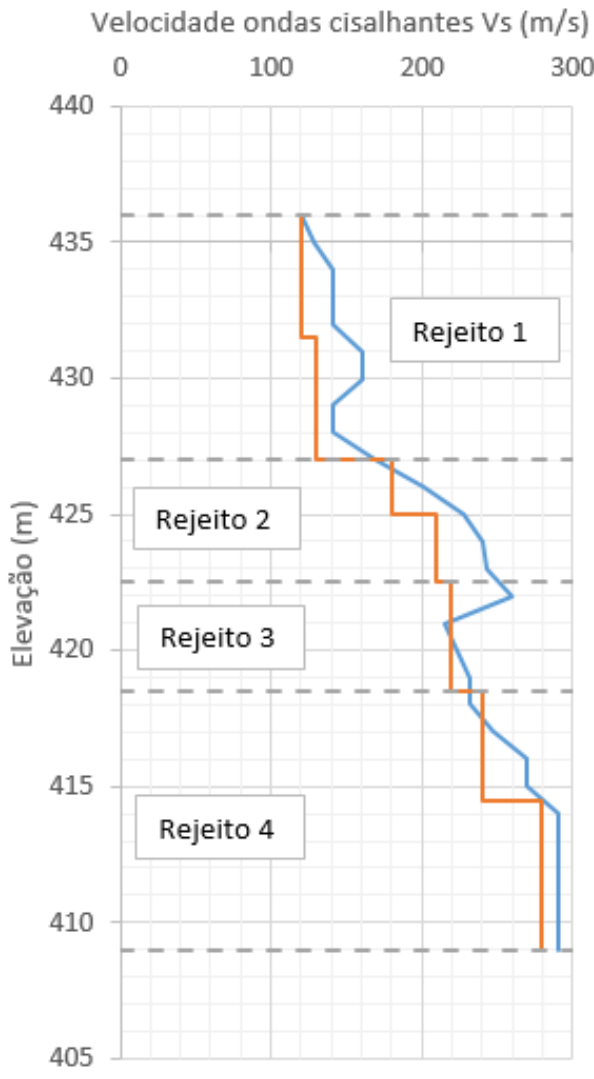

(a)

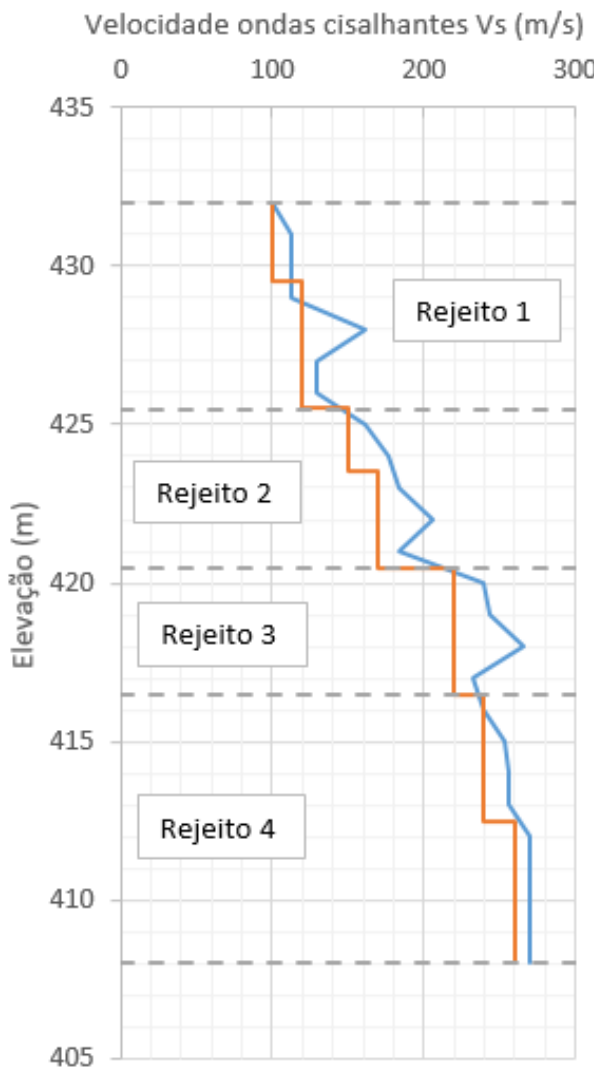

(b)

Figura 5.6- Discretização em camadas na sondagem (a) SPT-1 e (b) SPT-2.

No modelo constitutivo não linear é necessário informar as curvas de degradação do módulo de cisalhamento e do acréscimo do amortecimento histerético com o nível da deformação cisalhante imposto pelas tensões cisalhantes cíclicas. Nesta pesquisa foram adotadas as curvas propostas por Roblee e Chiou (2004) que consideram a porcentagem de finos e o índice de plasticidade (Figura 5.7 e Figura 5.8).

Na Figura 5.7- Curva (a) redução de módulo cisalhante e (b) variação da razão de amortecimento na sondagem SPT-1.Figura 5.7 é apresentada a curva de redução de módulo cisalhante e a variação da razão de amortecimento para os rejeitos 1 a 4 na sondagem SPT-1. 
Curva de redução de módulo Roblee e Chiou (2004)

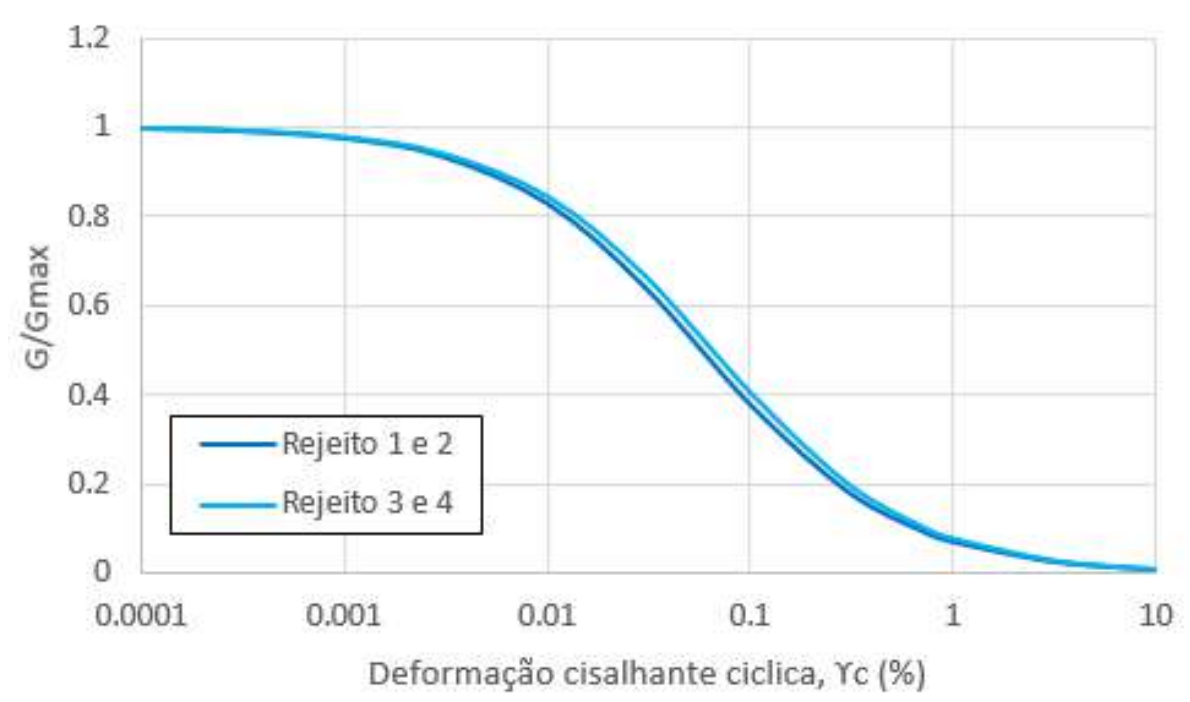

(a)

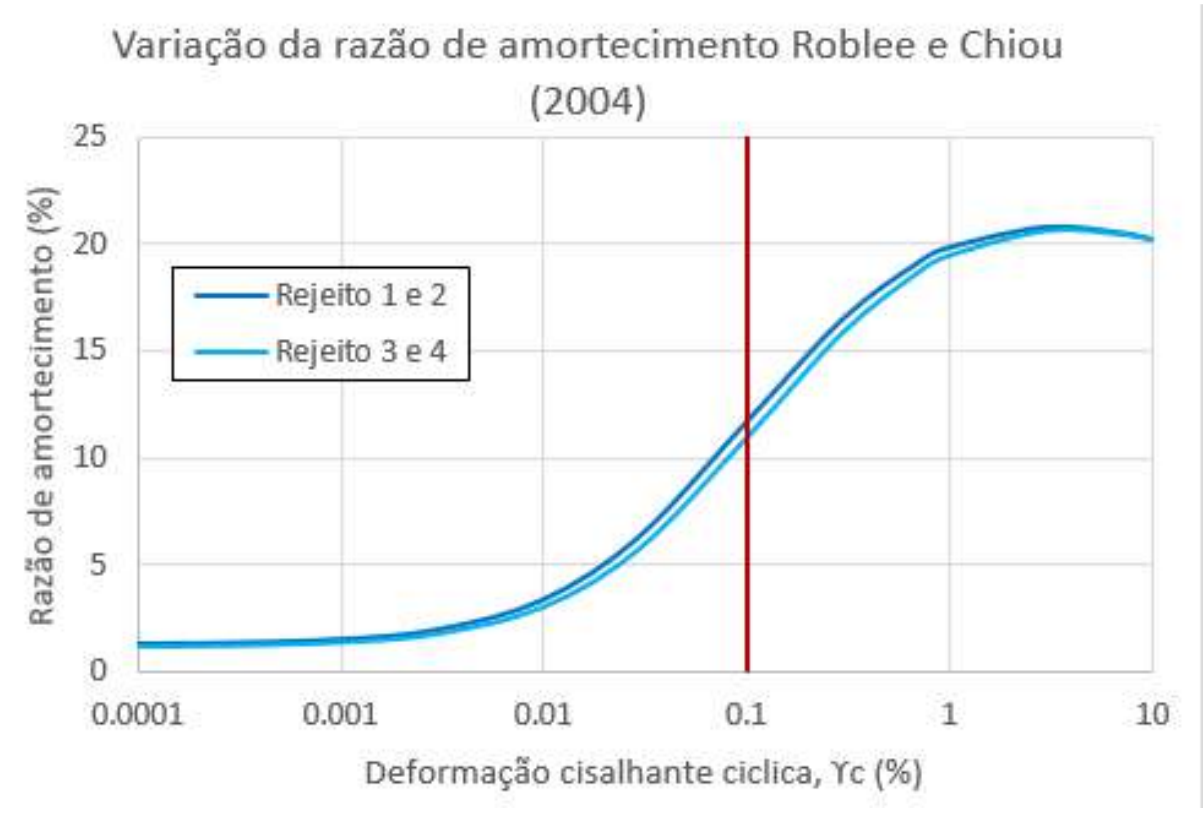

(b)

Figura 5.7- Curva (a) redução de módulo cisalhante e (b) variação da razão de amortecimento na sondagem SPT-1.

Na Figura 5.8 é apresentada a curva de redução de módulo cisalhante e a variação da razão de amortecimento para os rejeitos 1 a 4 na sondagem SPT-2. 
Curva de redução de módulo Roblee e Chiou (2004)

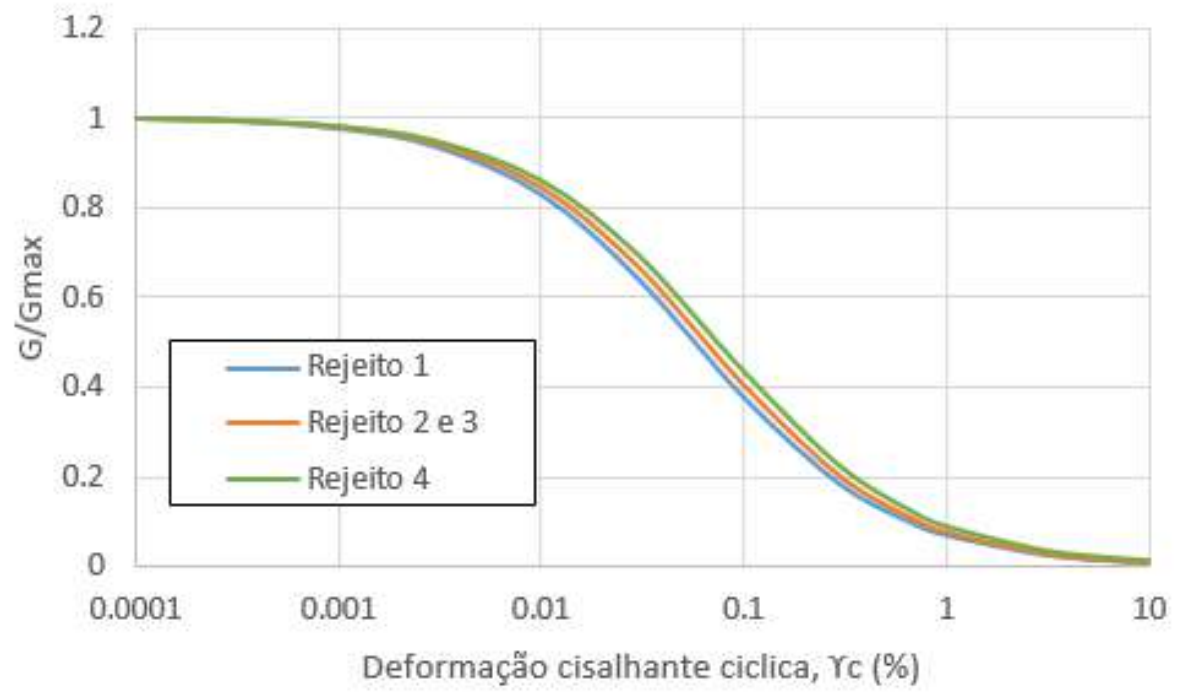

(a)

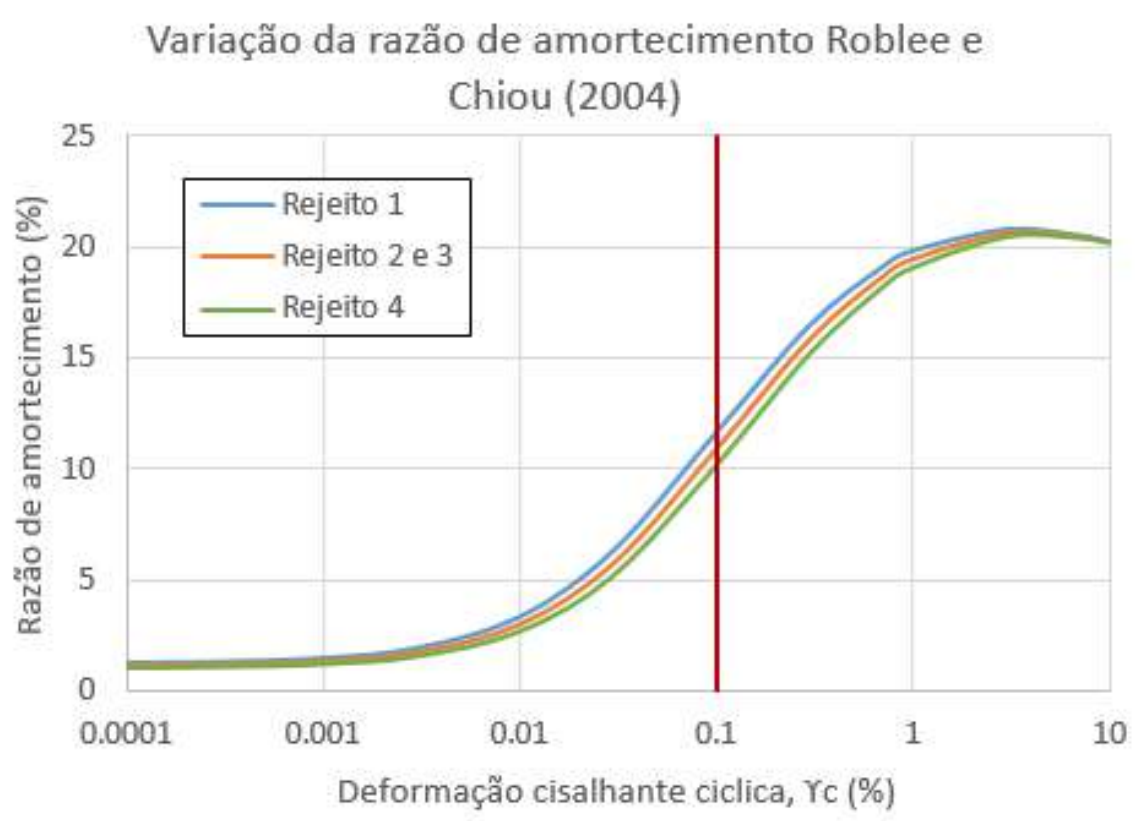

(b)

Figura 5.8- Curva (a) redução de módulo cisalhante e (b) variação da razão de amortecimento na sondagem SPT-2.

Finalmente temos os valores de aceleração em toda a camada de rejeitos. Esta avaliação foi feita para os sismos de Atico 2001, Lima 1974 e Maule 2010 ajustados espectralmente (Figura 5.9). 


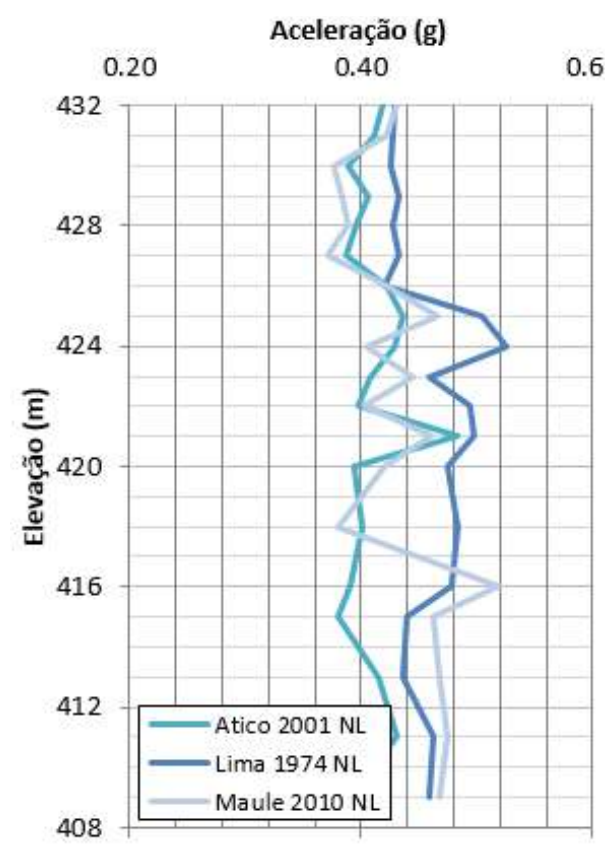

(a)

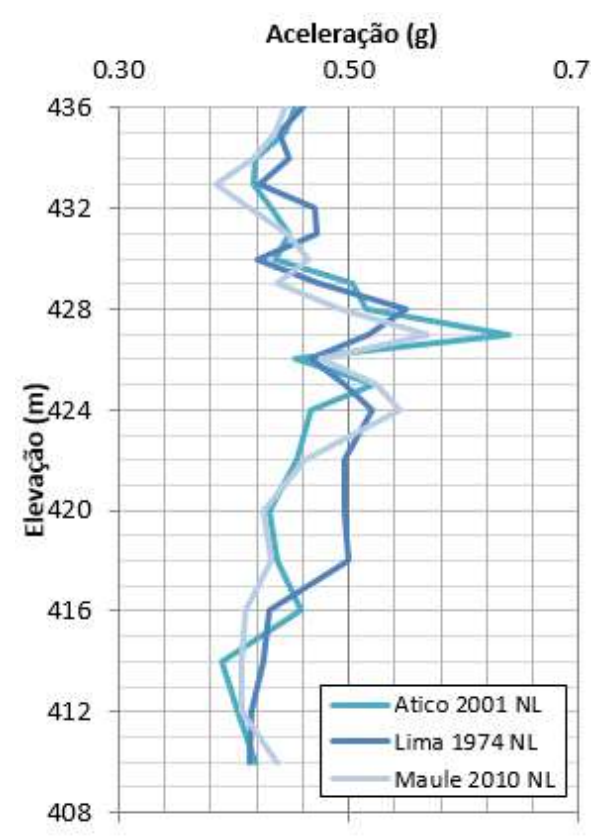

(b)

Figura 5.9- Aceleração a diferente elevação na sondagem (a) SPT-1 e (b) SPT-2.

\subsection{2.}

Metodo Boulanger e Idriss 2014

Determinados os valores de $\operatorname{CSR}_{(z)}$ e de $\operatorname{CRR}_{M} \sigma^{\prime}(z)$ é então possível calcular a distribuição dos fatores de segurança $F S_{\llcorner}$com a profundidade (Eq. 5.2). Da avaliação feita pelo método simplificado de Boulanger e Idriss (2014) na sondangem SPT-1 (Figura 5.2) a camada de rejeito com potencial de liquefação encontra-se entre os $432 \mathrm{~m}$ e $416 \mathrm{~m}$, tendo uma zona não liquefiável entre $421 \mathrm{~m}$ e 419m (Figura 5.10(a)). Na sondangem SPT-2 (Figura 5.2) a camada de rejeito com potencial de liquefação encontra-se entre os $436 \mathrm{~m}$ e $418 \mathrm{~m}$, tendo uma zona não liquefiável entre 423m e 421m (Figura 5.10(b)). 


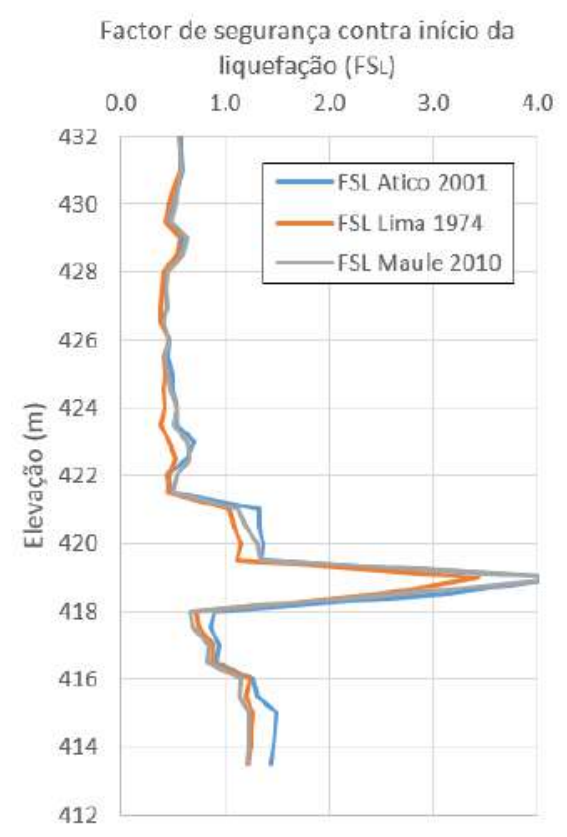

(a)

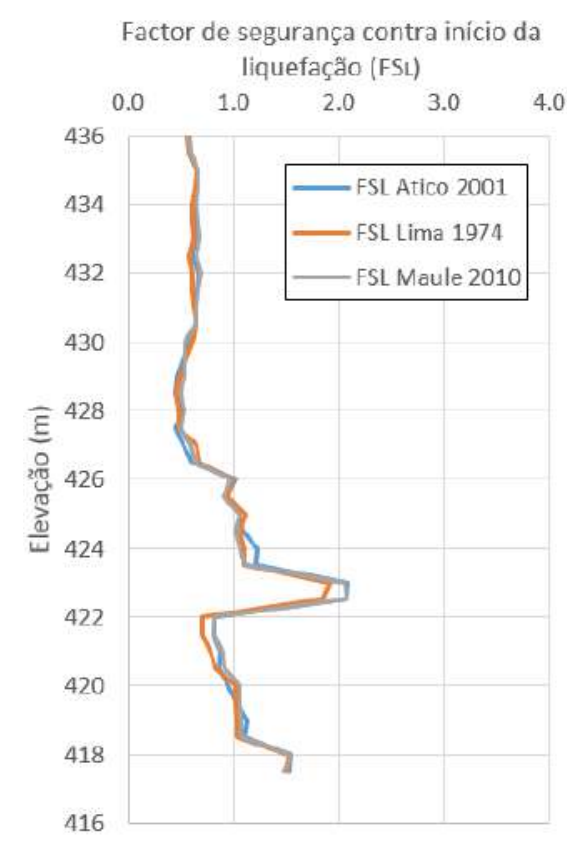

(b)

Figura 5.10- Variação do fator de segurança contra liquefação considerando os três sismos de projeto: a) furo SPT-1; b) furo SPT-2 (Boulanger e Idriss, 2014).

\subsection{3.}

\section{Metodo Youd et al 2001}

Determinados os valores de $\operatorname{CSR}_{(z)}$ e de $\operatorname{CRR}_{M} \sigma^{\prime}(z)$ é então possível calcular a distribuição dos fatores de segurança $\mathrm{FS}_{\llcorner}$com a profundidade (Eq. 5.2). Da avaliação feita pelo método simplificado de Youd et al (2001) na sondangem SPT1 (Figura 5.2) a camada de rejeito com um potencial de liquefação encontra-se entre os $430 \mathrm{~m}$ e $421 \mathrm{~m}$ (Figura 5.11(a)). Na sondangem SPT-2 (Figura 5.2) a camada de rejeitos com potencial de liquefação encontra-se entre os 430m e 426m (Figura $5.11(b))$. 


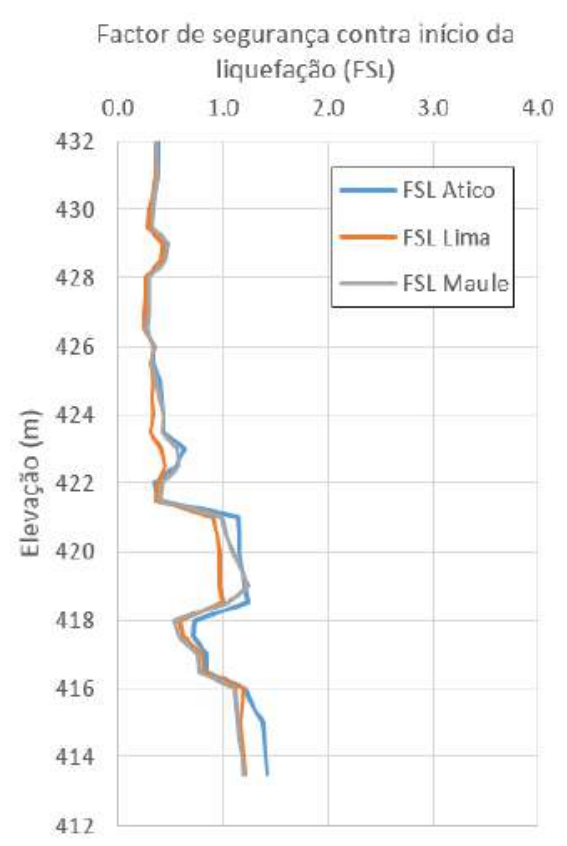

(a)

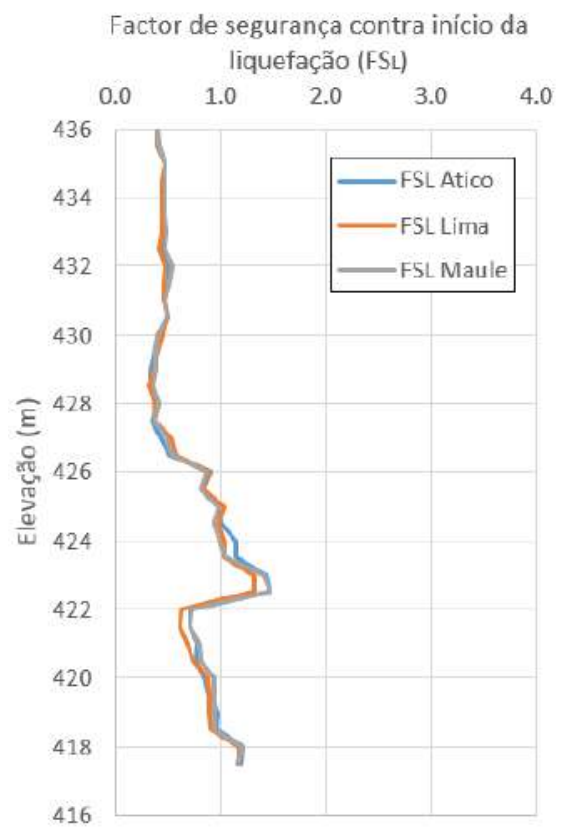

(b)

Figura 5.11- Variação do fator de segurança contra liquefação considerando os três sismos de projeto: a) furo SPT-1; b) furo SPT-2 (Youd et al., 2001).

\subsection{4.}

Metodo Castro 2014

De acordo com Castro (2014) a deformação cisalhante que ativa a liquefação encontra-se entre $0.2 \%$ a $1.0 \%$. Obtem-se uma boa concordação com o método de Boulanger e Idriss e Youd et al para uma deformação cisalhante de $0.4 \%$.

Da avaliação das deformações cisalhantes na sondangem SPT-1 temos deformações maiores a $0.4 \%$ nas elevações entre $432 \mathrm{~m}$ a $421 \mathrm{~m}$. Na sondagem SPT-2 temos deformações maiores a $0.4 \%$ nas elevações entre $436 \mathrm{~m}$ a $423 \mathrm{~m}$ (Figura 5.12 e Figura 5.13). 


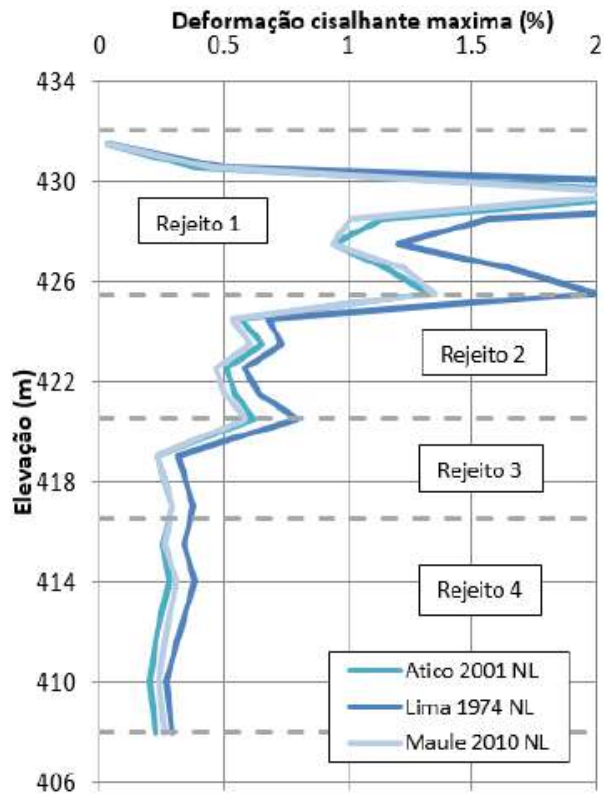

(a)

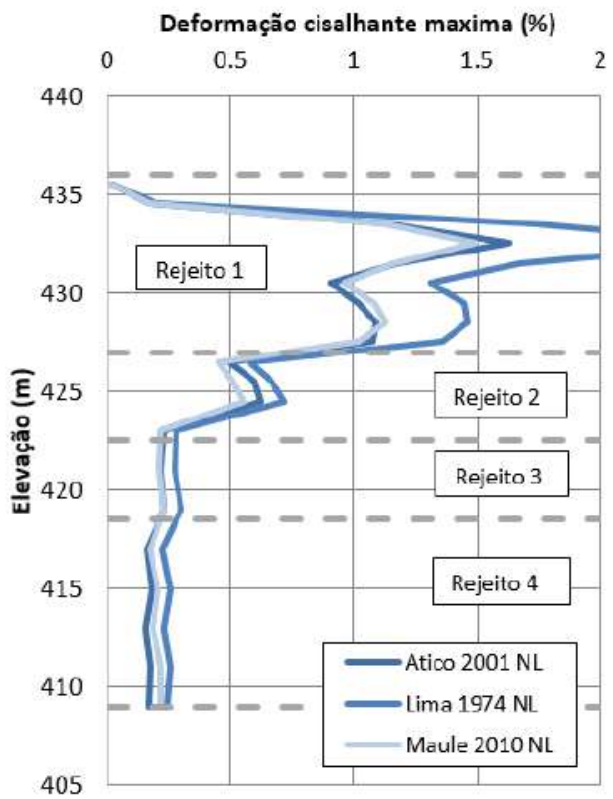

(b)

Figura 5.12- Deformação cisalhante máxima na sondagem (a) SPT-1 e (b) SPT-2.

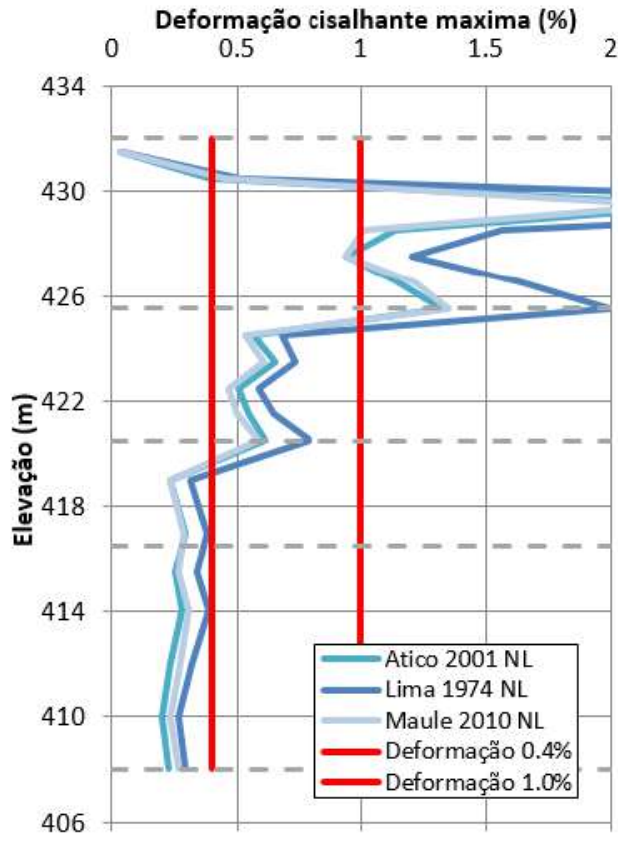

(a)

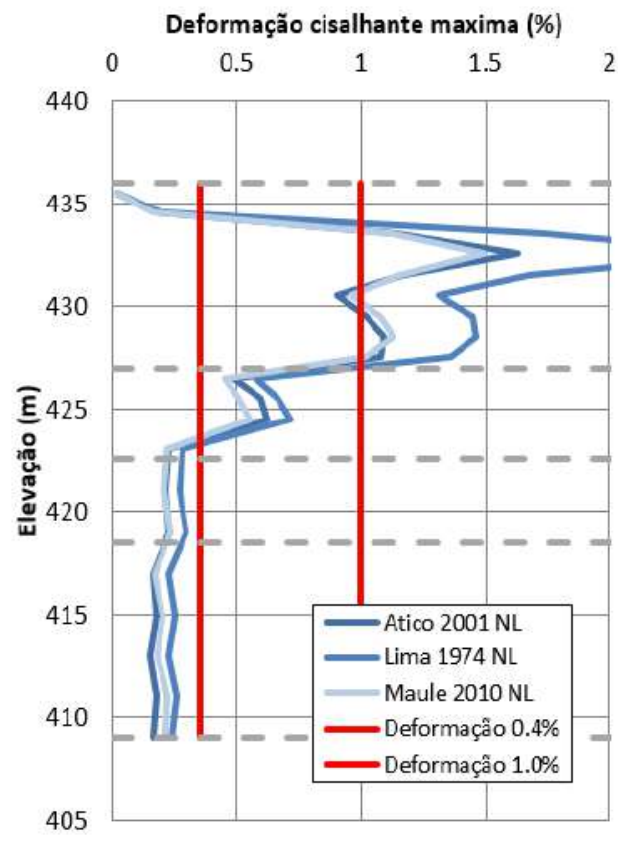

(b)

Figura 5.13- Deformação que ativa a liquefação na sondagem (a) SPT-1 e (b) SPT-2. 
Da avaliação do potencial de liquefação pelos diferentes métodos podemos considerar de forma conservadora que na sondagem SPT-1 teria liquefação entre as elevações $432 \mathrm{~m}$ ate $421 \mathrm{~m}$ e entre $418 \mathrm{~m}$ ate $416 \mathrm{~m}$. Na sondagem SPT-2 teria liquefação entre as elevações $436 \mathrm{~m}$ ate $424 \mathrm{~m}$ e entre $422 \mathrm{~m}$ ate $418 \mathrm{~m}$. 


\section{6 Aspectos da Modelagem do comportamento sísmico}

\section{1.}

\section{Análise numérica}

A solução de problemas tensão $\mathrm{x}$ deformação requer que as condições iniciais e de contorno sejam satisfeitas em termos de equilíbrio e compatibilidade, usando uma apropriada relação tensão x deformação. Técnicas numéricas como o método dos elementos finitos (MEF) ou diferenças finitas (MDF) são normalmente usadas para satisfazer, razoavelmente, essas condições.

Neste estudo foram executadas análises numéricas usando o programa PLAXIS 2D versão 2018.01. O programa usa o método de elementos finitos e satisfaz o equilíbrio dinâmico usando um procedimento no domínio do tempo implícito. O domínio geométrico é discretizado em uma malha triangular na qual cada elemento compreende seis ou quinze nós. Este programa permite o usuário implementar modelos constitutivos tensão x deformação específicos.

A equação básica para o movimento dependente do tempo de um volume sob a influência de uma carga (dinâmica) é:

$$
M \ddot{u}+C \dot{u}+K u=F
$$

onde $\mathrm{M}, \mathrm{C}$ e $\mathrm{K}$ são as matrizes de massa, amortecimento e rigidez, respectivamente, $\mathrm{F}$ é o vetor de carga. O deslocamento $(\mathrm{u})$, a velocidade $(u)$ e a aceleração $(u)$ podem variar com o tempo.

O comportamento dos solos pode ser drenado e não drenado. Neste último caso, a maior rigidez da água é adicionada à matriz de rigidez $\mathrm{K}$.

A matriz de massa $M$, leva em conta a massa dos materiais (partículas sólidas de solo, água e qualquer construção). 
A matriz C representa o amortecimento do material. De fato, este amortecimento de materiais é causado por fricção ou deformações irreversíveis (plasticidade ou viscosidade).

\subsection{1.}

\section{Amortecimento}

De acordo com Contreras (2014), o amortecimento é uma característica dos materiais submetidos a carregamento dinâmico, originado pela perda da energia devido ao atrito interno no material ou por deformação irreversível (plasticidade ou viscosidade). A consideração de amortecimento interno do solo é muito importante nos problemas de interação solo-estrutura sob carregamento sísmico, porque a coincidência das frequências fundamentais características do fenômeno sísmico $(1-10 \mathrm{~Hz})$ e as frequências próprias do solo podem produzir grandes amplificações nas respostas. Um cálculo aproximado da frequência natural de vibração de uma camada de solo homogêneo, elástico, isotrópico, de espessura $\mathrm{H}$ assente sobre um substrato rochoso, pode ser obtida pela equação (6.2) (Kramer, 1996).

$$
\mathrm{f}_{\mathrm{n}}=\frac{(2 \times \mathrm{n}+1)}{4 \times \mathrm{H}} \times \mathrm{V}_{\mathrm{s}}(\mathrm{Hz}) \quad \mathrm{n}=0,1,2, \ldots, \infty
$$

Onde $V_{S}$ é a velocidade da onda cisalhantes $(\mathrm{m} / \mathrm{s})$ e $\mathrm{H}$ é a altura do estrato $(\mathrm{m})$.

\subsubsection{1. \\ Amortecimento de Rayleigh}

De acordo com Huertas (2012), sistemas dinâmicos naturais contém algum grau de amortecimento da energia de vibração dentro do sistema; do contrário estes oscilariam indefinidamente. $\mathrm{O}$ amortecimento do material, ou melhor, a razão de amortecimento pode ser representada como sendo proporcional à frequência do carregamento (ondas elásticas). O amortecimento de Rayleigh é um modelo especial de amortecimento viscoso que admite a matriz de amortecimento como uma combinação linear das matrizes de massa e de rigidez, como originalmente proposto por Rayleigh e Lindsay (1945).

De acordo com Kramer (1996), define-se uma matriz de amortecimento ([C]) linearmente proporcional às matrizes de massa ([M]) e de rigidez ([K]), garantindo 
a ortogonalidade dos modos próprios de vibração do sistema, sem a introdução de nenhum modo adicional (equação 6.3).

$$
[\mathrm{C}]=\alpha[\mathrm{M}]+\beta[\mathrm{K}]
$$

onde os coeficientes $\alpha$ e $\beta$ são constantes de amortecimento, que podem ser obtidas definindo a fração de amortecimento crítico $\left(\xi_{i}\right)$, para duas frequencias predeterminadas $\left(\omega_{i}\right)$ que definem uma faixa de frequencias (equação 6.4).

$$
\xi_{i}=\frac{\alpha}{2 \times \omega_{i}}+\frac{\beta \times \omega_{i}}{2} \quad i=1,2
$$

Então a escolha de $\xi_{\mathrm{i}}$, assim como a faixa das frequências, é algo arbitrário, sugerindo-se que esta faixa inclua as frequências de excitação e as fundamentais do sistema. A Figura 6.1 apresenta valores de baixas frequências, $\alpha$ é a constante predominante, consequentemente a massa é o fator determinante, enquanto que para valores de altas frequências, predominam o coeficiente $\beta$ e a rigidez do sistema.

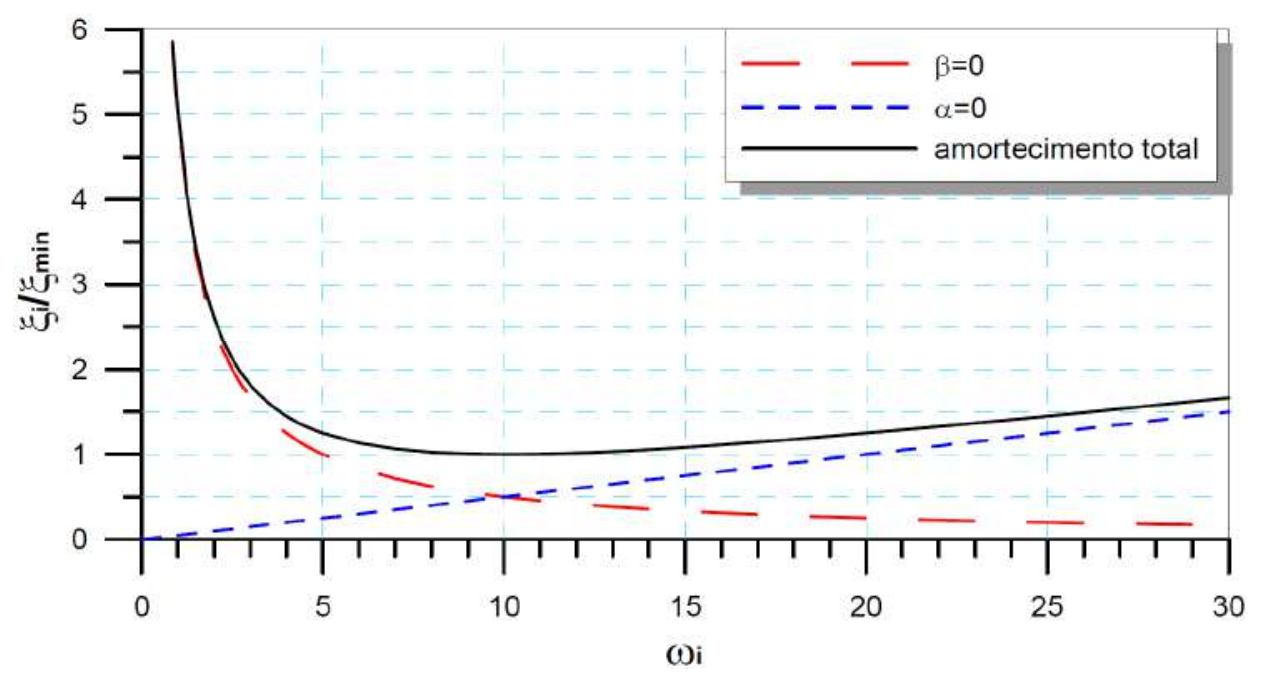

Figura 6.1- Variação da razão de amortecimento crítico normalizado em relação à frequência angular (adaptado Contreras, 2014).

De acordo com López (2015), para um único valor de frequência, a chamada frequência mínima $\left(f_{\min }\right)$, o amortecimento de Rayleigh está composto por partes igualmente proporcionais tanto de contribuções da massa quanto da rigidez. $O$ 
amortecimento de Rayleigh somente pode ser usado para um intervalo limitado de frequências.

\subsubsection{2.}

\section{Amortecimento histerético}

O amortecimento histerético é independente da frequência de excitação.

Este tipo de amortecimento representa o comportamento de solos sob carregamento cíclico.

Segundo Contreras (2014), em solos constata-se por meio de ensaios de laboratório que o amortecimento é independente da frequência, mas é função do nível de deformação cisalhante da amostra causado pelo carregamento dinâmico.

A razão de amortecimento histerético local é descrita pela seguinte fórmula:

$$
\xi=\frac{E_{D}}{4 \pi E_{S}}=\frac{1}{2 \pi} \frac{A_{\text {laço }}}{G_{s e c} \gamma_{c}^{2}}
$$

onde $E_{D}$ é a energia dissipada no ciclo, $E_{S}$ é a energia de deformação máxima, $A_{\text {laço }}$ é área do laço de histerese e $G_{\text {sec }}$ o módulo de cisalhamento secante.

Normalmente, as curvas de aumento de amortecimento estão fora do intervalo de deformações com aquelas obtidas em ensaios de laboratório, predominantemente na faixa de baixas deformações. Em consequência, os pesquisadores sugerem adotar uma solução intermediária, procurando-se concordar as curvas teóricas e de laboratorio no intervalo de níveis de deformações esperados.

\subsection{2.}

\section{Integração no tempo}

Na implementação numérica de problemas dinâmicos, a formulação do processo de integração no tempo constitui um fator importante para a estabilidade do método e precisão dos resultados. Os esquemas de integração utilizam um método explícito (programa FLAC) ou um método implícito (programa PLAXIS, usado nesta pesquisa). 
A vantagem da integração explícita é que esta é relativamente simples de formular. No entanto, a desvantagem é que o processo de cálculo não é tão robusto e impõe sérias limitações ao passo do tempo. O método implícito é mais complicado, mas produz um processo de cálculo mais confiável (mais estável) e geralmente uma solução mais precisa (Sluys, 1992).

O esquema de integração implícito no tempo de Newmark, o deslocamento e a velocidade do ponto no tempo $t+\Delta t$ são expressos como:

$$
\begin{gathered}
u^{t+\Delta \mathrm{t}}=u^{t}+\dot{u}^{t} \Delta t+\left[\left(\frac{1}{2}-\alpha\right) \ddot{u}^{t}+\alpha \ddot{u}^{t+\Delta \mathrm{t}}\right] \Delta t^{2} \\
\dot{u}^{t+\Delta \mathrm{t}}=\dot{u}^{t}+\left[(1-\beta) \ddot{u}^{t}+\beta \ddot{u}^{\cdot t+\Delta \mathrm{t}}\right] \Delta t
\end{gathered}
$$

onde $\Delta$ t é o intervalo de tempo, $\alpha$ e $\beta$ são coeficientes que determinam a precisão do tempo de integração numérica. Para obter uma solução estável, as seguintes condições são estabelecidas:

$$
\begin{gathered}
\alpha \geq \frac{1}{4}\left(\frac{1}{2}+\beta\right)^{2} \\
\beta \geq 0.5
\end{gathered}
$$

Com a integração em tempo implícito, a equação (6.10) deve ser obtida no final do intervalo de tempo $(t+\Delta t)$ :

$$
M \ddot{u}^{t+\Delta t}+C \dot{u}^{t+\Delta t}+K u^{t+\Delta t}=F^{t+\Delta t}
$$

\subsection{3.}

\section{Passo de tempo crítico}

Apesar das vantagens da integração implícita, o intervalo de tempo usado no cálculo está sujeito a algumas limitações. Se o intervalo de tempo for muito grande, a solução exibirá desvios substânciais e a resposta calculada não será confiável. O tempo crítico depende da freqüência máxima e da grossura (finura) da malha de elementos finitos. A equação usada para um único elemento é:

$$
\Delta t_{c r i ́ t i c o}=\frac{l_{\min }}{V_{S}}
$$


onde $I_{\min }$ é o comprimento mínimo entre dois nós de um elemento e Vs é a velocidade da onda de cisalhamento de um elemento. Em um modelo de elemento finito, o intervalo de tempo crítico é igual ao valor mínimo de $\Delta t$ de acordo com a Equação (6.11) sobre todos os elementos. Desta forma, o passo de tempo é escolhido para garantir que uma onda durante uma única etapa não se mova uma distância maior do que a dimensão mínima de um elemento.

\subsection{4.}

\section{Discretização da malha para a transmissão da onda}

Kuhlemeyer \& Lysmer (1973) concluíram que para uma representação exata da transmissão da onda através do modelo, o tamanho do elemento $\Delta l$, deveria ser menor que aproximadamente um décimo a um oitavo do comprimento de onda do carregamento dinâmico. Esta condição é expressa com a seguinte relação:

$$
\Delta l \leq \frac{\lambda}{10} a \frac{\lambda}{8}
$$

onde $\lambda$ é o comprimento de onda associado à frequência predominante que contem uma quantidade considerável de energia.

A frequência de corte pode ser determinada com a seguinte relação:

$$
f_{c}=\frac{V_{S}}{\lambda}
$$

onde $\mathrm{v}_{s}$ é a velocidade de onda cisalhante sendo:

$$
V_{S}=\sqrt{\frac{G}{\rho}}
$$

onde $G$ o módulo de cisalhamento e $\rho$ a massa específica do material.

Conhecidos os valores de $v_{S}$ e $f_{C} e$, pode-se calcular $0 \quad \lambda \quad e$ consequentemente $\circ \Delta$ (Equação 6.12) equivalente à dimensão máxima das zonas que compõem a malha. 


\subsection{5.}

\section{Considerações de contorno}

No caso de uma análise de deformação estática, os deslocamentos de contorno prescritos são introduzidos nos limites de um modelo de elemento finito. Os limites podem ser completamente livres ou fixos em uma ou duas direções. Particularmente, os limites verticais de uma malha são frequentemente limites não físicos (sintéticos) que foram escolhidos de modo a não influenciar o comportamento de deformação da construção a ser modelada. Em outras palavras, os limites estão distantes. Para cálculos dinâmicos, os limites devem, em princípio, estar muito mais distantes do que aqueles para cálculos estáticos, porque, caso contrário, ondas de tensão serão refletidas levando a distorções nos resultados computados. No entanto, localizar os limites longe requer muitos elementos extras e, portanto, muita memória extra e tempo de cálculo. Para neutralizar as reflexões, limites silenciosos ou absorventes são introduzidos.

\subsubsection{1. \\ Contornos de campo livre}

O contorno de campo livre consiste na simulação de colunas de solo junto aos contornos laterais da malha de elementos finitos

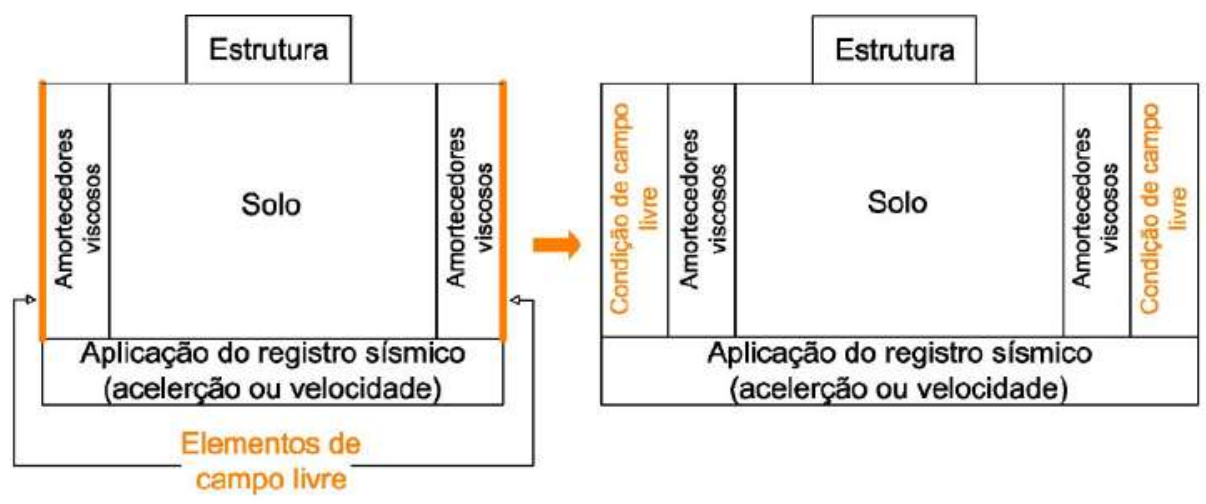

Figura 6.2), sujeitas à propagação 1D de ondas geradas pelo terremoto, propagando-se verticalmente. Na ausência da geoestrutura (condição de campo livre) obtem-se então a resposta do maciço de solo ao longo dos contornos laterais, que seriam praticamente as mesmas se a geoestrutura fosse também modelada, mas situada suficientemente distante dos contornos laterais. 

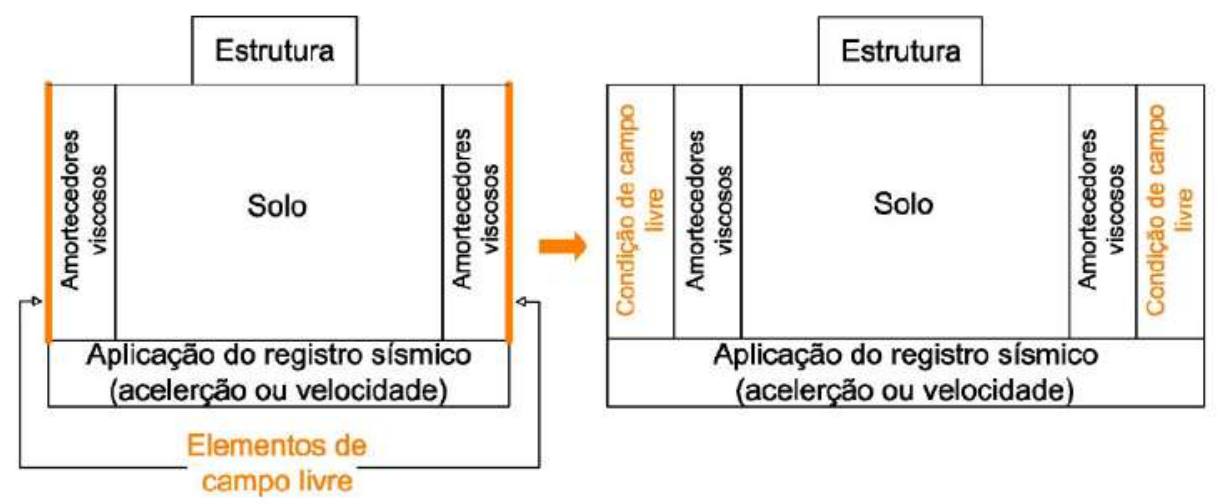

Figura 6.2- Condições de contorno de campo livre (Perez, 2013).

As colunas de solo laterais são acopladas à discretização principal por meio de amortecedores viscosos que atuam sempre que o movimento da discretização 2D principal se diferenciar do movimento 1D das colunas de solo. Fato que pode ser causado por reflexões de onda na geoestrutura, em interface não horizontais entre camadas de solo, entre outros.

\subsubsection{2.}

\section{Considerações sobre a base do modelo}

Quando o registro sísmico a ser aplicado na base do modelo numérico tiver sido adquirido em outra localização, normalmente na rocha aflorante (outcrop), a convolução do registro sísmico é geralmente feita.

A aplicação do registro sísmico assim processado pode ser feita considerando-se ainda 2 hipóteses: (1) base rígida - história das acelerações ou das velocidades é aplicada diretamente; (2) base flexível - história das tensões, obtida a partir da história das velocidades, é aplicada diretamente, no programa PLAXIS 2D 2018.01, se for utilizada a opção compliant base boundary, a história de acelerações é internamente transformada em uma história de tensões sem intervenção direta do usuário.

Para maioria das situações encontradas na prática, exceto apenas para o caso de substrato rochoso muito rígido, a hipótese de base flexível é admitida. 


\section{2. Metodo de equilíbrio limite}

Nos problemas de estabilidade de taludes sob condição estática, o método de equilíbrio limite (método das fatias) é geralmente empregado para cálculo do fator de segurança, subdividindo a região de solo delimitada pela potencial superfície de ruptura em um número qualquer de fatias verticais e analisando as condições de equilíbrio estático em cada fatia isoladamente.

As hipóteses propostas pelo método do equilíbrio limite são as seguintes:

- A superfície de falha potencial é bem definida;

- O colapso da massa do solo é incipiente;

- O critério de Mohr-Coulomb é encontrado ao longo de toda a superfície de ruptura ou algum outro critério previamente estabelecido;

- Um único FS é obtido ao longo de cada superfície de falta;

- Considera-se que o solo tem um comportamento mecânico como materiais rígidos perfeitamente plásticos.

Existem vários métodos para calcular o FS de uma massa deslizante. A mais utilizada na prática é o método de Spencer (1967), que satisfaz todas as equações de equilíbrio e é a mais estável numericamente; assume que as inclinações das forças laterais são as mesmas para cada segmento e a inclinação da força lateral é calculada no processo de solução.

Objeções teóricas em relação ao método de equilíbrio limite levaram à utilização de métodos numéricos na investigação da estabilidade de taludes procuram incorporar as relações tensão-deformação dos diversos solos que formam o maciço do talude.

Dentre as várias técnicas, prevalece o método da simulação do colapso ou da redução da resistência, incorporado no PLAXIS 2D. O fator de segurança é calculado pela redução progressiva dos parâmetros de resistência de MohrCoulomb (equações 6.15 e 6.16) até a iminência da ruptura do talude.

$$
c^{*}=\frac{c}{M}
$$




$$
\tan ^{*} \phi=\frac{\tan \phi}{M}
$$

onde M é um parâmetro que varia nas sucessivas análises não lineares, até a ruptura do talude quando $\mathrm{M}=\mathrm{FS}$ (fator de segurança).

\subsection{1.}

\section{Análise pseudo-estática}

Uma aproximação da análise sísmica de estabilidade de taludes é a utilização de uma abordagem pseudo-estática, usada na estimativa da estabilidade sob carregamento sismico há décadas (Kramer, 1996; Ribeiro, 2006; Macedo, 2013), com a primeira aplicação atribuída a Terzaghi (1950).

As diversas soluções de equilíbrio limite para análise da estabilidade de taludes de solo sob carregamento estático são possíveis de serem estendidas para um contexto pseudo-estático adicionando-se forças aplicadas no centróide da massa instável, conservando o mesmo módulo e direção, porém sentido oposto ao das forças inerciais geradas pela propagação da excitação sísmica (princípio de d'Alembert). Neste tipo de análise geralmente a componente vertical da força de inércia é desprezada em função da hipótese de que as ondas cisalhantes incidentes SV são verticais, e a componente horizontal é obtida pela multiplicação do coeficiente sísmico horizontal $\mathrm{k}$ pelo peso da massa de solo instável. Um aspecto a observar é que no método pseudo-estático as forças de inércia horizontais são consideradas permanentemente atuantes no mesmo sentido e com o mesmo módulo, quando na realidade sentido e módulo variam ao longo do tempo de duração do terremoto. Dentre as principais recomendações da literatura, o valor mínimo aceitável do coeficiente de segurança pseudo-estático varia entre 1 a 1,15 .

\section{3.}

\section{Deformações permanentes por métodos simplificados}

Todos os métodos baseados na deformação são aproximações simplificadas do mecanismo físico real da deformação do declive induzido pelo sismo. Existem três modelos fundamentais: (1) modelo de bloco rígido, (2) modelo desacoplado e (3) modelo acoplado, que podem ser simples ou complexos e diferem em algumas suposições e idealizações usadas para representar 0 
mecanismo de deslocamento induzido por terremoto. Na Tabela 6.1 mostra-se um resumo dos métodos de deslocamento permanente feito pelo Murphy (2010).

Tabela 6.1- Resumo dos métodos de deslocamento permanente (Murphy, 2010)

\begin{tabular}{|c|c|c|c|c|}
\hline No. & Metbod & Acrooym & $\begin{array}{c}\text { Model } \\
\text { Cattegury. }\end{array}$ & $\begin{array}{l}\text { Method } \\
\text { Type }\end{array}$ \\
\hline 1 & Newmark (1965) & N1965 & RB & s \\
\hline 2 & Serme (1975) & S1975 & RB & s \\
\hline 3 & Franklim and Coang (1977) & FC1977 & RB & s \\
\hline 4 & Ambraseys and Menu (1988) & AM1988 & RB & s \\
\hline 5 & Yegem et al (1991) & YMG1991 & RB & s \\
\hline 6 & Ambraseys and Situlov (1994) & AS1994 & RB & s \\
\hline 7 & Wrscon-Lamprey and Abrahmeon (2006) & WLA2006 & RB & s \\
\hline 8 & Bray and Tratasarou (2007) [Rigid] & BT200TR & RB & s \\
\hline 9 & Jibson (2007) [Method A] & ת2007A & RB & s \\
\hline 10 & hbsoa (2007) [Method B] & J2007B & RB & s \\
\hline 11 & Jibsoa (2007) [Metbod C] & J2007C & $\mathrm{RB}$ & s \\
\hline 12 & Saygh and Rachye (2008) [Method A] & SR2008A & RB & s \\
\hline 13 & Saygali and Rathje (2008) [Method B] & SR2008B & RB & s \\
\hline 14 & ISUIP & YSUP & RB & A \\
\hline 15 & Makdes and Seed (1978) & MS1978 & DEC & s \\
\hline 16 & Hyanes-Giffio and Franklin (1984) & HGF1984 & DEC & $\mathbf{s}$ \\
\hline 17 & Bray et al. (1998) & BRAM1988 & DEC & s \\
\hline 18 & ID FLC Decoupled & IDDEC & DEC & A \\
\hline 19 & 2D FUAC Decoupled & 2D DEC & DEC & A \\
\hline 20 & Bray and Travasarou (2007) [Coupled] & BT2007C & CPL & s \\
\hline
\end{tabular}

Abreviaturas:

(a) RB: modelo de bloque rigido; DEC: modelo desacoplado; CPL: modelo acoplado

(b) S: modelo tipo simplificado; $A$ : modelo analitico 


\subsection{1.}

Metodo de Swaisgood (2013)

Swaisgood (2013) analisou estatisticamente os casos históricos de deformação de barragens entre 1990-2003 procurando correlacionar os recalques de crista (Figura 6.3) com a aceleração de pico (PGA) e a magnitude de momento (M), envolvendo 82 terremotos com magnitudes entre 5,3 e 9. As relações obtidas por análise de regressão são mostradas nas equações 6.17 e 6.18. (Figura 6.3).

$$
\% \text { Deslocamento }=e^{(5.70 P G A+0.47 M-7.22)} \quad 6.17
$$

$\%$ Deslocamento

$$
=\frac{\text { Deslocamento }}{\text { Altura da barragem }+ \text { Espessura da fundação }} \times 100
$$

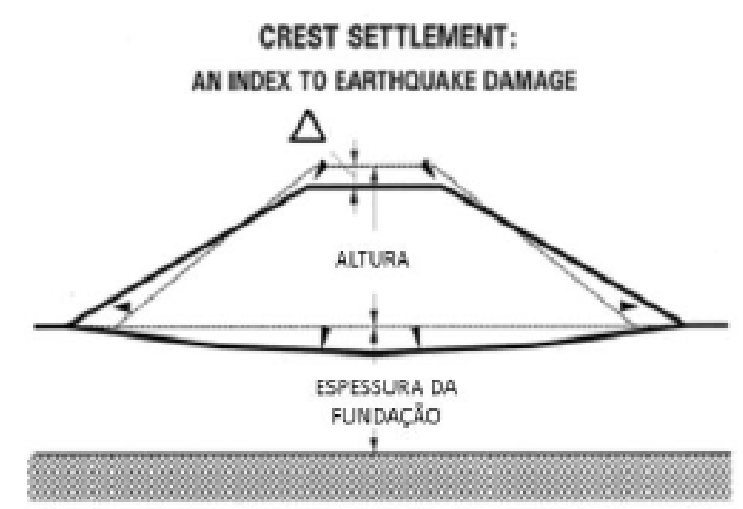

Figura 6.3- Seção na análise do deslocamento vertical permanente pelo método de Swaisgood (2013). 


\section{7 \\ Análise da resposta dinâmica da barragem de rejeitos Otapara}

Este capitulo tem como objetivo avaliar o comportamento dinâmico de uma barragem de rejeitos, localizada em Arequipa, Peru, para três sismos de projeto ajustados ao espectro de resposta obtido de estudo de ameaça sísmica. Os resultados da análise numérica pelo método dos elementos finitos foram comparados com valores do fator de segurança contra liquefação determinado por método empírico. Na modelagem numérica o comportamento mecânico dos rejeitos foi simulado com o modelo constitutivo elastoplástico UBC3D-PLM, capaz de estimar o potencial de liquefação dinâmica de materiais granulares submetidos a carregamentos cíclicos. Os principais aspectos analisados pesquisa foram os campos de deslocamento, história e distribuição final do parâmetro de poropressão (ru), acelerações espectrais e a história de deslocamentos verticais. Fatores de segurança para as condições estática, pseudo-estática e pós-sismo também foram determinados. A modelagem numérica permitiu identificar as áreas com potencial de liquefação dinâmica e avaliar a estabilidade da barragem para os três sismos de projeto considerados. Na Figura 7.1 mostra-se o fluxograma das etapas da modelagem numérica nas condições estáticas e dinâmicas.

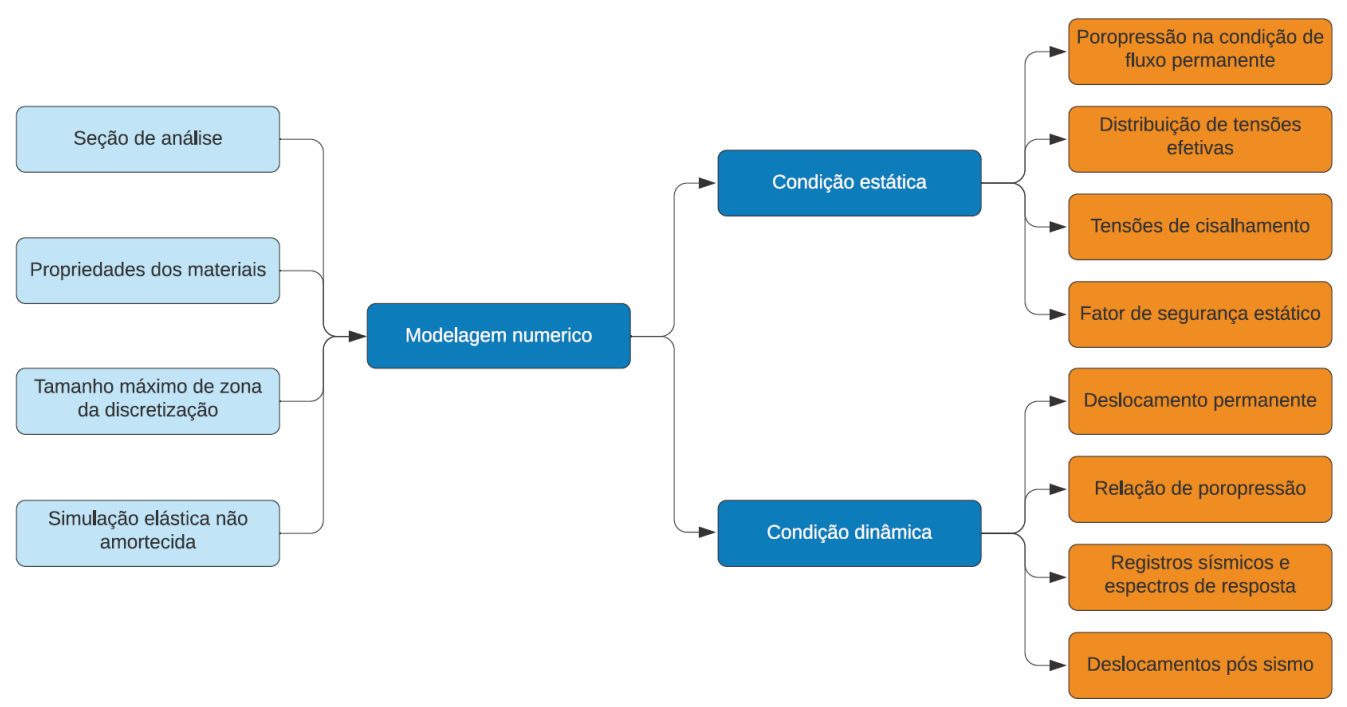

Figura 7.1- Fluxograma da modelagem numérica. 


\section{1.}

Considerações da modelagem

Com base em resultados de ensaios de campo e de laboratório, foram obtidos os parâmetros para simulação do comportamento mecânico dos materiais da barragem e depósito de rejeitos para condições estáticas e sob carregamento sísmico. Nesta pesquisa foi empregado o programa computacional Plaxis 2D para realizar a modelagem computacional.

\subsection{1.}

Unidades geotécnicas

De acordo com o mapeamento geológico-geotécnico, registros das sondagens e informações existentes, foram definidas quatro unidades geotécnicas.

\subsubsection{Depósito coluvial (Unidad Geotécnica I)}

Compostos por solos cuja formação é produzida pela ação da gravidade, composta de materiais rochosos, angulares a sub-angulares de vários tamanhos, mas litologia homogênea, incluídos em uma matriz arenosa de silte, esses depósitos de solo estão localizados nas encostas dos córregos, como resultado de intemperismo, erosão e transporte mínimo para os principais canais.

\subsubsection{2.}

\section{Depósito aluvial (Unidad Geotécnica II)}

Formados por solo transportado e/ou depositado temporariamente ou permanentemente por fluxo de água, correspondem a restos de fluxos de lama (escorregamentos recentes). Compostos principalmente por blocos de rocha formados por pedregulhos. e cascalhos sub arredondados, de várias dimensões, de natureza heterolítica, matriz pouco consolidada, com intercalação de camadas arenosas e pouco consolidada de silte.

Durante o mapeamento geotécnico geológico, foram observados depósitos recentes deste material localizados a montante do depósito. Da mesma forma, o material de fundação da represa do reservatório é composto do mesmo tipo de solo. 


\subsubsection{3. \\ Depósitos antrópicos (Unidad Geotécnica III)}

São gerados pela atividade humana, a qual modifica o grau de compacidade, umidade, granulometria, estado de repouso, etc para obter-se algum benefício. No entanto, uma vez que estão dispostos em sua localização final, eles adquirem suas próprias características.

Os tipos de depósitos antrópicos localizados na área de estudo são descritos: (1) Rejeitos: são aqueles que chegam da usina de beneficio e mediante o processo de cicloneado se dividem em underflow e overflow. Os underflow ou rejeitos grossos, conformam as encostas superiores do depósito de rejeitos; e os overflow ou rejeitos finos, são depositados na bacia do depósito de rejeitos. (2) Aterro compactado: é o material de corte de solo aluvial que forma a parte superior do dique de partida do depósito de rejeitos; este material foi compactado e é composto de cascalho siltoso, de compacidade muito compacta, com a presença de peregulhos e blocos de forma arredondada.

\subsubsection{4. \\ Basamento rocoso (Unidad Geotécnica IV)}

Esta unidade é composta de rocha granítica de grão médio a grosso, equigranular e holocristalino, correspondendo ao Cretáceo-Terciário; com boa resistência como rocha intacta e qualidade II (boa rocha). Sua distribuição está localizada na área onde encontra-se o depósito de rejeitos de Otapara e foi detectada em afloramentos rochosos e em alguns poços nas proximidades do depósito de rejeitos. No entanto, em algunas partes tem um forte grau de intemperismo o que diminui a qualidade da massa rochosa.

A caracterização da massa rochosa consiste no trabalho de observação, medidas e ensaios para obter parâmetros quantitativos úteis para identificar as características geotécnicas, o mesmo que está em função da resistência das rochas intactas, do índice de qualidade das rochas e da geometria das descontinuidades. Para determinar a qualidade da massa rochosa, foi utilizada a classificação RMR (Rock Mass Rating) de Bieniawski 1989. O mesmo que fornece uma estimativa de vários parâmetros: (Resistência à compressão da rocha, Índice da qualidade da rocha - RQD, Espaçamento das juntas, Estado das juntas e 
Presença de água); onde cada um desses parâmetros definidos possui intervalos e valores definidos; para finalmente obter o valor da qualidade da massa rochosa.

A Tabela 7.1 resume os valores médios de RMR para a estação geomecânica, sendo determinada como classe II de rocha (Boa Qualidade).

Tabela 7.1- Avaliação do maciço rochoso

\begin{tabular}{|c|c|c|c|}
\hline Localização & $\begin{array}{c}\text { RMR } \\
\text { Básico }\end{array}$ & Descrição & Classe \\
\hline $\begin{array}{c}\text { Periferia da barragem } \\
\text { de rejeitos }\end{array}$ & 61 & Roca & II \\
\hline
\end{tabular}

De acordo com Zafitovski (2016) é possível estimar o valor da velocidade de onda longitudinal $(\mathrm{Vp})$ em $\mathrm{m} / \mathrm{s}$ pela seguinte relação $\mathrm{RMR}=5684.8 \mathrm{~V}_{\mathrm{P}}^{1.4979}$, conservadoramente vai ser considerado uma velocidade de ondas de cisalhamento (Vs) de $1400 \mathrm{~m} / \mathrm{s}$ para a rocha.

\subsection{2.}

\section{Seção de análise}

Na Figura 7.2 apresenta-se a seção transversal representativa da barragem de rejeitos Otapara, onde a rocha $(R)$, o aterro compactado $(A C)$, o deposito aluvial (DA) e os rejeitos ( $R 0, R 1, R 2, R 3, R 4, R 5$ e R6) são os materiais considerados na análise numérica.

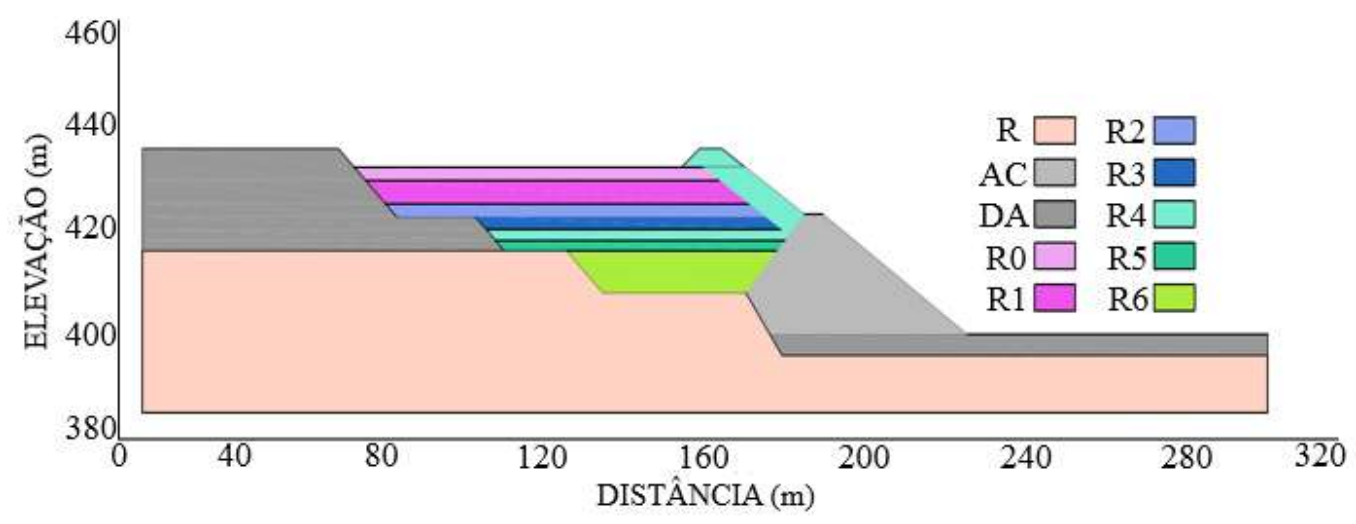

Figura 7.2- Corte transversal da barragem de rejeitos de Otapara. 


\subsection{3.}

\section{Propriedades dos materiais}

Em função do tipo de análise, os materiais são simulados mecanicamente pelo modelo elástico linear (rocha), pelo modelo elastoplástico HSM - Hardening Soil Model (aterro e depósito aluvial) e pelo modelo de solo elastoplástico UBC3DPLM (rejeitos). Em continuação se apresentam as propriedades dos materiais e suas respectivas condições de análise.

Baseado na investigação geotécnica, ensaios de laboratório e correlações, foram estimados os parâmetros elásticos dos materiais, os quais são apresentados na Tabela 7.2. O modelo elástico linear foi usado para simular o comportamento do material de rocha na condição estática e dinâmica, por ser mais rígido que as camadas de fundação e os materiais da barragem, e não espera-se que ocorra esforços plásticos.

Tabela 7.2- Propriedades elasticos dos materiais.

\begin{tabular}{|c|c|c|c|c|c|}
\hline Material & Descrição & $\begin{array}{c}Y_{\text {total }} \\
\left(k N / m^{3}\right)\end{array}$ & $\begin{array}{c}E \\
(\mathrm{MPa})\end{array}$ & $\begin{array}{l}v^{\prime} \\
(-)\end{array}$ & $\begin{array}{c}v_{s} \\
(m / s)\end{array}$ \\
\hline $\mathrm{R}$ & Rocha & 24 & 13500 & 0,20 & 1400 \\
\hline$A C$ & Aterro compactadot & 21 & 720 & 0,30 & 377 \\
\hline $\mathrm{DA}$ & Deposito aluvialt & 21 & 720 & 0,30 & 368 \\
\hline Ro & Rejeito 0 & 17 & 70 & 0,35 & 110 \\
\hline $\mathrm{R} 1$ & Rejeito 1 & 17 & 70 & 0,35 & 130 \\
\hline $\mathrm{R} 2$ & Rejeito 2 & 18 & 140 & 0,35 & 170 \\
\hline R3 & Rejeito 3 & 18 & 180 & 0,35 & 195 \\
\hline $\mathrm{R} 4$ & Rejeito 4 & 18 & 300 & 0,35 & 250 \\
\hline R5 & Rejeito 5 & 19 & 200 & 0,35 & 200 \\
\hline R6 & Rejeito 6 & 19 & 350 & 0,35 & 265 \\
\hline
\end{tabular}

Para a modelagem em condição estática foi considerado o modelo constitutivo Hardening soil model (HSM). As propriedades dos materiais são apresentadas na Tabela 7.3 
Tabela 7.3- Propriedades dos materias usadas na análise estática.

\begin{tabular}{|c|c|c|c|c|c|c|c|c|c|}
\hline Material & AC & DA & R0 & $\mathbf{R} 1$ & $\mathbf{R 2}$ & $\mathbf{R} 3$ & $\mathbf{R 4}$ & $\mathbf{R} 5$ & R6 \\
\hline $\mathrm{Y}\left(\mathrm{kN} / \mathrm{m}^{3}\right)$ & 21 & 21 & 17 & 17 & 18 & 18 & 18 & 19 & 19 \\
\hline$E_{50}^{r e f}\left(\mathrm{kN} / \mathrm{m}^{2}\right)$ & 48000 & 45000 & 15000 & 15000 & 18000 & 18000 & 25000 & 20000 & 25000 \\
\hline$E_{\text {oed }}^{r e f}\left(\mathrm{kN} / \mathrm{m}^{2}\right)$ & 48000 & 45000 & 15000 & 15000 & 18000 & 18000 & 25000 & 20000 & 25000 \\
\hline$E_{u r}^{r e f}\left(\mathrm{kN} / \mathrm{m}^{2}\right)$ & 144000 & 135000 & 45000 & 45000 & 54000 & 54000 & 75000 & 60000 & 75000 \\
\hline $\mathrm{m}(-)$ & 0,5 & 0,5 & 0,5 & 0,5 & 0,5 & 0,5 & 0,5 & 0,5 & 0,5 \\
\hline $\mathrm{c}^{\prime}(\mathrm{kPa})$ & 0 & 0 & 0 & 0 & 0 & 0 & 0 & 0 & 0 \\
\hline$\phi^{\prime}\left(^{\circ}\right)$ & 38 & 37 & 23 & 23 & 27 & 31 & 34 & 30 & 37 \\
\hline$\Psi\left(^{\circ}\right)$ & 0 & 0 & 0 & 0 & 0 & 0 & 0 & 0 & 0 \\
\hline $\mathrm{k}_{\mathrm{o}}\left(^{-}\right)$ & 0,38 & 0,40 & 0,61 & 0,61 & 0,55 & 0,48 & 0,44 & 0,50 & 0,40 \\
\hline
\end{tabular}

Para as condições de carregamento dinâmico foi considerado o modelo constitutivo Hardening soil small (HS-small). Este modelo foi empregado nos materiais que não são suscetíveis a liquefação como o aterro compactado e o deposito aluvial. As propriedades dos materiais são apresentadas na Tabela 7.4.

Tabela 7.4- Parãmetros utilizados na análise dinámica dos materiais não liquefiáveis.

\begin{tabular}{|c|c|c|c|c|}
\hline Material & Descrição & $\begin{array}{c}\boldsymbol{G}_{\mathbf{0}} \\
\mathbf{( k N / \mathbf { m } ^ { 2 } )}\end{array}$ & $\begin{array}{c}\boldsymbol{\gamma}_{\mathbf{0 . 7}} \\
\left(\mathbf{k N} / \mathbf{m}^{2}\right)\end{array}$ & $\begin{array}{c}\mathbf{v}_{\mathbf{u r}} \\
\left(\mathbf{k N} / \mathbf{m}^{2}\right)\end{array}$ \\
\hline $\mathrm{AC}$ & Aterro compactado & 239000 & 0,0001 & 0,1 \\
\hline $\mathrm{DA}$ & Deposito aluvial & 239000 & 0,0002 & 0,1 \\
\hline
\end{tabular}

Para as condições de carregamento dinâmico foi considerado o modelo constitutivo UBC3D-PLM. Este modelo foi empregado nos materiais que liquefiáveis como os rejeitos. As propriedades dos materiais são apresentadas na Tabela 7.5. 
Tabela 7.5- Parâmetros do modelo UBC3D-PLM empregados na análise dinámica dos materiais liquefiáveis.

\begin{tabular}{|c|c|c|c|c|c|c|c|}
\hline Material & $\mathbf{R 0}$ & $\mathbf{R 1}$ & $\mathbf{R 2}$ & $\mathbf{R 3}$ & $\mathbf{R 4}$ & $\mathbf{R 5}$ & $\mathbf{R 6}$ \\
\hline$\left(N_{1}\right)_{60}$ & 5,0 & 5,0 & 9,5 & 19,5 & 24,5 & 17,5 & 23,0 \\
\hline$K_{G}^{e}$ & 742,1 & 742,1 & 902,8 & 1070,3 & 1269,0 & 1115,9 & 1234,2 \\
\hline$K_{B}^{e}$ & 519,5 & 519,5 & 631,9 & 749,2 & 888,3 & 781,2 & 864,0 \\
\hline$K_{G}^{p}$ & 155,7 & 155,7 & 319,4 & 822,5 & 2479,4 & 1067,5 & 2058,7 \\
\hline $\mathrm{me}$ & 0,5 & 0,5 & 0,5 & 0,5 & 0,5 & 0,5 & 0,5 \\
\hline $\mathrm{ne}$ & 0,5 & 0,5 & 0,5 & 0,5 & 0,5 & 0,5 & 0,5 \\
\hline $\mathrm{np}$ & 0,4 & 0,4 & 0,4 & 0,4 & 0,4 & 0,4 & 0,4 \\
\hline$\varphi_{c v}$ & 23,0 & 23,0 & 27,0 & 31,0 & 34,0 & 30,0 & 37,0 \\
\hline$\varphi_{p}$ & 23,5 & 23,5 & 27,9 & 32,5 & 38,5 & 32,1 & 40,9 \\
\hline$R_{f}$ & 0,86 & 0,86 & 0,79 & 0,73 & 0,68 & 0,72 & 0,69 \\
\hline
\end{tabular}

\subsection{4.}

\section{Tamanho máximo de zona da discretização}

Antes da análise numérica, é importante definir os tamanhos máximos dos elementos para os diferentes materiais na malha de elementos finitos. Segundo o critério de Kuhlemeyer e Lysmer (1973), baseado no menor comprimento de onda de cisalhamento.

O procedimento consiste em verificar até qual frequência limite, conhecida como frequência de corte, o registro sísmico aplicado na base da malha pode ser filtrado sem comprometer significativamente a energia transmitida pelo sismo. Para isto é analisado o espectro de potência do registro de velocidades já que na análise sísmica da barragem será considerada uma condição de base flexível; sendo portanto, necessário inserir o carregamento em termos de tensões cisalhantes, as quais são função do registro de velocidades.

Os valores de frequência de corte e os correspondentes espectros de potência dos sismos considerados são apresentados na Erro! Fonte de referência não encontrada.Figura 7.3. 
Atico 2001

Frequência de corte $=5 \mathrm{~Hz}$

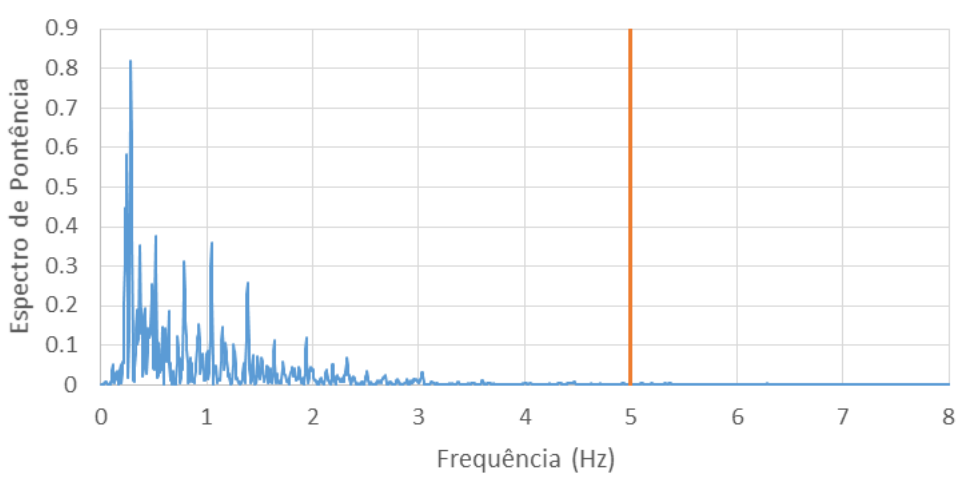

(a)

Lima 1974

Frequência de corte $=5 \mathrm{~Hz}$

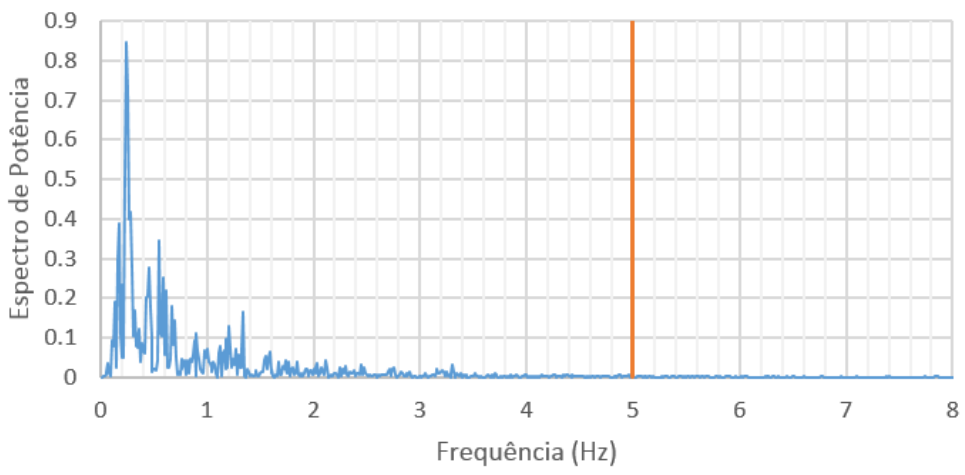

(b)

Maule 2010

Frequência de corte $=5 \mathrm{~Hz}$

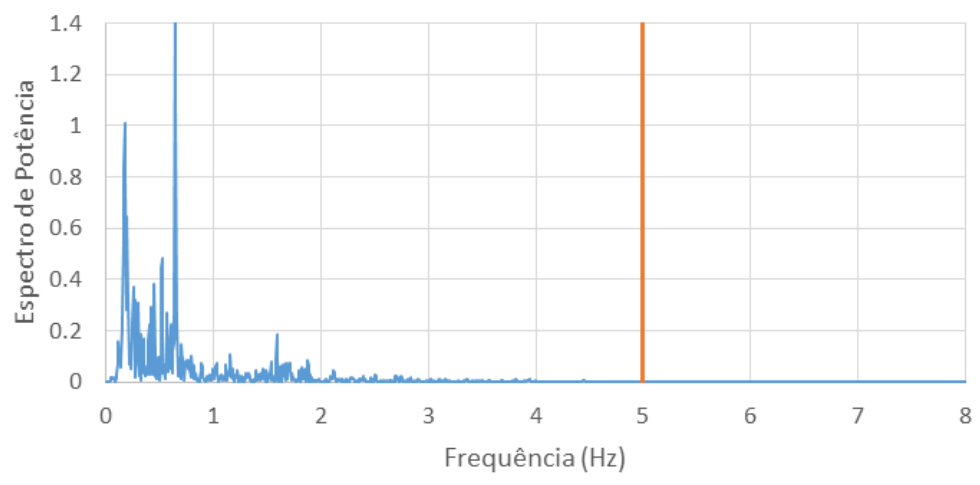

(c)

Figura 7.3- Espectros de potência das velociades e frequências de corte dos sismos artificiais (a) Atico 2001, (b) Lima 1974 e (c) Maule 2010. 
Determinada a frequência de corte $\left(\mathrm{f}_{\mathrm{c}}\right)$ e conhecidas as velocidades das ondas de cisalhamento $\left(v_{s}\right)$ nos diversos materiais que formam a barragem é possível calcular o máximo comprimento do elemento na direção de propagação da onda sísmica (direção vertical).

Conforme detalha-se na Tabela 7.6 os valores variam entre $2.8 \mathrm{~m}$ a $35.0 \mathrm{~m}$ para os materiais, mas nos rejeitos os tamanhos máximos dos elementos variam entre $2.8 \mathrm{~m}$ a $6.6 \mathrm{~m}$.

Para a modelagem em Plaxis 2D foi considerado como valor maximo nos rejeitos $2.0 \mathrm{~m}$.

Tabela 7.6- Determinação do tamanho máximo da discretização dos elementos.

\begin{tabular}{|c|c|c|c|c|c|c|c|c|}
\hline Material & Descrição & $\begin{array}{c}Y_{\text {total }} \\
k N / m^{3}\end{array}$ & $\begin{array}{c}\text { G } \\
\text { Mpa }\end{array}$ & $\begin{array}{c}\mathrm{Vs} \\
\mathrm{m} / \mathrm{s}\end{array}$ & $\begin{array}{l}\text { fc } \\
\mathrm{Hz}\end{array}$ & $\begin{array}{l}\lambda \\
\mathrm{m}\end{array}$ & $\begin{array}{l}\lambda / 8 \\
(\mathrm{~m})\end{array}$ & $\begin{array}{l}\text { PLAXIS } \\
\text { 2D (m) }\end{array}$ \\
\hline $\mathrm{R}$ & Rocha & 24 & 5625 & 1400 & 5 & 280 & 35.0 & 8.0 \\
\hline$A C$ & Aterro compactado & 21 & 277 & 377 & 5 & 75 & 9.4 & 6.0 \\
\hline $\mathrm{DA}$ & Depósito aluvial & 21 & 277 & 368 & 5 & 74 & 9.2 & 6.0 \\
\hline R0 & Rejeito 0 & 17 & 26 & 110 & 5 & 22 & 2.8 & 2.0 \\
\hline $\mathrm{R} 1$ & Rejeito 1 & 17 & 26 & 130 & 5 & 26 & 3.3 & 2.0 \\
\hline $\mathrm{R} 2$ & Rejeito 2 & 18 & 52 & 170 & 5 & 34 & 4.3 & 2.0 \\
\hline R3 & Rejeito 3 & 18 & 67 & 195 & 5 & 39 & 4.9 & 2.5 \\
\hline R4 & Rejeito 4 & 18 & 112 & 250 & 5 & 50 & 6.3 & 2.5 \\
\hline R5 & Rejeito 5 & 19 & 74 & 200 & 5 & 40 & 5.0 & 2.5 \\
\hline R6 & Rejeito 6 & 19 & 130 & 265 & 5 & 53 & 6.6 & 2.5 \\
\hline
\end{tabular}

\section{2.}

\section{Análise estático}

A análise estática da barragem foi realizada por incrementos de carregamento simulando o processo construtivo. O nível da água no interior do corpo da barragem foi determinado diretamente pela definição do nível freático, com base nas sondagens de SPT feitas na barragem. 


\subsection{1.}

Poropressão na condição de fluxo permanente

A Figura 7.4 mostra os resultados numéricos de poropressões estaveis no tempo, indicativos do fluxo em regime permanente.

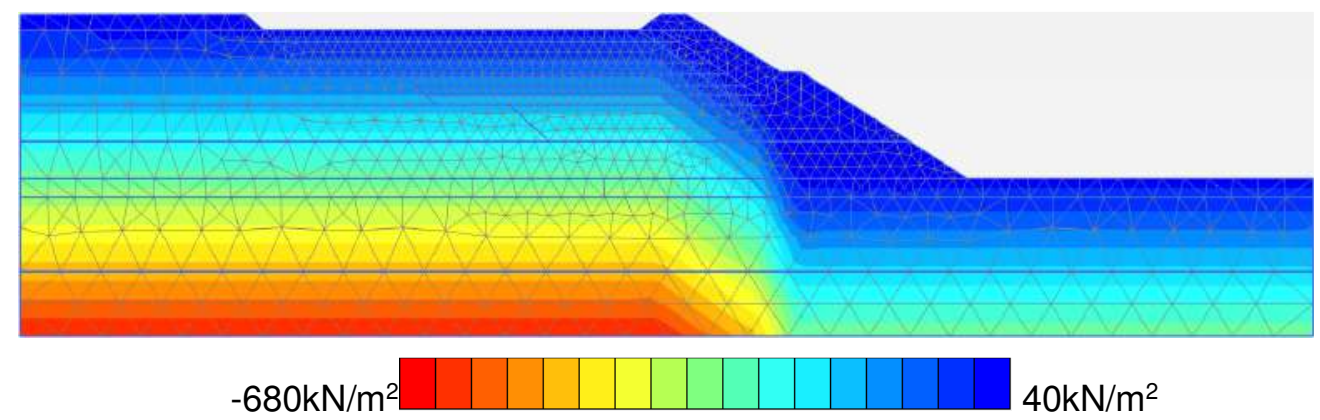

Figura 7.4- Poropressões ativas no corpo da barragem antes do terremoto.

\subsection{2.}

\section{Distribuição de tensão efetivas}

A Figura 7.5 mostra a distribuição das tensões efetivas verticais e horizontais da barragem.

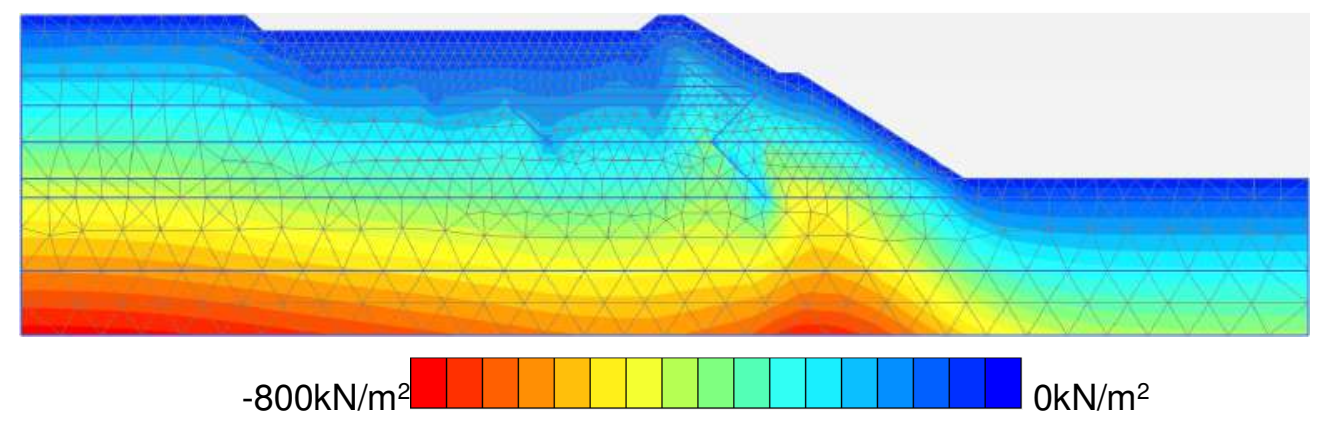

(a)
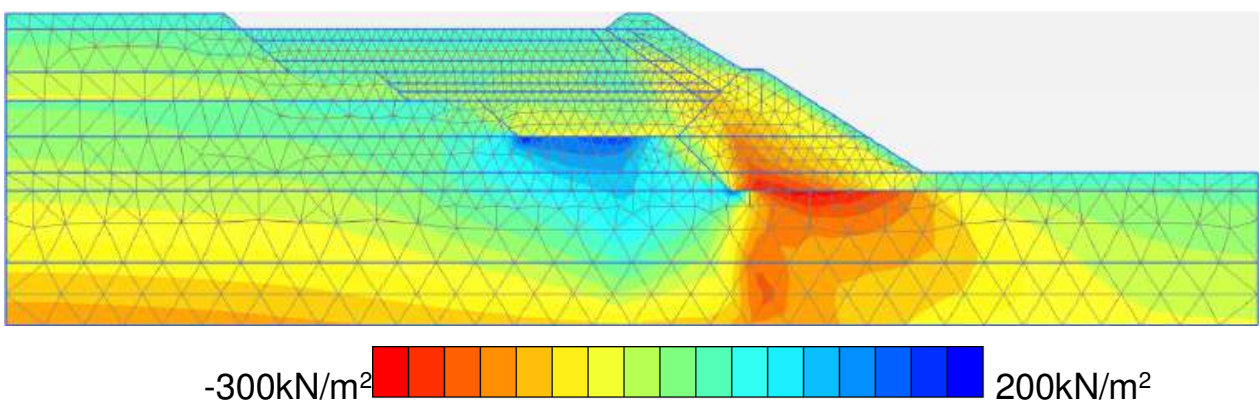

(b)

Figura 7.5- Distribuição das tensões efetivas verticais (a) e horizontais (b) na condição estática. 


\subsection{3.}

\section{Tensões de cisalhamento}

Na Figura 7.6 apresenta-se a distribuição de tensões de cisalhamento da barragem.

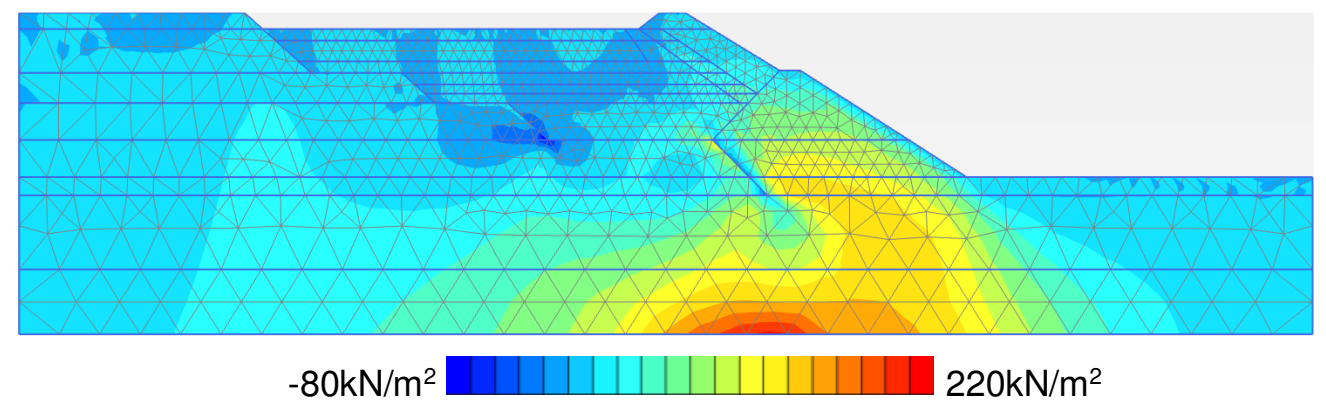

Figura 7.6- Tensões de cisalhamento no plano horizontal $\left(\tau_{x y}\right)$ em condição estática.

\subsection{4.}

\section{Fator de segurança estático}

O fator de segurança estático após a construção, determinado com a técnica de redução da resistência no programa PLAXIS 2D, é de 1.45. Na Figura 7.7 apresenta-se a superfície de ruptura da barragem.

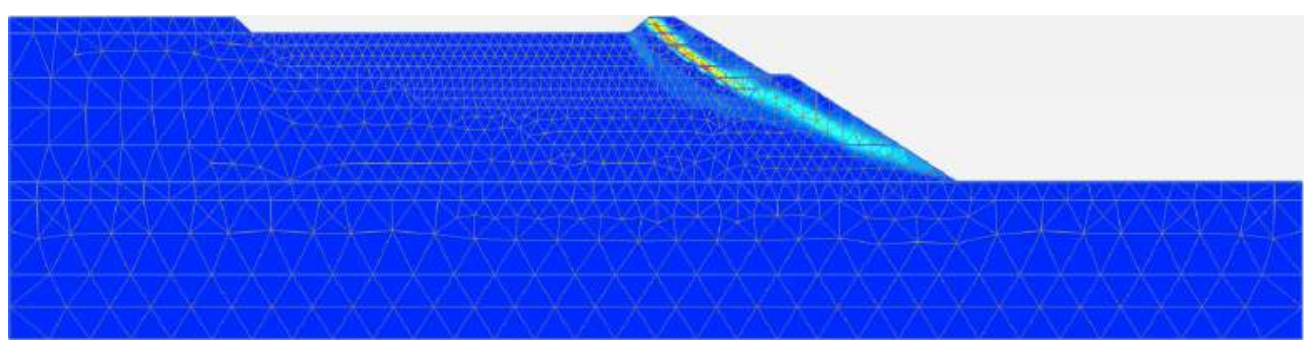

Figura 7.7- Superfície de ruptura da barragem em condição estática.

Uma vantagem de se empregar um método numérico como os elementos finitos é que a forma e a localização da superfície de ruptura não precisam ser previamente definidas, pois são determinadas durante o processo de solução. $\mathrm{Na}$ Figura 7.8 são apresentados os campos de deslocamento da barragem onde é definida a superfície de ruptura. 


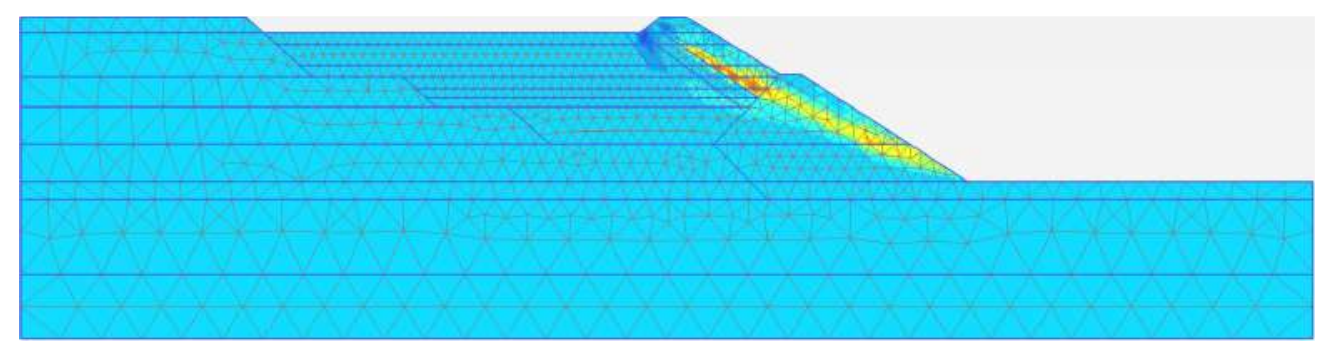

Figura 7.8- Campo de deslocamento da barragem em condição estática.

\subsection{5.}

\section{Análise estático}

Os valores dos fatores de segurança da barragem de rejeitos foram calculados com o programa SLIDE v.7 (Rocscience, 2017) pelo método das fatias (método de Spencer). A posição da potencial superfície de ruptura foi considerada semelhante com a análise de elementos finitos.

Na Figura 7.9 apresenta-se os resultados da análise pelo método de equilíbrio limite para as condições mais prováveis de ruptura. Os valores obtidos são menores que os permitidos, para o caso 1.5 . 
FOS: 1.35

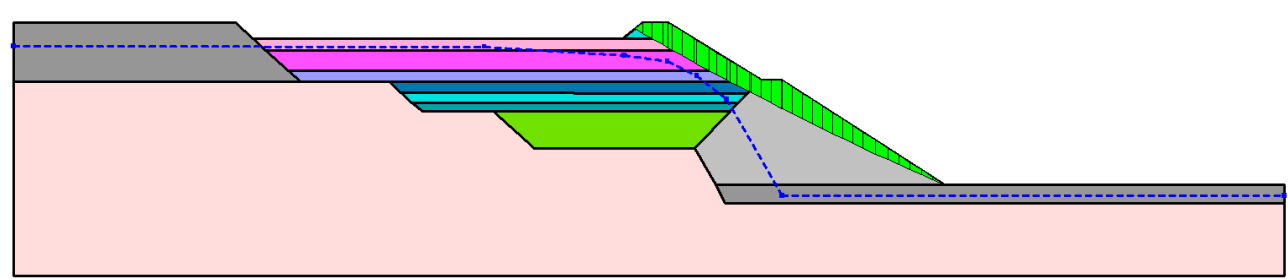

(a)

FOS: 1.27

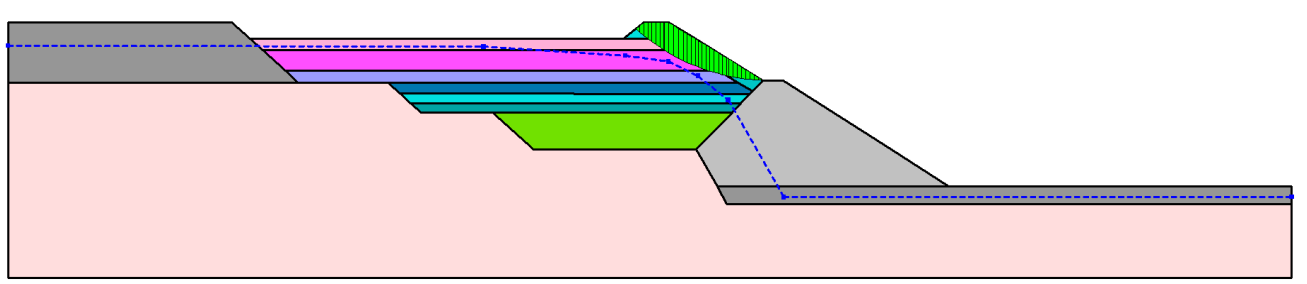

(b)

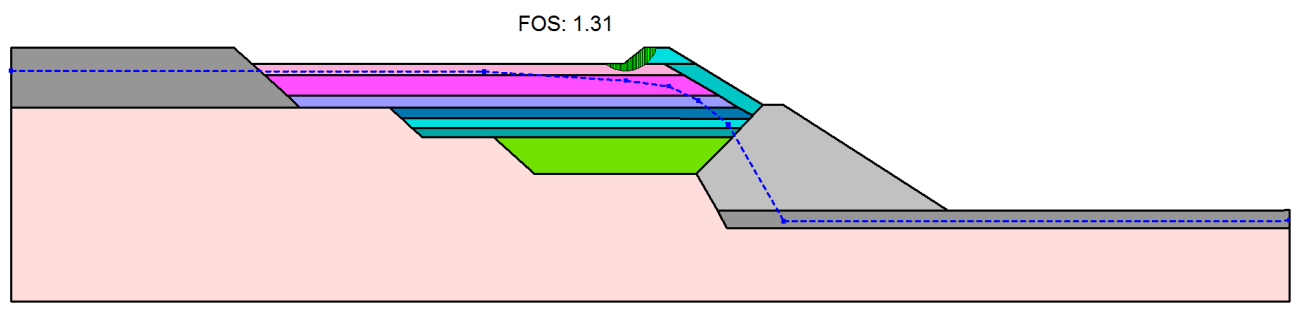

(c)

Figura 7.9- Análise estática de estabilidade (a) global a jusante, (b) local a jusante e (c) local a montante.

Na Tabela 7.7 é apresentada os fatores de segurança para uma análise estática.

Tabela 7.7- Fator de segurança análise estático.

\begin{tabular}{|c|c|c|}
\hline \multicolumn{2}{|c|}{ Superfícies de ruptura } & Fator de segurança \\
\hline a & Global jusante & 1.35 \\
\hline b & Local jusante & 1.27 \\
\hline c & Local montante & 1.31 \\
\hline
\end{tabular}

\subsection{6.}

\section{Análise pós-sismo}

As análises de estabilidade pós sismo foram realizadas através da análise de equilíbrio limite convencional. O método incorpora a resistência residual não drenada (Sur), como parâmetro de resistência ao cisalhamento para aqueles 
materiais suscetíveis a liquefação. A resistência residual (Sur) foi avaliada com base nas correlações propostas por Idriss e Boulanger (2007) para condições adequadas de drenagem. A Tabela 7.8 mostra os valores de resistência residual dos rejeitos suscetíveis a liquefação.

Tabela 7.8 - Parâmetros de resistência residual para rejeitos.

\begin{tabular}{|c|c|c|c|}
\hline Material & Descripção & $\begin{array}{c}\mathbf{Y}_{\text {total }} \\
\left(\mathbf{k N} / \mathbf{m}^{3}\right)\end{array}$ & $\left(\frac{\boldsymbol{S}_{\boldsymbol{u}}}{\boldsymbol{\sigma}_{\boldsymbol{v}}^{\prime}}\right)_{\text {LIQ }}$ \\
\hline R0 & Rejeito 0 & 17 & 0.10 \\
\hline R1 & Rejeito 1 & 17 & 0.10 \\
\hline R2 & Rejeito 2 & 18 & 0.15 \\
\hline R3 & Rejeito 3 & 18 & 0.15 \\
\hline R5 & Rejeito 5 & 19 & 0.20 \\
\hline
\end{tabular}

Na Figura 7.10, apresenta-se os resultados da análise pós sismo na barragem. O valor obtido na Figura 7.10(a) não compromete a estabilidade global; porém, os valores obtidos na Figura 7.10(b) e Figura 7.10(c) comprometem a estabilidade da barragem. 
FOS: 1.24

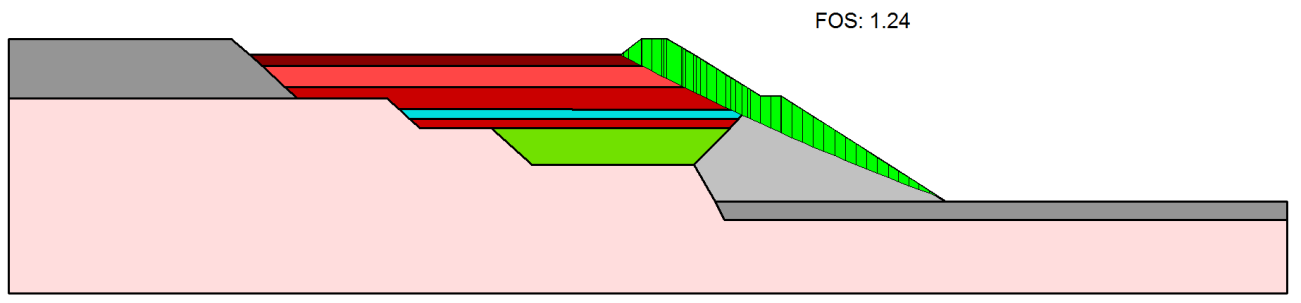

(a)

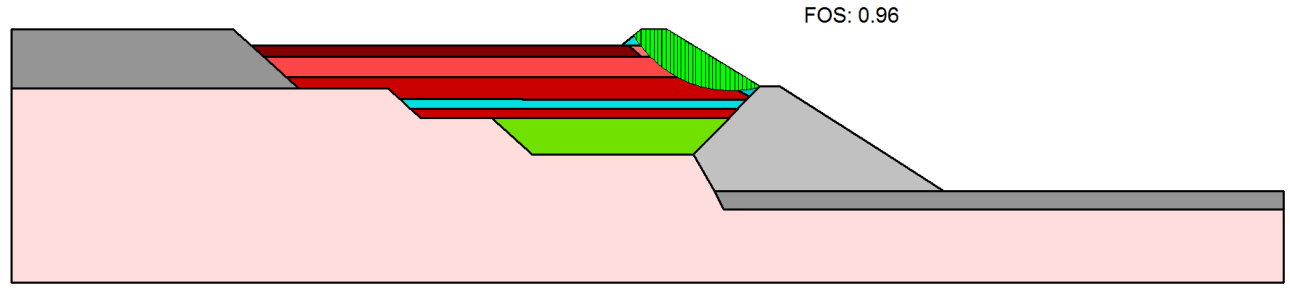

(b)

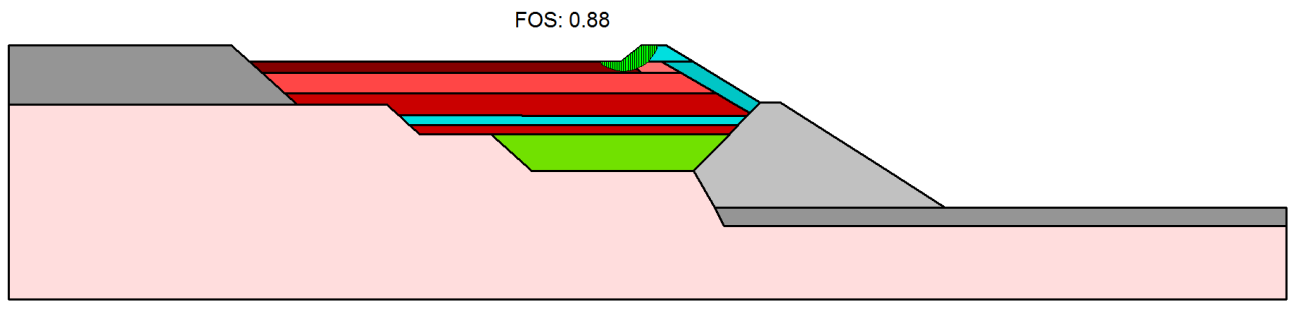

(c)

Figura 7.10- Análise pós sismo de estabilidade (a) global a jusante (b) local a jusante e (c) local a montante.

Os fatores de segurança para diferentes condições são apresentados na Tabela 7.9. A análise pseudo-estática produziu valores baixos indicando o possível colapso das encostas devido à carga sísmica.

Tabela 7.9- Fator de segurança para diferentes superfícies de ruptura e condições.

\begin{tabular}{|c|c|c|}
\hline \multicolumn{2}{|c|}{$\begin{array}{c}\text { Superfícies de } \\
\text { ruptura }\end{array}$} & Fator de segurança \\
\cline { 3 - 3 } & Global jusante & Post-sismo \\
\hline a & Local jusante & 1.24 \\
\hline b & Local montante & 0.96 \\
\hline c & Local mo & 0.88 \\
\hline
\end{tabular}

Uma das principais variáveis a ser avaliada após o término do sismo são os deslocamentos permanentes, que indicam o nível de servicibilidade da barragem. 


\section{3.}

\section{Análise dinâmico}

A análise dinâmica foi feita com o movimento de entrada e propriedades descritas anteriormente. O movimento de entrada foi aplicado como acelerações prescritas no leito rochoso. Para todos os materiais uma quantidade adicional de $\xi=2 \%$ de amortecimento Rayleigh foi adicionada.

\subsection{1.}

\section{Simulação elástica não amortecida}

A simulação elástica não amortecida permite fazer uma estimativa da frequência natural dos materiais constituintes da barragem, que é necessário conhecer quando for utilizado o amortecimento tipo Rayleigh.

Para determinação da frequência natural não amortecida, foram estimados os registros de velocidade em pontos representativos dos materiais da estrutura e gerados os respectivos espectros de Fourier, que permitem obter os maiores valores de frequência.

A Tabela 7.10 apresenta os resultados da análise dinâmica elástica não amortecida em termos de frequência natural de vibração para os diferentes materiais. Observou-se que as frequências predominantes variavam entre $0.25 \mathrm{~Hz}$ a $4.80 \mathrm{~Hz}$.

Como no caso de aplicação do amortecimento de Rayleigh a frequência natural deve ser definida em uma faixa de frequências aproximadamente constante, decidiu-se considerar como frequência natural não amortecida do sistema $2.70 \mathrm{HZ}$ com período de 0.37 segundos. 
Tabela 7.10- Frequências natural de vibração obtidas nos diferentes materiais.

\begin{tabular}{|c|c|c|c|c|}
\hline Material & $\begin{array}{c}\mathbf{1}^{\circ} \\
\text { Frequência } \\
\mathbf{( H z )}\end{array}$ & $\begin{array}{c}\mathbf{2}^{\circ} \\
\text { Frequência } \\
\mathbf{( H z )}\end{array}$ & $\begin{array}{c}\mathbf{3}^{\circ} \\
\text { Frequência } \\
\mathbf{( H z )}\end{array}$ & $\begin{array}{c}\mathbf{4}^{\circ} \\
\text { Frequência } \\
\mathbf{( H z )}\end{array}$ \\
\hline Rocha & 0.25 & 0.55 & 1.35 & 2.70 \\
\hline Deposito aluvial & 0.25 & 0.55 & 1.35 & 2.70 \\
\hline Aterro compactado & 0.25 & 0.55 & 1.35 & 2.70 \\
\hline Rejeito 0 & 2.70 & 0.25 & 4.80 & 0.55 \\
\hline Rejeito 1 & 2.70 & 0.25 & 0.55 & 1.35 \\
\hline Rejeito 2 & 2.70 & 0.25 & 0.55 & 1.35 \\
\hline Rejeito 3 & 2.70 & 0.25 & 0.55 & 1.35 \\
\hline Rejeito 4 & 2.70 & 0.25 & 0.55 & 1.35 \\
\hline Rejeito 5 & 2.70 & 0.25 & 0.55 & 1.35 \\
\hline Rejeito 6 & 0.25 & 0.55 & 2.70 & 1.35 \\
\hline
\end{tabular}

\subsection{2.}

\section{Deslocamento permanentes}

Os altos deslocamentos obtidos da modelagem numérica são devidos à densificação dos rejeitos pela técnica de construção a montante. Na Figura 7.11 indica-se os pontos de observação da barragem para medição dos deslocamentos permanentes, além de historia de poropressão, registros sísmicos e espectros de resposta.

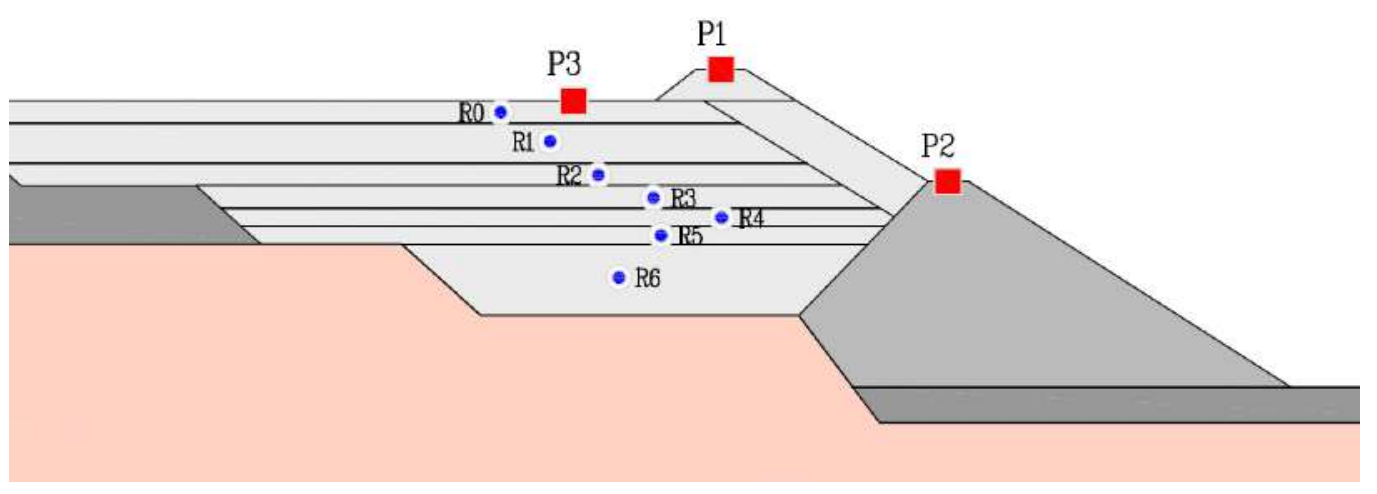

Figura 7.11- Pontos de controle para deslocamentos e poropressões.

Para o controle dos deslocamentos os pontos P1, P2 e P3 são escolhidos por estarem localizados na crista dos rejeitos, na crista do aterro compactado e na praia de rejeitos. 
Na Figura 7.12 são apresentados a história de deslocamentos gerados pelo sismo artificial de Atico (2001).

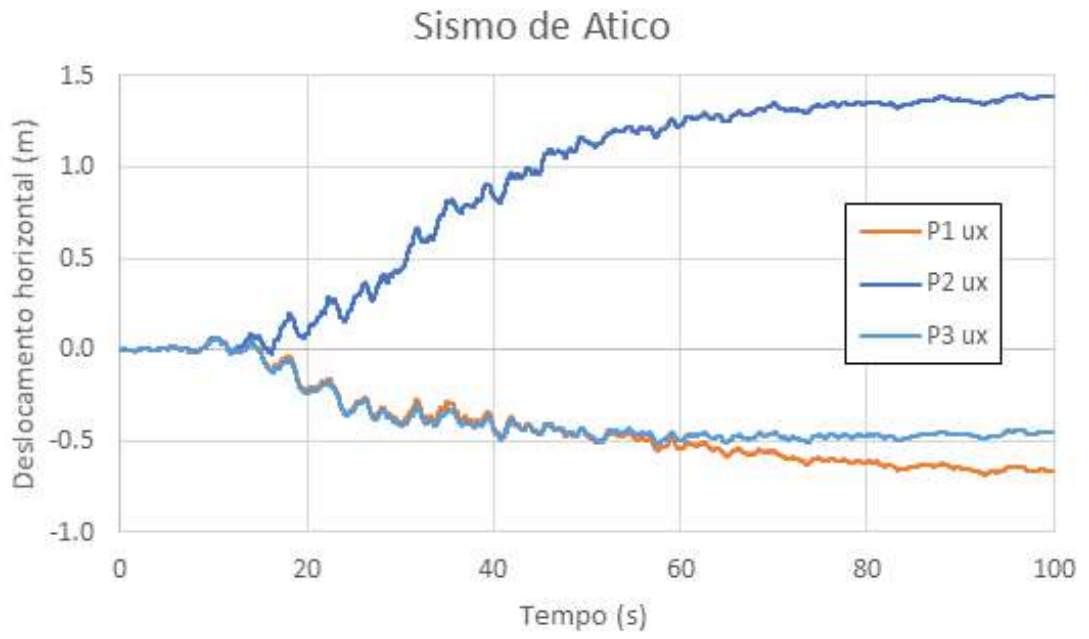

(a)

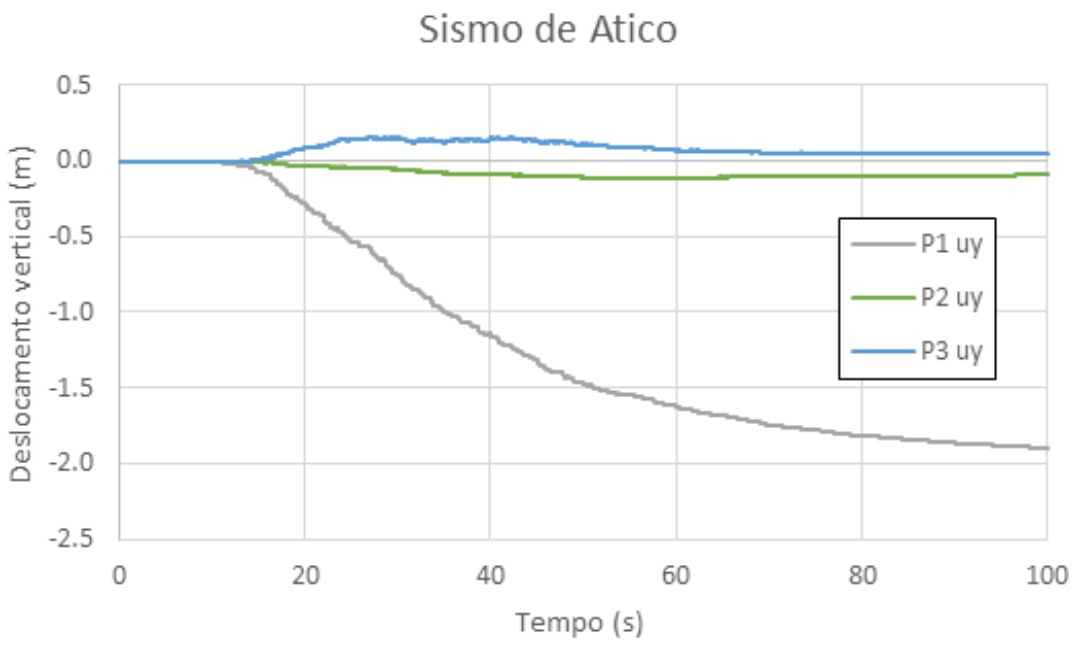

(b)

Figura 7.12- História de deslocamentos (a) horizontais (b) verticais provocados nos pontos $\mathrm{P} 1 \mathrm{e}$ P2 durante o sismo artificial Atico 2001. 
Na Figura 7.13 são apresentados a história de deslocamentos gerados pelo sismo artificial de Lima (2001).

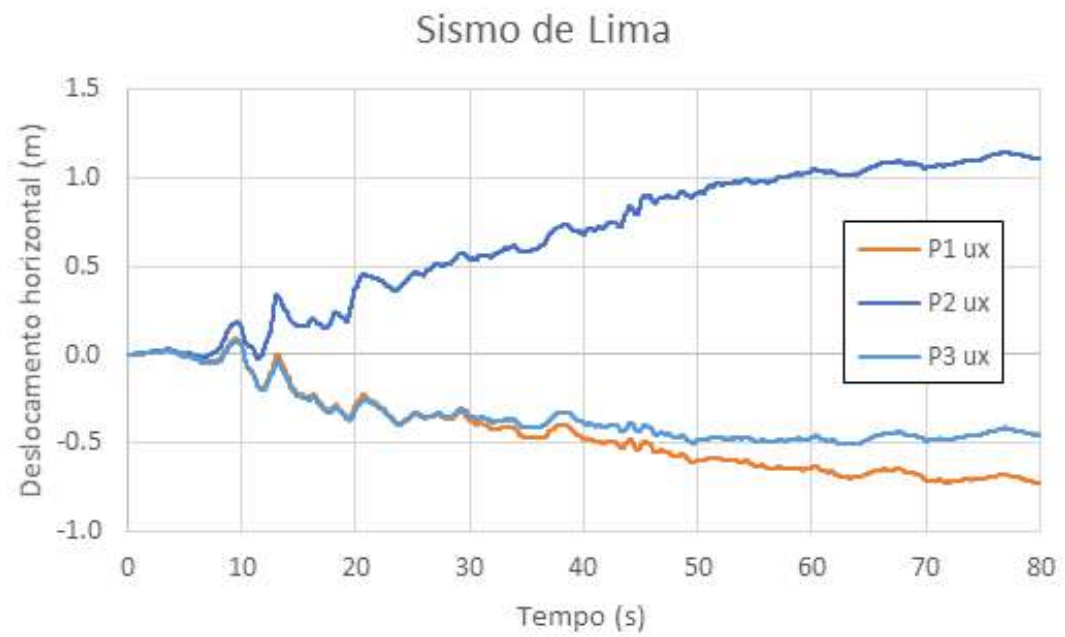

(a)

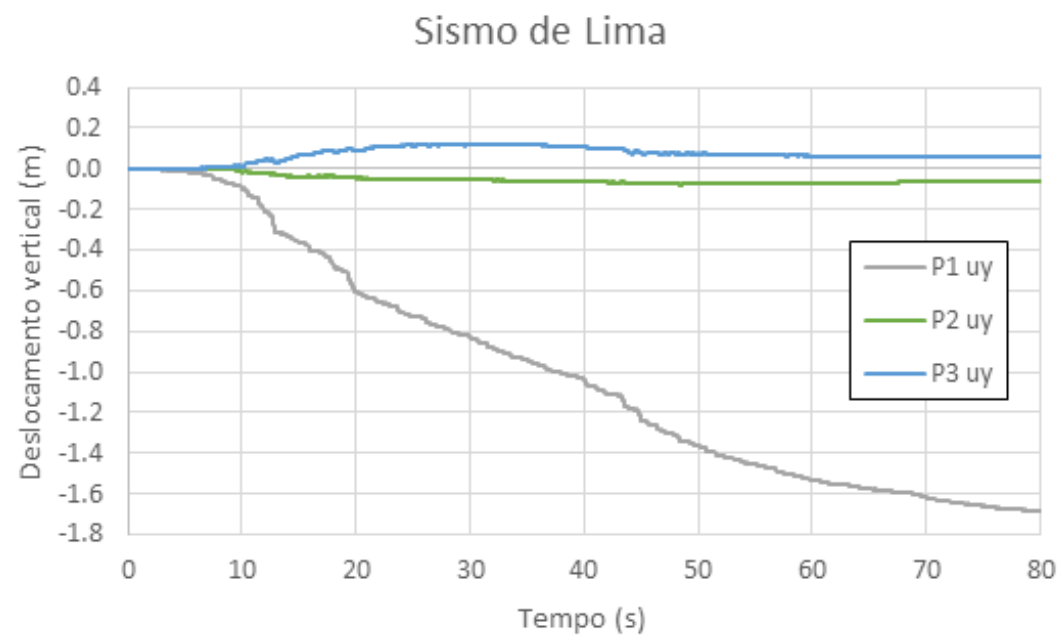

(b)

Figura 7.13- História de deslocamentos (a) horizontais (b) verticais provocados nos pontos $\mathrm{P} 1 \mathrm{e}$ P2 durante o sismo artificial Lima 1974. 
Na Figura 7.12 são apresentados a história de deslocamentos gerados pelo sismo artificial de Maule (2010).

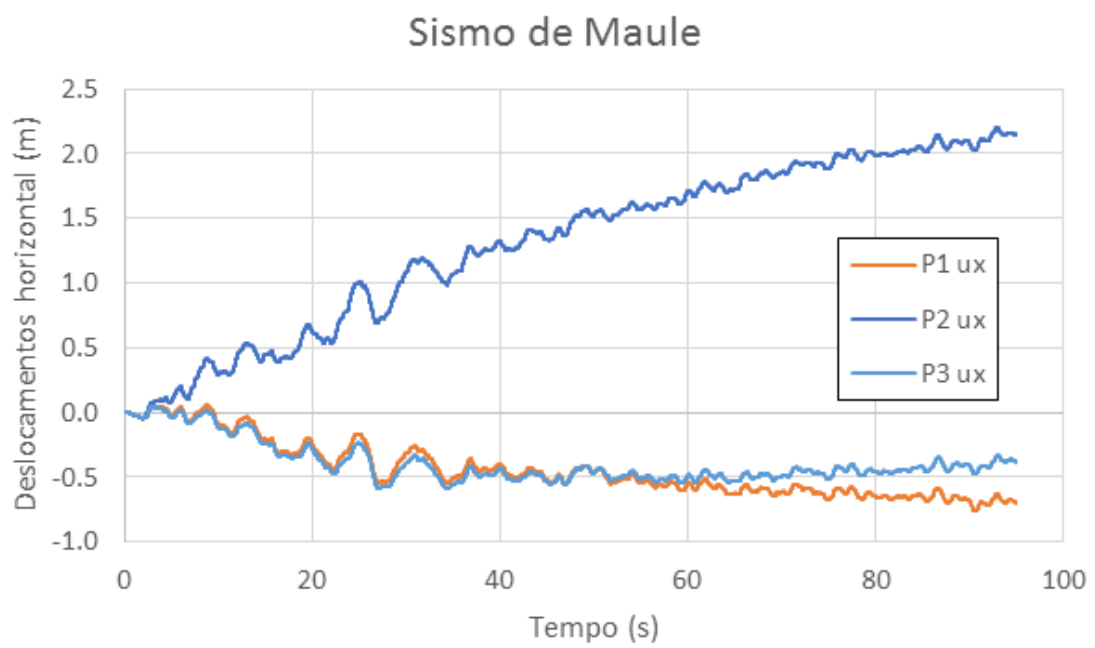

(a)

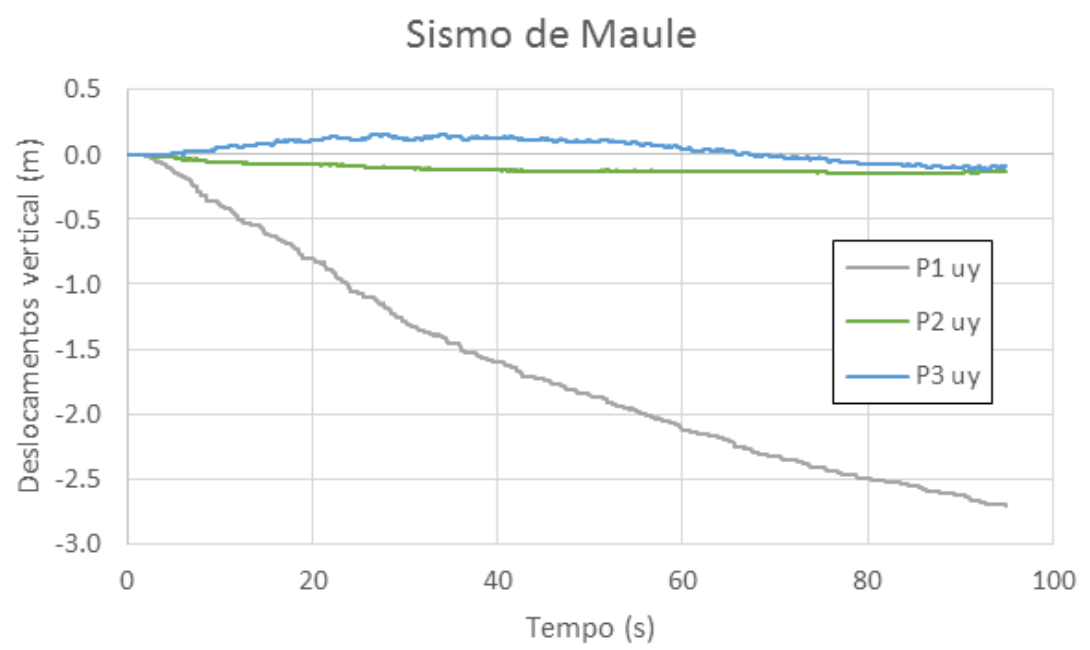

(b)

Figura 7.14- História de deslocamentos (a) horizontais (b) verticais provocados nos pontos $\mathrm{P} 1 \mathrm{e}$ P2 durante o sismo artificial Maule 2010. 
O resumo dos deslocamentos máximos gerados pelos sismos nos pontos P1, P2 e P3 (Figura 7.11) são indicados na Tabela 7.11.

Tabela 7.11- Deslocamentos permanentes máximos induzidos pelos sismos.

\begin{tabular}{|c|c|c|c|c|c|c|}
\hline \multirow{2}{*}{ Terremoto } & \multicolumn{2}{|c|}{ P1 } & \multicolumn{2}{c|}{ P2 } & \multicolumn{2}{c|}{ P3 } \\
\cline { 2 - 7 } & $\begin{array}{c}\mathbf{U}_{\mathbf{x}} \\
(\mathbf{m})\end{array}$ & $\begin{array}{c}\mathbf{u}_{\mathbf{y}} \\
(\mathbf{m})\end{array}$ & $\begin{array}{c}\mathbf{u}_{\mathbf{x}} \\
(\mathbf{m})\end{array}$ & $\begin{array}{c}\mathbf{u}_{\mathbf{y}} \\
(\mathbf{m})\end{array}$ & $\begin{array}{c}\mathbf{u}_{\mathbf{x}} \\
(\mathbf{m})\end{array}$ & $\begin{array}{c}\mathbf{u}_{\mathbf{y}} \\
(\mathbf{m})\end{array}$ \\
\hline Atico 2001 & -0.68 & -1.90 & 1.39 & -0.11 & -0.69 & 0.10 \\
\hline Lima 1974 & -0.73 & -1.68 & 1.14 & -0.08 & -0.70 & 0.12 \\
\hline Maule 2010 & -0.75 & -2.71 & 2.19 & -0.14 & -0.80 & -0.07 \\
\hline
\end{tabular}

Os campos de deslocamento causados pelos sismos são apresentados a seguir. Para o sismo de Atico 2001, o campo de deslocamentos é mostrado na Figura 7.15; podemos então observar que na crista dos rejeitos são gerados os maiores deslocamentos.

(a)

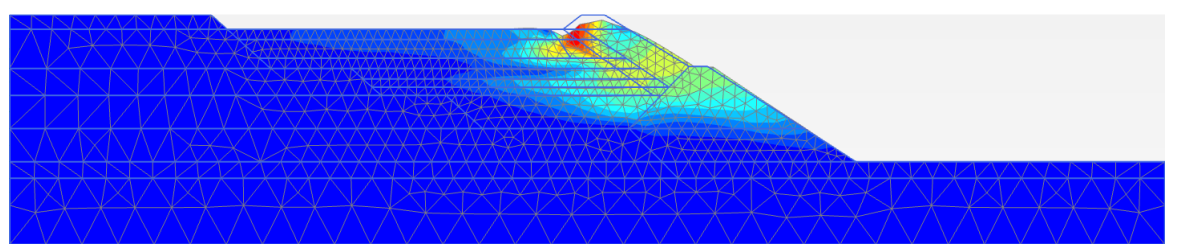

$0 \mathrm{~m}$

$2.6 \mathrm{~m}$

(b)

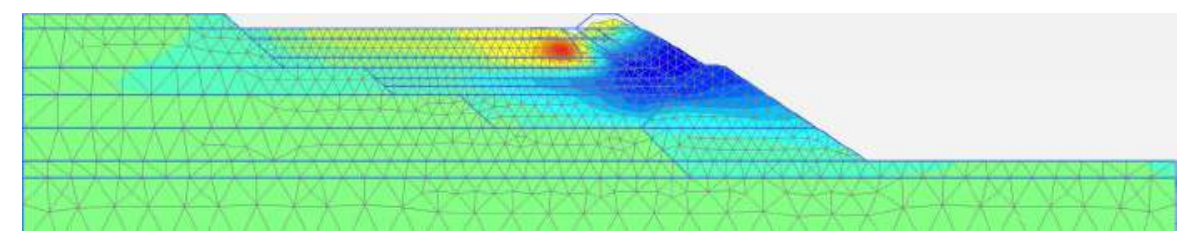

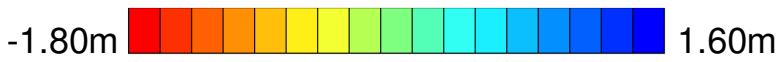

(c)

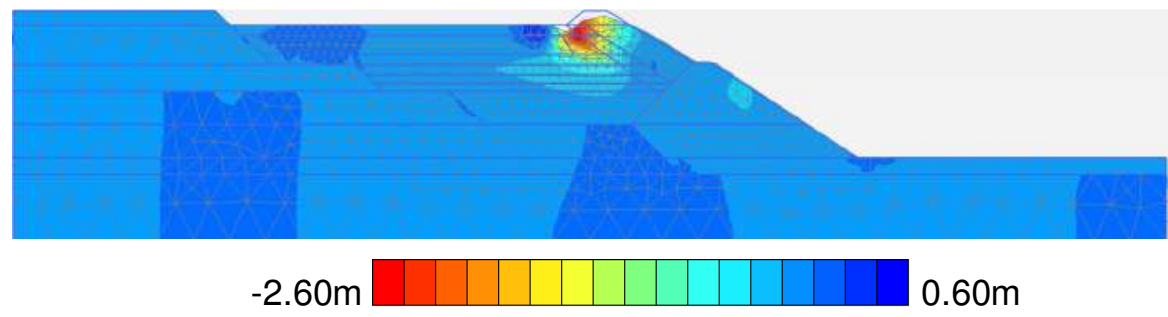

Figura 7.15-. Campos de deslocamento (a) Totais, (b) horizontais e (c) verticais provocados pelo sismo artificial Atico 2001. 
Para o sismo de Lima 1974, o campo de deslocamentos é mostrado na Figura 7.16; podemos observar que na crista dos rejeitos são gerados os maiores deslocamentos.

(a)
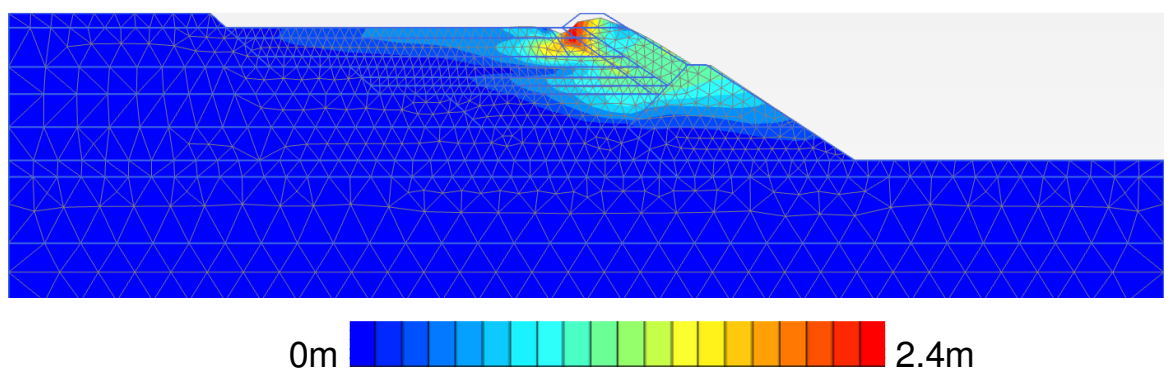

(b)

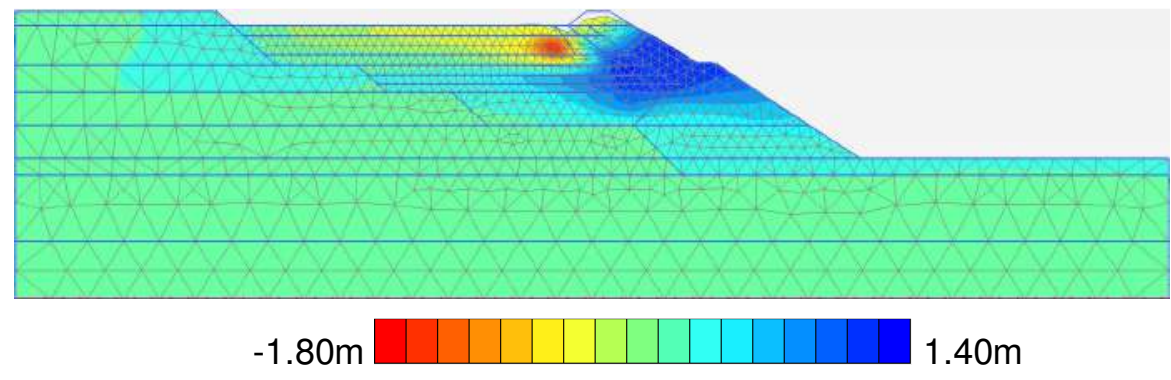

(c)

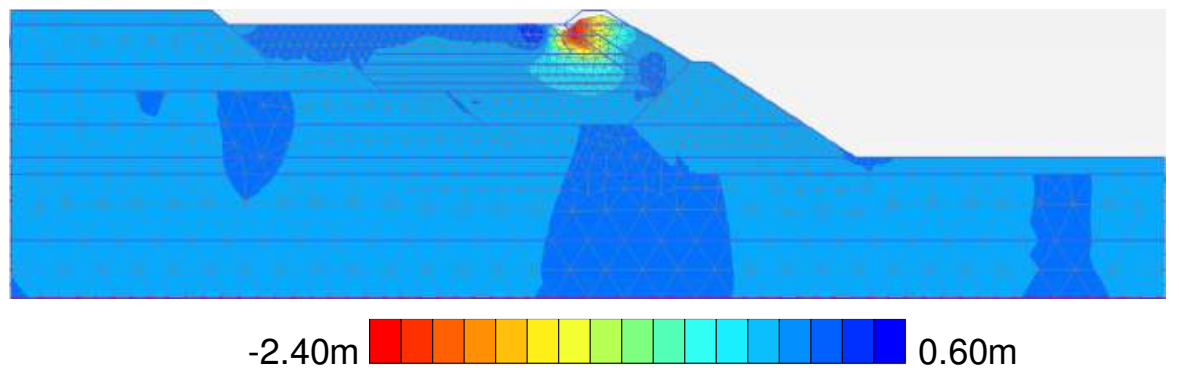

Figura 7.16- Campos de deslocamento (a) Totais, (b) horizontais e (c) verticais provocados pelo sismo artificial Lima 1974. 
Para o sismo de Maule 2010, o campo de deslocamentos é mostrado na Figura 7.17; podemos observar que na crista dos rejeitos são gerados os maiores deslocamentos.

(a)

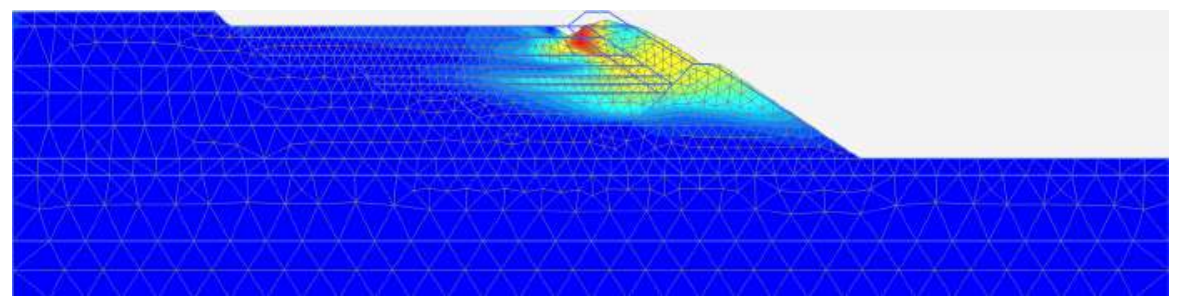

$0 \mathrm{~m}$

$3.6 m$

(b)

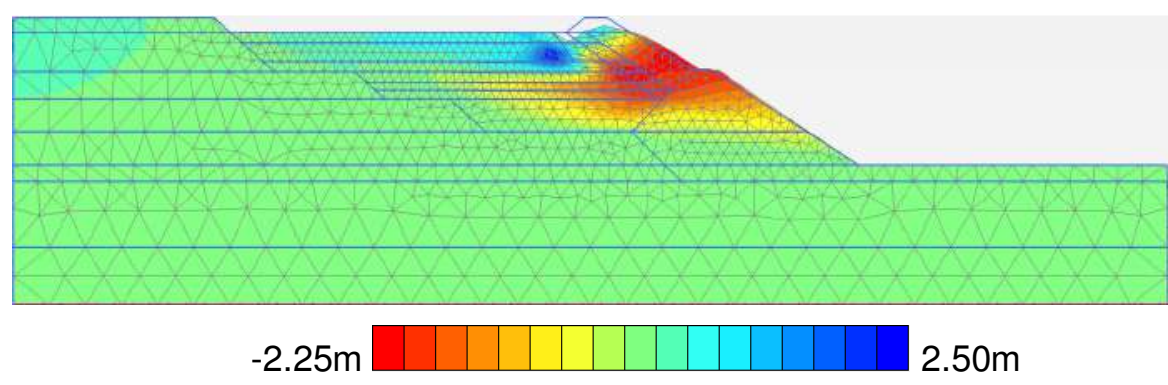

(c)

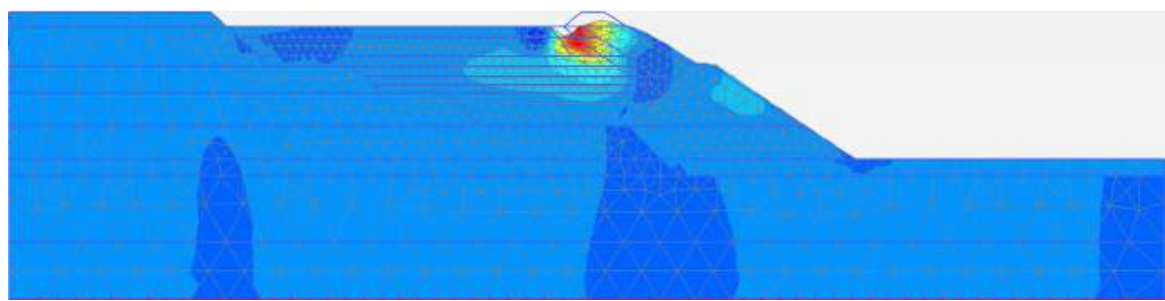

$-3.50 m$

$0.75 \mathrm{~m}$

Figura 7.17- Campos de deslocamento (a) Totais, (b) horizontais e (c) verticais provocados pelo sismo artificial Maule 2010.

\subsection{3.}

\section{Relação de poropressão}

Nesta pesquisa, a definição do parâmetro de poropressão (ru) dada por Beaty e Byrne (2011) foi usada:

$$
\mathrm{r}_{\mathrm{u}}=1-\left(\frac{\sigma_{\mathrm{v}}^{\prime}}{\sigma_{\mathrm{vo}}^{\prime}}\right)
$$

onde $\sigma^{\prime} v$ é a tensão vertical efetiva atual e $\sigma$ 'v0 a tensão vertical efetiva inicial. Quando $r u=1, \sigma_{v}^{\prime}=0$ e o solo está em estado liquefeito, mas de acordo com 
Makra (2013), os valores de ru iguais ou superiores a 0,85 já indicam a ocorrência de liquefação dinâmica.

Os resultados da análise numérica expressa em termos de histórias do parâmetro poropressão (ru), considerando os pontos de controle nos rejeitos da Figura 7.11, são apresentados a seguir.

Na Figura 7.18 observamos que os rejeitos R1, R2 R3 e R5 atinguem um valor de ru igual a 0.85 aos 20 segundos de transcurrido os sismos, enquanto os rejeitos R4 e R6 atinguem a 0.85 de ru após 60 segundos. Nos pontos de observação a liquefação aconteceu em todos os materiais suscetíveis a liquefação. 


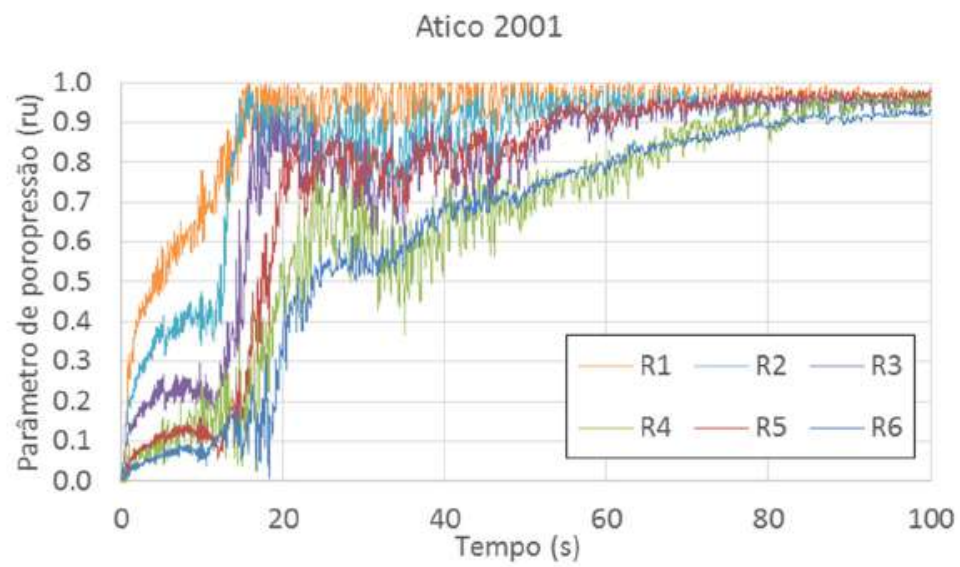

(a)

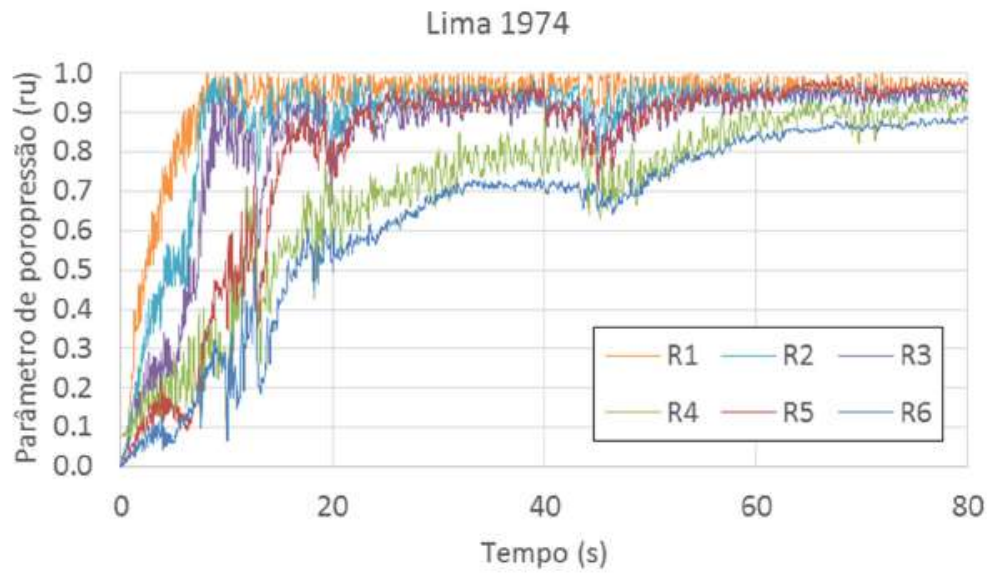

(b)

Maule 2010

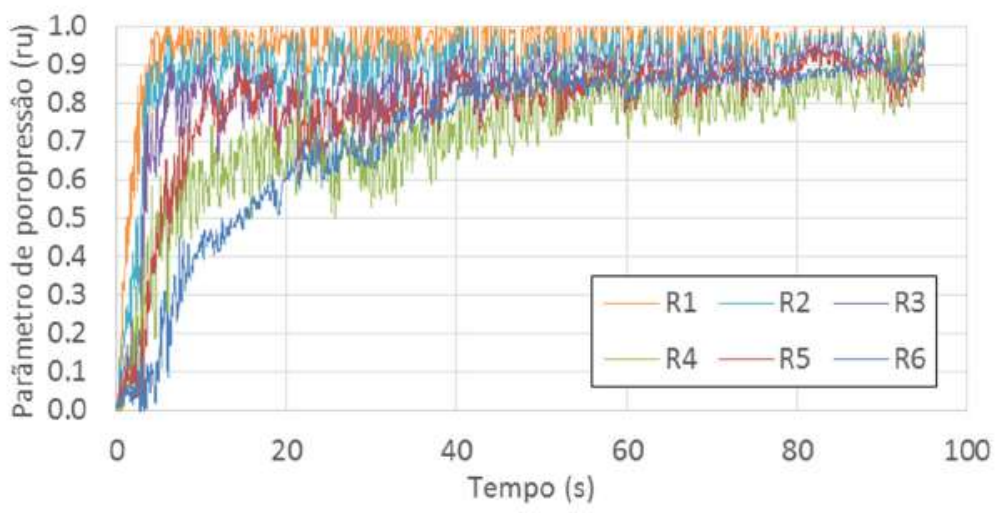

(c)

Figura 7.18-. História do parâmetro de poropressão (ru) em alguns pontos de controle durante os sismos artificiais (a) Atico 2001, (b) Lima 1974 e (c) Maule 2010. 
Na Figura 7.19, mostra-se a distribuição final do parámetro de poropressâo (ru) no corpo da barragem imediatamente após ocorrido os sismos. De acordo com os resultados, duas zonas nos rejeitos $\mathrm{R} 4$ e $\mathrm{R} 6$ têm um ru abaixo de 0.85 .

(a)

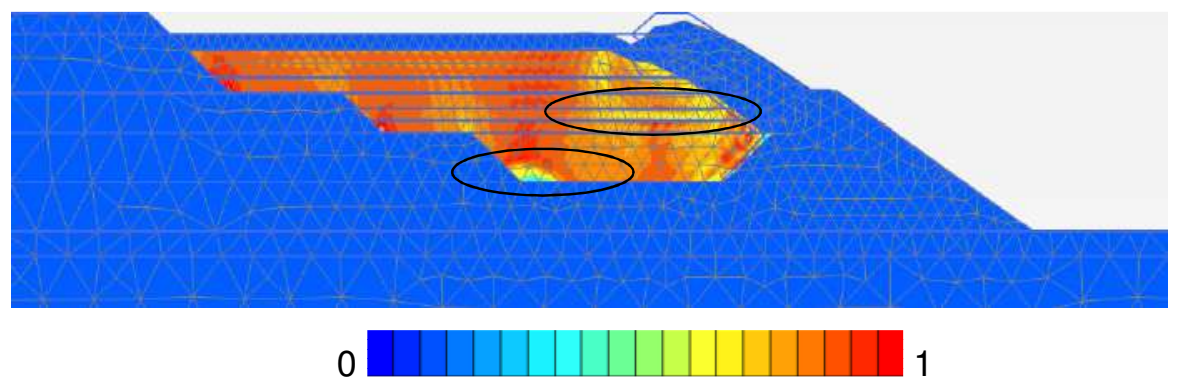

(b)
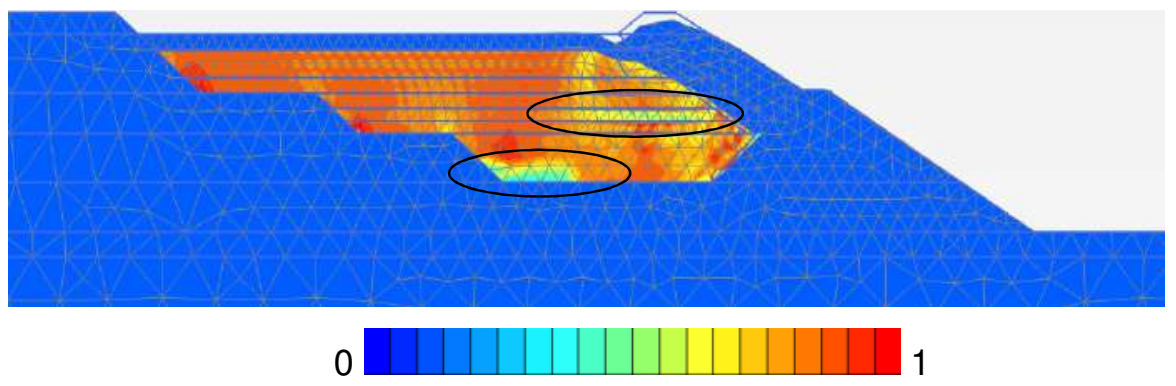

(c)

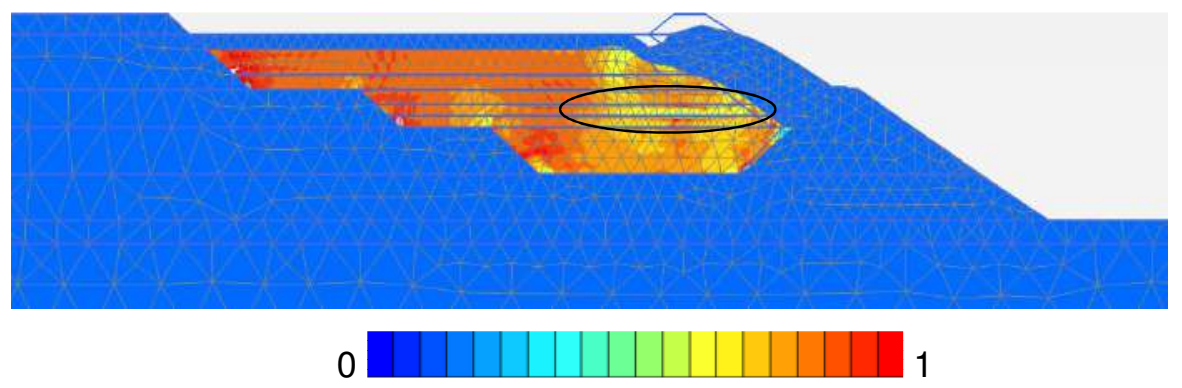

Figura 7.19-. Distribuição final do parâmetro de pressão de poros (ru) para os sismos artificiais (a) Atico 2001, (b) Lima 1974 e (c) Maule 2010.

Na Figura 7.20 indica-se os pontos de observação dentro da barragem onde o parâmetro de pressão de poros (ru) é menor a 0.85 .

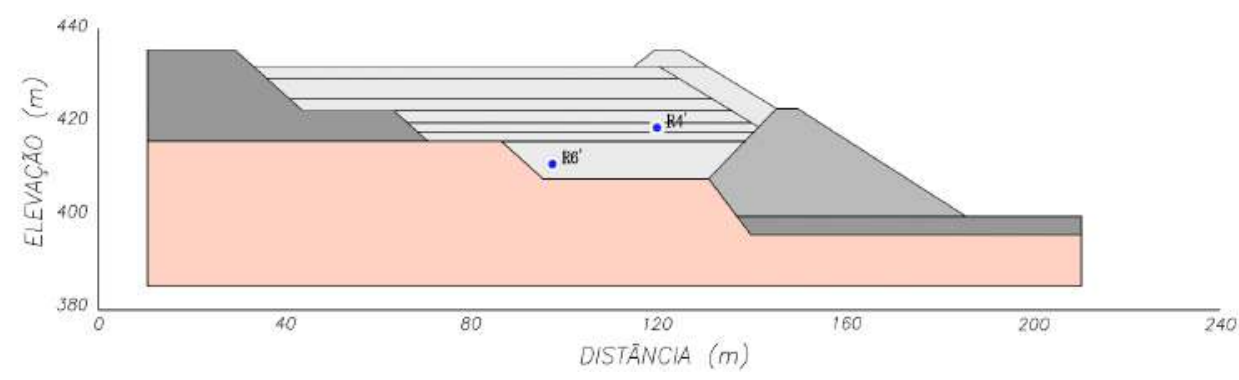

Figura 7.20- Pontos de controle das poropressões nas zonas que não liquefaçem. 
Na Figura 7.21 nos pontos de controle R4' e R6' observamos valores de ru menores a 0.85 para todos os sismos, pelo qual podemos afirmar que o fenômeno de liquefação não é gerado nessas zonas.

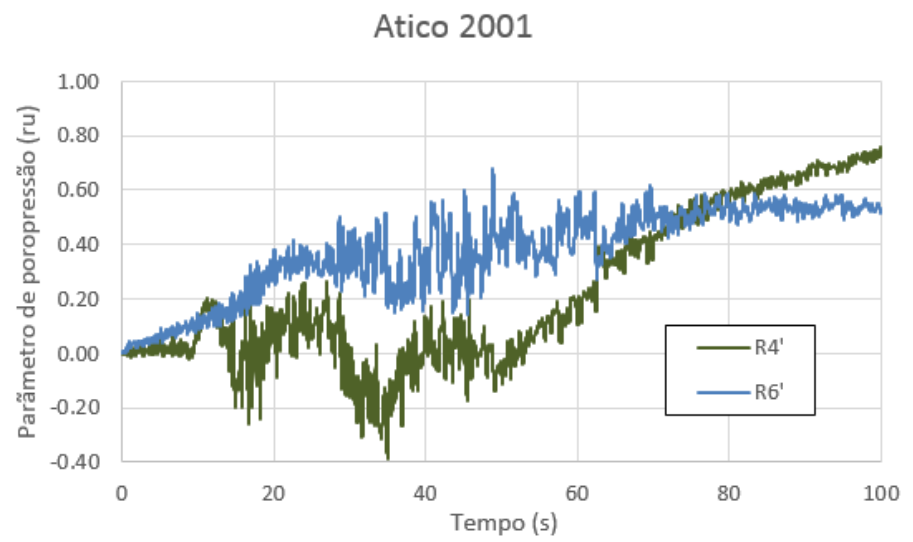

(a)

Lima 1974

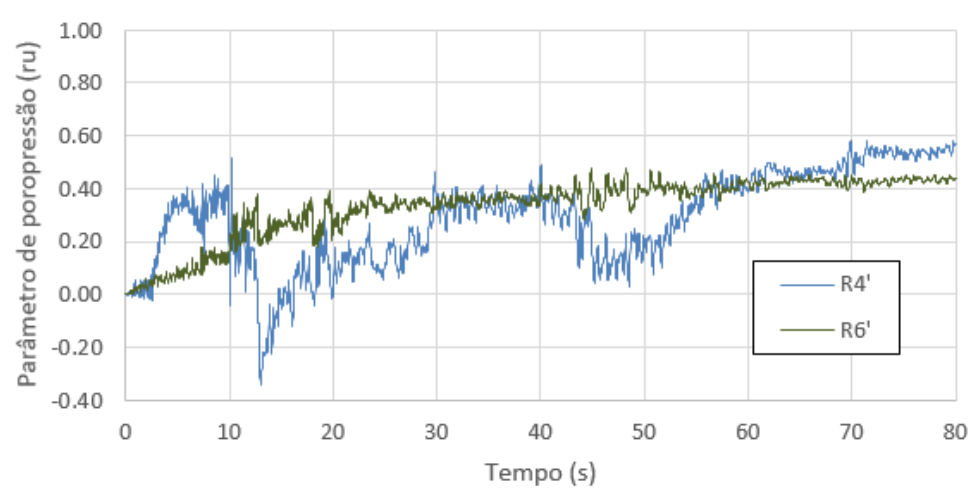

(b)

Maule 2010

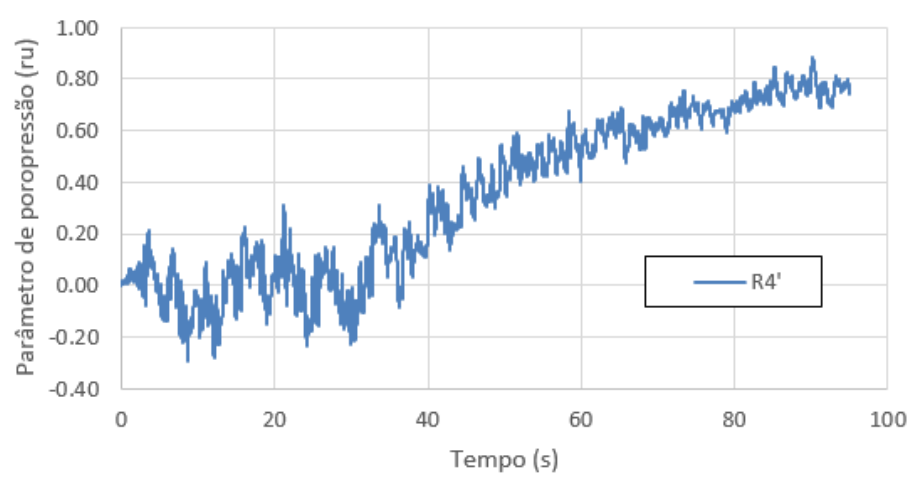

(c)

Figura 7.21 - História do parâmetro de poropressão (ru) nos pontos que não liquefaçem durante os sismos artificiais (a) Atico 2001, (b) Lima 1974 e (c) Maule 2010. 


\subsection{4. \\ Registros sísmicos e espectros de resposta}

Os resultados da análise numérica, expressa em termos de registro sísmico e espectros de resposta, são mostrados a seguir, considerando os pontos de controle da Figura 7.22.

Na Figura 7.22 apresenta-se os registros sísmicos e as acelerações máximas nos pontos P1 e P2. Para o sismo artificial de Atico 2001 na Figura 7.22 (a), os valores das acelerações máximas de $0.39 \mathrm{~g}(\mathrm{P} 1)$ e $0.35 \mathrm{~g}$ (P2) são menores que a aceleração máxima de $0.45 \mathrm{~g}$ do registro sísmico ajustado de Atico 2001 mostrado na Figura 3.24. Para o sismo artificial de Lima 1974 (Figura 7.22 (b)), os valores das acelerações máximas de $0.35 \mathrm{~g}$ (P1) e 0.46g (P2) são menores que a aceleração máxima de $0.48 \mathrm{~g}$ do registro sísmico de Lima 1974 mostrado na Figura 3.25. Para o sismo artificial de Maule 2010 (Figura 7.22 (c)), valor da aceleração máxima de $0.32 \mathrm{~g}$ (P1) e menor que a aceleração máxima de $0.45 \mathrm{~g}$ do registro sísmico ajustado de Maule 2010 mostrado na Figura 3.26 e o valor da aceleração máxima de $0.50 \mathrm{~g}$ (P2) e maior que a aceleração máxima de $0.45 \mathrm{~g}$ do registro sísmico ajustado de Maule 2010 (Figura 3.26). 


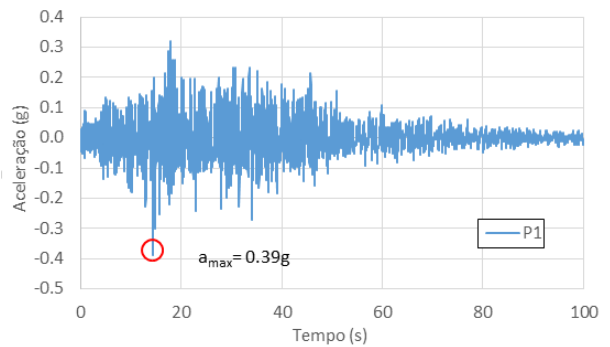

Ponto 1

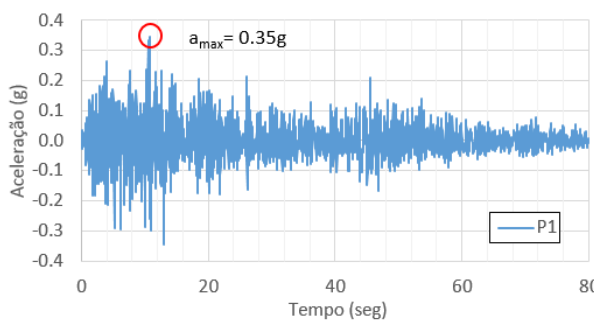

Ponto 1

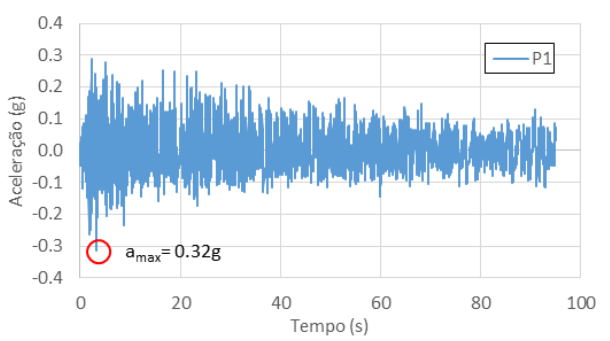

Ponto 1

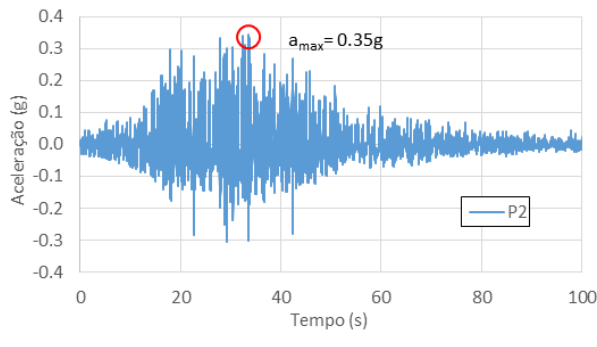

Ponto 2

(a)

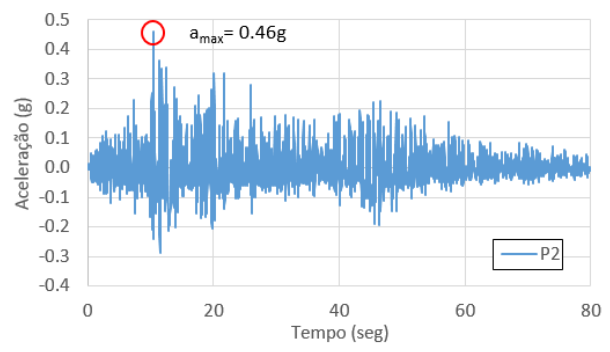

Ponto 2

(b)

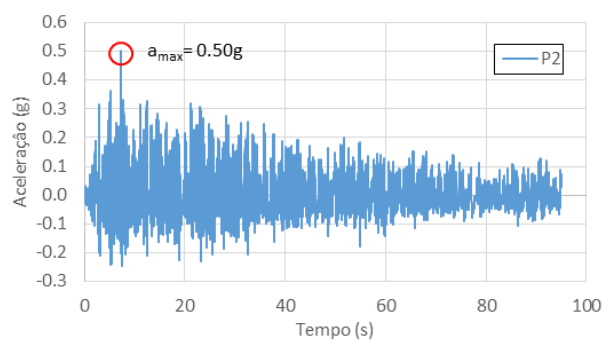

Ponto 2

(c)

Figura 7.22- Resposta em termos de aceleração dos pontos $\mathrm{P} 1$ e $\mathrm{P} 2$ durante os sismos artificiais (a) Atico 2001, (b) Lima 1974 e (c) Maule 2010.

Mostra-se na Figura 7.23 os espectros de resposta nos pontos P1 e P2, onde acontece uma amplificação para alguns períodos no ponto P2 e uma atenuação para todos os períodos no ponto P1. 


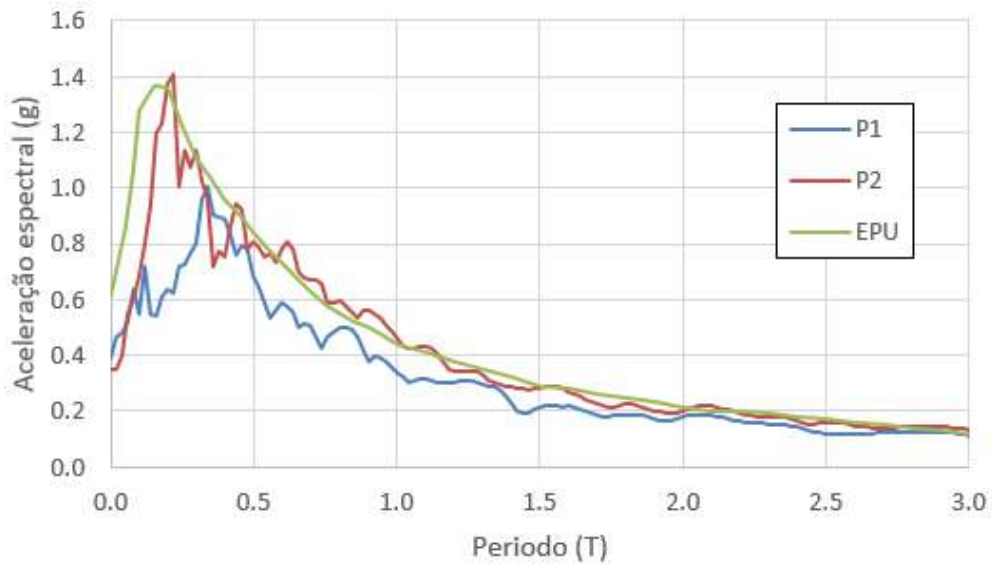

(a)

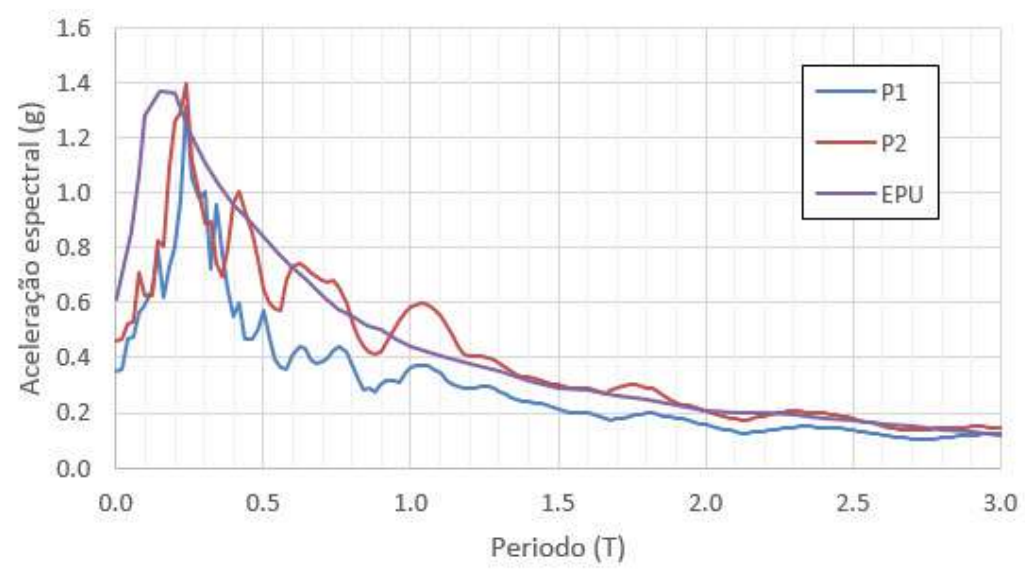

(b)

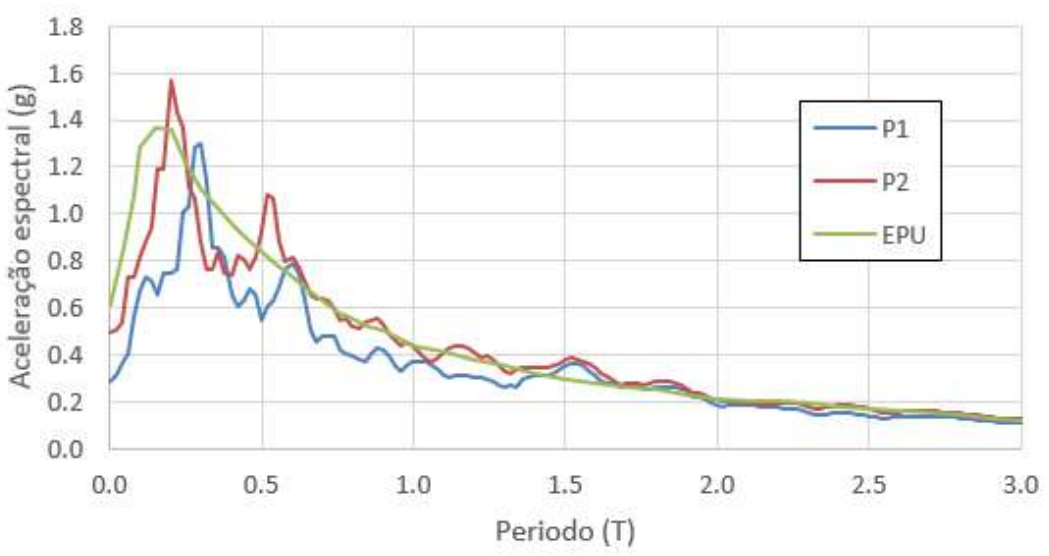

(c)

Figura 7.23-. Acelerações espectrais nos pontos P1 e P2 para os sismos artificiais (a) Atico 2001,

(b) Lima 1974 e (c) Maule 2010. 
A partir dos resultados apresentados acima, nota-se que o ponto P1 experimenta uma atenuação nos registros de aceleração para os sismos de Atico 2001, Lima 1974 e Maule 2010. Os espectros de resposta também mostram um aumento das acelerações espectrais, em especial entre os períodos de 0 ate 0.5 segundos.

Para o ponto P2, não se apresentou um comportamento definido nos registros de aceleração, porque as acelerações amplificaram para o sismo de Maule 2010 e atenuaram para os sismos de Atico 2001 e Lima 1974; porém, nos espectros de resposta pode-se observar uma amplificação das acelerações em alguns períodos ultrapassando o espectro de resposta uniformemente provável (EPU).

Na Figura 7.24, observa-se que os espectros de resposta nos pontos dos rejeitos (Figura 7.11) sofreram uma atenuação em todos os períodos de vibração. Nas camadas de rejeitos nos pontos R0, R1, R2, R3 e R5 tem-se maior atenuação em comparação com os pontos R4 e R6 para todos os períodos. 


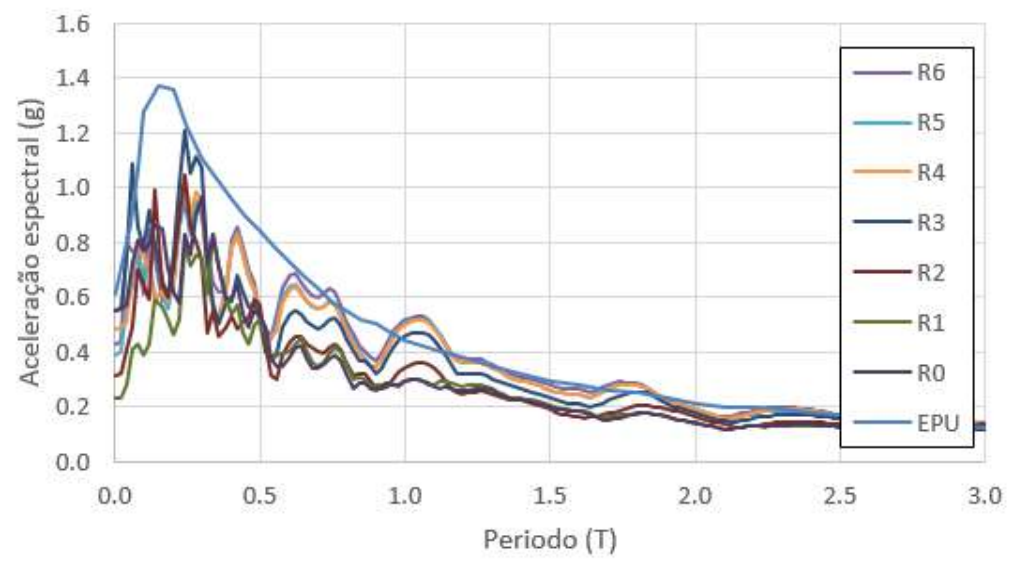

(a)

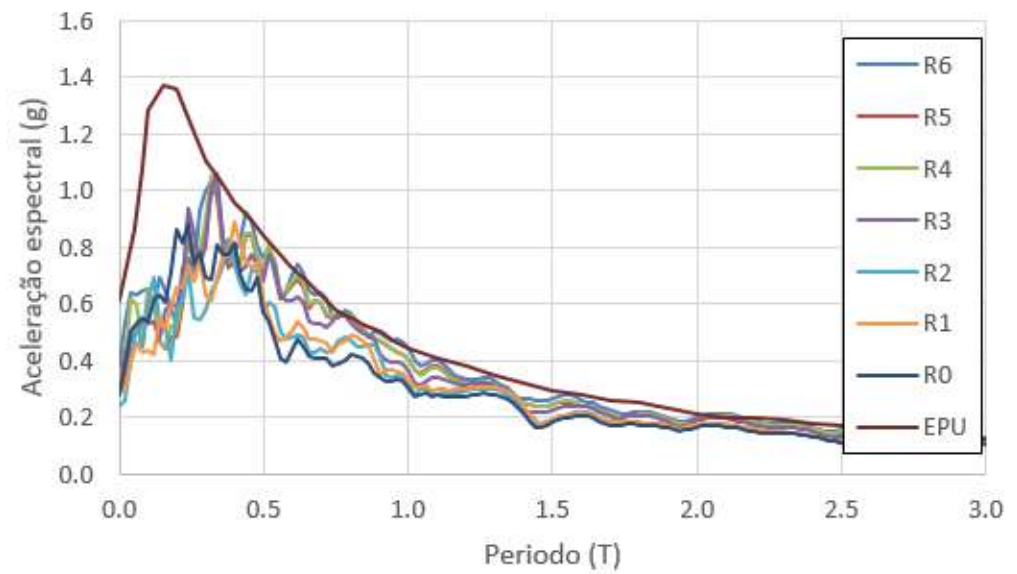

(b)

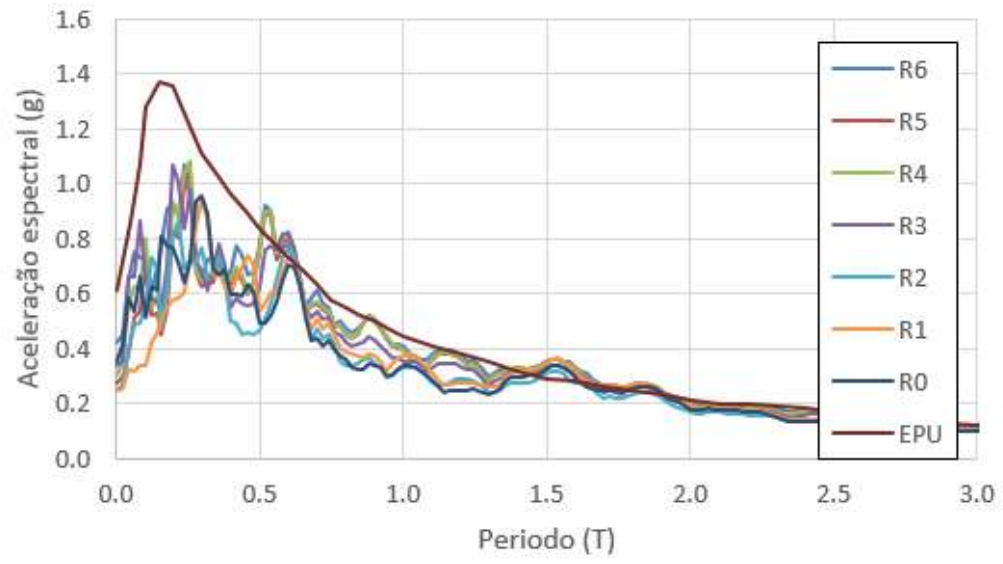

(c)

Figura 7.24- Acelerações espectrais em alguns pontos das camadas de rejeitos para os sismos artificiais (a) Atico 2001, (b) Lima 1974 e (c) Maule 2010. 


\subsection{5.}

\section{Deslocamentos pós sismo}

A variação dos deslocamentos verticais na superfície dos rejeitos é influenciado durante o evento sísmico e durante a fase de dissipação de poropressões. Com base na permeabilidade dos rejeitos, foram necessários 3 dias após dos sismos que o solo dissipa completamente as poropressões de água e são gerados os deslocamentos verticais finais na superfície dos rejeitos.

Para pontos P1 e P3 da Figura 7.11 se apresenta a historia de descolamentos verticais durante e após dos sismos artificiais Atico 2001 (Figura 7.25).

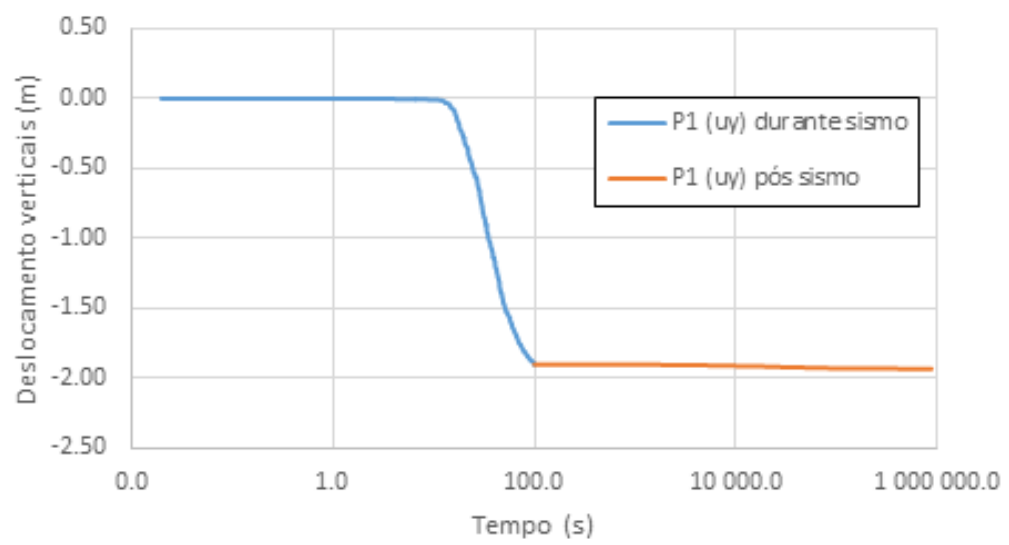

(a)

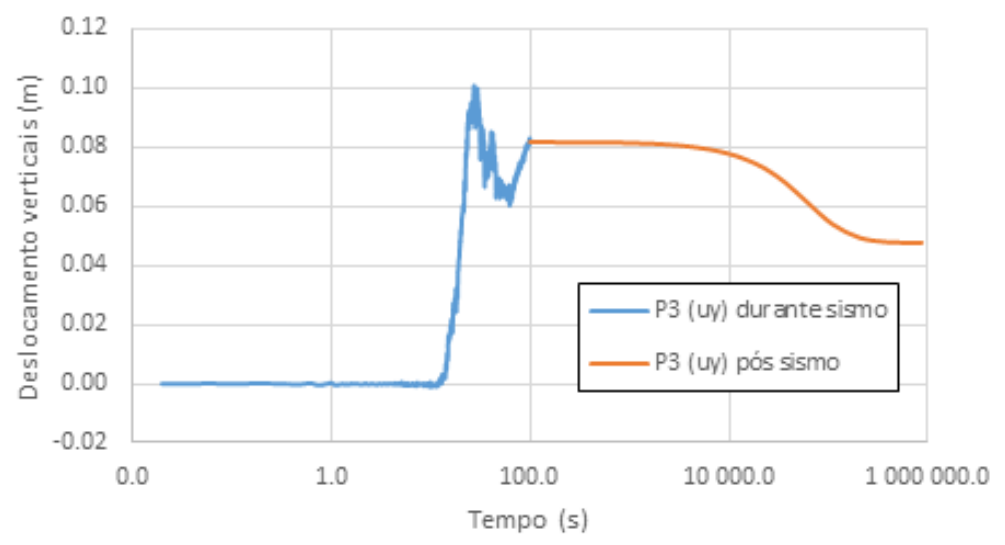

(b)

Figura 7.25- História de deslocamentos verticais provocados no (a) ponto P1 e (b) ponto P3 durante e pós do sismo artificial Atico 2001.

Na Figura 7.26 se apresenta a historia de descolamentos verticais durante e após dos sismos artificiais Lima 1974. 


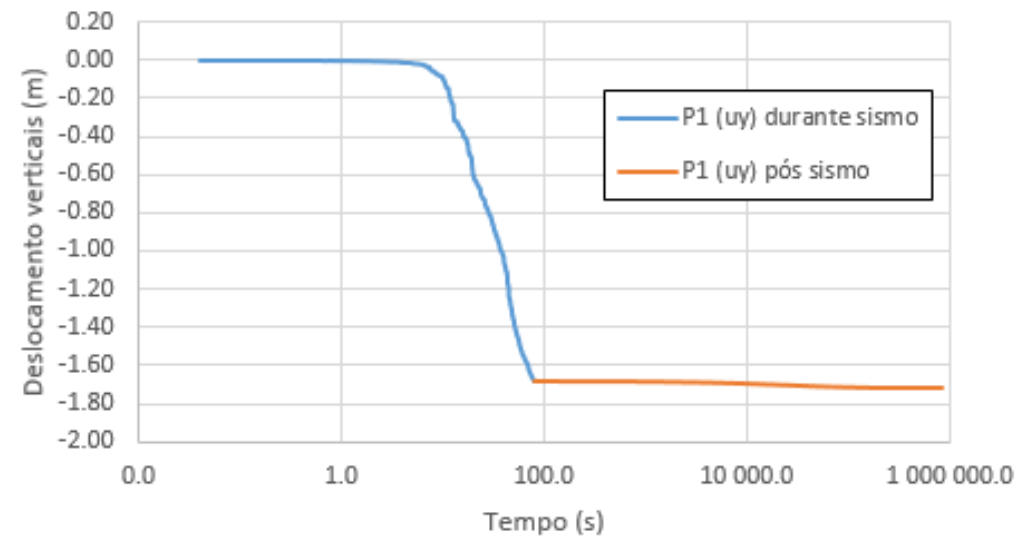

(a)

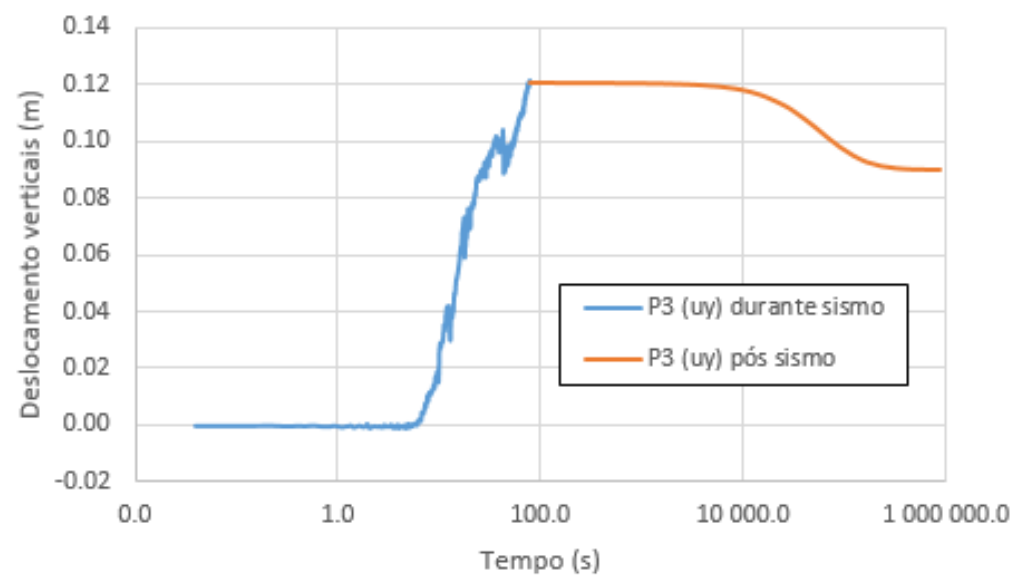

(b)

Figura 7.26- História de deslocamentos verticais provocados no (a) ponto P1 e (b) ponto P3 durante e pós do sismo artificial Lima 1974.

Na Figura 7.27 se apresenta a historia de descolamentos verticais durante e após dos sismos artificiais Maule 2010. 


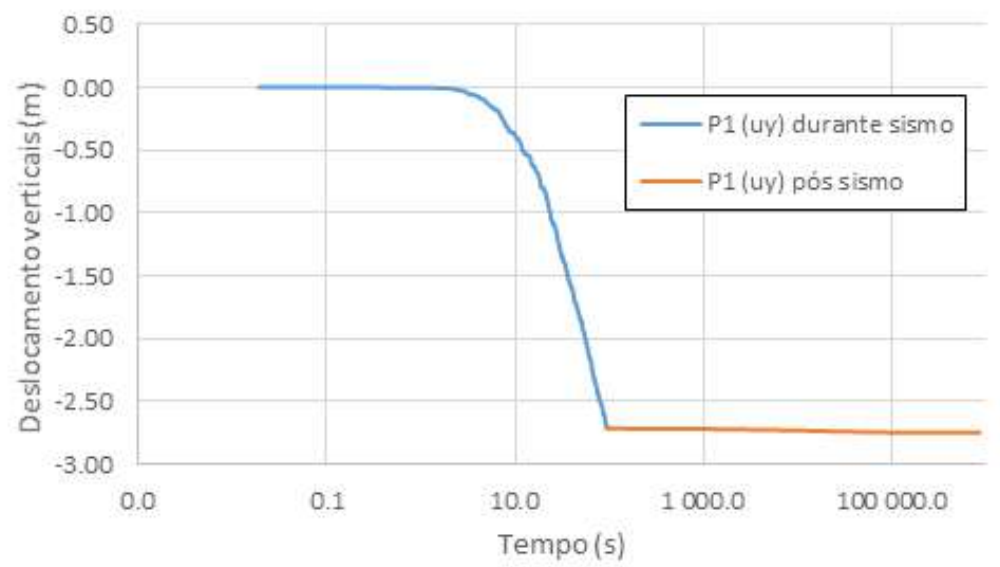

(a)

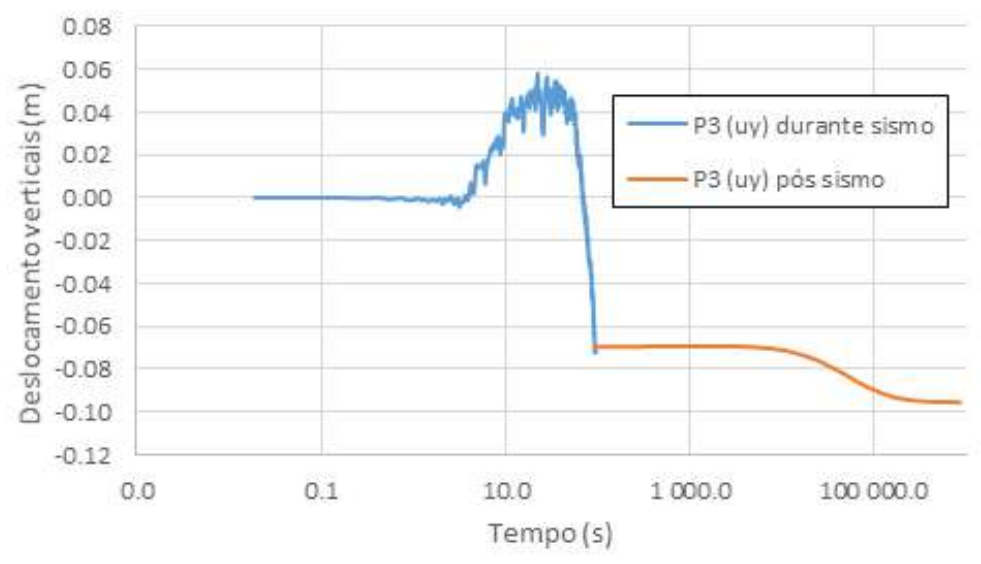

(b)

Figura 7.27- História de deslocamentos verticais provocados no (a) ponto P1 e (b) ponto P3 durante e pós do sismo artificial Maule 2010.

A seguir, é apresentado a comparação entre a modelagem numérica e a situação após 5 dias ocorrido o sismo em 2013 (Figura 7.28). 


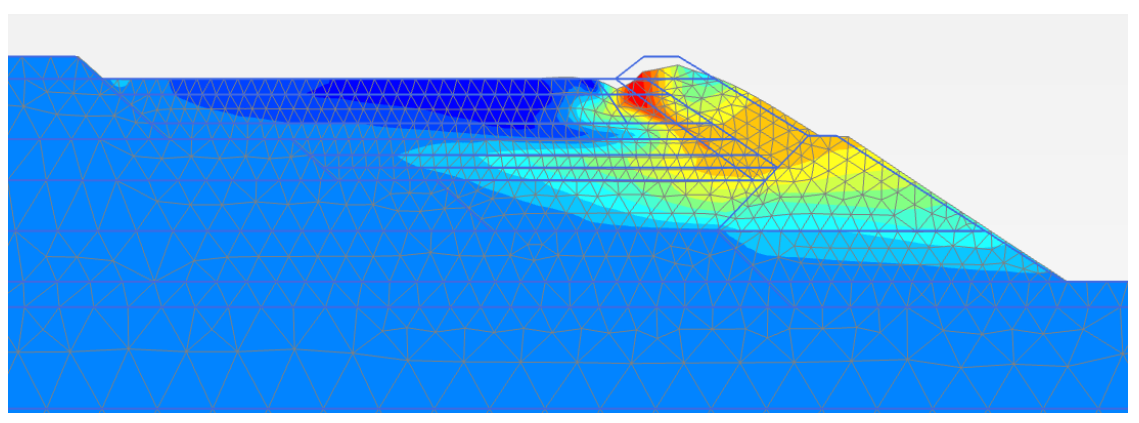

(a)

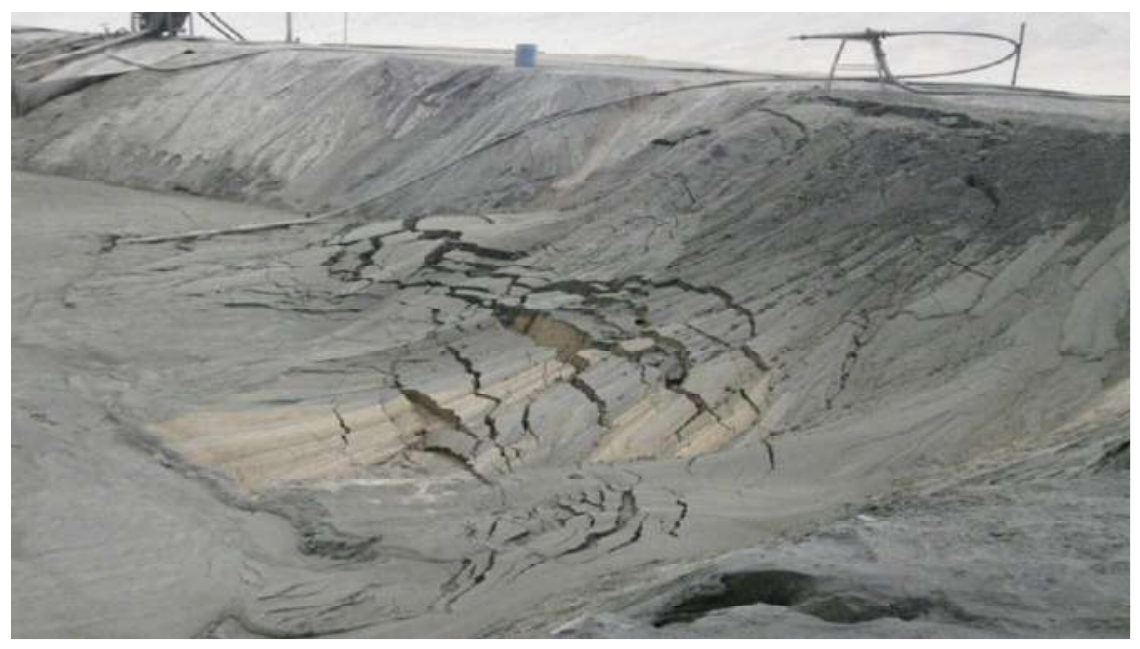

(b)

Figura 7.28- Comparação entre a modelagem numérica e a situação após 5 dias ocorrido o sismo em 2013.

\subsection{6.}

Deslocamentos verticais Swaisgood (2013)

$\mathrm{Na}$ Tabela 7.12, apresenta-se os resultados de deslocamento e grau de dano pelo método de Swaisgood (2013). Os pontos de avaliação foram, a crista do aterro compactado, e a crista dos rejeitos, para o sismo de projeto com período de retorno de 1000 anos. 


\begin{tabular}{|l|c|c|}
\hline $\begin{array}{c}\text { Condições de } \\
\text { Análise }\end{array}$ & $\begin{array}{c}\text { Crista do aterro } \\
\text { compactado }\end{array}$ & $\begin{array}{c}\text { Crista dos } \\
\text { rejeitos }\end{array}$ \\
\hline PGA & 0.610 & 0.610 \\
\hline Ms & 6.4 & 6.4 \\
\hline DH $(\mathrm{m})$ & 25 & 36 \\
\hline AT $(\mathrm{m})$ & 4 & 4 \\
\hline$\%$ Deslocamento & 0.14 & 0.48 \\
\hline Deslocamento $(\mathrm{cm})$ & 4.2 & 19.3 \\
\hline Grau de dano & Moderado & Sério \\
\hline Onde:
\end{tabular}

(DH): altura da barragem

(AT): espesura da camada de fundação

A correlação considerada entre a Magnitude do momento $(\mathrm{Mw})$ e a Magnitude das ondas de superfície (Ms) foi proposta Villalón e Palau (2018), determinado pela seguinte equação:

$$
M_{w}=0,67( \pm 0,005) M_{s}+2,18( \pm 0,03)
$$




\section{8 Conclusões e sugestões}

\section{1. Conclusões}

A estimativa da ameaça sísmica foi feita de acordo com metodologia probabilística, fazendo uso de relações de atenuação em rocha (solo Tipo B). Os valores obtidos mostraram coerência com pesquisas anteriores de ameaça sísmica já realizadas no Peru. Segundo informações compiladas no decorrer desta pesquisa, pode-se concluir que o sismo que gera maior contribuição para o período estrutural de 0.00 segundos (PGA) é de magnitude 6.3 Mw a uma distância de $65 \mathrm{~km}$, esse sismo é de mecanismo focal Interface. Também é importante falar que se tem outro pico de menor contribuição de magnitude 5.4 Mw a uma distância de 65 km, esse sismo é de mecanismo focal Intraplacao.

De acordo com a metodologia da CDA, a barragem de rejeitos Otapara é classificada como um risco potencial significativo, considerando um sismo para um período de retorno de 1000 anos, resultando na determinação da aceleração máxima de $0.610 \mathrm{~g}$, devido que o risco sísmico da barragem em estudo é melhor representado. Isso porque o risco sismico encontrasse associoado aos níveis de perdas e estar representados qualitativamente.

Os acelerogramas artificiais foram ajustados ao espectro de resposta de acelerações determinado na etapa de ameaça sísmica pelo método do ajuste espectral, utilizando 3 diferentes terremotos históricos.

Da caracterização geotécnica dos rejeitos da barragem em estudo podemos concluir que os rejeitos grossos (SM) e os rejeitos finos (ML) são suscetíveis à liquefação.

A partir de um procedimento de desencadeamento de liquefacção baseado no numero de glopes SPT pelo Boulanger e Idriss (2014) foi possível identificar a liquefacção dinâmica do material de rejeito ao longo do SPT-1 entre as elevações 
de $432 \mathrm{~m}$ e $416 \mathrm{~m}$, tendo uma zona não liquefiável entre $421 \mathrm{~m}$ e $419 \mathrm{~m}$. Na sondangem SPT-2 a camada de rejeito com potencial de liquefação encontra-se entre os $436 \mathrm{~m}$ e $418 \mathrm{~m}$, tendo uma zona não liquefiável entre $423 \mathrm{~m}$ e $421 \mathrm{~m}$.

Da avaliação feita pelo método simplificado de Youd et al (2001) na sondangem SPT-1 a camada de rejeito com um potencial de liquefação encontrase entre os $430 \mathrm{~m}$ e $421 \mathrm{~m}$. Na sondangem SPT-2 a camada de rejeitos com potencial de liquefação encontra-se entre os $430 \mathrm{~m}$ e $426 \mathrm{~m}$. Este fato foi confirmado pelo critério de deformação proposto por Castro (2014).

O modelo numérico da barragem de rejeitos, através do software de elementos finitos Plaxis 2D, permitiu uma investigação mais detalhada da condição estática e dinâmica, assim como a avaliação da liquefação dinâmica considerando as histórias dos parâmetros ru durante o movimento do solo provocadas por três diferentes sísmos de desenho.

O fator de segurança estático após a construção, determinado com a técnica de redução da resistência no programa PLAXIS 2D, é de 1.45. N. Uma vantagem de se empregar um método numérico como os elementos finitos é que a forma e a localização da superfície de ruptura não precisam ser previamente definidas, pois são determinadas durante o processo de solução.

Na condição dinâmica para os sismos treis sismos de projeto, o campo de deslocamentos mostrou que na crista dos rejeitos são gerados os maiores deslocamentos.

Considerando que o solo está em estado liquefeito para valores do parâmetro poropressão (ru) iguais ou superiores a 0,85 (Makra, 2013). Os resultados da análise numérica expressa em termos de histórias ru, observamos que toda a camada dos rejeitos $\mathrm{R} 1, \mathrm{R} 2, \mathrm{R} 3$ e R5 o valor de ru é igual ou superior a 0.85 após de transcurrido os sismos, enquanto os rejeitos R4 e R6 apresenta zonas onde o vaor de ru é inferior a 0.85 após de transcurrido os sismos.

Dos espectros de resposta nos pontos dos rejeitos sofreram uma atenuação em todos os períodos de vibração, para as camadas de rejeitos R0, R1, R2, R3 e 
R5 se tem maior atenuação em comparação com os rejeitos $\mathrm{R} 4$ e R6 em todos os períodos.

Dos deslocamentos pós sismo na superfície dos rejeitos são influenciados pelo evento sísmico e durante a fase de dissipação de poropressões. Com base na permeabilidade dos rejeitos, foram necessários 3 dias após dos sismos que o solo dissipa completamente as poropressões de água e são gerados os deslocamentos verticais finais na superfície dos rejeitos.

\section{2.}

Sugestões

O modelo constitutivo elastoplástico UBC3D-PLM empregado na dissertação gerou resultados satisfatórios, conseguindo simular os efeitos da liquefação durante e após o sismo de projeto. Existe outros modelos constitutivos com vantagens sobre este modelo na representação pós-sismo, como o modelo PM4SAND. Para futuras pesquisas se recomenda fazer uma comparação entre estes dois modelos constitutivos.

A vantagem do modelo UBC3D-PLM é que a partir da densidade relativa é possível obter a maioria dos parâmetros do modelo. Nesta pesquisa só foram considerados ensaios de SPT; para futuras pesquisas se recomenda trabalhar com uma data de investigação geotécnica maior, que além de SPT tenha ensaios de piezocone, dilatômetro, etc.

Devido a limitada quantidade de informação de campo e laboratório não foi possível realizar uma calibração dos parâmetros do modelo constitutivo com dados de ensaios de laboratório como DSS cíclico, Triaxial cíclico ou centrifuga com mesa vibratória. Teve-se que trabalhar com dados experimentais de outras pesquisas para materiais similares em origem, granulometria e forma de disposição.

Durante a investigação de campo foi identificado uma pequena camada material argiloso, o qual foi desconsiderado na analise, existe a possibilidade analisar este tipo de material com outros modelos constitutivos como o PM4SILT, o qual consegue representar o comportamento cíclico para materiais com 
plasticidade, pelo qual se sugere complementar a analise considerando este tipo de material. 


\section{9 \\ Referências bibliográficas}

ABRAHAMSON, N. A. Spatial variation of multiple support inputs. Proceedings, 1st U. S. Seminar on Seismic Evaluation and Retrofit of Steel Bridges, Department of Civil Engineering and California Department of Transportation, University of California at Berkeley, San Francisco, California, 1993.

ABRAHAMSON, N., NICHOLAS G., and KOFI A. "BC Hydro ground motion prediction equations for subduction earthquakes." Earthquake Spectra 32.1 (2016): 23-44.

ACEVEDO J., ANA B. Seismological criteria for selecting and scaling real accelerograms for use in engineering analysis and design, Dissertation Master Degree, European School of Advanced Studies in Reduction of Seismic Risk, June, 2003.

AGUILAR, Z. Análisis de peligro sísmico y estimado del movimiento sísmico de diseño, Centro de Investigaciones Sísmicas y Mitigación de Desastres, CISMID, 2001.

AIRES, A. D. Estudo tensão-deformação da barragem de Irapé, Dissertacao de Mestrado, Programa de Pós-graduação em Geotecnia, Universidade Federal de Ouro Preto, Agosto 2006.

ALTAREJOS-GARCÍA, L. Contribución a la estimación de la probabilidad de fallo de presas de hormigón en el contexto del análisis de riesgos. $\mathrm{PhD}$ thesis, Universidad Politécnica de Valencia, 2009.

AMBRASEYS N.N. and SARMA S.K. The Response of Earth Dams to Strong Earthquakes, Geotechnique, London, Vol. 17, pp. 180-213, 1967.

ATKINSON, G. M., BOORE, D. M. Empirical ground-motion relations for subduction zone earthquakes and their application to Cascadia and other regions, Bulletin of the Seismological Society of America, 93:4, 17031729, 2003.

BASSO, R. F. Estudo tensão-deformação de um enrocamento visando barragens de enrocamento com face de concreto, Dissertação de Mestrado, Escola Politécnica da Universidade de São Paulo, pp. 129, 2007.

BEATY, M.H.; BYRNE, P.M. UBCSand Constitutive Model Version 904aR, 
Report UBCSand Constitutive Model on Itasca UDM Website, disponível em www.itascacg.com/udms/ubcsand, 2011.

BRASIL. Ministério da Integração Nacional (MIN). Manual de Segurança e Inspeção de Barragens. Brasília. 2002, 148p.

BRAY, J. D., AUGELLO, A. J., LEONARDS, G. A., REPETTO, P. C. and BYRNE, R. J. Seismic Stability Procedures for Solid-Waste Landfills. J. Geotech. Engrg., ASCE, , Vol. 121, No. 2, pp. 139-151, 1995.

BRAY, J. D., RATHJE, E. M., AUGELLO, A. J. and MERRY, S. M. Simplified seismic design procedure for geosyntethic-lined, solid-waste landfills. Geosynthetics International, Vol. 5, No.1-2, pp. 203-235, 1998.

BOORE, D. M. and JOYNER W.B. The empirical prediction of ground motion, Bull. Seism. Soc. Am. 72, 269-286, 1982.

BOULANGER, R. W.; IDRISS, I. M. CPT and SPT based Liquefaction Triggering Procedures. Report No. UCD/CGM-14/01, Center for Geotechnical Modeling, University of California, Davis, 2014.

CALIFORNIA GEOLOGICAL SURVEY. Guidelines for evaluating and mitigating seismic hazards in California, Special Publication 117a, 2008.

CASAVERDE, L. y VARGAS, J. Zonificación Sísmica del Perú, II Seminario Latinoamericano de Ingeniería Sismo-Resistente, Organización de Estados Americanos y Pontificia Universidad Católica del Perú, Lima, Perú, 1980.

CASTILLO, J. y ALVA, J. - Peligro Sísmico en el Perú, VII Congreso Nacional de Mecánica de Suelos e Ingeniería de Cimentaciones, Lima, pp.409-431, 1993.

CASTRO G. Seismic Design of Tailing Dams, 2014.

CDA. Canadian Dam Association - Dam Safety Guidelines, 2013.

CDA. Canadian Dam Association - Application of Dam Safety Guidelines to Mining Dams, 2014.

CHAKRABORTY, D. and CHOUDHURY, D. Investigation of the Behavior of Tailings Earthen Dam Under Seismic Conditions, American J. of Engineering and Applied Sciences 2 (3): 559-564, 2009.

CHÁVEZ, J. Leyes de Atenuación para Aceleraciones Espectrales en el Perú, Tesis de Grado, Facultad de Ingeniería Civil, Universidad Nacional de Ingeniería Lima, 2006.

CHEN, Q., HUA ZOU, H., TANG, M. and RONG, C. Modelling the Construction of a High Embankment Dam, KSCE Journal of Civil Engineering, Vol. 18, $N^{\circ} 1$, pp. 93-102, 2014. 
Climent, A., ROJAS, W., AlvarAdO, G., BenitO, B. Proyecto ReSiS II: Evaluación de la amenaza sísmica en América Central, Centro de Coordinación para la Prevención de los Desastres Naturales en América Central (CEPREDENAC), 2008

CLOUGH, R., WOODWARD, R. - Analysis of embankment stresses and deformations, JSMFD, ASCE, No. SM4, 1967, pp.529-549, 1967.

CONTRERAS F., R. Previsão numérica do comportamento dinâmico da barragem de Breapampa no Peru. Dissertação de Mestrado, Departamento de Engenharia Civil, PUC-Rio, 2014.

CORNELL, A. Engineering Seismic Risk Analysis, Bulletin of the Seismological Society of America", Vol. 58, №5 págs. 1538 - 1606, 1968

DARBRE, G.R. State of practice in earthquake analysis of dams, ETH Zurich und Volkshochschule im Schwarzwald, Vol. 15, 2000.

DARENDELI, M., "Development of a new family of normalized modulus reduction and material damping curves". Ph.D. Thesis, Dept. of Civil Eng., Univ. of Texas, Austin. 2001.

DOBRY, R., R.S. LADD, F.Y. YOKEL, R.M. CHUNG AND D. POWELL, "Prediction of pore water pressure buildup and liquefaction of sands during earthquakes by the cyclic strain method," National Bureau of Standards Building Science Series 138, National Bureau of Standards and Technology, Gaithersburg, Md., 150. 1982.

DOBRY, R., PIERCE, W. G., DYVIK, R., THOMAS, G. E., AND LADD, R. S., "Pore pressure model for cyclic straining of sand." Rensselaer Polytechnic Institute, Troy, New York. 1985.

DOBRY, R. E VUCETIC, M., Dynamic properties and seismic response of soft clay deposits, Proceedings, International Symposium on Geotechnical Engineering of Soft Soils, Mexico City, Vol. 2, pp. 51-87. 1987.

DUNCAN, J. M.; WRIGHT, S. G. Soil Strength and Slope Stability, John Wiley \& Sons, Inc. 2005, 297p.

EBRAHIMIAN, B. Non-Linear Numerical Analysis of Earthquake-Induced Deformation of Earth-Fill Dams, University of Tehran, Iran, 2010.

ESTEVA, L. Criterios para la Construcción de Espectros de Diseño, Publicação № 19 do Instituto de Ingeniería, Universidad Nacional Autónoma de México (UNAM), 1970. 
FLORES-ESTRELLA, H. Método SPAC: Una alternativa para la Estimación de Modelos de Velocidades en el Valle de México, Dissertação de Mestrado, Instituto de Geofísica, UNAM, 2004.

GAMARRA, C. A. Nuevas Fuentes Sismogénicas para la Evaluación del Peligro Sísmico y Generación de Espectros de Peligro Uniforme en el Perú, Tesis de Grado, Facultad de Ingeniería Civil, Universidad Nacional de Ingeniería Lima, 2009.

GUI, M. and CHIU, H. Seismic response of renyitan earth-fill dam, Journal of GeoEngineering, Vol. 4, No. 2, pp. 41-50, August 2009.

GUTENBERG, R.; RICHTER, C. F. Frequency of Earthquakes in California. Bulletin of the Seismological Society of America, Volume 34, p. 185-188, 1944. HANCOCK, J., WATSON-LAMPREY, J.A., ABRAHAMSON, N.A., BOMMER, J.J., MARKATIS, A., MCCOY, E. and MENDIS, R. An improved method of matching response spectra of recorded earthquake ground motion using wavelets. Journal of Earthquake Engineering, 10:Special Issue 1, pp. 67-89, 2006.

HARDIN B O, BLACK W L. Vibration modulus of normally consolidated clay: design equation and curves. Journal of the Soil Mechanics and Foudations Engineering Division, ASCE, 1968. 94(2):353-369.

HERRERA, F. Introducción a la estabilidade de taludes, Curso de Geotecnia, Noviembre 2013.

HYNES-GRIFFIN M.; FRANKLIN A. Razionalizing the seismic coefficient method. U.S. Army Engineer Waterways Experiment Station, Miscellaneous Paper GL-84-13, Vicksburg, MS. 1984.

HUAMAN, C. J., and ROMANEL, C. "Numerical Analysis of the Seismic Behavior of Alpamarca Tailings Dam in Peru." Civil Infrastructures Confronting Severe Weathers and Climate Changes Conference. Springer, Cham, 2018.

HUDSON, D. E. Reading and Interpreting Strong Motion Accelerograms. EERI Engineering Monographs on Earthquake Criteria, Structural design, and Strong Motion Records, Vol.1, 1979.

HUERTAS, J. Procedimentos de análise não-linear para previsão de resposta sísmica em geoestruturas, Dissertação de Doutorado. Programa de PósGraduação em Engenharia Civil. PUC-Rio, 2012. 
HURTADO A., G. Aspectos de Liquefação na Estabilidade de Pilha de Lixiviação de Minério de Cobre sob Carregamento Sísmico. Diss. PUCRio, 2009.

ICOLD, Selecting seismic parameters for large dams, Bulletin 72, 2010.

ICOLD, Selecting seismic parameters for large dams, Bulletin 148, 2016.

IDRISS, I.M. Evaluating of seismic risk in engineering practice, Proc. 11th International Conference on Soil Mechanics and Foundation Engineering, San Francisco, v.1, pp. 255-320, 1985.

IDRISS I.M., BOULANGER R.W., Soil liquefaction during earthquakes, Earthquake Engineering Research Institute, USA, 2007.

IDRISS, I. M.; SUN, J. I. User's manual for SHAKE91. University of California, Davis, California, 1992, 13p.

ISHIHARA, K. Evaluation of Soil Properties for Use in Earthquakes Response Analysis, In: Geomechanical Modeling in Engineering Practice, R. Dungar and J.A. Studer, Eds., A.A. Balkema, Rotterdam, the Netherlans, 1986.

INSTITUTO GEOFÍSICO DEL PERÚ (IGP). Estudio de Peligro Sísmico en Perú - Primera Versión. Setiembre, 2012.

INTERNATIONAL BUILDING CODE (IBC), International Code Council, Inc., 2012. ITASCA Consulting Group Inc. FLAC, V.7.0 Mannual. Minneapolis, 2011.

JIRYAEI, M. The effect of Geometry Dimensions on the Earthquake Response of the Finite Element Method. World Academy of Science, Engineering and Technology. Pag 206-210. 2010.

KAVAZANJIAN, E., MATASOVIC, N., HADJ-HAMOU, T., SABATINI, P. J. Geotechnical engineering circular no. 3; design guidance: geotechnical earthquake engineering for highways; volume I - design principles. Rpt. No. FHWA-SA-97-076, U.S. Dept. of Trans., Fed. Hwy. Admin., Wash., DC, 1997.

KOKUSHO, T., YOSHIDA, Y. and ESASHI, Y. Dynamic properties of soft clays for wide strain range. Soil and Foundations. Vol. 22, № 4, pp. 1-18, 1982.

KRAMER, S.L. Geotechnical Earthquake Engineering. Prentice - Hall, New Jersey, 1996, p. 653.

KUROIWA, J., Japan and Peru Center for Earthquake Engineering Research and

Disaster Management. "Reducción de desastres: Viviendo en armonía con la naturaleza", Centro Peruano Japonés de Investigaciones Sísmicas y Mitigación de Desastres (CISMID-UNI), Lima - Perú, 2002. 
KUHLEMEYER, R. L.; LYSMER, J. Finite Element Method Accuracy for Wave Propagation Problems. Journal of the Soil Mechanics \& Foundation Division, ASCE, v. 99, n. SM5, 1973, p. 421-427.

LAW, TEAM-CHIE. Deformations of earth dams during construction, Ph.D. Thesis, University of Alberta, Edmonton, 1975.

LI, S. Computer Simulation of Sequential Impoundment Process of Concretefaced Rockfill Dam, Journal of Computers, Vol. 7, № 8, August 2012.

LILHANAND, K.; TSENG, W. S. Generation of Synthetic Time Histories Compatible With Multiple-Damping Response spetra, SMIRT-9, Lausanne, 1987.

LOAYZA, F. Modelagem do Comportamento Pós-Sismo de uma Barragem de Rejeito. Dissertação de Mestrado. Departamento de Engenharia Civil, Pontifícia Universidade Católica do Rio de Janeiro, Rio de Janeiro, 2009, $167 p$.

LOMNITZ, C. Fundamentals of earthquake prediction. New York: John Wiley \& Sons, Inc., 1994.

LYSMER, J.; KUHLEMEYER R.L. Finite dynamic model for infinite media. ASCE, Journal of Engineering and Mechanical Division, 1969, p. 859-877.

MACEDO, J. Análisis dinámico de la presa Yuracmayo, Tesis de Grado, Facultad de Ingeniería Civil, Universidad Nacional de Ingeniería Lima, 2008.

MACEDO, J. Evaluación de la respuesta sísmica de presas de tierra en términos de la variabilidad de los espectros de diseño, Tesis de Maestría, Facultad de Ingeniería Civil, Universidad Nacional de Ingeniería Lima, 2013. MACHARÉ, J., FENTON, C., MACHETTE, M., LAVENU, A., COSTA, C. and DART, R. Database and Map of Cuaternary Faults and Folds of Peru and its Offshore Regions, Open-File Report 03-451, US Geological Survey, U.S.A, 2003.

MAEDA, K.. The use of foreshocks in probabilistic prediction along the Japan and Kuril Trenches. Bulletin of the Seismological Society of America, 86, 242-254, 1996.

MANSOUR, Z., KALANTARY, B. Traditional Methods vs. Finite Difference Method for Computing Safety Factors of Slope Stability, Electronic Journal of Geotechnical Engineering, Vol. 16, pp.1119-1130, 2011.

MAKDISI, F. I.; SEED, H. B. A simplified procedure for estimating earthquake - induced deformation in dams and embankments. Earthquake 
Engineering Research Center, Report UCB/EERC-77/19, University of California, Berkeley, 1977, 66p.

MAKDISI, F. I.; SEED, H. B. Simplified Procedure for Estimating Dam and

Embankment Earthquake-Induced Deformations, Journal of the Geotechnical Engineering Division, ASCE volume 104, No. GT7, 1978, p. 849867.

MAKRA A. Evaluation of the UBC3D-PLM Constitutive Model for Prediction of Earthquake Induced Liquefaction on Embankment Dams. Delft University of Technology, 2013.

MARANGON, M. Barragens de terra e enrocamento, Notas de aula da matéria Tópicos em Geotecnia e Obras de Terra, 2004.

MARCUSON, W.F. Moderator's report for session on 'Earth dams and stability of slopes under dynamic loads'. Proceedings, International Conference on Recent Advances in Geotechnical Earthquake Engineering and Soil Dynamics, St. Louis, Missouri, Vol.3, p. 1175, 1981.

MCGUIRE, R. K. Seismic hazard and risk analysis, Earthquake Engineering Research Institute, 2004.

MEJIA, L. H.; DAWSON E. M. Earthquake deconvolution for FLAC, $4^{\text {th }}$ International FLAC Symposium on Numerical Modeling in Geomechanics 2006 - Hart \& Verona eds., paper n. 04-10, Itasca Consulting Group, Inc., Minneapolis, ISBN 0-9767577-0-2, 2006.

MENESES, J. Evaluación del peligro sísmico y determinación de acelerogramas de diseño, Colegio de Ingenieros del Perú, Julio 2009

MENQ, FARN-YUH. Dynamic properties of sandy and gravelly soils. Diss. 2003.

MEZCUA, J., GARCÍA BLANCO, R. M., \& RUEDA, J. On the strong ground motion attenuation in Spain. Bulletin of the Seismological Society of America, 98(3), 1343-1353, 2008.

MEM, 1998. Guías Ambientales del Ministerio de Energía y Minas del Perú MONROY O, BOLAÑOS A. Espectros de Peligro Sísmico Uniforme. Dissertação de mestrado, Pontifícia Universidade Católica do Peru, 2004.

MOROTE, C. Estabilidade e Deformação de Taludes de Solo sob Carregamento Sísmico. Dissertação de Mestrado. Departamento de Engenharia Civil, Pontifícia Universidade Católica do Rio de Janeiro, Rio de Janeiro, 2006, 136p.

NARITA, K. Design and construction of embankment dams. April 2000. 
NAYLOR, D. J., TONG, S. L. and SHAHKARAMI, A. - Numerical modelling of saturation shrinkage. Numerical Models in Geomechanics, Elsevier, pp.636-648, 1989.

NEHRP - National Earthquake Hazard Reduction Program.(2015) Recommended Seismic Provisions for New Buildings and Other Structures.

NEWMARK, N. Effects of Earthquakes on Dams and Embankments, Geotechnique, Volume 115, No. 2, p. 139-160, 1965.

NOBARI, E.S. and DUNCAN, J.M. - Effect of reservoir filling on stress and movements in earth and rockfill dams, Report TE 72-1, Department of Civil Engineering, University of California, Berkeley, 1972.

OLSON S. M., STARK T. D., Use of laboratory data to confirm yield and liquefied strength ratio concepts, Canadian Geotechnical Journal, 40: 1164-1184, 2002. ORDAZ, M.; AGUILAR, A.; ARBOLEDA, J. CRISIS2007: Program for Computing Seismic Hazard. Instituto de Ingeniería. Universidad Nacional Autónoma de México, 1999, 2007.

PEÑA, L. Análisis sísmico de presas de arena de relave, Maestría en Ciencias de la Ingeniería, Escuela de Ingeniería, Pontificia Universidad Católica de Chile, 2008.

PEREZ C., F. Análise de Ameaça e Resposta Sísmica de uma Pilha de Rejeito. Dissertação de Mestrado, Departamento de Engenharia Civil, PUC-Rio, 2013. PETALAS, Alexandros; GALAVI, Vahid. Plaxis Liquefaction Model UBC3DPLM. Plaxis Report, 2013.

POMACHAGUA, O. Características Generales de la Tectónica y Sismicidad de Perú, Revista de Trabajos de Investigación, CNDG, IGP, pp. 93 - 104. Lima, Perú, 2000.

QUISPE, E. Análise Dinâmica de un Aterro Reforçado com Geossintéticos. Dissertação de Mestrado, Departamento de Engenharia Civil, Pontifícia Universidade Católica do Rio de Janeiro, Rio de Janeiro, 2008, 134p.

REASENBERG, P. Second-order moment of central California seismicity, 1969-82, J. 641 Geophys. Res., 90, 5479-5495, 1985.

RIBEIRO, P. M. Uma metodologia analítica para a avaliação do campo de tensões em barragens de concreto durante terremotos, Dissertação de Mestrado, Departamento de Engenharia Civil e Ambiental, Universidade de Brasília, pp. 162, Março, 2006.

ROBLEE, C. and CHIOU, B. "A proposed Geoindex model for design selection of non-linear properties for site response analysis." International 
workshop on uncertainties in nonlinear soil properties and their impact on modeling dynamic soil response. PEER Headquarters, UC Berkeley. 2004.

RONCAL C. M. "Determinación del peligro sísmico en el territorio nacional y elaboración de aplicativo web”, Universidad Nacional de Ingeniería, 2017. SADIGH, K., CHANG, C., EGAN, J., MAKDISI, F. and YOUNGS, R. Attenuation Relationships for Shallow Crustal Earthquakes Based on California Strong Motion Data. Seismological Research Letters 68:1, 180-189, 1997.

SAUTER, F. Introducción a la Sismología, Editorial Tecnológica de Costa Rica, 1989.

SCHNABEL, P. B.; LYSMER, J; SEED, H. B. SHAKE: A Computer Program for Earthquake Response Analysis of Horizontally Sites, Report No. UCB/EERC-72/12, Earthquake Engineering Research Center, University of Caligfornia, Berkeley, 1972, 120p.

SCHWARTZ, D. P. and K. J. COPPERSMITH. Fault behavior and characteristic earthquakes: examples from the Wasatch and San Andreas faults, J. Geophys. Res. 89, 5681-5698, 1984.

SCORDILIS, E. Empirical global relations converting Ms and $\mathbf{m b}$ to moment magnitude, Journal of Seismology 10: pp. 225-236, 2006

SEED, H. B. Soil Liquefaction and Cyclic Mobility Evaluation for Level Ground During Earthquakes, Journal of the Geotechnical Engineering Division, ASCE, Vol. 105, No. GT2, pp. 201-255, 1979.

SEED R.B. AND HARDER L.F., SPT-based analysis of cyclic pore pressure generation and undrained residual strength, Proceedings H.B. Seed Memorial Symposium, Bitech Publishers, Vol. 2, pp 351-176, 1990.

SEED, H.B. and IDRISS, I.M. Soil moduli and damping factors for dynamic response analysis, Report No. EERC 70-10, University of California, Berkeley, 1970.

SEED, H. B., IDRISS, I. M., LEE, K. L., MAKDISI, F.I. Dynamic Analysis of the Slide in the Lower San Fernando Dam During the Earthquake of February 9, 1971, Journal of Geotechnical Engineering Division, ASCE, Vol. 101, No. 9 , pp. 889-911, 1975.

SEED H.B. and MARTIN G.R. The Seismic Coefficient in Earth Dam Design, Journal of the Soil Mechanics and Foundation Division, ASCE, Vol. 92 SM3, pp. 25-58, 1966. 
SEED, H.B., IDRISS, I.M. and KIEFER, F. W. Characteristics of rock motions during earthquakes, Jour. of the Soil Mech. and Found. Div., ASCE, Vol. 103, No GT6, pp. 607-625, 1969.

SEED, H.B., MAKDISI, I.F. and DE ALBA, P. Performance of earth dams during earthquakes, JGED, ASCE, Vol. 104, No. GT7, pp.967-998, 1978.

SEED, H.B. WONG, R.T., IDRISS, I.M. and TOKIMATSU, K. - Moduli and damping factors for dynamic analysis of cohesionless soils, Report No. EERC 84-14, University of California, Berkeley, 1984.

SEISMOSOFT LTD. SeismoMatch's Help System, 2018.

SEISMOSOFT LTD. SeismoSignal's Help System, 2018.

SENCICO Actualización del programa de cómputo orientado a la determinación del peligro sísmico en el país, 2016.

SERRRANO, A., ESCUDER, I., MEMBRILLERA, M., ALTAREJOS, L. Aplicación de métodos de equilibrio límite y de degradación de parámetros a la estimación de la seguridad de presas de materiales sueltos, XXXIII Jornadas Sudamericanas de Ingeniería Estructural, Mayo 2008.

SILGADO E. Historia de los Sismos más Notables ocurridos en el Perú 19551970, Geofísica Panamericana, Vol 2 pp. 179-243, 1973.

SILGADO E. Historia de los Sismos más Notables ocurridos en el Perú (15131974), Instituto de Geología y Minería, Boletín №3, Serie C, Geodinámica e Ingeniería Geológica, Lima, Perú, 1978.

SILGADO E. Investigación de Sismicidad Histórica en la América del Sur en los Siglos XVI, XVII, XVIII y XIX, CONCYTEC, Lima, Perú, 1992.

SILVA, W. J. Soil response to earthquake ground motion, EPRI Report NP5747, Electric Power Research Institute, Palo Alto, California, 1988.

SLEMMONS, D. B. Determination of design earthquake magnitudes for microzonation, Proceedings of Third International Earthquake Microzonation Conference 1,119-130, 1982.

SLIDE v.6, 2D Limit Equilibrium Slope Stability Analysis, Rocscience Inc. 2013.

STEPP, J.C. Analysis of completeness of the earthquake sample in the Puget Sound area and its effect on statistical estimates of earthquake hazard. Proc. of the 1st Int. Conf. on Microzonazion, Seattle, Vol. 2, pp. 897-910, 1972.

TERZAGHI, K. Mechanism of landslides, in application of geology to engineering practice, Berkey Vol., Geological Society of America, p.83-123, 1950. 
TORRES, P. Análisis numérico de la respuesta sísmica presa Convento Viejo, Departamento de Ingeniería Civil, Universidad de Chile, 2012.

U.S. GEOLOGICAL SURVEY (USGS). Preliminary Seismic Hazard Model for South America, Conferencia Internacional. Homenaje a Alberto Giesecke Matto, 2010.

VEIGA PINTO, A. A. - Previsão do comportamento estrutural de barragens de enrocamento, Tese para Especialista, Laboratório Nacional de Engenharia Civil, 1983.

VELEZ PARRA, D. “Análise numérica do comportamento de taludes de solo submetidos a carregamento dinâmicos”. Diss. PUC-Rio, 2017.

VENEGAS C., FRANCISCO, J. Respuesta sísmica reciente en balsas de relaves chilenas y presas de material suelto, Trabajo de Fin de Master, Escuela de caminos, Canales y Puertos, Universidad Politécnica de Madrid, Junio, 2011.

VIEIRA, B. F. Análise do comportamento estrutural de barragens abóbada com descarregadores de superfície de grandes dimensões, Dissertação de Mestrado, Faculdade de Engenharia da Universidade do Porto, Portugal, Junho, 2009.

VILCAHUAMÁN, P. J. P., HUERTAS, J. C., \& ROMANEL, C. Potencial de Liquefação Dinâmica em Barragem de Rejeitos. 2018.

WEICHERT, D. H. Estimation of the earthquake recurrence parameters for unequal observation periods for different magnitudes, Bull. Seism. Soc. Am. 70, 1337-1346, 1980.

WIEMER, S., and K. KATSUMATA. Spatial variability of seismicity parameters in aftershock zones, J. Geophys. Res. 104, 13,135-13,151, 1999.

WIEMER, S., and M. WYSS. Minimum magnitude of complete reporting in earthquake catalogs: examples from Alaska, the Western United States, and Japan, Bull. Seism. Soc. Am. 90, 859-869, 2000.

WIEMER, S. and ZÚÑIGA, R. ZMAP - a software package to analyze seismicity, EOS, Transactions, Fall Meeting, AGU, 75, 456., 1994.

WOOD, H. and NEUMANN F. Modified Mercalli Intensity Scale of 1931, Bulletin of the Seismological Society of America, v. 21, No. 4, p. 277-283. Dec. 1931. YOUNGS, R. R., CHIOU. S. J., SILVA, W. J. and HUMPREY, J. R. Strong Ground Motion Attenuation Relationships for Subduction Zone Earthquakes, Seismological Research Letters, Vol. 68, Numb. 1, Pp. 58 - 73, USA, 1997. 
YOUD, T. LESLIE, and IZZAT M. IDRISS. "Liquefaction resistance of soils: summary report from the 1996 NCEER and 1998 NCEER/NSF workshops on evaluation of liquefaction resistance of soils." Journal of geotechnical and geoenvironmental engineering 127.4 (2001): 297-313.

ZHAO, J., ZHANG, J., ASANO, A., OHNO, Y., OOUCHI, T. Attenuation Relations of Strong Ground Motion in Japan Using Site Classification Based on Predominant Period, Bulletin of the Seismological Society of America, Vol. 96, No. 3, pp. 898 - 913, June 2006 